Florida International University FIU Digital Commons

\title{
The role of market knowledge in recognizing and exploiting entrepreneurial opportunities in technology intensive firms
}

Anna-Maija Renko

Florida International University

DOI: $10.25148 /$ etd.FI08081539

Follow this and additional works at: https://digitalcommons.fiu.edu/etd

\section{Recommended Citation}

Renko, Anna-Maija, "The role of market knowledge in recognizing and exploiting entrepreneurial opportunities in technology intensive firms" (2008). FIU Electronic Theses and Dissertations. 38.

https://digitalcommons.fiu.edu/etd/38 


\section{FLORIDA INTERNATIONAL UNIVERSITY}

Miami, Florida

THE ROLE OF MARKET KNOWLEDGE IN RECOGNIZING AND EXPLOITING ENTREPRENEURIAL OPPORTUNITIES IN TECHNOLOGY INTENSIVE FIRMS

A dissertation submitted in partial fulfillment of the requirements for the degree of DOCTOR OF PHILOSOPHY

in

BUSINESS ADMINISTRATION

by

Anna-Maija Renko

2008 


\section{To: Dean Joyce Elam}

College of Business Administration

This dissertation, written by Anna-Maija Renko, and entitled The Role of Market Knowledge in Recognizing and Exploiting Entrepreneurial Opportunities in Technology Intensive Firms, having been approved in respect to style and intellectual content, is referred to you for judgment.

We have read this dissertation and recommend that it be approved.

Paul D. Reynolds

Alan L. Carsrud

Ronald M. Lee

Sumit K. Kundu, Major Professor

Date of Defense: March 7, 2008

The dissertation of Anna-Maija Renko is approved.

Dean Joyce Elam

College of Business Administration

Dean George Walker

University Graduate School

Florida International University, 2008 
C Copyright 2008 by Anna-Maija Renko

All rights reserved. 


\section{ACKNOWLEDGMENTS}

Support from several individuals and institutions has made this dissertation possible. First, I am extremely grateful for the guidance provided to me by an excellent dissertation committee chaired by Sumit Kundu, and including Alan Carsrud, Paul Reynolds, and Ronald Lee. I remember clearly the Christmas party in 2003, when Alan Carsrud and I had a conversation about me joining the doctoral program at FIU. If it wasn't for Alan's encouragement at that stage, I would have never started. Alan has also introduced me to the field of entrepreneurship, and this dissertation would not have been possible without his continuous support and guidance. Paul Reynolds has provided invaluable help and advice especially when it comes to conducting rigorous and meaningful empirical research. This dissertation has also greatly benefited from Sumit Kundu's expertise in the field of international entrepreneurship and Ronald Lee's advice on the importance of clarity and relevance in academic research. I will always be thankful of the numerous opportunities, guidance and generous support the committee members have given me along the way. I especially am appreciative of Alan's kindness and the extra effort he has made in always making me feel welcome in Miami and at FIU.

I have found my coursework throughout the $\mathrm{PhD}$ program to be stimulating and thoughtful. I would specifically like to thank Paul Reynolds for excellent instruction on large scale datasets and the field of entrepreneurship research. I am grateful for Professor Aya Chacar's excellent instruction in the field of strategy research, as well as for constructive and very useful comments to an earlier version of this dissertation. I would also like to thank Professors Sumit Kundu, Juan Sanchez, Galen Kroeck, Mary Ann von Glinow, and Steve Zanakis for excellent instruction in their areas of expertise.

In addition to my dissertation committee and faculty at FIU, there are students and staff that I wish to acknowledge. Amanda Bullough is a doctoral student, who shared with 
me many hours of research and coursework. I am glad I have had a chance to share this journey with Amanda and I know that our friendship will last for years to come. Other fellow doctoral students that came into the program about the same time with me also deserve mention: Silvia Salas, David Wernick, Andrea Roofe and Vincent Cheng. I have enjoyed learning and getting to know each one of them. I am also grateful to doctoral students Ivelina Pavlova and Pepe Rocha for their friendship. Colleen Post and Alina Rivero at the Eugenio Pino and Family Global Entrepreneurship Center have always been supportive and helpful, as has Sarah Latham at the Department of Management and International Business.

I wish to thank The Eugenio Pino and Family Global Entrepreneurship Center at Florida International University for their financial support for this dissertation and related conference travel. I have also received financial support from The Department of Management and International Business as well as The Center for International Education and Research (CIBER) at FIU.

This research was funded in part by the Ewing Marion Kauffman Foundation. As the proud recipient of the Kauffman Dissertation Fellowship Program Award in 2005, I was able to complete the extensive empirical data collection and pay travel expenses related to the dissertation. The contents of this publication are solely the responsibility of the author. The generous financial assistance provided by the Foundation for Economic Education in Finland throughout my doctoral studies in Finland and in the US is also well appreciated.

Malin Brännback was an instrumental professor of mine at Turku School of Economics in Finland, and continues to serve as a wonderful mentor and good friend. She is the key contributor to my decision to pursue academia and to travel to the US for research purposes in the first place. 
Outside of the academic world, I am appreciative of the great friends that I have in the US and in Finland. My loving parents Antti and Riitta have always encouraged me in my academic endeavors without trying to push me one way or another. I have appreciated their proud support over the years as well as that of my dear sister Elina. I would also like to express my deepest gratitude to my Jim for his unconditional love and encouragement. Thank you, all, for being by my side!

It has been an exciting journey and I am looking forward to new research adventures as a faculty member at the Managerial Department at University of Illinois at Chicago. 


\section{ABSTRACT OF THE DISSERTATION}

\section{THE ROLE OF MARKET KNOWLEDGE IN RECOGNIZING AND EXPLOITING}

ENTREPRENEURIAL OPPORTUNITIES IN TECHNOLOGY INTENSIVE FIRMS

$$
\text { by }
$$

Anna-Maija Renko

Florida International University, 2008

Miami, Florida

Professor Sumit K. Kundu, Major Professor

Entrepreneurial opportunity recognition is an increasingly prevalent phenomenon. Of particular interest is the ability of promising technology based ventures to recognize and exploit opportunities. Recent research drawing on the Austrian economic theory emphasizes the importance of knowledge, particularly market knowledge, behind opportunity recognition. While insightful, this research has tended to overlook those interrelationships that exist between different types of knowledge (technology and market knowledge) as well as between a firm's knowledge base and its entrepreneurial orientation. Additional shortfalls of prior research include the ambiguous definitions provided for entrepreneurial opportunities, oversight of opportunity exploitation with an extensive focus on opportunity recognition only, and the lack of quantitative, empirical evidence on entrepreneurial opportunity recognition.

In this dissertation, these research gaps are addressed by integrating Schumpeterian opportunity development view with a Kirznerian opportunity discovery theory as well as insights from literature on entrepreneurial orientation. A sample of 85 new biotechnology ventures from the United States, Finland, and Sweden was analyzed. While leaders in all 85 companies were interviewed for the research in 2003-2004, 42 firms provided data in 2007. Data was analyzed using regression analysis. 
The results show the value and importance of early market knowledge and technology knowledge as well as an entrepreneurial company posture for subsequent opportunity recognition. The highest numbers of new opportunities are recognized in firms where high levels of market knowledge are combined with high levels of technology knowledge (measured with a number of patents). A firm's entrepreneurial orientation also enhances its opportunity recognition. Furthermore, the results show that new ventures with more market knowledge are able to gather more equity investments, license out more technologies, and achieve higher sales than new ventures with lower levels of market knowledge. Overall, the findings of this dissertation help further our understanding of the sources of entrepreneurial opportunities, and should encourage further research in this area. 


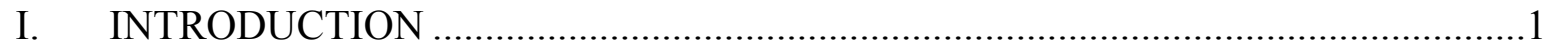

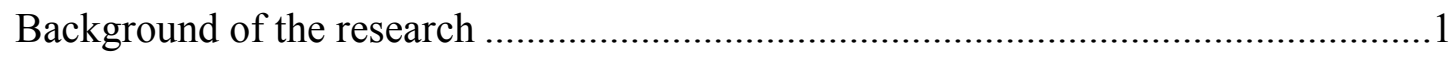

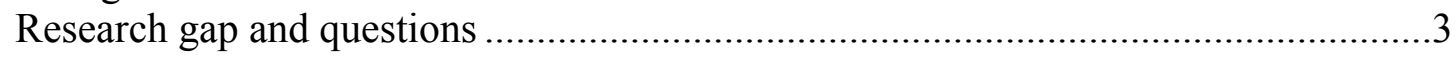

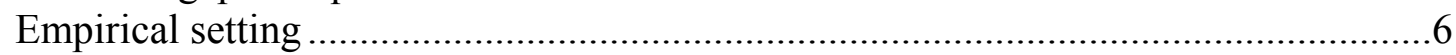

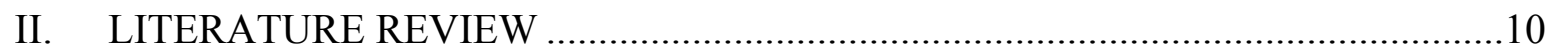

Entrepreneurial opportunities defined................................................................ 10

How are entrepreneurial opportunities recognized? .............................................19

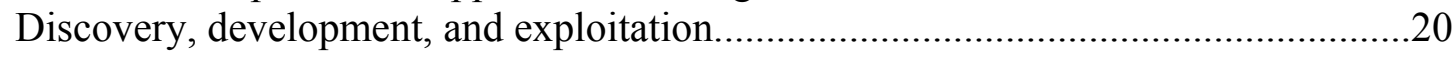

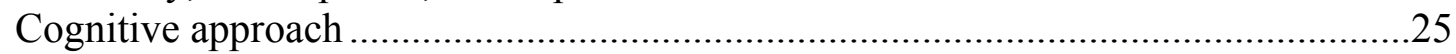

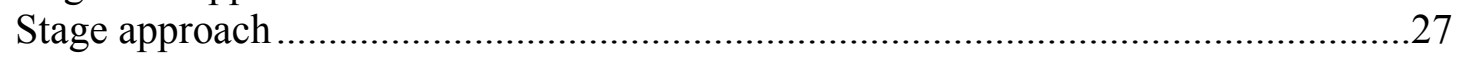

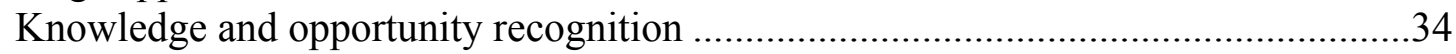

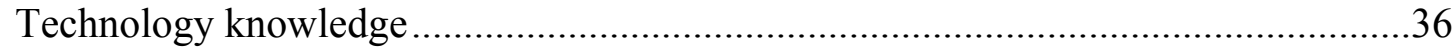

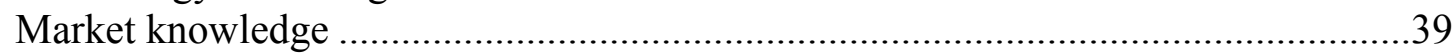

Market knowledge, new scientific knowledge and entrepreneurial opportunities ......44

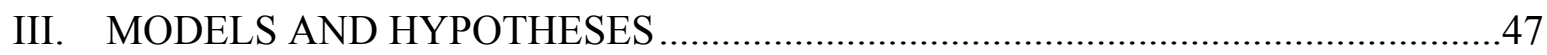

Market knowledge as a moderator between technology knowledge and

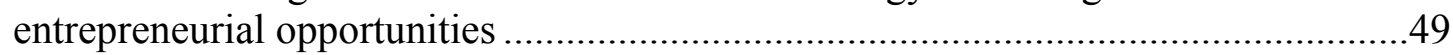

The direct effect of market knowledge on entrepreneurial opportunities....................53

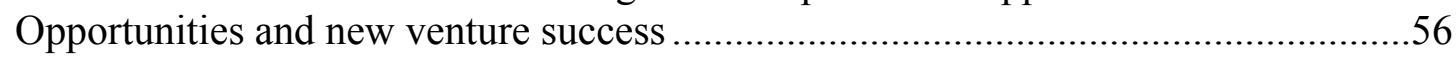

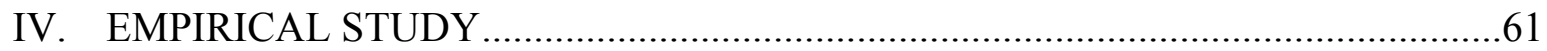

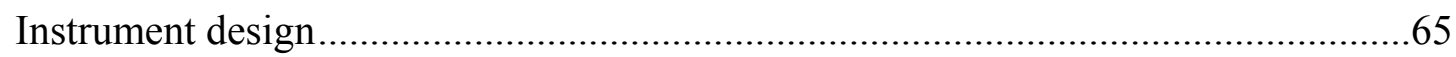

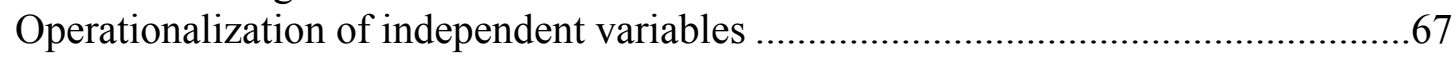

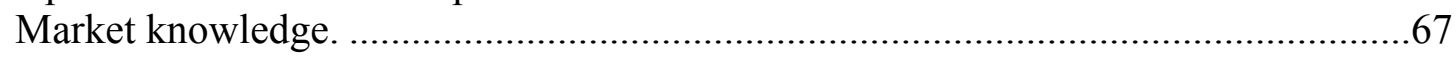

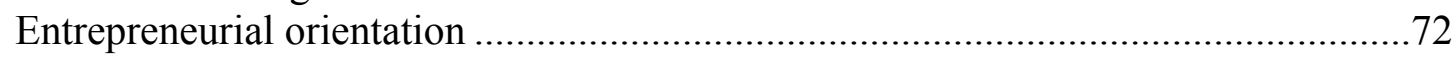

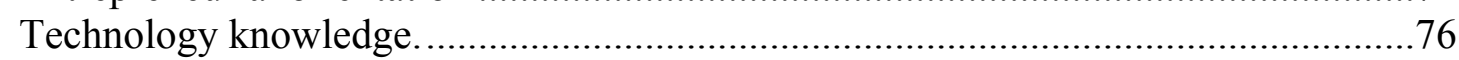

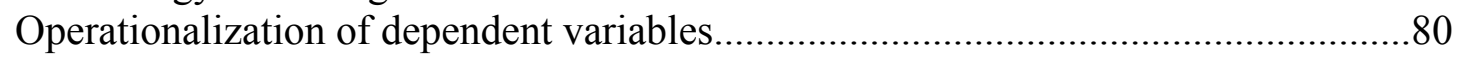

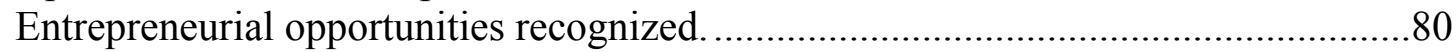

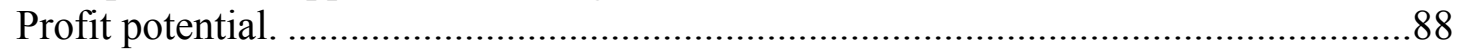

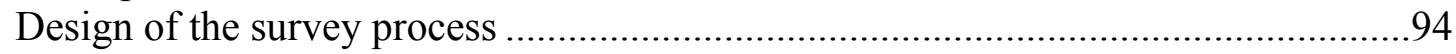

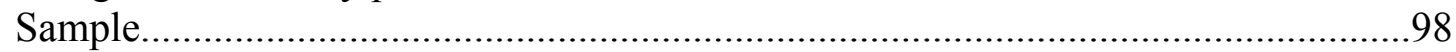

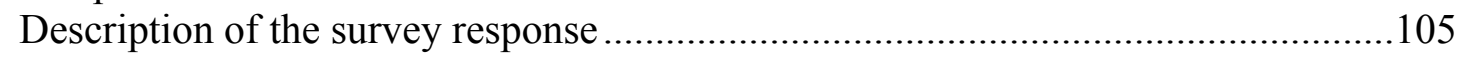

Quality of the study - testing, checking and validation procedures ..........................110

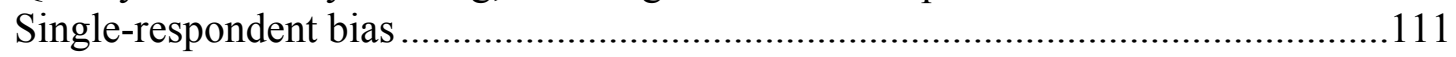

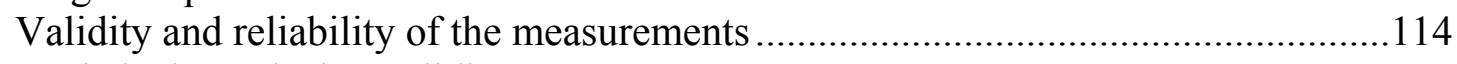

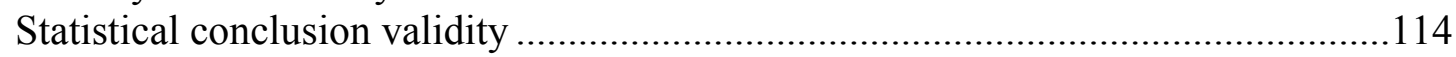

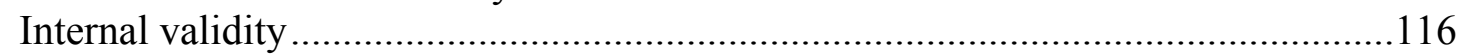

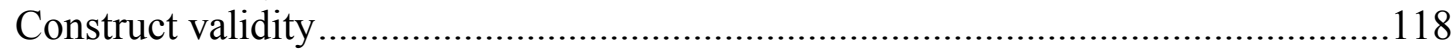

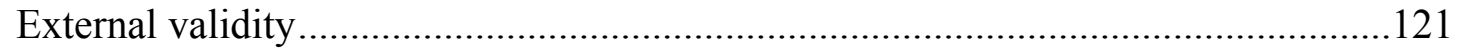

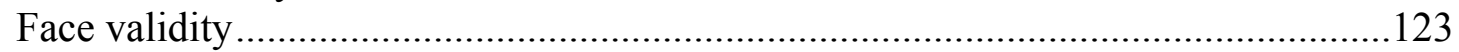

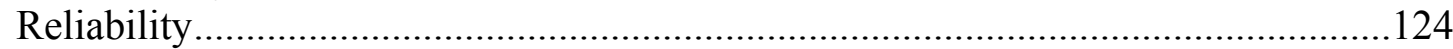

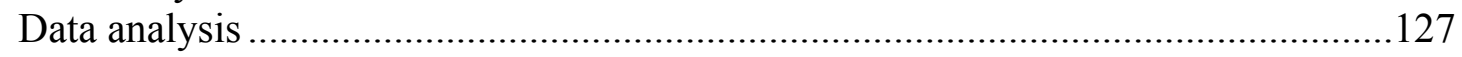




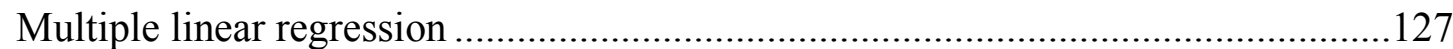

Normality and homoscedasticity in regression analysis ......................................128

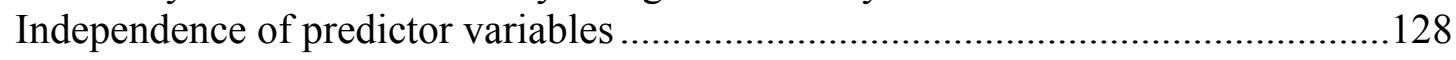

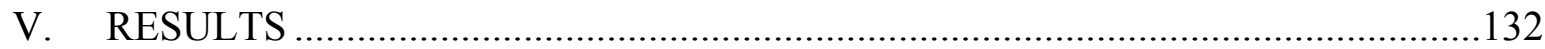

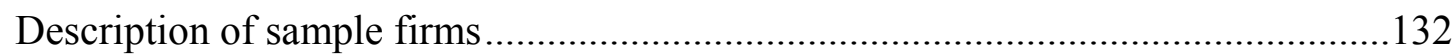

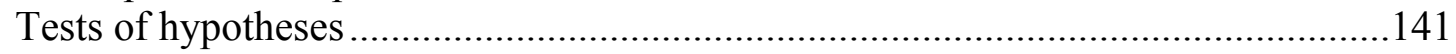

Factors behind entrepreneurial opportunity recognition........................................ 144

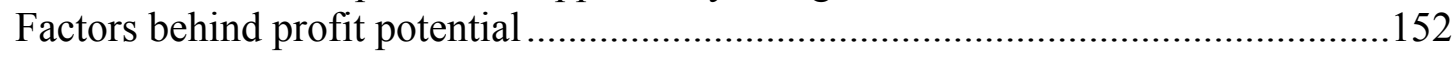

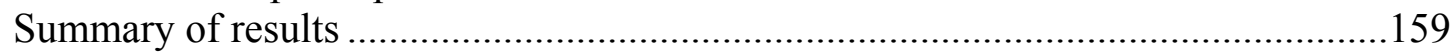

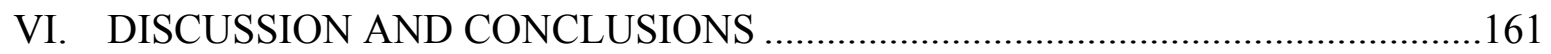

The role of market knowledge and technology knowledge in the recognition of

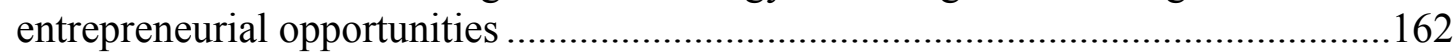

The role of market knowledge in the exploitation of technology based

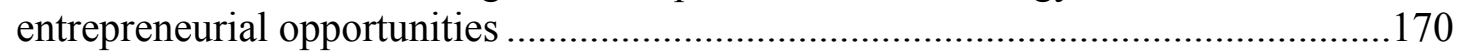

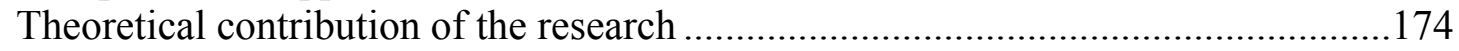

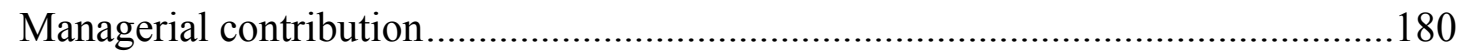

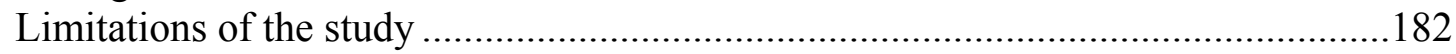

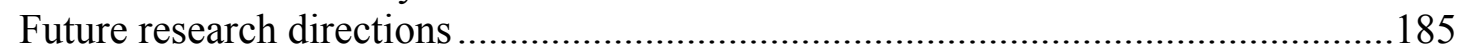

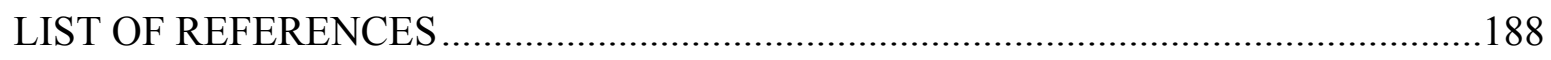

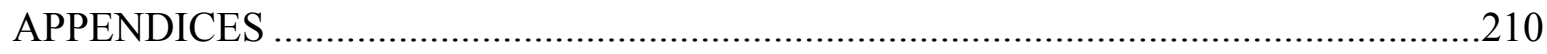

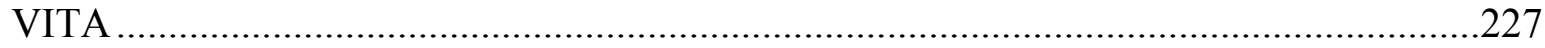




\section{LIST OF TABLES}

TABLE

PAGE

Table 1: Some definitions of entrepreneurial opportunity, 2000-2007 12

Table 2: Sources and types of entrepreneurial opportunities .17

Table 3: Comparing the three views of entrepreneurial opportunity..... .22

Table 4: Schumpeterian and Kirznerian opportunities .35

Table 5: Constructs and measurements in the empirical study...... .66

Table 6: Refinement of market knowledge scale.

Table 7: Entrepreneurial orientation scale reliability, item statistics. .73

Table 8: Comparison of patent data from USPTO and interviewees. .78

Table 9: Correlations between patent data from USPTO and interviewees. .79

Table 10: Primary and secondary sales data...... 91

Table 11: Position of interviewees, phase 1 100

Table 12: Age of sample firms and non-respondents 109

Table 13: Correlations between recognized and exploited opportunities . 119

Table 14: Correlations between market knowledge and business philosophy 120

Table 15: Scale reliabilities 125

Table 16: Test-retest correlations and mean differences 126

Table 17: Data characteristics (original data) 130

Table 18: Data transformations. 131

Table 19: Survey response by geographic region 133

Table 20: Correlations for selected phase 1 variables and company status in phase $2 \ldots . .135$

Table 21: T-test for differences in variables, USA vs. Nordic firms 140

Table 22: Data characteristics. 142 
Table 23: Pearson correlations for dependent and independent variables in the regression analysis

Table 24: Regression results. Dependent variable: Entrepreneurial opportunities recognized (phase $2, \log$ ).

Table 25: Regression results, part 2. Dependent variable: Entrepreneurial opportunities recognized (phase $2, \log$ )

Table 26: Regression results for firm profit potential (phase 2)

Table 27: Regression results for firm profit potential (phase 2) continued..... 154

Table 28: Results by hypothesis 160

Table 29: Position of respondents. 225

Table 30: Phase of most advanced product .226 


\section{LIST OF FIGURES}

FIGURE

PAGE

Figure 1: Supply, demand, and the nature of entrepreneurial opportunities.

Figure 2: Alertness and the opportunity identification process .28

Figure 3: Technology knowledge as a source of entrepreneurial opportunities .39

Figure 4: Market knowledge as a source of entrepreneurial opportunities. .42

Figure 5: Equilibrium, disequilibrium, and entrepreneurial opportunities in time

Figure 6: The direct and moderating effects of market knowledge on entrepreneurial opportunity recognition. Ex ante model.

Figure 7: The moderating effect of market knowledge on the relationship between entrepreneurial opportunities and profit potential. Ex ante model.

Figure 8: Phases of empirical data collection

Figure 9: Biopharmaceutical product development pipeline and questionnaire items E1-E9.

Figure 10: Response patterns in the empirical study .....

Figure 11: Error bars showing 95\% confidence interval of mean for market knowledge by phase 2 status category

Figure 12: Error bars showing 95\% confidence interval of mean for opportunities recognized by phase 2 status category.

Figure 13: The interaction of market knowledge and technology knowledge (patents) in influencing entrepreneurial opportunities recognized.

Figure 14: The interaction of entrepreneurial orientation and market knowledge in influencing entrepreneurial opportunities recognized.

Figure 15: The direct and moderating effects of market knowledge on entrepreneurial

opportunity recognition. Ex post model.

Figure 16: The relationships between market knowledge, entrepreneurial opportunities recognized, and profit potential. Ex post model.

Figure 17: Sample companies (phase $1, \mathrm{n}=85$ ) by field of business. 


\section{INTRODUCTION}

"But perhaps most importantly, an inquiry into entrepreneurial opportunity has the potential to unlock one of the greatest intellectual puzzles of our time, namely the creation of new value in society".

Sarasvathy, Venkataraman, Dew, \& Velamuri (2003)

\section{Background of the research}

It is a widely held belief that dynamic high technology industries are composed of entrepreneurial firms (Maidique and Hayes 1984) and that these markets encourage entrepreneurial firm-level behavior (Khandwalla 1987; Oakey 2003; Hindle and Yencken 2004). Entrepreneurial opportunity discovery is a necessary step on the path to commercializing science and technologies (Venkatarman 1997; Shane 2000; Shane and Venkataraman 2000). Instances of entrepreneurial discovery are social and purposeful developments of previously nonexistent knowledge. Opportunities are results of idiosyncratic emergences of knowledge that are inherently novel. It follows that entrepreneurial opportunities, as breakouts from the limits of prior knowledge, are unpredictable (Murphy and Shrader 2004). As statistical predictions are based on reliable causes that are known, trying to predict entrepreneurial discovery is impossible.

Some researchers argue that the subjective or socially constructed nature of opportunity makes it impossible to even separate opportunity from the individual; undiscovered opportunities are impossible to know and impossible to study (Singh 2000). Others contend that opportunity is an objective construct visible to or created by the knowledgeable 
entrepreneur. Either way, a set of weakly held assumptions about the nature and sources of entrepreneurial opportunities appear to dominate much of the discussion in the literature (McMullen, Plummer and Acs 2007). Given this ambiguity, one would initially be discouraged to study the nature, sources, or social and cognitive processes of entrepreneurial opportunities. However, entrepreneurial opportunities also present one of the most exciting topics of research within entrepreneurship. Since researchers have only recently started to understand the importance of opportunity recognition as a distinctive area of enquiry for entrepreneurship research, there are numerous contributions yet to be made on the topic. Although it is hard to get any group of entrepreneurship researchers to agree on a definition of their field, the key concept of an opportunity that either exists objectively or is perceived subjectively by the entrepreneur is in the heart of entrepreneurship (Sanders 2007).

The potential sources of entrepreneurial opportunities in the society are almost as numerous as the opportunities that are recognized. Each entrepreneurial opportunity has its own story; a distinct narrative that describes how this opportunity came into being. In an attempt to categorize these potential sources of opportunities, Drucker (1985) suggested the following twelve sources that may potentially lead to entrepreneurial opportunity recognition: the unexpected success, the unexpected failure, the unexpected outside event, inconsistent economic events, inconsistency between reality and our assumption about reality, inconsistency between our perceptions and actual customer expectations, inconsistency within the logic of a process, process need, industry and market structures, demographics, change in perception, and new knowledge. It is clear that it is impossible to consider all these sources and their sub-groups within one study. This research focuses on new knowledge as a driver of entrepreneurial opportunities and the resulting economic growth (Wennekers and Thurik 1999). 


\section{Research gap and questions}

This research contributes to the expanding literature on entrepreneurial opportunities. It has been argued that although the examination of opportunities is a central aspect of entrepreneurship, it is largely overlooked (Shane and Venkataraman 2000; Ardichvili, Cardozo and Ray 2003; Shane 2003). Shane and Venkataraman (2000) thus suggest that future entrepreneurship research should concentrate on three fundamental questions (p. 218):

1) "why, when, and how opportunities for the creation of goods and services come into existence;

2) why, when, and how some people and not others, discover and exploit these opportunities and;

3) why, when, and how different modes of action are used to exploit entrepreneurial opportunities." (Shane and Venkataraman 2000)

This study directly contributes to answering all of these three categories of questions. More specifically, the research is based on Austrian economic theories and the work of Kirzner (1973; 1979; 1997). Following Kirzner, numerous researchers have emphasized the role of knowledge in entrepreneurial opportunity discovery (Christensen, Madsen and Peterson 1994; Gaglio 1997; Shane 2000; Gaglio and Katz 2001; Sarasvathy 2001b; Ardichvili et al. 2003; Eckhardt and Shane 2003; Holcombe 2003; Hills and Singh 2004; McKelvie and Wiklund 2004; Murphy and Shrader 2004; Lumpkin and Lichtenstein 2005; Park 2005; Sanz-Velasco 2006; Cohen and Winn 2007; Ozgen and Baron 2007). More specifically, based on this stream of literature one concludes that there is something magical about market knowledge and coming up with entrepreneurial opportunities. Idiosyncratic knowledge of markets and customers makes it possible for some individuals to recognize entrepreneurial opportunities in conceptual models on opportunity recognition (Gaglio and 
Katz 2001; Ardichvili et al. 2003; Shane 2003; Gaglio 2004), and there is also some empirical research that supports this claim (Teach, Schwartz and Tarpley 1989; Hills, Shrader and Lumpkin 1999; Shane 2000; Hills and Singh 2004; McKelvie and Wiklund 2004).

Despite the growing research base, the mechanisms through which different forms of knowledge contribute to entrepreneurial opportunities are still unclear. Few empirical tests of entrepreneurial opportunities are reported in the existing literature, not least because of the difficulties in defining and measuring opportunities. The studies that have tried to empirically test the role of different types of knowledge in entrepreneurial opportunity recognition are mostly limited to case evidence (Shane 2000; McKelvie and Wiklund 2004; Park 2005; Sanz-Velasco 2006) with only a few exceptions of empirical research with quantitative data (Teach et al. 1989; Singh 2000; Choi and Shepherd 2004; Saemundsson and Dahlstrand 2005). Still, entrepreneurship researchers agree that entrepreneurial opportunities and recognizing them is one of those critical areas that distinguishes the study of entrepreneurship from other business disciplines. Hence, the more comprehensive assessment of the knowledge behind entrepreneurial opportunities conducted in this research should advance our understanding of entrepreneurial opportunities in particular and the field of entrepreneurship in general.

Entrepreneurship researchers that have followed the Austrian economics tradition essentially argue for a linear relationship between the amount of knowledge the individual has and the amount of entrepreneurial opportunities recognized by the individual, given the same level of alertness (Christensen et al. 1994; Gaglio 1997; Shane 2000; Gaglio and Katz 2001; Sarasvathy 2001b; Ardichvili et al. 2003; Eckhardt and Shane 2003; Holcombe 2003; Hills and Singh 2004; McKelvie and Wiklund 2004; Murphy and Shrader 2004; Lumpkin and Lichtenstein 2005; Park 2005; Sanz-Velasco 2006; Cohen and Winn 2007; Ozgen and 
Baron 2007). However, elsewhere in the literature researchers have demonstrated that there are interrelationships between different types of knowledge; possessing one kind of knowledge may blind sight an entrepreneur or a firm to another type of knowledge. These interrelationships have best been demonstrated as tradeoffs between technology knowledge and market knowledge. (Hamel and Prahalad 1991; Leonard-Barton 1995; Christensen and Bower 1996; Christensen 1997; Leonard-Barton and Rayport 1997; O’Connor 1998; Takayama and Watanabe 2002; Thieme and Song 2002)

The purpose of this research is to understand the role of market knowledge in entrepreneurial opportunity recognition in technology intensive firms. In order to achieve this, the nature of entrepreneurial opportunities - as well as the processes through which they are discovered and developed - has to be explored. Based on this research, we will have a better understanding of

1) how opportunities for the creation of goods and services come into existence,

2) why some people, and not others, discover and exploit these opportunities: What is the role of idiosyncratic market knowledge and new scientific knowledge in the creation and discovery of technology based entrepreneurial opportunities?

3) how different modes of action are used to exploit entrepreneurial opportunities: How does market knowledge contribute to the exploitation of technology based entrepreneurial opportunities?

Following the literature review presented in this paper, specific hypotheses (refutable assertions) are developed regarding the role of market knowledge in entrepreneurial opportunity recognition and exploitation. These hypotheses specify three different mechanisms through which market knowledge influences entrepreneurial opportunity recognition and exploitation. The mechanisms suggested are (1) the moderating role of market knowledge (positive or negative, depending on the amount of market knowledge) in 
the relationship between technology knowledge and entrepreneurial opportunities recognized in a young venture, (2) the direct positive effects of market knowledge on the entrepreneurial opportunities recognized in a young venture, and (3) the positive moderation of market knowledge in the relationship between entrepreneurial opportunities recognized in a young venture and the subsequent profit potential of the venture. The hypotheses are tested in a dataset from young biotechnology ventures.

In line with Shane and Venkataraman (2000), this study is based on the premise that the discovery, evaluation, and exploitation of opportunities is a defining feature of the field of entrepreneurship. Entrepreneurship has also been defined as the creation of new organizations (Gartner 1989; Thornton 1999; Reynolds 2007). The domain of potential business opportunities includes those that can lead to new startups (Fiet 2002).

\section{Empirical setting}

A wealth of research efforts has been devoted to examining the cognitive characteristics of individuals that discover entrepreneurial opportunities (Mitchell, Busenitz, Bird, Gaglio, McMullen, Morse and Smith 2007). Also, researchers have studied the economic nature of the opportunities themselves, and typically considered them as situations following from uneven distribution of information in the marketplace (Kirzner 1997). Entrepreneurial opportunities also have a contextual component to them, even though this aspect has not received much attention from researchers. For one, even alert individuals only discover opportunities in industries they are familiar with (Shane 2000). In addition, idiosyncratic knowledge characterizes especially industries that are dynamic in nature and experience rapid obsolescence of information and products. In a high growth industry the population

density is low and the carrying capacity of the industry is high (Hannan 1998). There has 
been a disturbing lack of consideration of the industry situation as a basis for modeling entrepreneurial opportunities and their discovery. As an entrepreneurial opportunity results from the interaction of a person with his or her environment, an approach sensitive to both the actor and the industry environment is needed to understand entrepreneurial opportunity recognition.

This research focuses on technology intensive industries. Technology-intensive industries are characterized by products that are based on significant amounts of scientific and technical know-how. Complexity and speed of change are corollaries of know-how intensity, not foundational concepts of technology intensive markets. (John, Weiss and Dutta 1999) Biotechnology is an example of a technology intensive sector and also the empirical context of this research. Biotechnology provides an excellent setting for the examination of the entrepreneurial opportunity recognition. Roughly speaking, biotechnology is defined as the application of knowledge of living organisms and their components to industrial products and processes (Brink, McKelvey and Smith 2004). Out of the different technology categories underneath the biotechnology "umbrella", this study focuses on pharmaceuticals, diagnostics, medicine and the application of biomaterials for medical purposes.

Modern biotechnology is a field characterized by dynamism and rapid obsolescence of scientific and technological information. Idiosyncratic knowledge among players in the field of biotechnology should result in plentiful entrepreneurial opportunities, if we follow the Austrian logic (Hayek 1945; Kirzner 1973; Kirzner 1997; Shane 2003). Two characteristics are typical of biotechnology products in the categories specific above. First, at the launching of a project, the product still requires a functional definition. This means that the idea has been identified, the patent has most likely been filed, but the business opportunity is still unclear. Second, the development requires a program of scientific research of the main phenomena associated with the product. This development, including the typical preclinical 
and clinical test phases, is highly regulated by authorities such as the Food and Drug Administration (FDA). Hence, the "components" of the opportunity discovery and development process are given; if the idea is to be developed into a commercial product, it should be patented and has to go through certain phases of testing and development. A wealth of the research that has tried to encapsulate the peculiarities of entrepreneurial opportunity recognition has focused on identifying various motivations of or stages in the opportunity recognition process (Teach et al. 1989; Gaglio and Taub 1992; Krueger 1993; Bhave 1994; Gaglio 1997; Krueger, Reilly and Carsrud 2000; Gaglio and Katz 2001; Lumpkin, Hills and Shrader 2004; Lumpkin and Lichtenstein 2005; Park 2005; Mitchell et al. 2007). If entrepreneurial opportunities are a function of the characteristics of an entrepreneur, the new venture idea, and the environmental variables as suggested by Singh (2000), then holding factors in the "environment" constant makes it easier to study the role of the entrepreneur as well as the venture idea. By focusing on entrepreneurial opportunities in biotechnology, the main components of the opportunity recognition environment are given in that the underlying technical knowledge behind the opportunity has to be patented, and that in order to be commercialized, the opportunity typically has to go through a highly regulated and standardized development process. Hence, instead of trying to draw generalizations on the components of opportunity recognition and development process - a task that has proven to be a challenging and controversial one, not least because of the great variations in the ways that individuals come up with business opportunities - we can truly focus on the role of market knowledge in entrepreneurial opportunity recognition and exploitation. 
Even though individuals initially discover opportunities, they are typically developed in firms. Recognizing (or discovering) ${ }^{1}$ an entrepreneurial opportunity is perceiving a possibility to introduce innovative (rather than imitative) goods or services to a marketplace through (a) the founding and formation of a new venture, or (b) the significant improvement of an existing venture (Singh 2000; Gaglio 2004). Because recognition only entails perception, it follows that exploitation of an opportunity is a separate activity. The exploitation of an opportunity refers to those activities committed to (a) the founding and formation of a new venture, or (b) the significant improvement of an existing venture in order to introduce innovative (rather than imitative) goods or services to marketplace.

Because undiscovered opportunities are impossible to identify for research purposes, it follows that the level of analysis in the current study is a firm. Previous attempts to examine entrepreneurship on the organizational level have been mostly limited to the study of entrepreneurial orientation / corporate entrepreneurship (Miller and Friesen 1982; Khandwalla 1987; Covin and Slevin 1991; Zahra 1993) but recently opportunity recognition has also been increasingly linked to organizational context (Lumpkin and Lichtenstein 2005; Park 2005; Companys and McMullen 2007). Further, it should be noted that opportunity recognition is a process and that it can occur both prior to firm founding and after firm founding throughout the life of the firm (Singh 2000).

By focusing on technology based startups, the research provides important information on organizations that are considered to be the driving force of knowledge based economy (Reynolds 2007). A better understanding of opportunity recognition processes used in such technology sectors has obvious benefits in helping governments develop and refine appropriate policies and support programs. (Park 2005)

\footnotetext{
${ }^{1}$ A detailed discussion on the different views of opportunity recognition vs. discovery follows in section II of the dissertation.
} 


\section{LITERATURE REVIEW}

\section{Entrepreneurial opportunities defined}

Researchers' interest in economic opportunities cuts across a broad swathe of disciplines including management, organization theory, marketing, and entrepreneurship (Ardichvili et al. 2003), and the concept of opportunity is a key concept especially within entrepreneurship and marketing theory (Blenker, Philipsen and Damgaard 2005). For example, the stylized fact that the actor that has a superior understanding of what is "knowable" about production and the market (i.e., superior knowledge schemas) is more likely to spot opportunities (Dickson 1992) is relevant for entrepreneurship as well as marketing researchers. Economic opportunities include both the technological opportunities that make the creation of new goods and services possible, as well as the market opportunities that enable these new goods and services to be commercialized for wealth creation (Companys and McMullen 2007).

Since entrepreneurial opportunities have been a subject of increasing research interest one would expect to find clear definitions for the term in the existing literature. How do entrepreneurial opportunities differ from the rest of the business opportunities, or do they? Vesper (1993) distinguishes a business opportunity from a new venture opportunity by saying that a business opportunity is one in which an entrepreneur within an established business recognizes an opportunity for new profit potential, whereas a new venture opportunity is one that can only be taken advantage of through the founding of an independent new venture. Both categories include both incremental and radical opportunities. Like Vesper, many in the entrepreneurship discipline use the term 
"opportunity" to mean the chance to start a business (Long and McMullan 1984; Hills et al. 1999; De Carolis and Saparito 2006; Mueller 2007), but few researchers are explicit about the condition that in order for a business opportunity to be entrepreneurial, it needs to be related to starting up a new business.

Overall, a look at the various definitions offered for the term "entrepreneurial opportunity" in the new millennium leads to confusion. Researchers have suggested a myriad of definitions with varying foci (See Table 1). What is more, some researchers study entrepreneurial opportunities without ever defining the term. For example, a recent article by Ozgen and Baron (2007) focuses on entrepreneurial opportunity recognition without ever defining what is being recognized. However, Ozgen and Baron (2007) measure opportunity recognition on the level of an individual using a three item scale, where the items are as follows: (1) While going about day-to-day activities, I see potential new venture ideas all around me, (2) I have a special alertness or sensitivity toward new venture opportunities, (3) Seeing potential new venture opportunities does not come very naturally to me (reverse scored). From the way that they operationalize opportunity recognition one can assume that opportunities are perceived as some things "out there", which can be recognized by alert individuals and lead to new venture formation (Ozgen and Baron 2007).

Summarizing the articles in a recent issue of Small Business Economics devoted to entrepreneurial opportunities, McMullen et al. (2007) point out that most of the articles in the special issue equated an entrepreneurial opportunity with the generation of new goods or services. Newness (novelty) also seems to be the common characteristic in a number of definitions of opportunity provided in Table 1. 
Table 1: Some definitions of entrepreneurial opportunity, 2000-2007

\begin{tabular}{|c|c|c|c|c|c|c|c|c|c|}
\hline \multirow[t]{2}{*}{ Author(s) } & \multirow[t]{2}{*}{ Exact term } & \multirow[t]{2}{*}{ Definition } & \multicolumn{2}{|c|}{ Actor } & \multicolumn{5}{|c|}{ Attributes ( $\mathrm{O}=$ =implicit; $\mathrm{X}=$ =explicit) } \\
\hline & & & 晃 & 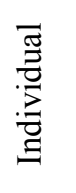 & $\begin{array}{l}\frac{3}{0} \\
\stackrel{2}{0} \\
z\end{array}$ & 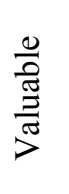 & 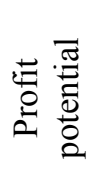 & 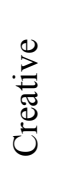 & 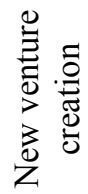 \\
\hline $\begin{array}{l}\text { Denrell, } \\
\text { Fang \& } \\
\text { Winter } \\
(2003)\end{array}$ & $\begin{array}{l}\text { Strategic } \\
\text { opportunity }\end{array}$ & $\begin{array}{l}\text { Exists whenever prices fail to reflect the value of a } \\
\text { resource's best use. }\end{array}$ & $\mathrm{X}$ & & & & $\mathrm{X}$ & & \\
\hline $\begin{array}{l}\text { Singh } \\
(2000)\end{array}$ & $\begin{array}{l}\text { Entrepreneurial } \\
\text { opportunity }\end{array}$ & $\begin{array}{l}\text { A feasible, profit-seeking, potential venture that provides an } \\
\text { innovative new product or service to the market, improves } \\
\text { on an existing product /service, or imitates a profitable } \\
\text { product / service in a less-than-saturated market. (p. } 23 \text { ) }\end{array}$ & & $\mathrm{X}$ & $\mathrm{X}$ & & $\mathrm{X}$ & & $\mathrm{X}$ \\
\hline Goss (2007) & $\begin{array}{l}\text { Schumpeterian } \\
\text { opportunity }\end{array}$ & $\begin{array}{l}\ldots \text { are disequilibrating, depend upon new } \\
\text { information, are highly innovative, rare, and involve } \\
\text { processes of creation [...] to establish new ways of doing } \\
\text { things and turning these into a viable business. }\end{array}$ & & $\mathrm{X}$ & $\mathrm{X}$ & & $\mathrm{X}$ & $\mathrm{X}$ & $\mathrm{X}$ \\
\hline $\begin{array}{l}\text { Sanz- } \\
\text { Velasco } \\
(2006)\end{array}$ & Opportunity & $\begin{array}{l}\text { (1) involves a definite offer to the customer, (2) envisages a } \\
\text { definite customer segment, (3) creates definite value, (4) has } \\
\text { a definite revenue model; and (5) is accomplished through } \\
\text { technology. }\end{array}$ & & $\mathrm{O}$ & & $\mathrm{X}$ & $\mathrm{X}$ & & \\
\hline $\begin{array}{l}\text { Dutta \& } \\
\text { Crossan } \\
(2005)\end{array}$ & $\begin{array}{l}\text { Entrepreneurial } \\
\text { opportunity }\end{array}$ & $\begin{array}{l}\text { [Entrepreneurial opportunities are] a set of environmental } \\
\text { conditions that lead to the introduction of one or more new } \\
\text { products or services in the marketplace by an entrepreneur or } \\
\text { by an entrepreneurial team through either an existing venture } \\
\text { or a newly created one. (p. } 426)\end{array}$ & $\mathrm{O}$ & $\mathrm{X}$ & $\mathrm{X}$ & & & & $\mathrm{X}$ \\
\hline
\end{tabular}




\begin{tabular}{|c|c|c|c|c|c|c|c|c|c|}
\hline \multirow[t]{2}{*}{ Author(s) } & \multirow[t]{2}{*}{ Exact term } & \multirow[t]{2}{*}{ Definition } & \multicolumn{2}{|c|}{ Actor } & \multicolumn{5}{|c|}{ Attributes (O=implicit; $\mathrm{X}=$ =xplicit) } \\
\hline & & & 声 & 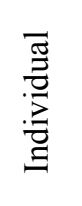 & $\begin{array}{l}\frac{3}{0} \\
\stackrel{2}{0} \\
z\end{array}$ & $\begin{array}{l}\frac{0}{0} \\
\frac{\pi}{\tilde{\pi}} \\
>\end{array}$ & 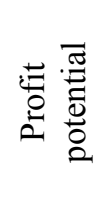 & 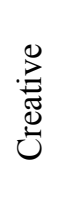 & 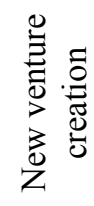 \\
\hline $\begin{array}{l}\text { Eckhardt \& } \\
\text { Shane } \\
\text { (2003) }\end{array}$ & $\begin{array}{l}\text { Entrepreneurial } \\
\text { opportunity }\end{array}$ & $\begin{array}{l}\text { [Entrepreneurial opportunities are] situations in which new } \\
\text { goods, services, raw materials, markets and organizing } \\
\text { methods can be introduced through the formation of new } \\
\text { means, ends, or means-ends relationships. (p. 336) }\end{array}$ & & & $\mathrm{X}$ & & & & \\
\hline $\begin{array}{l}\text { Gaglio } \\
(2004)\end{array}$ & Opportunity & $\begin{array}{l}\text { The chance to introduce innovative (rather than imitative) } \\
\text { goods, services, or processes to an industry or economic } \\
\text { marketplace. (p. 534) }\end{array}$ & & $\mathrm{X}$ & $\mathrm{X}$ & & & $\mathrm{X}$ & \\
\hline $\begin{array}{l}\text { Sarasvathy, } \\
\text { Venkataram } \\
\text { an, Dew \& } \\
\text { Velamuri } \\
\text { (2003) }\end{array}$ & $\begin{array}{l}\text { Entrepreneurial } \\
\text { opportunity }\end{array}$ & $\begin{array}{l}\text { An entrepreneurial opportunity [...] consists of a set of ideas, } \\
\text { beliefs and actions that enable the creation of future goods } \\
\text { and services in the absence of current markets for them. } \\
\text { Original definition Venkataraman (1997) }\end{array}$ & & & & & & $\mathrm{X}$ & \\
\hline $\begin{array}{l}\text { Ardichvili, } \\
\text { Cardozo \& } \\
\text { Ray (2003) }\end{array}$ & Opportunity $^{2}$ & $\begin{array}{l}\text { Underutilized or unemployed resources, as well as new } \\
\text { capabilities or technologies may offer possibilities to create } \\
\text { and deliver new value for prospective customers, even } \\
\text { though the precise forms that new value will take may be } \\
\text { undefined. (p. 108) }\end{array}$ & $\mathrm{X}$ & $\mathrm{X}$ & $\mathrm{X}$ & $\mathrm{X}$ & & $\mathrm{X}$ & \\
\hline $\begin{array}{l}\text { Casson \& } \\
\text { Wadeson } \\
(2007)\end{array}$ & Opportunity & $\begin{array}{l}\text { An unexploited project which is perceived by an individual } \\
\text { to afford potential benefit. }\end{array}$ & & $\mathrm{X}$ & & $\mathrm{X}$ & & & \\
\hline $\begin{array}{l}\text { Shane \& } \\
\text { Venkataram }\end{array}$ & $\begin{array}{l}\text { Entrepreneurial } \\
\text { opportunity }\end{array}$ & $\begin{array}{l}\text { Situations in which new goods, services, raw materials, and } \\
\text { organizing methods can be introduced and sold at greater }\end{array}$ & & $\mathrm{X}$ & $\mathrm{X}$ & & $\mathrm{X}$ & & \\
\hline
\end{tabular}

${ }^{2}$ Ardichvili et al. (2003) do not provide one clear definition for an opportunity. Instead, they reflect multiple perspectives of opportunity that have been presented in precious research. The sentence provided here as their definition for opportunity best summarizes the essence of what the authors themselves seem to describe as an opportunity. 


\begin{tabular}{|c|c|c|c|c|c|c|c|c|c|}
\hline \multirow[t]{2}{*}{ Author(s) } & \multirow[t]{2}{*}{ Exact term } & \multirow[t]{2}{*}{ Definition } & \multicolumn{2}{|c|}{ Actor } & \multicolumn{5}{|c|}{ Attributes (O=implicit; $\mathrm{X}=$ =xplicit) } \\
\hline & & & 茫 & 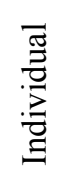 & $\begin{array}{l}\stackrel{\gtrsim}{E} \\
0 \\
0 \\
z\end{array}$ & 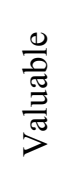 & 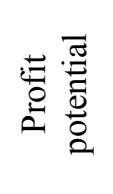 & 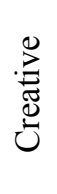 & 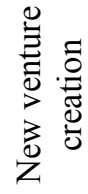 \\
\hline an $(2000)$ & & than their cost of production. (Original: Casson 1982) & & & & & & & \\
\hline $\begin{array}{l}\text { Companys } \\
\& \\
\text { McMullen } \\
(2007)\end{array}$ & $\begin{array}{l}\text { Entrepreneurial } \\
\text { opportunity }\end{array}$ & $\begin{array}{l}\text { An opportunity to engage in entrepreneurial action, in which } \\
\text { entrepreneurial denotes a sub-class of some broader category } \\
\text { of human action. Because all human action is arguably } \\
\text { motivated by profit (Homans, 1974), the adjective } \\
\text { entrepreneurial is used to qualify the manner by which this } \\
\text { profit is sought - i.e., through the introduction of new goods } \\
\text { or services. }\end{array}$ & $\mathrm{X}$ & $\mathrm{X}$ & $\mathrm{X}$ & & $X$ & & \\
\hline $\begin{array}{l}\text { Mueller } \\
(2007)\end{array}$ & $\begin{array}{l}\text { Entrepreneurial } \\
\text { opportunity }\end{array}$ & Startup activity & & $\mathrm{O}$ & & & & & $\mathrm{X}$ \\
\hline $\begin{array}{l}\text { Ozgen \& } \\
\text { Baron } \\
(2007)\end{array}$ & Opportunity & $\mathrm{N} / \mathrm{A}$ & & $\mathrm{O}$ & & & & & $\mathrm{O}$ \\
\hline $\begin{array}{l}\text { Wiklund \& } \\
\text { Shepherd } \\
(2003)\end{array}$ & Opportunity & $\begin{array}{l}\text { N/A, but reference is made to Shane \& Venkataraman, } \\
\text { (2000); opportunities to bring into existence future goods } \\
\text { and services. }\end{array}$ & $\mathrm{O}$ & & $\mathrm{X}$ & & & & \\
\hline $\begin{array}{l}\text { DeCarolis \& } \\
\text { Saparito } \\
(2006)\end{array}$ & $\begin{array}{l}\text { Entrepreneurial } \\
\text { opportunity }\end{array}$ & $\begin{array}{l}\text { N/A. Imply that entrepreneurial opportunity equals starting } \\
\text { up a new organization. }\end{array}$ & & $\mathrm{O}$ & & & & & $\mathrm{O}$ \\
\hline $\begin{array}{l}\text { Cohen \& } \\
\text { Winn (2007) }\end{array}$ & $\begin{array}{l}\text { Entrepreneurial } \\
\text { opportunity }\end{array}$ & N/A & & $\mathrm{O}$ & & & & & \\
\hline
\end{tabular}


To summarize the definitions of entrepreneurial opportunity in Table 1, out of the 13 definitions provided by various researchers, four state or imply that a firm can be the actor that discovers or recognizes opportunities. In addition, Wiklund \& Shepherd (2003), who do not provide a clear definition for opportunity, empirically test the following hypothesis on the firm level: "A bundle of knowledge-based resources applicable to the discovery and exploitation of opportunities is positively related to firm performance". This implies that firm is perceived as capable of discovering and exploiting opportunities. Outside of Table 1, it should be mentioned that Lumpkin and Lichtenstein (2005) link organizational learning to opportunity recognition of an organization, and define opportunity recognition as the firm's ability to identify a good idea and transform it into a business concept that adds value and generates revenues (Lumpkin and Lichtenstein 2005). Even though terminology for organizational learning and organizational resources, for example, has been established in the literature, organizational opportunity recognition is still almost unheard of ${ }^{3}$. This is most likely a result of the fact that for many entrepreneurship scholars, the establishment of a new organization is an essential part of the definition of entrepreneurship (Katz and Gartner 1988).

Out of the 13 researchers who define opportunity (Table 1), ten state or imply that individuals discover (recognize) opportunities. Regarding the attributes that researchers have attached to (entrepreneurial) opportunities, novelty is the most common attribute among the definitions in Table 1; nine out of the seventeen studies listed in the table talk about newness or novelty. Profit potential and new venture creation are both characteristics of six conceptualizations out of the total of seventeen presented here. Finally, creativity is an

\footnotetext{
${ }^{3}$ Two exceptions in the recent literature include Rice, Kelley, Peters \& O'Connor (2001) who use opportunity recognition terminology in their study of eight radical innovation projects in six large, multinational, $R \& D$ intensive firms, and Brown, Davidsson \& Wiklund (2001) who operationalize opportunity-based firm behavior.
} 
integrated characteristic of an opportunity in four studies, and three studies attach the attribute "valuable" to the opportunity concept.

Based on Table 1 one arrives to the same conclusion with McMullen et al. (2007): There is no consensus on the very nature of entrepreneurial opportunities. McMullen et al. (2007) summarize the main sources of confusion as follows: (1) the "objectivity" of opportunity, (2) the perceived importance of one particular individual in determining the direction of the social world, and (3) what distinguishes the sub-class of "entrepreneurial" opportunity from the broader category of opportunity in general (McMullen et al. 2007). With regards to this third source of confusion, it is especially the relationship between innovations and entrepreneurial opportunities that remains blurred in the existing literature. For example, Companys \& McMullen (2007) review existing literature and summarize the sources of opportunities into three categories: Economic, cultural cognitive, and sociopolitical (Table 2). Economic opportunities encompass technological and market opportunities resulting from material innovation, whereas cultural cognitive opportunities consist of cultural innovations introduced into the marketplace by either producers or consumers. Sociopolitical opportunities include network opportunities resulting from the structural features of social networks and political opportunities attributable to changes in the governance structures of these networks. 
Table 2: Sources and types of entrepreneurial opportunities

\begin{tabular}{llll}
\hline & Economic & Cultural cognitive & Sociopolitical \\
\hline Sources & $\begin{array}{l}\text { Resources and } \\
\text { capabilities, } \\
\text { information }\end{array}$ & $\begin{array}{l}\text { Templates, } \\
\text { knowledge }\end{array}$ & $\begin{array}{l}\text { Network and } \\
\text { governance } \\
\text { structures }\end{array}$ \\
& Technological & Producer & Network \\
Subtypes & Market & Consumer & Political \\
& Technological: & Producer: & Network: \\
Examples & Product innovation & Cultural & Knowledge \\
& Factor innovation & communities & Seterogeneity \\
& & Robust designs & Structural holes \\
& Market: & Consumer: & Political: \\
& Latent needs & Fads & Elite cleavages \\
& User innovation & User practices & Deregulation \\
\hline
\end{tabular}

Source: Companys \& McMullen 2007, 308

What is interesting about the Companys \& McMullen (2007) discussion of economic opportunities is that they use the terms innovation and opportunity interchangeably. In addition, since innovation equals entrepreneurial opportunity, it follows that: "Entrepreneurial opportunities for innovation exist at the individual, firm, and industry levels" (Companys \& McMullen 2007, 319).

Yet another source of confusion in the existing literature seems to prevail around the profitability requirement that some researchers attach to the opportunity concept. According to Shane and Venkataraman $(2000,220)$, entrepreneurial opportunities are defined as "those situations in which new goods, services, raw materials, and organizing methods can be introduced and sold at greater than their cost of production" (For original definition, see Casson 1982). From this it follows that the "better" the entrepreneurial opportunity, the more substantial its contribution to the firm's bottom line performance. This definition of entrepreneurial opportunity has been criticized because the profit potential of an opportunity 
can only be evaluated in retrospect (Singh 2001). Also, opportunities in the Casson (1982) sense are not discovered until they are being exploited because it is only then that the entrepreneur knows if new things can be introduced and sold at prices higher than their costs (McKelvie and Wiklund 2004). In a more recent publication, Shane $(2003,18)$ redefines an entrepreneurial opportunity as "a situation in which a person can create a new means-ends framework for recombining resources that the entrepreneur believes will yield a profit". It is worthwhile to note that in this definition, the profit requirement of an opportunity has been released. Entrepreneurial opportunities are not necessarily profitable and because of this they should not be thought as Ricardian, Schumpeterian, or other kinds of rents. (Shane 2003) In line with the definition above, also Sarasvathy, Venkataraman, Dew, \& Velamuri (2003) propose a definition of entrepreneurial opportunities, where the belief in profit is central: Entrepreneurial opportunity consists of (1) new idea/s or invention/s that may or may not lead to the achievement of one or more economic ends that become possible through those ideas or inventions; and (2) beliefs about things favorable to the achievement of those ends (Sarasvathy et al. 2003).

Based on the research insights presented above it is clear that there is no current consensus concerning the exact meaning of the entrepreneurial opportunity concept. However, based on the definitions offered in existing literature we can conclude that some unifying themes exist; many researchers share the innovation-emphasis evident initially in the writings of Kirzner (1979) and Schumpeter (1934b) (See also McMullen et al. 2007). To distinguish from "non-entrepreneurial" opportunities, some researchers have also added the element of starting a firm. Ultimately, however, the firm is started with the purpose of introducing a new good or service (McMullen et al. 2007). For the purposes of this study, entrepreneurial opportunity is defined as the possibility to introduce innovative (rather than imitative) goods or services to a marketplace through starting a firm or through the 
significant improvement of an existing venture (Inspired especially by the definitions of Gaglio 2004, 534, Singh 2000, 23, and Mueller 2007, 356).

If this is the definition given to an entrepreneurial opportunity, then the logical next question is how are these opportunities discovered and turned into real - and sometimes profitable - products or services in the marketplace? As already mentioned in the introductory chapter, discovering (or recognizing) an entrepreneurial opportunity is $a$ process (Shane 2000; Fiet 2002; Shane 2003) in which the perception about the presence of an opportunity is a driving force. This process of recognizing opportunities is discussed next.

\section{How are entrepreneurial opportunities recognized?}

Even if there is no consensus in the research community over what exactly constitutes entrepreneurial opportunities, it would be hard to find a scholar in economics or management who would challenge the argument that entrepreneurial opportunities are important (McMullen et al. 2007). Given the importance of opportunities, the next big questions are who, when, and how recognizes those opportunities? As expected, there are no unambiguous answers to these questions either. For one, the philosophical nature of the opportunity itself (over which there is obviously no agreement in the research community) has implications on how that very opportunity is recognized. Second, even if we decide on the nature of the opportunity, establishing boundaries around whatever constitutes "recognition" is still challenging. Is recognition limited to the kind of "Eureka" experience described, for example, in Gaglio's work? Or is opportunity recognition a process that spans over time, as many would suggest (Shane 2000; Fiet 2002; Shane 2003; Park 2005)? And how active or passive is the role of an alert entrepreneur in the process that brings opportunities from the philosophical world of ideas to the everyday world of business? 
Technology entrepreneurs can use the knowledge accumulated in science as their raw material for thinking up new products and services. Vision and entrepreneurial talent are required to formulate commercially viable ideas for products and services from this stock of fundamental knowledge. Knowledge can be considered an input, together with entrepreneurial vision and effort, in the generation of potential new products (Sanders 2007) (p. 349).

Discovery, development, and exploitation

Whether entrepreneurial opportunities are discovered, recognized, or developed is a matter of debate between entrepreneurship researchers (Alvarez and Barney 2007).

Discovery. Shane (2003, p. 42) stresses that opportunities may exist as objective realities even though their discovery may require a creative act by the entrepreneur. A shortcoming of the conceptualization of opportunity discovery in Austrian economics (Hayek 1945; Kirzner 1979, 1997; Denrell et al. 2003) - the tradition followed by Shane - is the prevailing view of opportunity discovery as a discrete event. Many of the examples given concerning a discovery of an opportunity for profit deal with simple arbitrage gains, presented as discrete events (Sanz-Velasco and Magnusson 2003). While the Austrian perspective may be radical and challenging within the discourse on economics, it does not take into account the development efforts that an entrepreneur makes to create value over and beyond arbitrage in an uncertain setting.

Development. According to Ardichvili, Cardozo, \& Ray (2003), while elements of opportunities may be "out there" waiting to be recognized, opportunities are first and foremost made, not found. Careful investigation of and sensitivity to market needs as well as an ability to spot suboptimal deployment of resources may help an entrepreneur to develop 
an opportunity. This development may or may not result in the formation of a business. Either way, the role of an entrepreneur or a team is not a passive one; opportunity development also involves entrepreneurs' creative work. (Ardichvili et al. 2003)

A consensus regarding the discovery vs. development arguments can be found in the work of Sarasvathy et al. (2003), who distinguish between three types of entrepreneurial opportunity. Each type of opportunity is related to a distinct view of market coordination in economics (Buenstorf 2007) (See Table 3). Opportunity recognition is linked to the tradition of neoclassical economics in that recognition of opportunities is sufficient if both demand and supply factors "exist rather obviously" (Sarasvathy et al. 2003). In this case, the entrepreneurial venture exploits already existing markets with already existing technologies. Arbitrage and franchising are given as examples of these kinds of opportunities. If either demand or supply factors are absent in the market prior to the entrepreneurial activity, then this activity is characterized as opportunity discovery (Sarasvathy et al. 2003). Opportunities may also be actively created by the entrepreneur herself. According to Sarasvathy et al. (2003), this happens when neither demand nor supply exists prior to the entrepreneurial venture, and both sides of the market have to be created.

It is worthwhile to note that the Companys \& McMullen (2007) description of the sources of economic opportunity described earlier is similar to the conceptualization of entrepreneurial opportunities in the intersection of technology supply and market demand (Sarasvathy et al. 2003).

If novelty is an essential characteristic of an entrepreneurial opportunity as suggested based on the summary of Table 1, then one can argue that arbitrage opportunities (allocative view) are not inherently entrepreneurial. They are, indeed, economic opportunities, but not entrepreneurial opportunities since they are based on existing knowledge in the existing markets. 
Table 3: Comparing the three views of entrepreneurial opportunity

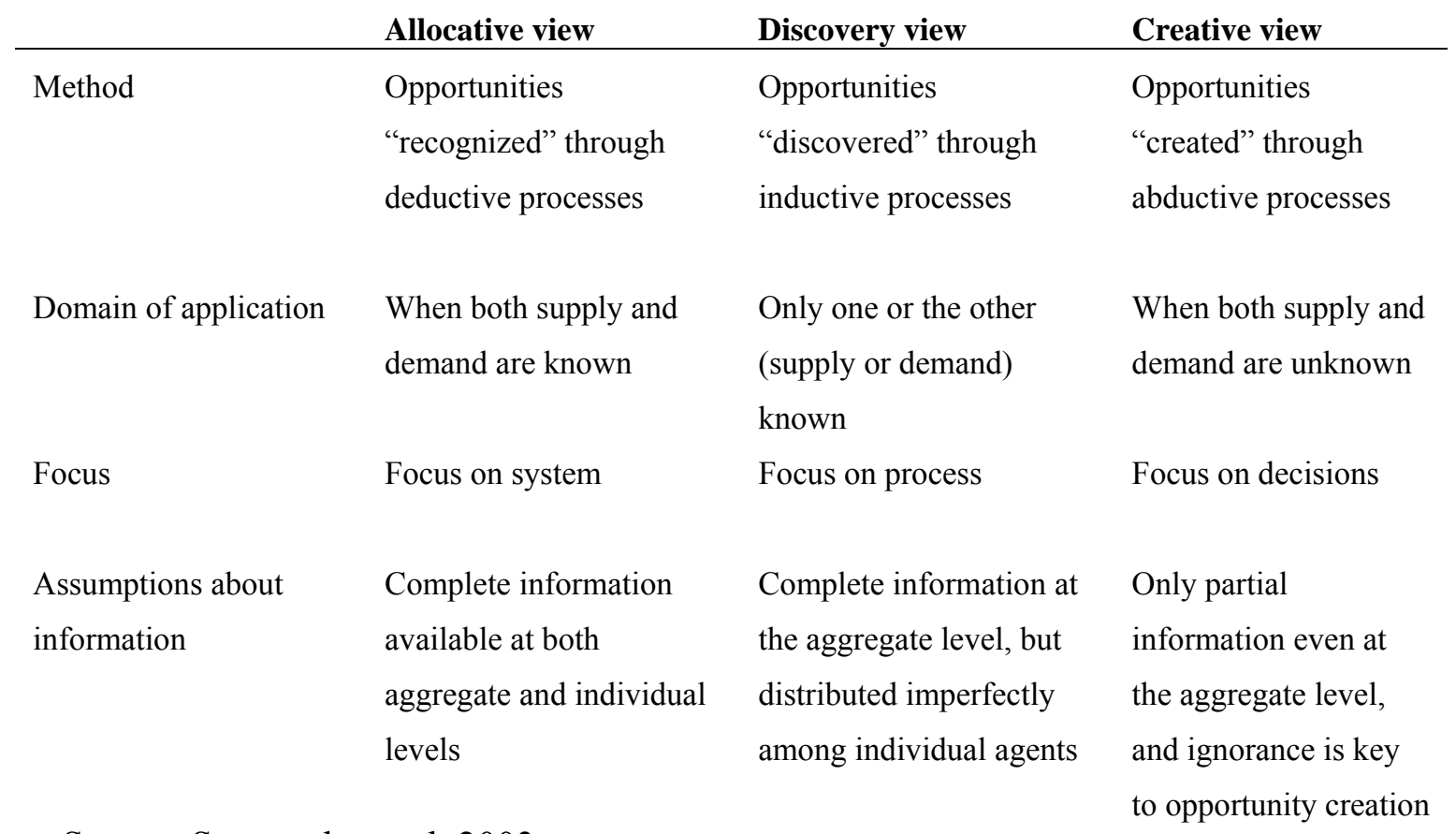

Source: Sarasvathy et al. 2003.

Many biotechnological inventions as well as the inventions studied by Christensen and Bower (1996) and Christensen (1997) help to solve user problems for which only limited or no solutions have been available in the past. Hence, we come to the domain of the "discovery view" (Sarasvathy et al. 2003) in that either supply or demand is unknown. For example, at the outset many medical biotechnology inventions can be applied for the development of cures and / or diagnostics for a variety of medical conditions (Renko 2006a). Once these technologies are patented, their areas of commercial application are defined. After this, the creativity in the opportunity process has to be directed towards developing demand (customers) rather than supply (technology). Essentially, entrepreneurial opportunities can be discovered based on a technological innovation (Schumpeter 1934b; Drucker 1985), in which case the supply of technology is known and demand is unknown (Sarasvathy et al. 2003) and / or they can be discovered because different market participants have unequal access to information about the market conditions (customers, markets, and 
ways to serve markets) (Kirzner 1973; Shane 2000, 2003), in which case the demand in the market is known to some, but the supply has to be developed.

These two sides of opportunity recognition process are illustrated in Figure 1, which has been adapted from Blenker et al. (2005) and Sarasvathy et al. (2003).

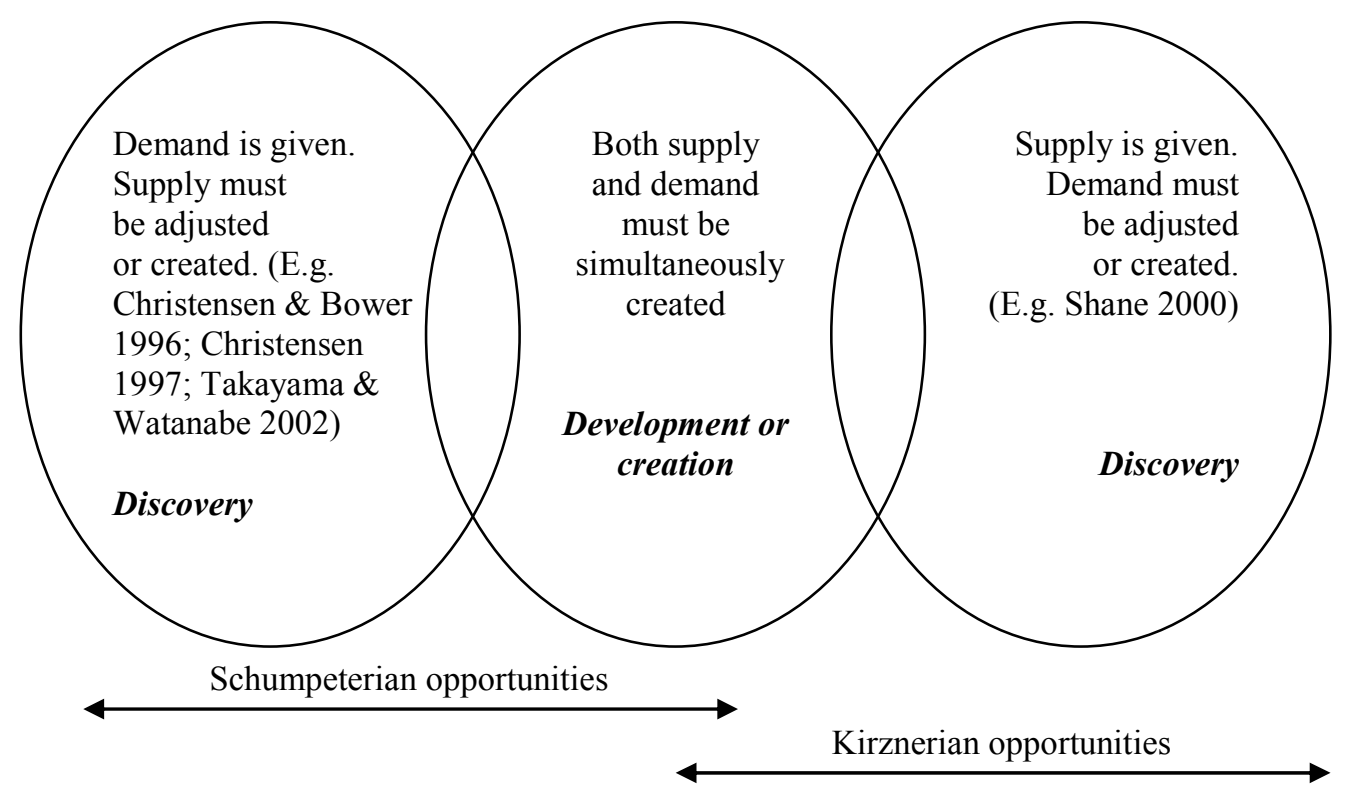

Figure 1: Supply, demand, and the nature of entrepreneurial opportunities.

Even though Sarasvathy et al. (2003) suggest a specific meaning for the term "opportunity recognition" that distinguishes it from opportunity development/creation and discovery, most entrepreneurship researchers have used the term opportunity recognition as a rather general word pair, often synonymous to discovery or creation. In the context of the current research, recognizing an entrepreneurial opportunity is perceiving a possibility to introduce innovative (rather than imitative) goods or services to a marketplace through (a) the founding and formation of a new venture, or (b) the significant improvement of an existing venture (Singh 2000; Gaglio 2004). Because recognition only entails perception, it follows that exploitation of an opportunity is a separate activity (Choi and Shepherd 2004). Inspired by March (1991), Choi and Shepherd (2004, 377) define opportunity exploitation as 
"those activities and investments committed to gain returns from the new product arising from the opportunity through the building of efficient business systems for full-scale operations". In the context of this research, the exploitation of an opportunity refers to those activities committed to (a) the founding and formation of a new venture, or (b) the significant improvement of an existing venture in order to introduce innovative (rather than imitative) goods or services to marketplace.

Whether conceptualized as discovery or development, opportunity recognition (OpR) is one of the central areas of entrepreneurial research (Teach et al. 1989; Gaglio and Taub 1992; Bhave 1994; Gaglio 1997; Kirzner 1997; Shane 2000; Shane and Venkataraman 2000; Gaglio and Katz 2001; Hills and Singh 2004; Pech and Cameron 2006; Alvarez and Barney 2007; Shepherd, McMullen and Jennings 2007). In general, two approaches to the study of entrepreneurial opportunity recognition can be identified in existing literature. First, there are those researchers that have studied the "black box" of opportunity recognition. Most of these studies have adopted a cognitive approach in order to understand "How do entrepreneurs think, reason, and behave such that they create value and wealth through the identification and implementation of market opportunities?" (Mitchell et al. 2007). Still, other researchers have tried to divide the "black box" of entrepreneurial opportunity recognition into components that describe the overall process. Second, there are those studies that have, instead of cognitive aspects or components, focused on the inputs that go to the opportunity recognition process.

In the following, literature on the cognitive approach is summarized first, after which some key typologies of the opportunity recognition process are described. However, neither the cognitive approach nor the modeling approach to opportunity recognition really helps in answering the research questions that were presented above. Even though these parts of the literature review set the scene for understanding entrepreneurial opportunity recognition, 
neither approach informs us about the mechanisms through which different forms of knowledge contribute to entrepreneurial opportunities. Hence, a major part of the literature review that follows is devoted to describing research on the sources of entrepreneurial opportunities, that is, the knowledge inputs that go into the opportunity recognition process. This literature is directly related to the research questions of this study. However, let us first take a look at those streams of literature that view opportunity recognition from a cognitive perspective.

\section{Cognitive approach}

Mitchell et al. (2007) identify four different categories in which research on entrepreneurial cognition has contributed to the understanding of identification and implementation of opportunities: (1) The use of heuristic-based logic; (2) perceptual processes/entrepreneurial alertness; (3) the entrepreneurial information processing-based expertise approach; and (4) the effectuation approach.

The heuristic-based logic approach argues that individuals and situations do vary in the extent to which these decision shortcuts - called heuristics - are used. Furthermore, entrepreneurial decision making is thought to be at least partially subjective and based on informal processes and experience (Busenitz and Barney 1997). Based on this logic, one would suggest that entrepreneurs may regularly find themselves in situations that tend to maximize the potential impact of a more heuristic-based logic (Alvarez and Busenitz 2001). Situations like this include complex entrepreneurial decisions. The decisions that lead to the recognition of innovative opportunities may require significant leaps in thinking, leading to innovative ideas that are not always very linear and factually based. A heuristic-based logic 
often enables entrepreneurs to make sense of uncertain and complex situations more quickly and, relative to more orthodox approaches to decision making, perhaps expedite opportunity recognition (Baron 2007; Mitchell et al. 2007).

Perceptual processes and entrepreneurial alertness have had a growing presence in entrepreneurship research in the last decade. Perceiving and interpreting information, and reaching some unique conclusions about entrepreneurial opportunities, seem to involve some unique mental processes (Mitchell et al. 2007). Gaglio \& Katz (2001) argue that entrepreneurial alertness is very plausible, testable, and relevant as a model of the cognitive dynamics driving the opportunity-identification process. Krueger (1993) suggests that entrepreneurial intentions should derive from feasibility and desirability perceptions of an individual, plus a propensity to act on opportunities. He finds empirical support for a link between positive prior entrepreneurship-related experiences and perceived feasibility of entrepreneurship. Intentions-based models are also tested by Krueger, Reilly \& Carsrud (2000). Mitchell et al. (2007) summarize that some frameworks involving alertness and perceived connections hold much potential for understanding the discovery of new opportunities.

Entrepreneurial expertise approach suggests that expert information processing theory can explain why some (i.e. experienced entrepreneurs) can use information significantly better than nonexperts / nonentrepreneurs to come up with business opportunities. (Busenitz and Lau 1996; Mitchell, Smith, Seawright and Morse 2000). Finally, Sarasvathy's (2001b) "effectuation" approach suggests that thinking and action proceed together in an attempt to create one of several possible outcomes. Effectuation assumes that entrepreneurs can utilize the means at their disposal to influence their future without having to predict it (Sarasvathy 2001b). From an opportunity recognition perspective, this approach suggests that entrepreneurs make decisions not based on definite goals they set based on analyzing 
markets as given, but rather based on the means they have available for their use. They play by ear and adapt their decisions based on feedback from customers and other stakeholders. An important factor in decision making is risk and / or uncertainty. Entrepreneurs, according to Sarasvathy, can tolerate high levels of uncertainty.

\section{Stage approach}

Researchers have tried to understand the entrepreneurial opportunity recognition process by dividing it into various stages or components. Some key contributions in this area are described in the following. It should be noted that most of these typologies assume that the creation of a new organization as a central action of the opportunity recognition process.

As Gaglio \& Taub (1992) point out, most researchers describe opportunity recognition as a linear process. For example, Long \& McMullan's (1984) creative structuring process includes four conceptual elements that may relate to the pursuit of new business opportunities: Pre-vision, Point of Vision, Opportunity Elaboration, and Decision to Proceed. The findings from Manion, Hills, Lumpkin, \& Shrader (2000) do provide partial support for this four-stage model that is useful in understanding the opportunity recognition process. Gaglio \& Taub (1992) summarize existing literature on the typical opportunity recognition process as having four major steps: (1) the Pre-recognition Stew, (2) the Eureka! Experience, (3) the Development of the Idea, and (4) the Decision to Proceed. However, like many other researchers that have studied entrepreneurial opportunities, Gaglio and Taub (1992) do not explicitly define what entrepreneurial opportunities are. One can assume that the forth stage, "Decision to Proceed", refers to establishing a new venture. Still, without a more specific alignment of the domain of these opportunities, it could also be interpreted as a decision to proceed with a business idea within an existing organization or even, as 
referred to in the research paper, painters' definitions of their artistic opportunities and the pursuit of these opportunities (Gaglio and Taub 1992). Gaglio \& Taub (1992) categorization reflects OpR as a cognitive process. Gaglio's work has since progressed towards a more comprehensive model of OpR (Figure 2) (Gaglio 2004) (p. 536).

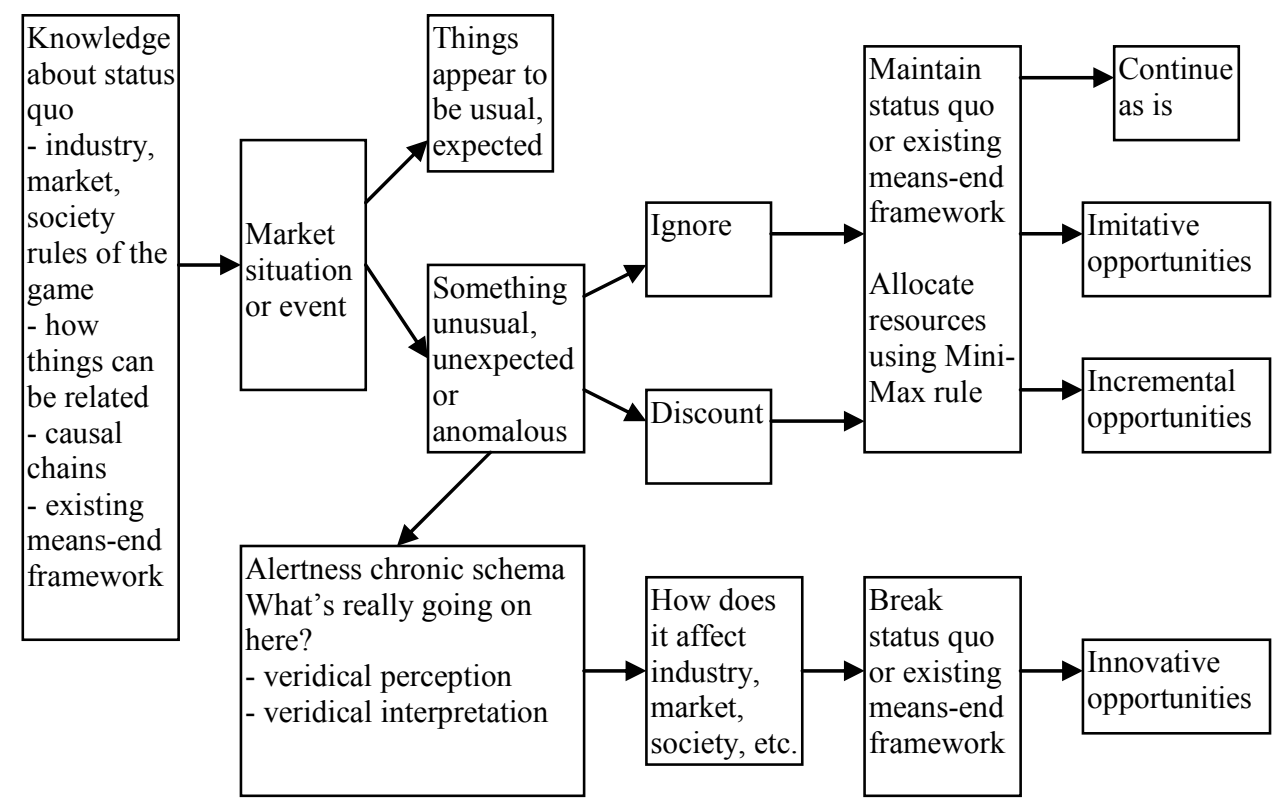

Figure 2: Alertness and the opportunity identification process

The "opportunity outcomes" on the right hand side of the Figure 2 above (Gaglio, 2004) have striking similarities with the mainstream innovation research. The distinction between refining and improving an existing design and introducing a new concept that departs in a significant way from past practice is a central theme in the existing literature on technical innovation (Freeman 1982; Clark and Henderson 1990). Incremental innovation draws from no dramatically new science and introduces relatively minor changes to the existing products (Tushman and Anderson 1986; Clark and Henderson 1990). Radical innovation, in contrast, is based on new scientific / technological knowledge and often opens up whole new markets, creates industries, and gives rise to potential novel, improved applications (Clark and 
Henderson 1990). Within innovation literature, especially radical innovations have been proposed to create great difficulties for established firms (Tushman and Anderson 1986) and can be the basis for the successful entry of new firms.

Even though the process of opportunity recognition shares many similarities with innovation processes, the two streams of literature have developed rather independently of each other. For example, Gaglio (2004) does not refer to any research results regarding innovations and innovation processes outside of entrepreneurship literature. Overall, entrepreneurship researchers seldom make use of the technology and innovation management literature, and vice versa. To some extent, this is probably due to the different levels of analysis in the two research streams; innovations have typically been studied within the context of established organizations, whereas individuals and new firm formation have been in the heart of entrepreneurship research (Lumpkin and Lichtenstein 2005). However, because of the similarity of the two constructs, entrepreneurial opportunities and innovations, there are certainly opportunities for cross-fertilization between the two literature streams that have - so far - gone unnoticed by researchers.

Similarities between opportunity recognition processes and innovation processes can be illustrated, for example, by analyzing the results of the Minnesota Innovation Research Program. In a structured attempt to understand innovation processes in existing organizations, the Minnesota Innovation Studies provide a valid framework for understanding innovation. As a part of the research undertaking, developmental phases in innovation process models were summarized and compared (Schroeder, Ven, Scudder and Polley 2000). These process models have, by and large, three phases: The Beginning, Activity phases, and the End (Schroeder et al. 2000). Schroeder et al. (2000, 109-112) provide an extensive list of various (early) innovation process models, and many of the models have apparent similarities with the entrepreneurial opportunity recognition models 
(Long and McMullan 1984; Gaglio and Taub 1992; Gaglio 2004) or the "core process" of opportunity identification and development (Ardichvili et al. 2003). For example, the early innovation process model by Usher has the following stages: (1) Perception of the problem: Recognition of partial or incomplete need satisfaction; (2) Setting the stage: Elements necessary for the solution are brought together; (3) Act of insight: Essential solution is found; (4) Critical revision: New relations become understood and worked into context (Usher 1954). These stages are very similar to the stages in many of the linear opportunity recognition models.

As illustrated by the definitions of "opportunity" in Table 1, by the similarities between OpR and innovation process models described above (See also economic opportunities of Companys \& McMullen, 2007), as well as by the opportunity "outcomes" of Gaglio (2004) (Figure 2), there is significant overlap between the two constructs of entrepreneurial opportunity and innovation. This conceptual ambiguity is seldom discussed by authors on either topic, but it does not come as a surprise; Schumpeter wrote about new combinations and innovations, and it was only later that his writings were "translated" into opportunity recognition terminology (Buenstorf 2007).

Even though this research is based on entrepreneurship literature and aims to contribute to the understanding of opportunity recognition in technology intensive environments, it is important to reflect on the research findings also in the light of innovation literature. This will be achieved by the use of theoretical triangulation when the results of the empirical research will be discussed. Triangulation refers to the establishment of validity of propositions by using a variety of methods (Webb, Campbell, Schwartz and Sechrest 1966). The four types of triangulation include data triangulation, investigator triangulation, theory triangulation, and methodological triangulation (Denzin 1978). Theory triangulation refers to the use of more than one theoretical position in interpreting data. The value of theoretical 
triangulation is that it avoids conducting research in a vacuum, in the absence of some relevant theoretical perspective. Theory triangulation is most appropriate for the analysis of areas characterized by high theoretical incoherence (Denzin 1978). Entrepreneurial opportunity recognition is, indeed, an area where coherence is yet to be achieved, as illustrated by the wealth of even somewhat contradictory definitions regarding the nature of these opportunities (See Table 1). Hence, theory triangulation in the form of reflecting research results not only in the light of entrepreneurship literature but also through insights from technology \& innovation management literature should strengthen the new knowledge that is to be created in this research.

The opportunity recognition (and innovation) processes described above are linear. A non-linear - and maybe more comprehensive - categorization is suggested by Ardichvili et al. (2003), who divide the major factors that influence the process of opportunity recognition and development into five categories: (1) entrepreneurial alertness; (2) information asymmetry and prior knowledge; (3) social networks; (4) personality traits, including optimism, self-efficacy, and creativity; and (5) the type of opportunity itself. This categorization includes the components that need to be present simultaneously for opportunity recognition to take place. Even if the whole model proposed by Ardichvili et al. (2003) is not necessarily linear, their core process has linear elements: Opportunity development process includes recognition of an opportunity, its evaluation, and development. An entrepreneur is likely to conduct evaluations several times at different stages of development, and these evaluations could lead to recognition of additional opportunities or to adjustments to the initial idea. The "core process" only starts if the entrepreneur has an above-threshold level of entrepreneurial alertness (Ardichvili et al. 2003). 
In a study of software firms, Teach, Schwartz, \& Tarpley (1989) identify four clusters of entrepreneurs with different OpR processes. The first cluster, the Searchers, did their homework as part of a deliberate search for opportunities. The second cluster, the Pin Stripes, were committed to planning and evaluation processes. The third cluster, the Innocents, developed their software on their own time, outside of their regular work hours. Finally, the Blue Jeans, envisioned OpR as an accidental process and avoided any type of formal planning and evaluation.

Basing his ideas on the work of Cyert \& March (1963), Bhave (1994) defined two types of OpR: the externally stimulated OpR, where the decision to start a venture precedes OpR (i.e., entrepreneurs search for ideas, filter opportunities, develop them, and engage in elaboration of ideas) and internally stimulated OpR, where entrepreneurs first discover customer needs or identify problems that need solving and only then decide to create a venture and become an entrepreneur. These two categories emerged from an exploratory research: Using an open-ended interview technique, Bhave surveyed 27 New York City firms in an effort to better understand the venture creation process. These categories (although under different titles) have subsequently been employed in the empirical data collection for the Global Entrepreneurship Monitor as well as for the Panel Study of Entrepreneurial Dynamics.

The linear opportunity recognition model of Christensen, Madsen, \& Peterson (1994) highlights the importance of desirability and feasibility as antecedents to the identification of the opportunity. The feasibility emphasis is also apparent in the work of Krueger (1993; 2000), as described above. However, unlike Krueger, Christensen, Madsen, and Peterson (1994) specify individual resources that lead to opportunity recognition. These resources are separated into four categories, which are both within and outside the control of the 
entrepreneur. Entrepreneurs can control the Firm Specific Factors, Management Behavior, and Strategic Thinking, while Environmental Factors lie outside their control.

Dorf and Byers (2005) identify the following six stages of acting as a technology entrepreneur: 1) identifying the opportunity; 2) determining the entrepreneur's capabilities and interests; 3) evaluating the opportunity; 4) deciding to act on the opportunity or look elsewhere; 5) writing a summary of the concept; and 6) testing the summary and the concept with potential customers and investors. They also distinguish between an opportunity pull and a capability push (i.e., an opportunity that flows from a capability or resource availability). In the context of technology based organizations, the terms "market pull" and "science push" are also used. Science push results from research and scientific discovery in, for example, physics, medicine, chemistry and biology. New entrepreneurial opportunities can arise from science push, "hunting" for use as a potential solution to a problem. In the terminology of Sarasvathy et al. (2003) presented earlier, these kinds of opportunities are discovered because the supply becomes known, but the demand in the marketplace remains unknown. Cohen and Levinthal (1989) suggest that in order for a firm to be able to exploit external technological knowledge, it needs to have the internal skills to understand this knowledge and its potential uses. This ability to exploit knowledge from external sources is called absorptive capacity. At the other end of the innovation continuum are markets that 'pull' discovery by demanding solutions to specific problems. Optimally, innovation processes in a technology based firm combine both the market pull and science push to end up with successful solutions for markets (Rice et al. 2001; Renko, Carsrud, Brannback and Jalkanen 2005). In the following, these two inputs to the entrepreneurial opportunity recognition process in technology based fields are discussed separately. First, technology knowledge is discussed as a critical component in opportunity recognition. After this, the attention moves to market knowledge. 
Knowledge and opportunity recognition

Chance favors the prepared mind.

- Louis Pasteur

A common theme in much research on opportunity recognition has been the suggestion that information plays a crucial role in the OpR process. Many different perspectives and theories converge on the view that in order to identify opportunities, entrepreneurs must somehow gather, interpret, and apply information about specific industries, technologies, markets, government policies, and other factors (Ardichvili et al. 2003; Shane 2003; Ozgen and Baron 2007). Baron (2004), for example, combines the informational approach with a cognitive approach to $\mathrm{OpR}$ in suggesting that opportunity recognition involves cognitive structures possessed by specific persons-frameworks for organizing and interpreting information developed through life experience. Cognitive frameworks help individuals to "connect the dots" between seemingly independent pieces of information, and the patterns they then perceive in the information may constitute the basis for identifying specific business opportunities. These assumptions have gained empirical support in the research by Ozgen and Baron (2007).

At extremes, the opportunities that stem from predominantly technological knowledge (science push) versus those that are based on idiosyncratic information about customers, markets, and ways to serve markets (market pull) have very different characteristics. In line with Shane (2003), we call the "science push" opportunities Schumpeterian and the "market 
pull" opportunities Kirznerian. To contrast the two categories, Table 4 has been borrowed from Shane $(2003)^{4}$ (p. 21).

Table 4: Schumpeterian and Kirznerian opportunities

Schumpeterian vs. Kirznerian Opportunities

\begin{tabular}{ll}
\hline Schumpeterian opportunities & Kirznerian opportunities \\
\hline Disequilibrating & Equilibrating \\
Requires new information & Does not require new information \\
Very innovative & Less innovative \\
Rare & Common \\
Involves creation & Limited to discovery
\end{tabular}

Essentially, Kirzner (1973) and Schumpeter (1934b) disagreed over whether the existence of entrepreneurial opportunities involves the introduction of new information or just differential access to existing information (Shane 2003). Kirzner's $(1973 ; 1997)$ view is that the existence of opportunities only requires differential access to existing information. People use the idiosyncratic information that they have to form beliefs about the efficient use of resources - owned or controlled. Because people's decision making frameworks are not always accurate, they make errors (Gaglio and Katz 2001), which, in turn, create opportunities for others to access and recombine resources in a way that creates entrepreneurial rents (Alvarez and Busenitz 2001; Alvarez and Barney 2004). Schumpeter's (1934a) contrasting view is that new information is important in explaining the existence of entrepreneurial opportunities. Changes in technology, political forces, regulation, macroeconomic factors and social trends create new information that entrepreneurs use to

\footnotetext{
${ }^{4}$ Some other authors essentially talk about the same division between Kirznerian and Schumpeterian opportunities when they use the terms opportunity discovery vs. opportunity creation (e.g. Alvarez \& Barney 2007; Baron 2007; Miller 2007).
} 
recombine resources in a more productive manner. In technology intensive markets, especially the changes in existing technology base can result in the kind of new information that, in Schumpeter's view, leads to entrepreneurial opportunity recognition.

A clear-cut distinction between opportunities that are based on new versus existing information is, in reality, hard to establish. In a review of Shane's interpretation of Schumpeterian and Kirznerian opportunities, Buenstorf (2007) arrives at a conclusion that all opportunities must be created by new knowledge. The crucial difference between opportunities for arbitrage (Kirznerian) and opportunities for innovation (Schumpeterian) is the extent to which the existence of an opportunity is signaled by the price system, i.e. whether or not the new knowledge exists in the market or only outside of markets (Buenstorf 2007). This condition, again, would not in reality distinguish Schumpeterian new knowledge from Kirznerian new knowledge. Schumpeterian new knowledge is characterized as something revolutionizing, "new-to-the-world". By definition, this new knowledge cannot be accounted for by the price mechanism until the knowledge is disseminated among actors in the marketplace. The knowledge will not be learned simultaneously by all actors, which creates the situation of idiosyncratic knowledge in the market. This is characterized as information asymmetry in the marketplace, and the neoclassical market (price) mechanism cannot account for information asymmetry (perfect information is assumed instead). So the conclusion is that neither Schumpeterian new information (new-to-the-world) nor Kirznerian new information (idiosyncratic in nature) is signaled by the price system.

\section{Technology knowledge}

Before technological change leads to new products or markets, entrepreneurs have to discover the technological opportunities and exploit the new technology. Schumpeter's 
(1934a, 1934b) approach to entrepreneurship has deeply influenced the history of economic thought, and is still a major influence. (Blaug 2000; Swedberg 2000) After Schumpeter (1934b) drew attention to the central role of entrepreneur in the innovation process, technology entrepreneurship research has emphasized the roles of entrepreneurs in the process of bringing technologies to markets (Roberts 1991; Klofsten 1997; Kelley and Rice 2001).

Schumpeter does not explicitly feature the opportunity concept. Instead, his point of departure is the notion of innovation characterized as a new combination. The entrepreneur is an individual who creates a new combination and pursues it in the market. This happens possibly - but not necessarily - through forming a new firm. (Dutta and Crossan 2005; Buenstorf 2007). Schumpeter's new combinations (opportunities) are discontinuous by nature (p. 51):

"To produce means to combine materials and forces within our reach. To produce other things, or the same things by a different method, means to combine these materials and forces differently. In so far as the 'new combination' may in time grow out of the old by continuous adjustment in small steps, there is certainly change, possibly growth, but neither a new phenomenon nor development in our sense. In so far as this is not the case, and the new combinations appear discontinuously, then the phenomenon characterising development emerges”. (Schumpeter 1934a)

As is illustrated by the focus on new combinations, the central message in Schumpeter's writings about entrepreneurship concerns the concept of novelty. Schumpeter repeatedly pointed that while ordinary economic behavior is more or less automatic in nature, the entrepreneur always has to think very carefully about what action to take since she is involved in doing something that is fundamentally new (Swedberg 2000; Dutta and Crossan 2005). Schumpeter's entrepreneurs utilize novel information on, for example, technology 
and science to figure out how to recombine resources in a more productive way (Shane 2003). Schumpeter's approach differs from the Kirznerian tradition (to be introduced in detail in the next section) in that opportunities are not pre-supposed for entrepreneurial activity to occur, but are created by the innovative entrepreneur herself (Sarasvathy et al. 2003; Buenstorf 2007).

Underutilized or unemployed resources, as well as new capabilities or technologies may offer possibilities to create and deliver new value for prospective customers, even though the precise products and services to be offered may be undefined. For example, it took years to understand and prove the positive effects of penicillin in treating infections in humans, even though the discovery of penicillin by the Scottish scientist Alexander Fleming happened in 1928. Actually, Fleming was initially convinced that penicillin could not last long enough in the human body to kill pathogenic bacteria. Not only was the inventor unconvinced, but the general public could not even dream about the effects of penicillin, even less was there any kind of "market pull" for this new medicine. .

As the market need for a technology- or science based discovery becomes more precisely defined in terms of customer benefits and resources become more precisely defined in terms of potential uses, the opportunity progresses from its elemental form and a business concept begins to emerge. This concept contains the core notions of how the market need might be served and the resources deployed. (Ardichvili et al. 2003)

Shane (2003) lists some empirical evidence that demonstrates the relationship between sources of Schumpeterian opportunities (introduction of new information) and the existence of those opportunities. Bhide (2000) explained that about half of the founders of fast growing private companies (from the Inc 500 list) in the US that he interviewed indicated that they initiated their businesses in response to a change in technology, regulation, or some other external factor. Blau (1987) found that an increase in the rate of technological change 
led to an increase in the self employment rate in the US. Shane (2001) examined inventions patented by the Massachusetts Institute of Technology between 1980 and 1996, and found that more heavily cited patents (a proxy for more new information) were more likely to lead to firm formation (proxy for entrepreneurial opportunities) than less heavily cited patents.

Figure 3 below summarizes and simplifies the core message of this part of the paper into a drawing. Entrepreneurial opportunities (or new combinations, as Schumpeter called them) stem from new knowledge. This new knowledge often comes in the form of new technologies or new scientific advances. The entrepreneur is an individual who creates an opportunity (a new combination) and pursues it in the market. This happens possibly - but not necessarily - through forming a new firm. (Buenstorf 2007). If we think of Schumpeterian new knowledge as something new to everyone in the marketplace, then the patent system would help in identifying these new pieces of technological knowledge.

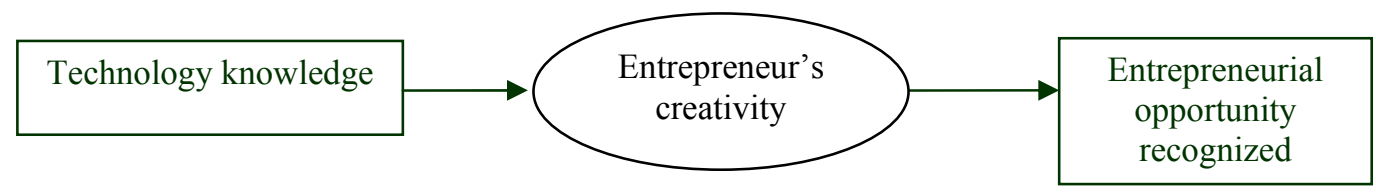

Figure 3: Technology knowledge as a source of entrepreneurial opportunities

As illustrated by Figure 3, according to the Schumpeterian tradition, opportunities are recognized as a result of the creativity of an entrepreneur. This assumption of the central role of creativity contrasts the Kirznerian tradition, which will be discussed in the next section.

\section{Market knowledge}

"Some would-be entrepreneurs have a new technology and often mistake it for a solution. Customers want a solution to their problem and usually do not care what technology is 
employed. Unfortunately, some believe that entrepreneurship is having a great technological idea. Entrepreneurship is really about creating a new business that solves a problem." (Dorf and Byers, 2005, 25)

More than the other two major schools of thought in entrepreneurship, namely neoclassical equilibrium theories and psychological theories, Austrian theories emphasize the role of individuals' information in seeing entrepreneurial opportunities (Hayek 1945). Psychological theories propose that entrepreneurship is a function of stable characteristics possessed by some individuals (McClelland 1961; Begley and Boyd 1987) and neoclassical economists (Khilstrom and Laffont 1979) have proposed equilibrium theories of entrepreneurship. Austrian economists believe that a viable theory of market system - and entrepreneurship - cannot assume equilibrium but must explain how a market achieves equilibrium starting from disequilibrium initial conditions (Kirzner 1997; Shane 2000). Disequilibrium enables entrepreneurs to discover market imbalances that offer ways to earn economic rents provided that entrepreneurs can protect their discoveries from imitation by others (Fiet 2002). In Austrian economists' view, existing idiosyncratic information and knowledge provides the basis for entrepreneurial opportunities.

Austrian economists (Hayek 1945; Kirzner 1997) believe that the possession of information that is appropriate to a particular opportunity leads to discovering this opportunity $^{5}$; people and firms recognize those opportunities related to information that they already possess (Denrell et al. 2003). Fiet (2002) sees an entrepreneur as a person that is an investor in specific information. From this, Fiet's (2002) focus moves on to an attempt to uncover how entrepreneurs can most efficiently invest in the acquisitions of signals - like market signals - to uncover valuable venture ideas.

\footnotetext{
${ }^{5}$ Note that the terms like opportunity identification or opportunity discovery, widely used within the Kirznerian tradition, involve passive search or accidental discovery. The fundamental assumption is that opportunities exist by themselves in the environment and can be discovered. Also, it is impossible for actors to actively search for opportunities that cannot be clearly defined ex ante.
} 
Shane (2000) finds that three major dimensions of prior knowledge are important to the process of entrepreneurial discovery in high technology context: prior knowledge of markets, prior knowledge of ways to serve markets, and prior knowledge of customer problems. New information about a technology may be complementary with an individual's prior information about how particular markets operate; the discovery of an entrepreneurial opportunity related to a specific technology requires prior information about markets. This information may be achieved e.g. through previous work in a certain organizational unit (Aldrich and Wiedenmayer 1993; Shane 2000). Shane's (2000) in-depth case studies of eight entrepreneurs / entrepreneurial teams show that in every case, prior knowledge led entrepreneurs to see the usefulness of a technology ${ }^{6}$ in solving different customer problems. Similar paths were also found in the study of Sarasvathy (2001a). McKelvie \& Wiklund (2004) employ a case study approach to demonstrate that while prior knowledge may be of great importance, constantly gaining new market knowledge and adapting strategies according to this new knowledge is essential to the successful discovery and exploitation of opportunities. Hence, even though their cases demonstrate the importance of idiosyncratic (market) knowledge, the findings also challenge the Kirznerian assumption that entrepreneurs passively discover opportunities and then exploit them. Instead, entrepreneurial opportunity discovery and exploitation are closely entwined and exploitation influences discovery just as discovery influences exploitation (McKelvie and Wiklund 2004). The positive effects of market knowledge in discovering and evaluating opportunities are, according to McKelvie \& Wiklund (2004) due to: a) awareness of customer problems as sources of potential opportunities; b) the ease of determining the market value of new technological discoveries or other market changes; and c) increased communicability of tacit knowledge of new technology between user and end-customer.

\footnotetext{
${ }^{6}$ Three-dimensional printing technology developed at MIT.
} 
Finally, empirical evidence for the importance of idiosyncratic knowledge in OpR also comes from the Panel Study of Entrepreneurial Dynamics dataset: In PSED, industry- and market experience were a source of opportunity for 56 per cent of nascent entrepreneurs (Hills, Singh, Lumpkin and Baltrušaitytė 2004).

Even though entrepreneurs in the Kirznerian tradition do not deliberately search for opportunities, they can still be alert to the potential discovery of such opportunities. Kirzner (1979) defines entrepreneurial alertness as the "ability to notice, without search, opportunities that have hitherto been overlooked" (Kirzner, 1979: 48). Higher alertness increases the likelihood of an opportunity being recognized (Gaglio and Katz 2001). Lumpkin, Hills, and Shrader (2001) maintain that Austrian economics approach is restricted to exploring Kirzner's concept of alertness. The Austrian view provides a very limited view of how opportunity recognition actually happens because it suggests that when market changes create economic disequilibria, opportunities appear 'fully formed,' in essence, and waiting to be noticed (Lumpkin et al. 2001).

Figure 4 below summarizes the core of Kirznerian opportunity discovery into a simple model. Entrepreneurial opportunities stem from knowledge that is unevenly distributed among market participants. Alert individuals are able to discover these knowledge gaps in the marketplace and exploit them to create economic rents.

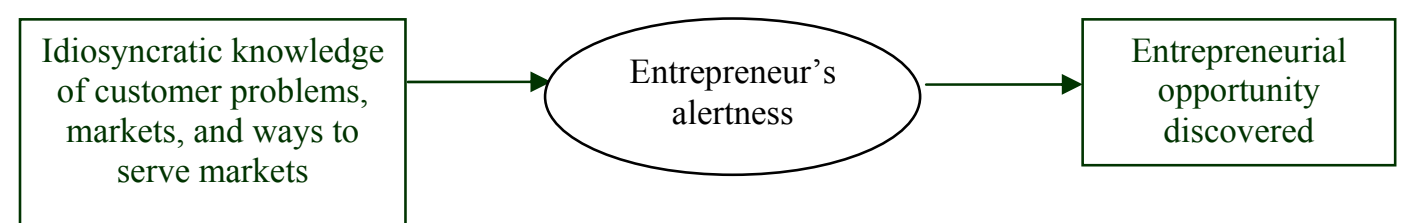

Figure 4: Market knowledge as a source of entrepreneurial opportunities 
It is clear by now that the Schumpeterian and Kirznerian views of opportunity recognition are based on different assumptions about the very ontological nature of these opportunities. In terms of the fundamental "What is?" question, the Kirznerian answer is "exists out there" and the Schumpeterian answer is in the lines of "created from within". In the first perspective the opportunity is out there in the world (markets) - but separated from the entrepreneur / firm - because he, due to his idiosyncratic knowledge or his particular constellation of human capital, has no access to the relevant information. In the second perspective the opportunity is within the entrepreneur (or the firm), who is gifted with a special ability to perform a conceptual extension. However, the opportunity is separated from the world - until the entrepreneur transcends the distinction. (Blenker et al. 2005)

Despite these profound differences, other researchers have interpreted the Kirznerian and Schumpeterian opportunity recognition propositions as complementary rather than competing. Blaug (2000) actually states that:

"There is a subtle change of emphasis in Kirzner's discussion of entrepreneurship from that of Schumpeter's: Schumpeter always portrayed the entrepreneurinnovator as a disequilibrating force disturbing the previous equilibrium, whereas Kirzner $[\ldots]$ depicts him as seizing upon a disequilibrium situation and working to restore equilibrium" (p. 84).

Even this subtle difference can, according to Blaug (2000), be mostly accounted for by the general changes in the state of contemporary economic theory between 1911 (when Schumpeter first outlined his ideas) and 1973 the publication of Kirzner's work). The complementarity of the Schumpeterian and Kirznerian approaches is obvious when we consider the realities of opportunity recognition in practice, discussed in the following.

Some individuals or organizations are so sensitive to market needs or problems that they perceive possibilities for new products continuously in any environment. This sensitivity (or alertness, see e.g. Gaglio \& Katz 2001) to problems or possibilities does not necessarily 
extend to generation of ideas for solutions to the problems; not everyone who is good at asking questions is equally adept at creating answers. Other individuals or organizations may be particularly sensitive to identifying un- or underemployed resources, such as unused land, idle production facilities, or unexploited technology or inventions. Having identified such resources, however, these individuals or firms may not be able to define particular uses or users for which the resources could create value. Inventors or scientists may generate ideas for new products and services without regard to the commercial viability of these inventions. (Ardichvili et al. 2003)

Even though practical examples illustrate that both Schumpeterian and Kirznerian opportunity recognition are needed (Ardichvili et al. 2003) and even though it has been stated that the two approaches are only minimally different (Blaug 2000), the reader may still be skeptical about the combination of Schumpeterian and Kirznerian opportunity recognition in one model since the economic assumptions (equilibrium vs. disequilibrium) of the two approaches are at odds (Blaug 2000; Shane 2003). The argument that equilibrium and disequilibrium cannot simultaneously exist in the marketplace is, without a doubt, a reasonable one. However, if we add a temporal aspect to our opportunity recognition process an argument can be made that disequilibrating and equilibrating forces can co-exist in the same model. This argument is addressed in more detail in the following section of the paper.

\section{Market knowledge, new scientific knowledge and entrepreneurial opportunities}

The first research question presented in the beginning of the paper concerns the creation as well as discovery of entrepreneurial opportunities: What is the role of idiosyncratic market knowledge and new scientific knowledge in the creation and discovery of technology based entrepreneurial opportunities? Before moving to the development of a model and 
hypotheses for empirical testing, the arguments made above concerning the idiosyncratic market knowledge (Kirznerian) and "new combinations" (Schumpeterian) behind new opportunities is summarized.

Both Schumpeterian and Kirznerian knowledge create entrepreneurial opportunities. Temporally, however, Schumpeterian opportunities are created prior to Kirznerian opportunities. First, we can have a technological change which leads to other changes that alter the value of resources, thus upsetting the equilibrium price for resources. Consider the invention of polymerase chain reaction (PCR), a biochemistry and molecular biology technique for enzymatically replicating DNA. PCR created the opportunity to manufacture and sell DNA based products (e.g. for the detection of hereditary diseases, the identification of genetic fingerprints, the diagnosis of infectious diseases, and the cloning of genes) in a scale that was unheard of before. The knowledge of this Schumpeterian opportunity suggested that the resources used for PCR were mis-priced and could be profitably recombined into a new form. Hence, the market for resources had moved from an equilibrium to a state of disequilibrium. This disequilibrium, again, created opportunities that were of a Kirznerian type. This illustrates how instances of equilibrium and disequilibrium can exist in the same opportunity creation process (See Figure 5).

\section{$\underline{\text { Equilibrium market }}$}
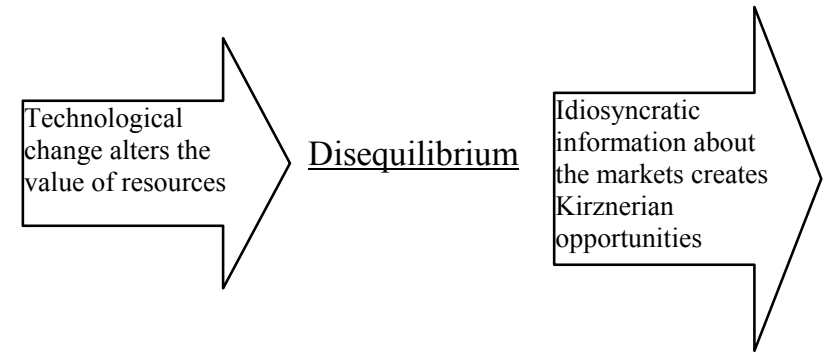

Figure 5: Equilibrium, disequilibrium, and entrepreneurial opportunities in time 
Even if the market eventually learns from the entrepreneur, it is the diffusion of that knowledge and the resulting responses that create much of the disequilibrium (Dickson 1992). The creative forces of entrepreneurs disequilibrate markets whenever they introduce radical new knowledge to the marketplace. When opportunities arise as a result of the innovative activity of the potential entrepreneur, the innovator is initially the only one who is in a position to observe the existence of the opportunity. The introduction of the new innovation to the marketplace gives rise to disequilibrium, and the new disequilibrium state gives rise to opportunity discovery by those who are alert and have access to the radical new knowledge before the rest of the market. Hence, we arrive at a conclusion similar to that of Holcombe (2003); entrepreneurship creates opportunity for more entrepreneurship, which leads to economic progress. 


\section{MODELS AND HYPOTHESES}

Previous pages have outlined two major sources of entrepreneurial opportunities: Technology knowledge and market knowledge. Few empirical tests of entrepreneurial opportunities are reported in the existing literature, not least because of the difficulties in defining and measuring opportunities. Even though we are seeing more conceptual (theoretical) models that aid in understanding, for example, the cognitive processes of entrepreneurs (Gaglio and Katz 2001; Ardichvili et al. 2003; Gaglio 2004; Lumpkin and Lichtenstein 2005; Cohen and Winn 2007), empirical tests of those models are scarce. Even more so, the studies that have tried to empirically test the role of different types of knowledge in entrepreneurial opportunity recognition are mostly limited to case evidence (Shane 2000; McKelvie and Wiklund 2004; Park 2005; Sanz-Velasco 2006) with only a few exceptions of empirical research with quantitative data (Teach et al. 1989; Choi and Shepherd 2004; Saemundsson and Dahlstrand 2005). Still, entrepreneurship researchers agree that entrepreneurial opportunities and recognizing them as one of those critical areas that distinguishes the study of entrepreneurship from other business disciplines. Hence, the more comprehensive assessment of the knowledge behind entrepreneurial opportunities conducted in this research should advance our understanding of entrepreneurial opportunities in particular and the field of entrepreneurship in general.

Entrepreneurship researchers that have followed the Austrian economics tradition essentially argue for a linear relationship between the amount of knowledge the individual has and the amount of entrepreneurial opportunities recognized by the individual, given the 
same level of alertness. Each person's idiosyncratic prior knowledge creates a "knowledge corridor" that allows him/her to recognize certain opportunities.

However, elsewhere in the literature researchers have demonstrated that there are interrelationships between different types of knowledge; possessing one kind of knowledge may blind sight an entrepreneur or a firm to another type of knowledge. These interrelationships have best been demonstrated as tradeoffs between technology knowledge and market knowledge.

In the following, hypotheses are developed regarding the role of market knowledge in entrepreneurial opportunity recognition and exploitation in a technology intensive environment. Building on previous literature, these hypotheses specify three different mechanisms through which market knowledge influences entrepreneurial opportunity recognition and exploitation. The mechanisms suggested are (1) the moderating role of market knowledge (positive or negative, depending on the amount of market knowledge) in the relationship between technology knowledge and entrepreneurial opportunities recognized in a young venture, (2) the direct effects of market knowledge on the entrepreneurial opportunities recognized in a young venture, and (3) the positive moderation of market knowledge in the relationship between entrepreneurial opportunities recognized in a young venture and the subsequent profit potential of the venture.

Even though individuals initially discover opportunities, they are typically developed in firms. Recognizing an entrepreneurial opportunity is perceiving a possibility to introduce innovative (rather than imitative) goods or services to a marketplace through (a) the founding and formation of a new venture, or (b) the significant improvement of an existing venture (Gaglio, 2004; Singh, 2000). Because recognition only entails perception, it follows that exploitation of an opportunity is a separate activity. The exploitation of an opportunity refers to those activities committed to (a) the founding and formation of a new venture, or 
(b) the significant improvement of an existing venture in order to introduce innovative (rather than imitative) goods or services to marketplace.

Because undiscovered opportunities are impossible to identify for research purposes, it follows that we have to look inside existing firms to find opportunities that have been recognized and are being exploited. This is also the most likely reason for the trend that recently opportunity recognition has been increasingly linked to organizational context (Companys \& McMullen, 2007; Lumpkin et al., 2005; Park, 2005). Opportunity recognition is a process (Shane 2000; Fiet 2002; Shane 2003; Park 2005) that can occur both prior to firm founding and after firm founding throughout the life of the firm (Singh, 2000).

Market knowledge as a moderator between technology knowledge and entrepreneurial opportunities

As was demonstrated earlier, previous research has established a relationship between new scientific and technology knowledge and entrepreneurial opportunity recognition (See Figure 3). Based on the literature summarized in section II, the first hypothesis is as follows:

Hypothesis 1: If all other factors are constant, the greater the degree of technology knowledge in a new venture the larger the number of entrepreneurial opportunities that will be recognized.

However, understanding technology and science is not enough for entrepreneurial opportunity recognition; in order for entrepreneurs to recognize business opportunities they need to understand markets and customers in addition to technology (Shane 2003). Market knowledge also contributes to exploitation of opportunities; Saemundsson and Dahlstrand 
(2005) find that firms seeking to exploit opportunities based on new technical knowledge and existing market knowledge attain substantial growth.

Even though there are few empirical studies that have investigated the market knowledge - business opportunity link in the entrepreneurship domain, extant research in new product development (NPD) supports the claim that NPD projects, which rely on carefully defined customer needs, are more likely to succeed than those that are "only" based on new technological opportunities (Holt, Geschka and Peterlongo 1984; Cooper 1993). From marketing research we know that new product opportunities are recognized by firms who stay close to their customers and markets (Athuene-Gima 1995, 1996; Hurley and Hult 1998). The question then arises, if new opportunities are recognized based on Schumpeterian, new technology knowledge, what is the role of idiosyncratic market knowledge in this opportunity recognition process?

When dealing with radically new technology knowledge and developing radically new products, conventional market knowledge is often of limited utility; many firms do not incorporate users' or customers' opinions in their NPD processes because of the customers' limited domains of expertise, their inability to articulate their underlying needs, and the belief that user-developed concepts tend not to be innovative or creative (Leonard-Barton 1995; Leonard-Barton and Rayport 1997; Adams, Day and Dougherty 1998; O’Connor 1998). For example, Im \& Workman (2004) found that understanding customers influences new product novelty significantly but negatively. From their study, it appears that knowing more about customers is not helpful when it comes to creating truly innovative, novel products (entrepreneurial opportunities) because customers may not approve novel product ideas due to their inertia towards existing products in the market.

In their sample of 239 radical innovation projects Thieme and Song (2002) found that under conditions of increasing market turbulence, the impact of market intelligence 
gathering activities is negatively related to performance in the early stages of the product development and commercialization process, but steadily progresses towards a positive relationship as the project advances. When translated into the language of entrepreneurial opportunity recognition, this finding would suggest that there may be a negative relationship between market knowledge and recognizing entrepreneurial opportunities, but a positive one between market knowledge and exploiting those opportunities that have already been recognized. (Thieme and Song 2002) These results provide evidence that for a successful completion of the opportunity development process, both the Schumpeterian (science push) and Kirznerian (market pull) effects have to be in place. However, there is a tradeoff between the two types of knowledge in that idiosyncratic knowledge about current markets and customers is "impeding the search for unconventional business opportunities" (Hamel and Prahalad 1991). Customer and market knowledge is probably pivotal in recognizing opportunities for arbitrage (Sanz-Velasco and Magnusson 2003; Sarasvathy et al. 2003), but the creativity that drives radical, Schumpeterian opportunities cannot be achieved through adapting the majority view (Nemeth 1997).

Christensen and Bower (1996) provide evidence from the computer disk drive industry in support of their claim that the power of dominant customers contributes to the failure of leading firms. These firms devote so much attention to customers in high margin segments that they miss out on technologies that emerge in low margin, niche markets that ultimately supplant earlier technology. Christensen (1997) subsequently examined a variety of industries and identified the same pattern. Takayama and Watanabe (2002) conclude that in the pharmaceutical context, technology knowledge promotes new product development. In contrast, market knowledge sometimes inhibits this process. In the case of totally new products, Schumpeterian-style disruptive innovations, successful development is not derived 
from market knowledge creation but is initiated by technology knowledge while "freezing" market knowledge (Takayama and Watanabe 2002).

Obviously, the simple "more knowledge - more opportunities recognized" kind of thinking that is currently prevalent in studies of entrepreneurial opportunities seems naïve in the light of the above-presented research insights from related fields. The mechanisms through which entrepreneurial opportunities are recognized vary from a discovery of an arbitrage to the creation of a radical opportunity, and the knowledge foundations of the different OpR mechanisms are different. Building on the relationship suggested in hypothesis one for technology intensive new ventures, the next hypotheses propose that market knowledge moderates the positive relationship between technology knowledge and entrepreneurial opportunities. However, this moderation is more complex than what is suggested by the existing research based on Austrian economics. More specifically, in an organizational context where the level of market knowledge is very low or very high, technology knowledge is likely to give rise to fewer new entrepreneurial opportunities than in an organizational context where the amount of market knowledge is moderate. This follows from the literature review presented above which suggests that the favorable conditions for radical, technology based opportunities are neither characterized by very detailed understanding of current markets nor by a total lack of market knowledge.

Hypothesis 1a: If all other factors are constant, when a new venture has a moderate level of market knowledge, there will be a strong positive relationship between the level of technological knowledge in the new venture and the recognition of entrepreneurial opportunities. 
Hypothesis $1 b$ : If all other factors are constant, when a new venture has a low level of market knowledge, there will be a weak positive relationship between the level of technological knowledge in the new venture and the recognition of entrepreneurial opportunities.

Hypothesis 1c: If all other factors are constant, when a new venture has a high level of market knowledge, there will be a weak positive relationship between the level of technological knowledge in the new venture and the recognition of entrepreneurial opportunities.

The direct effect of market knowledge on entrepreneurial opportunities

Even if the most radical new opportunities in technology intensive fields are based on technological and scientific advances, it does not mean that entrepreneurial opportunities cannot be discovered based on idiosyncratic market knowledge as outlined in the section II and summarized in Figure 4 above.

Even if the relationship between market knowledge and entrepreneurial opportunities is hypothesized to have an inverted U-shape when technology knowledge is the basis of those opportunities (Hypotheses 1a-1c), there are also other kinds of opportunities (arbitrage) that are not based on new technological knowledge. These entrepreneurial opportunities stem from knowledge that is unevenly distributed among market participants. Alert individuals are able to discover these knowledge gaps in the marketplace and exploit them to create economic rents. It should also be noted that the established view within marketing is that market knowledge affects performance through innovativeness, customer loyalty and quality (Kirca, Jayachandran and Bearden 2005). As far as innovativeness is a construct 
similar to entrepreneurial opportunities, this stylized fact together with insights from Austrian economics suggests the following:

Hypothesis 2: If all other factors are constant, the greater the degree of market knowledge in a new venture the greater the recognition of entrepreneurial opportunities.

According to the existing research on entrepreneurial cognition and the work of Kirzner (1979), entrepreneurs have to be alert to the potential discovery of opportunities (Gaglio and Katz 2001; Lumpkin et al. 2001; Baron 2004; Gaglio 2004; Lumpkin et al. 2004). Kirzner (1979) defines entrepreneurial alertness as the "ability to notice, without search, opportunities that have hitherto been overlooked" (Kirzner, 1979: 48). Consequently, the initial empirical investigations of alertness focused on the means by which an individual might literally "notice without search.” (Gaglio and Katz 2001).

The concept of "corporate entrepreneurship" or "intrapreneurship" has been used in literature to refer to entrepreneurial attitudes and behaviors within existing organizations. In general, being intrapreneurial is predicted to have a beneficial effect on revitalization and performance of firms (Schollhammer 1982; Burgelman 1983). When assessing entrepreneurship at the organizational level, researchers have typically used measures such as the firm entrepreneurial orientation or posture (Covin and Slevin 1988, 1989, 1991), which basically suggest that an entrepreneurial organization, regardless of its size, is exhibits innovative, proactive, and risk-taking behaviors.

Miller (1983) describes entrepreneurial orientation as one that emphasizes aggressive innovation, risky projects and a proclivity to pioneer innovations that pre-empt competition. Covin and Slevin (1989) have developed a scale for the measurement of the three components of entrepreneurial orientation, namely innovativeness, proactiveness and risk 
taking. Innovativeness reflects a tendency to support new ideas, novelty and creative processes, thereby departing from established practices and technologies. Proactiveness refers to a posture of anticipating and acting on future wants and needs in the marketplace, and risk taking is associated with a willingness to commit large amounts of resources to projects where the likelihood and cost of failure may be high (Wiklund and Shepherd 2003). Empirical studies have found that those businesses that adopt a more entrepreneurial strategic orientation perform better (Zahra 1991; Zahra and Covin 1995; Wiklund 1999; Wiklund and Shepherd 2005).

Since market knowledge has been suggested to sometimes even inhibit radical innovativeness (Leonard-Barton 1995; Christensen and Bower 1996; Christensen 1997; Leonard-Barton and Rayport 1997; O’Connor 1998) it is likely that the relationship outlined in Hypothesis 2 is moderated by a construct that allows potential entrepreneurs to "think outside of the box". In the research on entrepreneurial cognition, this construct has been alertness, as described above. In the current context, where the opportunities that we observe are found within organizations, entrepreneurial orientation is suggested to be the moderator.

Hypothesis 2a: If all other factors are constant, when a new venture has a higher level of entrepreneurial orientation, the relationship between the degree of market knowledge and the recognition of entrepreneurial opportunities will be enhanced.

Figure 6 illustrates the hypotheses presented above in the form of an a priori model. Both new technological knowledge (Schumpeterian) and existing market knowledge (Kirznerian) are essential parts of the proposed opportunity recognition model. In addition to the constructs incorporated in the model, it should be noted that time (noted with a " $\mathrm{t}$ " in the model) is an essential element. Since especially those opportunities that are based on 
technological knowledge typically take time to develop, there needs to be a time lag between the measurement of the knowledge variables and entrepreneurial orientation as predictors on one hand $\left(\mathrm{t}_{1}\right)$, and recognized opportunities as a dependent variable on the other hand $\left(\mathrm{t}_{2}\right)$.

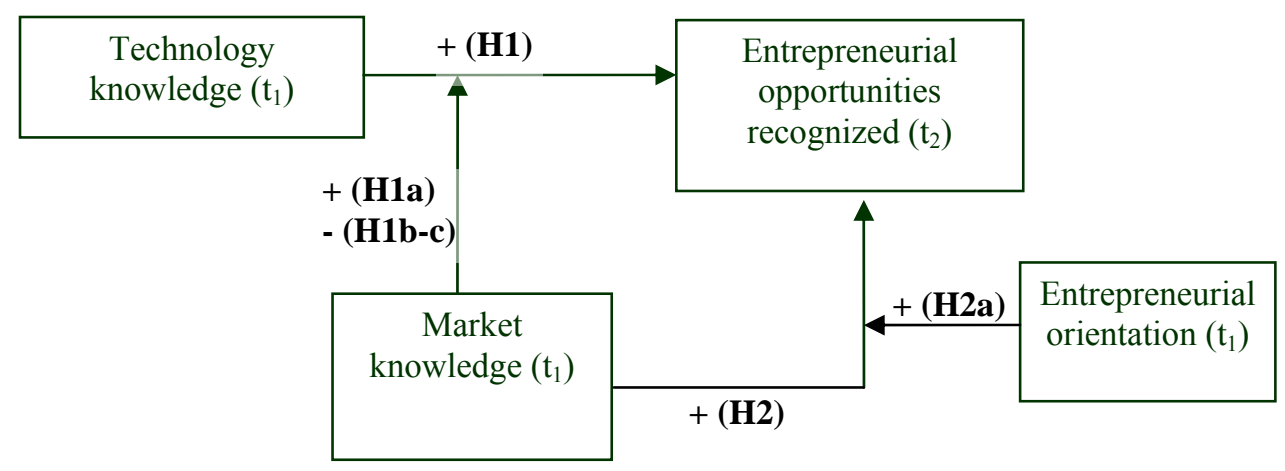

Figure 6: The direct and moderating effects of market knowledge on entrepreneurial opportunity recognition. Ex ante model.

\section{Opportunities and new venture success}

Once opportunities have been recognized, they also need to be exploited for rent appropriation. As mentioned above in section II, profit potential is an integrated element in many of the definitions of entrepreneurial opportunity. For example, the Shane and Venkataraman $(2000,220)$ definition of entrepreneurial opportunity essentially means that the "better" the entrepreneurial opportunity, the more substantial its contribution to the firm's bottom line performance. Later, both Shane $(2003,18)$ as well as Sarasvathy et al. (2003) have proposed definitions of entrepreneurial opportunities, where the belief in profit is central. This belief in profit is also evident in the concept of entrepreneurial opportunity as 
defined by Singh (2000), Goss (2007), Sanz-Velasco (2006) and Companys \& McMullen (2007).

The profit potential of an opportunity can only be determined in retrospect (Singh 2001). It is only when the opportunity is being exploited that the entrepreneur knows if the "new combination" can be introduced and sold at a price higher than the costs (McKelvie and Wiklund 2004). Because undiscovered opportunities are impossible to identify for research purposes, it follows that we have to look inside existing firms to find opportunities that have been recognized and are being exploited. If entrepreneurial opportunities are at least believed to result in a profit at the outset, it should follow that recognizing more of those opportunities would have positive economical consequences. Hypothesis 3 follows:

Hypothesis 3: If all other factors are constant, the greater the number of entrepreneurial opportunities recognized in a new venture the greater the subsequent profit potential.

In the empirical context of biotechnology (especially medical biotechnology), it can take companies up to fifteen years to progress form the discovery of a new product candidate to the profitable launch of the product in the marketplace. Consequently, rather than introducing profitability of the product or the firm as a dependent variable in Hypothesis 3, the dependent variable is profit potential. Even though more subjective than a pure profit measure, profit potential can be assessed after a shorter period of time than what it would take to measure the realized profits from entrepreneurial opportunities. For example, successful out-licensing of a product candidate from a new venture to a large pharmaceutical company signals future profit potential of this very product. Also, continuous investments from venture capitalists in the new venture tell about those external equity investors' belief in future profit potential of the venture and its products. 
According to Penrose (1959), firm growth in any single time period is made possible by opportunities identified by the firms' entrepreneurs. In order to accomplish growth, the firms' managers need to be willing to act upon these opportunities and to obtain the necessary resources to exploit the plans. Even though the focus of Penrose's writings is firm growth, her predictions about the positive consequences of opportunities are in line with the more recent opportunity literature and Hypothesis 3 presented above.

Market knowledge is one of those necessary resources needed for exploitation of entrepreneurial opportunities (Chrisman and McMullan 2000). Unlike for established products, entrepreneurs exploiting new products are likely to face considerable demand uncertainty (Knight 1921). A repeated finding from research in the field of marketing is that market knowledge contributes to the success of new products or services in the marketplace. For example, Veldhuizen, Hultink, \& Griffin (2004) find that the acquisition of customer information in a high-technology context is directly associated with product advantage in the marketplace. More often, however, it has been argued that market information has to be disseminated and used within an organization for it to have positive effects on firm performance (Narver and Slater 1990; Jaworski and Kohli 1993; Baker and Sinkula 1999; Matsuno and Mentzer 2000; Harris 2001).

Matsuno, Mentzer \& Ozsomer (2002) hypothesize that the positive performance impact of market intelligence generation, dissemination and responsiveness hinges on the firm's level of entrepreneurial proclivity (entrepreneurial orientation). They argue that a business can achieve market orientation's full performance impact only if the market orientation is driven by an entrepreneurial spirit and appropriate organizational structures, processes and incentives. Within a sample of US-based manufacturing companies, Matsuno et al. (2002) find support for their hypothesis that entrepreneurial proclivity is an antecedent to business performance, and this effect is mediated by market orientation of the firm. 
Based on data collected from 55 incubator based high technology ventures in the US, Choi \& Shepherd (2004) found that entrepreneurs were more likely to exploit opportunities when they perceived more knowledge of customer demand for the product. They use elements of the resource-based view to gain a deeper understanding of entrepreneurs' decisions to exploit opportunities based upon perceptions of the attributes of the new products and perceptions on the resources and capabilities required for full-scale operations. In addition to knowing customer demand, other perceptions that positively influenced entrepreneur's decision to exploit opportunities were perceptions of more fully developed enabling technologies, greater managerial capability, and greater stakeholder support (Choi and Shepherd 2004).

Based on the existing research findings summarized above, hypothesis 3a follows:

Hypothesis 3a: If all other factors are constant, when a new venture has a high level of market knowledge the relationship between recognition of entrepreneurial opportunities and subsequent profit potential will be enhanced.

The relationships proposed in Hypotheses 3 \& 3a are illustrated in Figure 7 below. Again, in addition to the constructs incorporated in the model, time (noted with a " $\mathrm{t}$ " in the model) is an essential element. The positive performance outcomes from entrepreneurial opportunities take time to develop, so there needs to be a time lag between the measurement of the recognized opportunities as a predictor and market knowledge as a moderator on one hand $\left(\mathrm{t}_{1}\right)$, and profit potenail as a dependent variable on the other hand $\left(\mathrm{t}_{2}\right)$. 


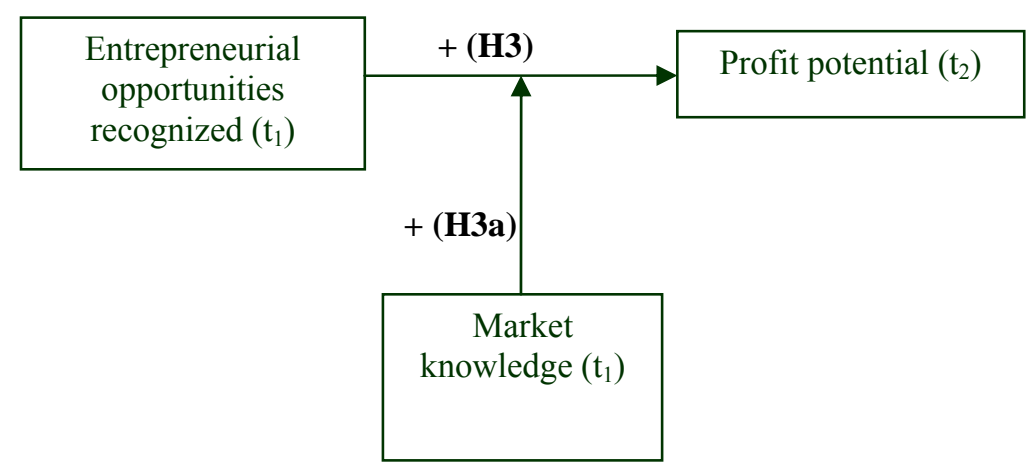

Figure 7: The moderating effect of market knowledge on the relationship between entrepreneurial opportunities and profit potential. Ex ante model.

In some cases, for example, when a new biotechnology-based product addresses a completely unmet medical need, no market knowledge may be available but the product may still become a blockbuster in the marketplace. Hence, the proposed relationship between product innovations and their market performance is moderated (and not mediated, see e.g. Matsuno et al. 2002) by market knowledge. However, in a typical case, market knowledge about an existing market would be available, and this market knowledge should be a strong moderator of the opportunity - performance relationship.

The following section describes the empirical study completed to test the hypotheses. 


\section{EMPIRICAL STUDY}

As illustrated by the literature review, entrepreneurial opportunities that have been recognized by entrepreneurs are typically developed and exploited within firms. Since unrecognized opportunities are impossible to identify for research purposes, it follows that an empirical research on entrepreneurial opportunities has to look into opportunities within a firm context. Hence, the level of analysis in the current empirical study is a firm.

Based on existing literature (Singh 2000; Gaglio 2004), the definition established for entrepreneurial opportunity recognition in this research is as follows: Recognizing an entrepreneurial opportunity is perceiving a possibility to introduce innovative (rather than imitative) goods or services to a marketplace through (a) the founding and formation of a new venture, or (b) the significant improvement of an existing venture. In addition, the literature review demonstrated how a bulk of research on entrepreneurial opportunities treats opportunity recognition as a process (linear or non-linear). What is more, previous researchers either explicitly state that profit potential is an integrated characteristic of an entrepreneurial opportunity, or they implicitly assume that this is the case by studying opportunities exploited in the form of new business enterprises.

To make the theoretical opportunity concept empirically testable, it is suggested that new product development process is an example of an entrepreneurial opportunity when:

(1) It is based on new knowledge (not incremental/ continuous innovations),

(2) A new venture is founded to conduct new product development, or the new product development leads to the significant improvement of an existing venture, and 
(3) It aims at eventually creating a profit (not a necessary outcome but goal).

As mentioned in the introductory part of the paper, the empirical setting of this research is the global biotechnology industry. More specifically, the focus is on young, new ventures that have been established to exploit scientific advances in the fields of pharmaceuticals, diagnostics, medicine and the application of biomaterials for medical purposes.

In order for a product in these fields to be launched in the marketplace, it has to go through a regulated process of development that typically spans over multiple years (Renko 2006a). Most product opportunities developed in new biotechnology ventures are based on patented intellectual property, that is, new scientific knowledge. What is more, introducing incremental innovations to the biotechnology marketplace is typically the domain of existing, large companies that can fund the continuous product development with sales income. New ventures in the field of biotechnology are heavily dependent on external equity financing. These funding sources, typically venture capitalists and business angels, want to see a potential return on investment in the category of hundreds of percents once the product reaches the market. Incremental improvements on existing products cannot deliver these kinds of returns, which means that the products developed in new biotechnology ventures most likely have to be radical in nature and based on new knowledge (See condition 1 above).

The empirical scope of this research is limited to the ventures that have been founded to conduct new product development in order to exploit an entrepreneurial opportunity (See condition 2 above). What is more, the empirical analysis is limited to business organizations, that is, for-profit ventures (See condition 3 above). Many initial scientific advances in the field of biotechnology are developed and even exploited within non-profit organizations, especially university laboratories. However, because profit potential has been established as 
one of the key characteristics of entrepreneurial opportunities in past research, this study only focuses on commercial new ventures.

Data collection for this research has taken place in two phases (See Figure 8). The first phase of data collection (in-person interviews) happened between October 2003 and June 2004 (t1). The second phase (mail questionnaire) took place in May - October 2007 (t2). The development timescales in the field of biotechnology are long. For example, the journey of a pharmaceutical product from initial discovery of an active compound to the launch of a drug typically takes 12 to 15 years (Rothaermel and Deeds 2004). In this light, the time lag of approximately 3.5 years between the first data collection (1) and the second round of data collection from the same companies (t2) seems justifiable. The different phases of data collection are illustrated below in Figure 8.

Biotechnology was chosen as the empirical field for this research since, like mentioned in the introduction, the lengthy and highly regulated $R \& D$ processes make it easier to separate the sources of entrepreneurial opportunities throughout the opportunity recognition process. Also, biotechnology is a growing field of industrial activity, and the growth companies in this sector represent firms that are of interest for governments and politicians because of their high earning potential. The global nature of the biotechnology business and, especially, the international scope of biotechnology markets - be it global markets for medicines or the licensing markets for inventions - make it feasible to assume that despite location, opportunity recognition manifests in the same ways in R\&D-intensive biotechnology SMEs. Having said that, there are national differences on the supply side of biotechnology. The role of the public sector in supplying the soft infrastructure of innovation support for enterprises is not uniform from country to country, continent to continent. Critics say that the public sector is the source of Europe's innovation gap with the United States because reliance on public intervention in Europe signifies a major market failure (Cooke 2001). Because of the 
potential influence of institutional setting on the opportunity recognition process, data is collected from two geographic areas, namely the US and Nordic countries. The results reported in Renko (2006a) show that, overall, there are no major differences in perceptual variables between the two continents. However, American firms do get more outside investments than their Nordic competitors (Ernst\&Young 2004; Renko 2006a).

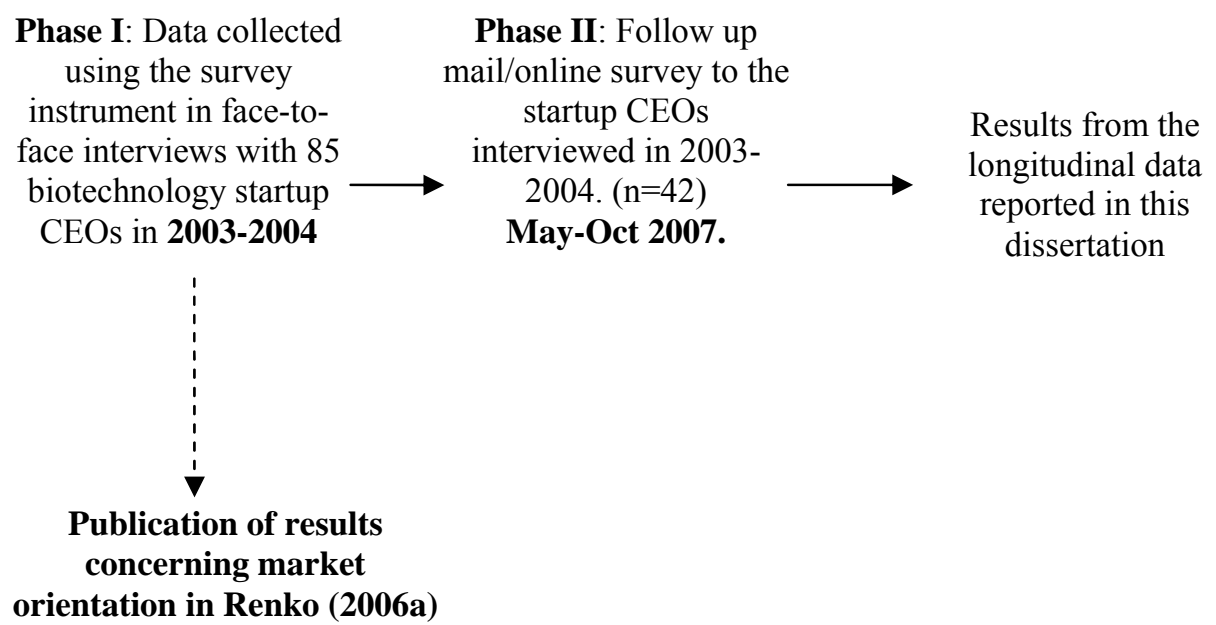

Figure 8: Phases of empirical data collection

Even prior to phase 1 data collection, a qualitative study was conducted that addressed the nature of market knowledge, market orientation, and other types of knowledge in young biotechnology ventures (Renko 2006a, b). This inductive preliminary study helped in understanding the study phenomena in the empirical context of young biotechnology ventures and was pivotal for subsequent instrument development. The approach in the preliminary study was a qualitative one, not one geared towards testing existing hypotheses (either overtly or unconsciously). 
A quantitative hypothesis testing approach (deductive approach) is applied in the main empirical study reported here. The purpose of this chapter is to describe the research instrument and procedures applied for empirical testing of the hypotheses. Towards the end of the chapter I will also discuss the quality of the empirical study focusing on validity and reliability.

Since the instrument employed in this study has been used before (Renko 2006a, b), parts of the description of instrument design and empirical procedures reported in the following can also be found in Renko (2006a).

\section{Instrument design}

The challenge in instrument design for concepts such as market knowledge, technology knowledge, entrepreneurial opportunities, and entrepreneurial orientation is in finding the items that are clearly related to the domain construct but at the same time discriminate between the construct we want to measure and other related but unequal constructs. The selection of items used to capture each study construct was guided by existing literature as well as the qualitative preliminary study reported elsewhere (Renko 2006a, b). Table 5 summarizes all the measurements used in hypothesis testing in this study. "Entrepreneurial opportunities exploited" is not used in hypothesis testing, but the scale was created to test the discriminant and convergent validity of "entrepreneurial opportunities recognized". 
Table 5: Constructs and measurements in the empirical study

\begin{tabular}{|c|c|c|c|c|}
\hline Hypotheses & Construct & Variable(s) & Type & Scale, data source etc. \\
\hline \multirow{8}{*}{$\begin{array}{l}\mathrm{H} 1,1 \mathrm{a}, 1 \mathrm{~b} \\
1 \mathrm{c}, \mathrm{H} 2,2 \mathrm{a}\end{array}$} & $\begin{array}{l}\text { Entrepreneurial } \\
\text { orientation }\end{array}$ & Entrepreneurial orientation & $\begin{array}{l}\text { Continuous } \\
\text { (5-point } \\
\text { Likert) }\end{array}$ & $\begin{array}{c}\text { 9-item scale based on Knight (1997). } \\
\text { Scale: Mean of } 7 \text { variables selected after measure } \\
\text { refinement. }\end{array}$ \\
\hline & Market knowledge & Market intelligence generation \& dissemination & $\begin{array}{l}\text { Continuous } \\
\text { (5-point } \\
\text { Likert) }\end{array}$ & $\begin{array}{c}\text { 22-item scale based on Kohli et al. (1993). Scale: } \\
\text { Mean of } 22 \text { variables selected after measure } \\
\text { refinement. }\end{array}$ \\
\hline & \multirow[t]{2}{*}{ Technology knowledge } & Number of patents (approved) & Continuous & $\begin{array}{c}\text { Self reported by interviewees, checked against } \\
\text { USPTO database }\end{array}$ \\
\hline & & R\&D intensity & Continuous & Self reported by interviewees $(\%)$ \\
\hline & \multirow{4}{*}{$\begin{array}{l}\text { Entrepreneurial } \\
\text { opportunities } \\
\text { recognized }\end{array}$} & a) New inventions & Continuous & \multirow{4}{*}{$\begin{array}{l}\text { Self reported by interviewees. } \\
\text { Scale: Mean of the four variables. }\end{array}$} \\
\hline & & b) Therapeutic areas where inventions are useful & Continuous & \\
\hline & & c) Domestic patent applications & Continuous & \\
\hline & & d) International patent applications & Continuous & \\
\hline \multirow{3}{*}{$\mathrm{H} 3,3 \mathrm{a}$} & \multirow{3}{*}{ Profit potential } & External equity investments & Continuous & Self reported, USD thousands per year \\
\hline & & Early sales & Continuous & $\begin{array}{l}\text { Self reported sales data checked against secondary } \\
\text { sources whenever possible }\end{array}$ \\
\hline & & Out-licensing & Continuous & $\begin{array}{l}\text { Self-reported number of technologies sold or } \\
\text { licensed out from the firm. }\end{array}$ \\
\hline \multirow{3}{*}{--} & \multirow{3}{*}{$\begin{array}{l}\text { Entrepreneurial } \\
\text { opportunities exploited }\end{array}$} & a) New product introductions to markets & Continuous & \multirow{3}{*}{$\begin{array}{l}\text { Self reported by interviewees. } \\
\text { Scale: Sum of the } 3 \text { variables. }\end{array}$} \\
\hline & & b) New product development projects started & Continuous & \\
\hline & & $\begin{array}{l}\text { c) End products that are / have been developed } \\
\text { based on the company's invention(s) }\end{array}$ & Continuous & \\
\hline
\end{tabular}




\section{Operationalization of independent variables}

Instead of single-item measurements, methodologists advocate the use of multiple-item measurements. Single-item measurements are popular because they are quick and easy to administer to large samples, but single-item measurements cannot provide reliable measurements of relatively complex constructs. Thus multiple-item measurements have been the norm for over 50 years (Loo 2002; Shadish, Cook and Campbell 2002). In this study, (1) market knowledge, (2) entrepreneurial opportunities recognized, and (4) entrepreneurial orientation are measured by multi-item scales as described in the following. Technology knowledge is captured through the use of two single-item measurements, and profit potential is assessed through three single-item measurements. All of these measurements are described in detail in the following.

Market knowledge.

Measurement development. The measurement of market knowledge in this study relies primarily on the scales used in the existing literature. Since market knowledge has predominantly been of interest to marketing scholars, the search for an appropriate scale was conducted primarily within marketing literature.

Li and Calantone (1998) have measured market knowledge competence, defining the construct of interest as the processes that generate and integrate market knowledge (p. 14). However, their 21-item scale for the measurement of market knowledge competence has an explicit focus on formal processes and knowledge integration between marketing and R\&D departments. Since the qualitative preliminary study had shown that the kinds of firms focused upon in the current study neither have clearly defined borders between marketing 
and $\mathrm{R} \& \mathrm{D}$ nor rely on purely formal processes in their market intelligence gathering, the Li and Calantone (1998) scale as such was not deemed suitable for the current study.

Li and Calantone (1998) based their measurement to a large extent on previous measures on market orientation. Two of the most extensively used measurements of market orientation are the "MARKOR" scale developed by Kohli, Jaworski and Kumar (1993), and the "MKTOR" scale developed by Narver and Slater (1990). The scale of Kohli et al. (1993) focuses on market oriented firm level behaviors, whereas the Narver \& Slater (1990) scale measures market orientation as an element of company culture (Ngai and Ellis 1998). Deshpandé and Farley (1998) conclude that both scales are reliable and valid, generalize well internationally, and are similar in terms of validity measurements and correlations with performance. In this study, two of the three subscales ${ }^{7}$ of market orientation developed by Kohli et al. (1993), namely (1) market intelligence generation and (2) dissemination, form the basis for a measurement for market knowledge. This measure captures the behaviors of a firm that are geared towards understanding customers and competitors throughout the company. The "MARKOR" scale developed by Kohli et al. (1993) has been subsequently employed in a wealth of empirical studies (Siguaw, Simpson and Baker 1998; Matsuno et al. 2002; Perry and Shao 2002; Kyriakopoulos and Moorman 2004; Kara, Spillan and DeShields 2005).

Measurement refinement. The 18 intelligence generation and dissemination items from the measurement by Kohli et al. (1993) were further developed to reflect the current empirical context, i.e. small, young biotechnology firms. Instead of "business unit" (the original focus of Kohli et al. 1993) the items were re-worded to reflect the firm. Other changes to the original scale are outlined in Table 6.

\footnotetext{
7 These three subscales are market intelligence generation, dissemination within a firm, and firm's responsiveness to market intelligence.
} 
Table 6: Refinement of market knowledge scale.

\begin{tabular}{|c|c|c|}
\hline Scale item in Kohli et al. (1993) & Scale item in this study. (R) denotes a reverse coded item. & Comments \\
\hline $\begin{array}{l}\text { Our company meets customers at least once } \\
\text { a year to find out what } \\
\text { Products / services they will need in the } \\
\text { future. }\end{array}$ & $\begin{array}{l}\text { Our company meets end customers or potential end customers } \\
\text { of our products at least once a year to find out what their future } \\
\text { needs are. } \\
\text { Our company meets opinion leaders (e.g. recognized medical } \\
\text { doctors) at least once a year to find out about the future needs of } \\
\text { our end customers. }\end{array}$ & $\begin{array}{l}\text { Potential end customers are included because } \\
\text { most sample firms do not have sales for the } \\
\text { time being. Opinion leaders are included } \\
\text { because, based on the preliminary study, they } \\
\text { were deemed to be important in reflecting end } \\
\text { users' preferences and needs. }\end{array}$ \\
\hline
\end{tabular}

Individuals from our manufacturing

department interact directly with customers

to learn how to serve them better.

Individuals from our R\&D and / or manufacturing department

interact directly with customers to learn how to serve them better.

Our company conducts market research in-house.

Our company does a lot of in-house market research.

Our company subscribes to industry (market) databases.

Our company outsources market research.

Our company is slow to detect changes in our customers' product / service preferences (R)

Our company polls customers at least once a year to assess the quality of our products / services.

We often talk with or survey those who can influence our end users' purchases.

We collect industry information by informal means (e.g. lunch with industry friends)

In our company intelligence on our

competitors is generated independently by
Our company is slow to detect changes in our customers' or potential customers' product / service preferences $(\mathrm{R})$
We often talk with or survey those who can influence our end users' purchases (e.g. medical doctors)

We collect industry information by informal means (e.g. lunch with industry friends)

In our company intelligence on our competitors is generated independently by several individuals / departments.

$R \& D$ is included in addition to manufacturing because most sample firms do not have manufacturing.

Sample firms do not necessarily have resources to conduct market research in-house but they may still outsource these services.

Potential customers included

Item deleted. Quality in medical biotechnology is mostly not determined by customers but regulators, such as the FDA or EMEA.

Departmental boundaries are unclear in the smallest firms. 


\begin{tabular}{l}
\hline Scale item in Kohli et al. (1993) \\
\hline several departments. \\
Our company is slow to detect fundamental \\
shifts in our industry (e.g. competition,
\end{tabular}

shifts in our industry (e.g. competition,

technology, regulation). (R)

Our company periodically reviews the likely effect of changes in our business environment on customers (e.g. regulation, competition, technology).

A lot of informal "hall talk" in this business unit concerns our competitors' tactics or strategies. Scale item in this study. (R) denotes a reverse coded item.

\section{Comments}

Our company is slow to detect fundamental shifts in our industry (e.g. competition, technology, regulation). (R)

Our company periodically reviews the likely effect of changes

in our business environment on customers (e.g. regulation,

competition, technology).
A lot of informal "hall talk" in our company concerns our competitors' tactics or strategies.
Our company holds regular interdepartmental meetings to

We have interdepartmental meetings at least discuss market trends and developments. once a quarter to discuss market trends and developments

Marketing personnel in our business unit spend time discussing customers' future needs with other functional departments.

Our business unit periodically circulates documents (e.g. reports, newsletters) that provide information on our customers.
Our company holds regular meetings with other companies to discuss market trends and developments.

Our company's marketing personnel / business developmen personnel spend time discussing customers' future needs with the other functions.

Our company periodically circulates documents (e.g. newspapers, e-mail alerts) that provide information on customers.
Intelligence dissemination can also take place between companies.

Small firms are more likely to have business development personnel before marketing / sales.
When something important happens to a major customer of market, the whole
When something important happens to customers in our (potential) markets, the whole company knows about it within a
Potential customers included. 


\begin{tabular}{|c|c|c|}
\hline Scale item in Kohli et al. (1993) & Scale item in this study. (R) denotes a reverse coded item. & Comments \\
\hline $\begin{array}{l}\text { business unit knows about it within a short } \\
\text { period. }\end{array}$ & short period. & \\
\hline $\begin{array}{l}\text { Data on customer satisfaction are } \\
\text { disseminated at all levels in this business } \\
\text { unit on a regular basis. }\end{array}$ & $\begin{array}{l}\text { Our company disseminates data on customer satisfaction at all } \\
\text { levels in the company on a regular basis. }\end{array}$ & \\
\hline $\begin{array}{l}\text { There is minimal communication between } \\
\text { marketing and manufacturing departments } \\
\text { concerning market developments. (R) }\end{array}$ & $\begin{array}{l}\text { There is minimal communication between people in this firm } \\
\text { concerning market developments. (R) } \\
\text { There is a lot of market related communication between } \\
\text { individuals in our top management team. }\end{array}$ & $\begin{array}{l}\text { Departments not relevant for the smallest } \\
\text { firms; rather, communication blocks arise } \\
\text { between individuals. }\end{array}$ \\
\hline $\begin{array}{l}\text { When one department finds out something } \\
\text { important about competitors, it is slow to } \\
\text { alert the other departments. (R) }\end{array}$ & $\begin{array}{l}\text { When someone in our firm finds out something important about } \\
\text { the market (e.g. customers, competitors) he / she is slow to share } \\
\text { this information with others. (R) }\end{array}$ & $\begin{array}{l}\text { Departments not relevant for the smallest } \\
\text { firms; rather, communication blocks arise } \\
\text { between individuals. }\end{array}$ \\
\hline
\end{tabular}


After the changes, the final market knowledge scale included 22 items (Cronbach's alpha in phase 1 data $(n=85) 0.753$; in phase 2 data $(n=36) 0.877)$. This indicates that the reliability of the scale is good (Nunnally 1978) and all the items reflect one underlying construct, i.e. market knowledge. Interestingly, a meta analysis of Cronbach's alpha reliabilities in behavioral research by Peterson (1994) revealed that interviewer administration (here in phase 1) typically produced lower alpha than did self administration (here phase 2).

\section{Entrepreneurial orientation}

Measurement development. The entrepreneurial orientation (EO) measurement used in this survey is based on Knight's (1997) 8-item scale for entrepreneurial orientation. It measures the three components of entrepreneurial orientation, namely innovativeness, proactiveness and risk taking. Knight's (1997) scale, again, is a slightly modified version of Covin and Slevin's (1989) 9-item scale. To be consistent with the market knowledgemeasurement part of the survey, the EO scale was formulated as a 5-point Likert scale (Knight's scale is a 7-point scale), where the two ends of each question "continuum" present opposites to each other, and higher values stand for more entrepreneurial orientation (See questionnaire in Appendix 1).

Knight (1997) employs numerous techniques to assess the validity and reliability of the scale for the measurement of entrepreneurial orientation. All in all, Knight (1997) finds that the scale performs well with regard to consistency and pattern of factor structure, internal consistency and convergent, as well as discriminant validity.

Measurement refinement. In this study, one item was added to the Knight (1997) scale: "How many new lines of products or services does your firm have under research and development right now?", the answers ranging from "1" that represents "no new lines of 
products or services" and "5" that stands for "very many new lines of products or services". This addition was necessary since most firms included in the current empirical study did not have any products on the markets at the time of the interview. The reliability measurements are reported item by item in Table 7 . As the Table shows, the items in phase 1 of data collection behave in a similar way to Knight's (1997) items: items 6, 7, and 8 have high item-to-total correlations, whereas items $1,2,3$, and 5 have lower item-to-total correlations.

Table 7: Entrepreneurial orientation scale reliability, item statistics

\begin{tabular}{lccc}
\hline Item $^{8}$ & $\begin{array}{c}\text { Current study, phase 1 } \\
\text { data, item-to-total } \\
\text { correlation }\end{array}$ & $\begin{array}{c}\text { Current study, phase 2 } \\
\text { data, item-to-total } \\
\text { correlation }\end{array}$ & $\begin{array}{c}\text { Knight (1997), item- } \\
\text { to-total correlation }\end{array}$ \\
\hline 1. Product lines & 0.065 & .525 & 0.490 \\
2. Product changes & 0.270 & .318 & 0.560 \\
(Product lines under & 0.336 & .604 & \\
R\&D) & & & 0.512 \\
3. R\&D leadership & 0.298 & .491 & 0.585 \\
4. New techniques & 0.432 & .466 & 0.455 \\
5. Competitive posture & 0.294 & .321 & 0.629 \\
6. Risk-taking proclivity & 0.456 & .243 & 0.636 \\
7. Environmental & 0.363 & .366 & 0.666 \\
boldness & & & .107 \\
8. Decision-making style & 0.453 & 0.704 & 0.834 \\
\hline Cronbach's alpha & 0.631 & 29 & 204 \\
\hline N of cases & 85 & & \\
\hline
\end{tabular}

As shown in Table 7, the 9-item scale for entrepreneurial orientation employed for hypothesis testing in this study (phase 1 of data collection) has a Cronbach's alpha of .631. After an analysis of the item-total statistics of the scale, items one and two were dropped from the scale. Item one in particular has a poor item-to-total correlation in phase 1, which is probably due to the fact that most study firms had either not launched any products on the markets or had only launched a few. After removing the two first items, the resulting 7-item

\footnotetext{
${ }^{8}$ For exact items, see questionnaire in Appendix 1.

${ }^{9}$ This item was not in the Knight (1997) scale but was added to the measurement in this study because of the young age of the study firms.
} 
scale has a Cronbach's alpha of .719 (phase 1 data), and the mean value on this scale is used as a proxy for entrepreneurial orientation in the dependence models.

Overall, the item-to-total correlations in this study are worse than those reported by Knight (1997). However, as mentioned above, the item-to-total correlation patterns in phase 1 data are similar to Knight's (1997) study. The most likely explanation for the lower correlations in this study is the fact that the respondents typically ranked their companies very high on the entrepreneurial orientation items; by definition, most biotechnology startups are taking huge risks and have to be proactive and innovative if they wish to recover their R\&D costs one day. The mean value for entrepreneurial orientation in phase 1 of this study is 3.86, which is also the median value for the scale (5-point Likert scale). The standard deviation of the scale is 0.608 . Knight's (1997) companies come from medium-sized firms in the textiles, clothing, electronic goods and electrical parts industries in Canada. Within this population of firms you are likely to see more variation and also possible co-variation for entrepreneurial orientation items. Unfortunately, Knight (1997) does not report scale means or standard deviations for his items.

The Wiklund and Shepherd (2005) study is used here to compare the level of entrepreneurial orientation of the biotechnology firms included in this sample with the results from other industries. Wiklund and Shepherd (2005) measure entrepreneurial orientation using Miller's (1983) eight items, which also reflect innovativeness, proactiveness and risk taking, like the items in this study. Each item is measured on a 7-point Likert scale, and Wiklund and Shepherd (2005) obtain a mean of 28.93 for the summated scale (standard deviation 6.19). The sample firms of Wiklund and Shepherd (2005) represent Swedish firms in the following sectors: knowledge-intensive manufacturing, labor-intensive manufacturing, professional services and retail. The mean value of the Wiklund and 
Shepherd (2005) summated EO scale would translate into a mean of $2.58^{10}$ on a five-point scale like the one employed in this study. This value is 1.28 points lower (on a five-point scale) than the sample mean of this study. This indicates that at least compared with the sample firms of Wiklund and Shepherd (2005), the firms in this study exhibit higher levels of entrepreneurial orientation.

Interestingly, the item-total statistics of the entrepreneurial orientation in phase 2 data are quite different from phase 1 data. There are two plausible explanations for this. First, in the second phase of data collection complete data for the EO scale was only obtained from 29 firms. This low number of cases may affect the numbers reported in Table 7. Second, the most dramatic change between the two data collection periods concerns the first scale item, namely "How many new lines of products or services has your firm marketed since 2000". The companies that have survived as independent organizations until 2007 and have been available for data collection in phase 2 have most likely been under pressure from investors and other stakeholders to get their products to the markets. The mean value in phase 2 data for this item is 3.39 and median 4, whereas in 2003-2004 (phase 1) the same item had a mean value of 2.48 and a median of 2 . Surviving companies are the ones that have been able to push products to markets as well as start new, promising product development projects (Item "How many new lines o f products or services does your firm have under research and development right now" also shows a dramatic change in the scale statistics, Table 7). Hence, the relative importance of these items in the EO scale has shifted between phases 1 and 2.

${ }^{10}[28.93 /(7 * 8)] * 5=2.58$ 


\section{Technology knowledge.}

Measurement development. Technological knowledge is mostly an unobservable construct and researchers need to analyze different indicators, which each offer clues about the construct without directly measuring it. Here, technology knowledge of a firm is measured with two items, namely (1) "share of R\&D expenses out of total expenses of the firm ${ }^{11 ",}$, and (2) number of patents. Measurements of R\&D activity, such as the total amount of R\&D spending and R\&D spending divided by total sales, have been used as indicators of technological capability in previous research (Coombs and Bierly 2001). Nelson and Winter (1982) suggest that the probability of a firm coming up with an innovation is proportional to the firm's $R \& D$ spending. At the same time, $R \& D$ is regarded as a highly uncertain activity, and institutional structures supporting innovation are complex and diverse (Nelson and Winter 1977). R\&D spending reflects investment in knowledge, rather than knowledge itself, and is a questionable proxy because knowledge generation is cumulative. Hence patents are used as an additional proxy for technology knowledge.

Patents are output measurements of technological knowledge (Coombs and Bierly 2001). Firms, laboratories and individuals can apply for a patent to protect a new technology, to signal technological competence, or "to mark technological territory" (Ramani and Looze 2002). In biotechnology, most new technology is protected by patents. The protection of technology - prevention of copying by competitors - is the typical reason for patenting innovations, but the positive "signaling" impact of patent applications is also considered to be particularly strong in the biotechnology sectors (Lemarié, Looze and Mangematin 2000). Whatever the strategic motivations, a patent can only be granted if the invention has an industrial use. However, using a firm's number of patents as a proxy for its technological

\footnotetext{
${ }^{11}$ The more conventional way is to estimate R\&D spending as a share of total sales, but since most sample firms did not have sales at the time of the interview this estimate was not deemed feasible.
} 
knowledge is problematic for many reasons (Pavitt 1985). Patents differ greatly in their technical and economic significance, not all types of technological knowledge can be patented, and patenting strategies - i.e. what to patent, where to patent and how frequently to patent - vary widely between industries and even between firms in the same industry. To overcome these problems, researchers have, for example, measured the quality of the patent by how often others cite it (Coombs and Bierly 2001). Even though R\&D spending and patent counts are both problematic measurements of technology knowledge, using them both should capture the variation in the sample firms' technological knowledge base.

In both phase 1 and phase 2 data collection the respondents were asked to estimate the share of R\&D expenses (\%) out of the total expenses of their respective firms. They were also asked to provide information on the patent count of the firm. However, only data from the first phase of data collection are used as independent variables in the tests of proposed models. In phase 1, two interviewees (out of 85 ) refused to give out this information. In phase 2, two respondents (out of 42) left the patent questions of the questionnaire blank. Most interviewees were confident in answering the patent questions, but in phase 1 six interviewees were unsure of the actual counts. These interviewees were asked to check the numbers after the interview, and all of them replied later with the patent numbers.

Measurement refinement. The United States Patent and Trademark Office's (USPTO) publicly available database was searched to verify the patent data given by the interviewees. However, many of the sample firms have obtained rights to patents that have not actually been developed by the firms themselves; for example, university spin-offs often have rights to patents developed by university research groups. Thus the USPTO patent search by company names is not likely to catch all the patents the interviewees were referring to when providing patent numbers during the interviews. Still, it is important to check interview data against a more objective source, and even though those patents that are not assimilated with 
the firm's name are missed in the search, the resulting numbers should still correlate positively with the numbers provided by the interviewees. Comparison of patent data from the interviews with the USPTO patent data (Table 8) reveals that the numbers given by the interviewees are higher. They commonly reported that the same patents have been approved or applied for both in the home country as well as internationally, hence no large differences between "domestic" and "international" patent figures. Table 8 below summarizes the means and medians for patent data.

Table 8: Comparison of patent data from USPTO and interviewees.

\begin{tabular}{|c|c|c|c|c|c|c|c|c|c|}
\hline & & \multicolumn{4}{|c|}{ USA-based firms } & \multicolumn{4}{|c|}{ Finland and Sweden-based firms } \\
\hline & & Mean & Median & SD & $\begin{array}{l}\text { Skew } \\
\text { ness }\end{array}$ & Mean & Median & SD & $\begin{array}{l}\text { Skew } \\
\text { ness }\end{array}$ \\
\hline \multirow{5}{*}{ 䆓 } & $\begin{array}{l}\text { Data from } \\
\text { interviewees: }\end{array}$ & & & & & & & & \\
\hline & $\begin{array}{l}\text { Number of } \\
\text { domestic patent } \\
\text { approvals }\end{array}$ & 7 & 2 & 10 & 1.939 & 4.7 & 2 & 6.5 & 2.667 \\
\hline & $\begin{array}{l}\text { Number of } \\
\text { international patent } \\
\text { approvals }\end{array}$ & 7.7 & 1 & 23 & 5.881 & 4.7 & 2 & 7 & 2.436 \\
\hline & USPTO: & & & & & & & & \\
\hline & $\begin{array}{l}\text { Patents (approved) } \\
\text { under company } \\
\text { name, June } 2004 . \\
\end{array}$ & 4 & 0 & 7.3 & 2.463 & 1.46 & 0 & 2.5 & 1.952 \\
\hline \multirow{5}{*}{ 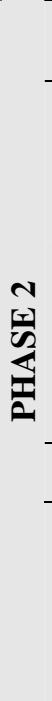 } & $\begin{array}{l}\text { Data from } \\
\text { interviewees: }\end{array}$ & & & & & & & & \\
\hline & $\begin{array}{l}\text { Number of } \\
\text { domestic patent } \\
\text { approvals since } \\
\text { June } 2004\end{array}$ & 5.36 & 2 & 12 & 3.256 & 1.12 & 0 & 1.8 & 1.271 \\
\hline & $\begin{array}{l}\text { Number of } \\
\text { international patent } \\
\text { approvals since } \\
\text { June } 2004\end{array}$ & 5 & 0.5 & 11 & 3.370 & 1.31 & 0.5 & 1.7 & 1.023 \\
\hline & USPTO: & & & & & & & & \\
\hline & $\begin{array}{l}\text { Patents (approved) } \\
\text { under company } \\
\text { name between June } \\
2004 \text { - Oct } 31^{\text {st }} \\
2007 \text {. }\end{array}$ & 2.6 & 0 & 5.0 & 2.909 & 0.86 & 0 & 1.5 & 2.348 \\
\hline
\end{tabular}


As indicated by Table 8, the numbers reported by the interviewees are higher than the numbers obtained from the USPTO. Nevertheless, for the reasons mentioned above, this does not mean that the interviewees were not truthful when answering the questions about patents. Because there are no large differences between numbers reported for domestic and international patents, the correlations between the subjective data and the USPTO data were calculated for the whole sample, not making a difference between US- based and Nordic companies. There is a significant positive correlation between the USPTO patent numbers and the numbers provided by the interviewees. The correlations are listed in Table 9.

Table 9: Correlations between patent data from USPTO and interviewees.

\begin{tabular}{|c|c|c|c|c|c|c|}
\hline Variables & 1 & 2 & 3 & 4 & 5 & 6 \\
\hline $\begin{array}{l}\text { 1. PHASE } 1 \text { : Number of } \\
\text { domestic patent approvals }\end{array}$ & 1 & & & & & \\
\hline $\begin{array}{l}\text { 2. PHASE } 1 \text { : Number of } \\
\text { international patent approvals }\end{array}$ & $.832 * * *$ & 1 & & & & \\
\hline $\begin{array}{l}\text { 3. PHASE 1: USPTO patents } \\
\text { (approved) under company } \\
\text { name, May } 31^{\text {st }} 2004 \text {. }\end{array}$ & $.433 * * *$ & $.299 * * *$ & 1 & & & \\
\hline $\begin{array}{l}\text { 4. PHASE } 2 \text { : Number of } \\
\text { domestic patent approvals } \\
\text { since June } 2004\end{array}$ & $.562 * * *$ & $.511 * * *$ & .222 & 1 & & \\
\hline $\begin{array}{l}\text { 5. PHASE } 2 \text { : Number of } \\
\text { international patent approvals } \\
\text { since June } 2004\end{array}$ & $.539 * * *$ & $.526 * * *$ & .186 & $.940 * * *$ & 1 & \\
\hline $\begin{array}{l}\text { 6. PHASE 2: USPTO patents } \\
\text { (approved) under company } \\
\text { name between June 2004-Oct } \\
2007\end{array}$ & $.364 * * *$ & .157 & $.746 * * *$ & $.689 * * *$ & $.682 * * *$ & 1 \\
\hline
\end{tabular}

Despite the positive correlations between the numbers of patents obtained from the interviewees and from the USPTO, the Wilcoxon Signed-Rank test has a significant p-value 
$(p<0.01)$ for tests of both domestic and international patents as reported by the interviewees against the USPTO data. This indicates that the distribution of the patent data obtained from the USPTO is different to the patent data provided by the interviewees. This is problematic for the analyses; the USPTO numbers are objective, but, as mentioned earlier, the numbers given by the managers also include patents for which the very company is not listed as "assignee" in the patent database. In the case of many young firms, and especially spin-off firms, ignoring this data would be problematic. Thus, for the analyses, an average of the number of patents reported by the interviewees and the number of approved patents listed in the USPTO database was computed from phase 1 data. This mean is used as a proxy for patents in the analyses.

Operationalization of dependent variables.

The first hypotheses of this study test the effects of market knowledge, technology knowledge, and entrepreneurial orientation in phase 1 on the number of entrepreneurial opportunities recognized in phase 2. The latter hypotheses, then, focus on the relationship between the number of entrepreneurial opportunities recognized by the firm in phase 1 and the firm's subsequent profit potential (phase 2). Hence, the dependent variables of interest are (1) entrepreneurial opportunities recognized; and (2) profit potential.

Entrepreneurial opportunities recognized.

There are few attempts in the existing research to quantitatively measure entrepreneurial opportunities. For example, Ardichvili et al. (2003) produce a comprehensive theoretical 
model and propositions concerning entrepreneurial opportunities, but remain silent on how these opportunities (supposedly dependent variables) would exactly be measured.

Baron \& Ensley (2006) compare the business opportunity prototypes of novice (firsttime) and repeat (serial) entrepreneurs. They conclude that serial entrepreneurs show greater agreement than novice entrepreneurs concerning the central attributes or dimensions of the concept "business opportunity", and that experienced entrepreneurs include more distinct dimensions in their opportunities than novice entrepreneurs do (Baron and Ensley 2006). By studying entrepreneurs who are members of entrepreneurship network organizations Baron \& Ensley (2006) imply that these are the people who have recognized opportunities. They ask entrepreneurs to "Describe the idea on which your new venture was based," and "Why did you feel this was a good idea-one worth pursuing?". Hence, a new venture idea that leads to a business startup seems to be the operationalization of a business opportunity for Baron \& Ensley (2006).

Busenitz (1996) does not explicitly state what entrepreneurial opportunities are, but since his empirical research compares managers in publicly traded large corporations to founders of new ventures it can be assumed that founders of new ventures have recognized entrepreneurial opportunities whereas managers in large corporations have not. More specifically, to qualify as an entrepreneur (and supposedly then having recognized an entrepreneurial opportunity) an individual should have established a firm. This should have happened within the past two years or, alternatively, the individual should be planning to start a second venture within the next five years (Busenitz 1996). Young firms are also the incarnation of opportunities in the Saemundsson and Dahlstrand (2005) study. Two measures were used to quantify the newness of market and technical knowledge behind the opportunity. First, if the new firm had any business relations at start-up with former employers, the business opportunity was considered to be based on existing market 
knowledge. Second, if the respondent reported that universities or research institutes had been important at start-up, the business opportunity was considered to be based on new technical knowledge (Saemundsson and Dahlstrand 2005). These measures are barely measures of newness of any kind. If anything, they tell about the social network of the entrepreneur(s) at the time of the business startup.

Shane (2000) focuses on one patented technology, made available through a university (MIT) technology licensing office. The opportunities - that is, the units of analysis - are startup activities by eight different entrepreneurs (or teams), geared at commercialization of this patented technology.

Park (2005) demonstrates opportunity recognition through a case study of an innovative firm. For Park (2005) entrepreneurial opportunity seems to equal "effective innovation and resultant market success" (p. 747). However, the construct is not operationalized in more detail. For Sanz-Velasco (2006), an opportunity must include the following elements: a definite offer to the customer; a definite customer segment; definite value; a definite revenue model; accomplished through technology. According to this "operationalization", a new firm startup would not demonstrate entrepreneurial opportunity if, for example, it was a nontechnological service business that had not segmented its markets.

Gaglio \& Katz (2001) devote extensive discussion to the difficulties of operationalizing entrepreneurial alertness research. However, they do not make concrete suggestions as to how entrepreneurial opportunities should be measured. They do warn researchers about the dangers of confusing opportunities with successful opportunities when conducting research: "the commonly accepted practice of asking successful entrepreneurs recount how they "found" their opportunities is problematic for alertness investigators because it allows respondents to collapse all the stages into one moment" (p. 107). 
Brown, Davidsson \& Wiklund (2001) operationalize "opportunity based firm behavior" by developing and testing a scale. Some of the scale items ask respondents to assess opportunities in their firms (For example, "We limit the opportunities we pursue on the basis of our current resources" and "In exploiting opportunities, having the idea is more important than just having the money"). However, the interpretation of what constitutes an opportunity or its exploitation seems to be left to the respondents (Brown et al. 2001). The same is true in the empirical study of Ozgen \& Baron (2007), who measure opportunity identification by six items selected from previous research (Singh, Hills, Hybels and Lumpkin 1999), but they never explain how the respondents are supposed to interpret the term "opportunity" that appears in the scale items (Items such as "I can recognize new venture opportunities in industries where I have no personal experience" and "I have a special alertness or sensitivity toward new venture opportunities"). (Ozgen and Baron 2007) This latter item was also used as an item in the alertness scale of Singh (2000, 69), whose sample included 303 entrepreneurs, defined as presidents and/or CEOs of small and young companies. Singh's (2000) mail questionnaire included a simple model description of a difference between an idea and a new venture opportunity, and the respondents were asked to provide information on the numbers of new ventures ideas, new venture opportunities, and pursued opportunities over the past year (Singh 2000).

Given the ambiguity surrounding the entrepreneurial opportunity construct, it is not surprising that only a few researchers, as described above, have tried to turn entrepreneurial opportunities into measurable units. For those who have tried, new firm startups seem to be the place where individuals reside after having recognized entrepreneurial opportunities. Hence, the choice of startup firms in the field of biotechnology as the data source concerning entrepreneurial opportunities is in line with previous research (Busenitz 1996; Shane 2000; Singh 2000; Park 2005; Saemundsson and Dahlstrand 2005; Ozgen and Baron 2007). 
In line with the definition established for entrepreneurial opportunities in this research, it was suggested above that new product development process can be an example of an entrepreneurial opportunity. To quantify the opportunities recognized by the sample firms we should look into their product development pipelines to count the number of opportunities. In order to understand the variables chosen to reflect entrepreneurial opportunities in the current empirical context the reader should have a general understanding of new product development processes in biotechnology. In the development pipeline typical for biotechnology products, the projects evolve from discovery (invention) and scientific development via clinical development and commercialization. The development from invention and preclinical testing to a commercialized product typically takes $12-15$ years for biomedical products. One aspect related to the complexity of the biotechnology innovation process is that there is not normally a one-to-one relationship between a specific scientific discovery and a certain industrial application. Any given biotech invention may be used in a variety of applications and industries (McKelvey, Rickne and Laage-Hellman 2004), and often firms have to select which one of the many potential commercialization avenues they want to pursue for any one invention. Small R\&D firms are typically heavily dependent on the success of their lead development projects. In biotechnology, the huge costs of R\&D effectively limit the number of projects that can be run within one firm. Failures in the lead projects can break the whole company, whereas success in them can attract investors and speed up the development process. Signaling the science- and technology oriented business models typical for biotechnology firms, managerial tasks in these firms reflect science, product development, business development and the few administrative functions necessary to keep any organization running. (Renko 2006a)

Figure 9 below illustrates the product development pipeline of a typical biopharmaceutical company and how the items in questionnaire section E (Items E1-E9 in 
the figure) capture different parts of the pipeline (See Appendix 1 for questionnaire). Question E1 asks about the number of "new inventions for which the firm has filed domestic or international patent application(s)". The fact that patent has been applied for implies that there is possible industrial use. However, as illustrated in Figure 9, these inventions are still far from being commercialized. As mentioned earlier, some inventions can be developed towards a variety of commercial applications. Still, some firms may choose to focus on one business area only and all their inventions may be targeted towards one usage area. Hence, it is important to know the number of "therapeutic areas where these inventions are useful (your own estimate)", item E2 in the questionnaire (could not be placed in Figure 9). Some inventions may be abandoned without pursuing them further for commercial purposes. Hence, item E3 is needed to capture the extent of the firm's pipeline as well as those inventions that originate from the focal firm but are developed in a partner firm of some kind: "End products that are / have been developed based on this/these inventions in your firm or your partners". Items E4-E7 ask about patent protection that has been applied for or granted to a firm's inventions. Both domestic and international patent applications and approvals are captured; even though it has turned out that the US is the primary patenting location for those firms wishing to launch products to international distribution, there are still firms that pursue more local patenting strategies as well. Item E8 captures the end of the development pipeline: "New product introductions to the markets", whereas item E9 asks about the entrepreneurial opportunities that move from having been identified (invention) to a stage where the company invests in their development towards commercialization: "New product development projects started". Note that this item differs from E3 in that a firm may have started numerous development projects (high value in E9) but may have abandoned many of them before they ever reach the markets (low value in E3). 


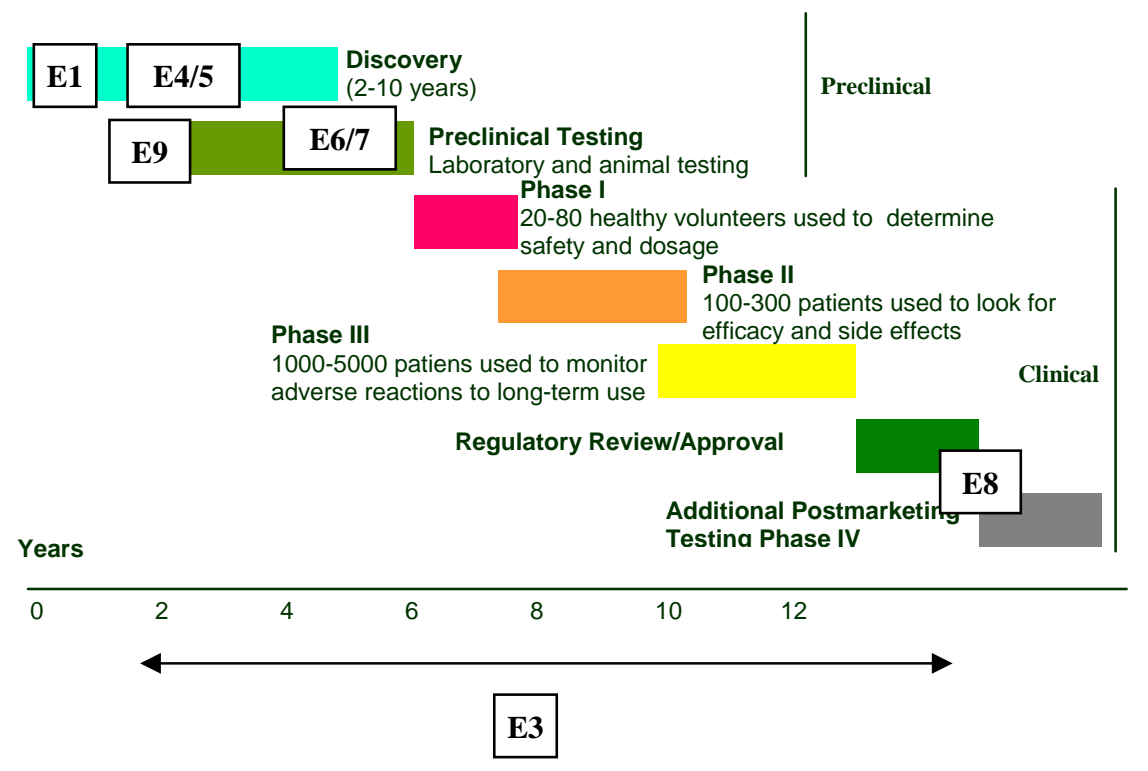

Figure 9: Biopharmaceutical product development pipeline and questionnaire items E1-E9

Having defined entrepreneurial opportunity recognition as perceiving a possibility to introduce innovative (rather than imitative) goods or services to a marketplace through (a) the founding and formation of a new venture, or (b) the significant improvement of an existing venture, it follows that recognized entrepreneurial opportunities in biotechnology ventures have the following characteristics:

- novel (invention),

- patentable (potential industrial use)

- lead to a significant improvement of the venture.

Hence, the following four items were selected as scale items for "Entrepreneurial opportunity recognition":

- number of new inventions for which the firm has filed domestic or international patent application(s); 
- number of therapeutic areas where these inventions are useful;

- number of domestic patent applications; and

- number of international patent applications (The same application submitted to multiple countries counts as one).

The inventions captured by these questions in phase 1 of data collection should reflect the ideas that got the company started in the first place. Hence, they have essentially led to the founding and formation of a new venture. In phase 2 the respondents were asked to provide numbers since June 2004 only. It is assumed that these inventions then have a potential to lead to significant improvement of an existing venture. Especially those that have potential use in multiple therapeutic areas can be valuable since a firm can license out development rights to those indications it does not pursue in house.

The 4-item scale has a Cronbach's alpha reliability value of .664 in phase 1 data. In phase 2 data, the corresponding value is .882 .

Entrepreneurial opportunities exploited ${ }^{12}$. Because the definition of opportunity recognition only entails perception, it follows that exploitation of an opportunity is a separate activity. As defined earlier, the exploitation of an opportunity refers to those activities committed to (a) the founding and formation of a new venture, or (b) the significant improvement of an existing venture in order to introduce innovative (rather than imitative) goods or services to marketplace (See also Choi and Shepherd 2004). Since the units of analysis in this research are independent, young ventures that have already been established, the current study focuses on the "significant improvement of an existing venture in order to introduce innovative goods to the marketplace".

\footnotetext{
12 This construct is only operationalized to show the discriminant and convergent validity of "entrepreneurial opportunities recognized". This variable will not be used in the hypothesis testing.
} 
Choi \& Shepherd (2004) study opportunity exploitation and measure entrepreneurs' engagement in exploitation as their likelihood to commence "immediate full-scale operations on the product or service arising from the opportunity, where full-scale operation is the scale required to ship the first product for revenues [...] - not market testing" (p. 385) (Likert scale items for various scenarios). This translates to an "operationalization" of an opportunity as something that can be anchored in a product or service.

A common indicator of expertise in the biopharmaceutical industry is the number of drugs in development or in the "pipeline". The strength of a firm's pipeline is considered an important indicator of a company's future cash flows, and the number of products under development by a biotechnology firm has a direct relationship to firm financial performance (DeCarolis and Deeds 1999).

The measurement of entrepreneurial opportunity exploitation in this study includes the following continuous items: (1) New product introductions to markets, (2) New product development projects started, and (3) End products that are / have been developed based on the company's invention(s). A composite measurement (sum) of these three items is used. This measurement combines the new firm context of opportunities (Busenitz 1996; Shane 2000; Singh 2000; Park 2005; Saemundsson and Dahlstrand 2005; Ozgen and Baron 2007) with innovativeness (Park 2005; Sanz-Velasco 2006) and product- or service relatedness (Choi and Shepherd 2004) of these opportunities. The three-item scale has a Cronbach's alpha value of 0.882 in phase 2 data.

\section{Profit potential.}

How to assess company performance in biotechnology? Conventional internal performance evaluation is based on comparable and well-accepted measurements, which are 
also backward looking (Cumby and Conrod 2001). In the pharmaceutical industry, sales, profits, customer base, or the richness of the $\mathrm{R} \& \mathrm{D}$ pipeline are commonly used as performance indicators. However, for most biotechnology companies that have no products on the markets yet, these measurements are irrelevant. When asked about the development stage of their lead products, 48.8 per cent of the respondents of the empirical study indicated that their firms either marketed their own lead product or had a partner company taking care of this task at the time of data collection. This means that more than half of the sample firms (at both phase 1 and phase 2) had not yet launched their lead product. One could have assumed that the share of companies with products on the markets would have been larger in 2007 than in 2003-2004 but this was not the case. At both times, 51.2 per cent of respondents represented firms with no products on markets.

Essentially, business performance can be investigated by both subjective (e.g., selfreported) and objective (e.g., market share, sales, profit) measurements. However, even some "objective" financial data is subject to managerial decisions such as evaluation of investments and assets, reporting of liabilities and costing (Rodriguez Cano, Carrillat and Jaramillo 2004). The difficulty in obtaining objective data contributes to the wide use of subjective measurements (Dawes 1999; Harris 2001). Especially for the kinds of small and young (mostly private) firms included in the sample for this study, objective information is not readily available. Rather, managers, especially in the US-based companies, tend to disclose as little financial information as possible. Thus performance in this study is measured through items reported by the respondents that capture the profit potential of the venture.

Early sales. Growth in sales (sales growth rate) is a traditional accounting measurement of a firm's performance widely used in the entrepreneurship literature (Lumpkin and Dess 1996). In this study the respondents were asked whether or not their firm currently sells 
products. If the answer was yes, they were further asked to provide information on the way the product(s) is / are marketed: licensing agreement / own distribution and sales / selling through a partner company (non-licensing agreement). Furthermore, these respondents were asked to provide objective (numeric) information about sales turnover for 2001 and 2002 financial years (phase 1) as well as 2005 and 2006 financial years (phase 2). If the respondent answered "No" to the question "Do you currently sell products?", he/she was not asked about sales figures; instead, there was a question whether the firm is planning to reach end markets through a licensing agreement / own distribution and sales / selling through a partner company (non-licensing agreement) in the future.

Self reported sales data was checked against data obtained from secondary sources whenever secondary data was available. Secondary sales data was obtained from the following databases: Hoover's, Inc ${ }^{13}$, FIB (Finnish Biotechnology Index), The Swedish Biotech Industry Guide ${ }^{14}$, and Thomson-Gale, Business \& Company Resource Center. The correlations between primary and secondary sales data are reported in Table 10. The correlations between the self reported figures and those obtained from secondary sources are comfortably high, all significant at $\mathrm{p}<.05$. Based on sales data obtained in interviews in phase 1 and survey data collected from respondents in 2007, sales growth in USD was calculated for 15 companies. In addition, it was possible to calculate sales growth for an additional 16 companies based on sales data obtained from secondary sources. Consequently, sales growth variable (\%) is available for 31 companies. This sales growth serves as a dependent variable in the tests of hypotheses 3 and $3 \mathrm{a}$. In addition, absolute sales

\footnotetext{
${ }^{13}$ Hoover's offers proprietary business information and features a database of information on more than 12 million corporations and organizations.

${ }^{14} \mathrm{http}: / /$ biotech.idg.se/industryguide
} 
numbers from 2006 will be used in the analyses since those numbers are available for 44 firms.

Table 10: Primary and secondary sales data

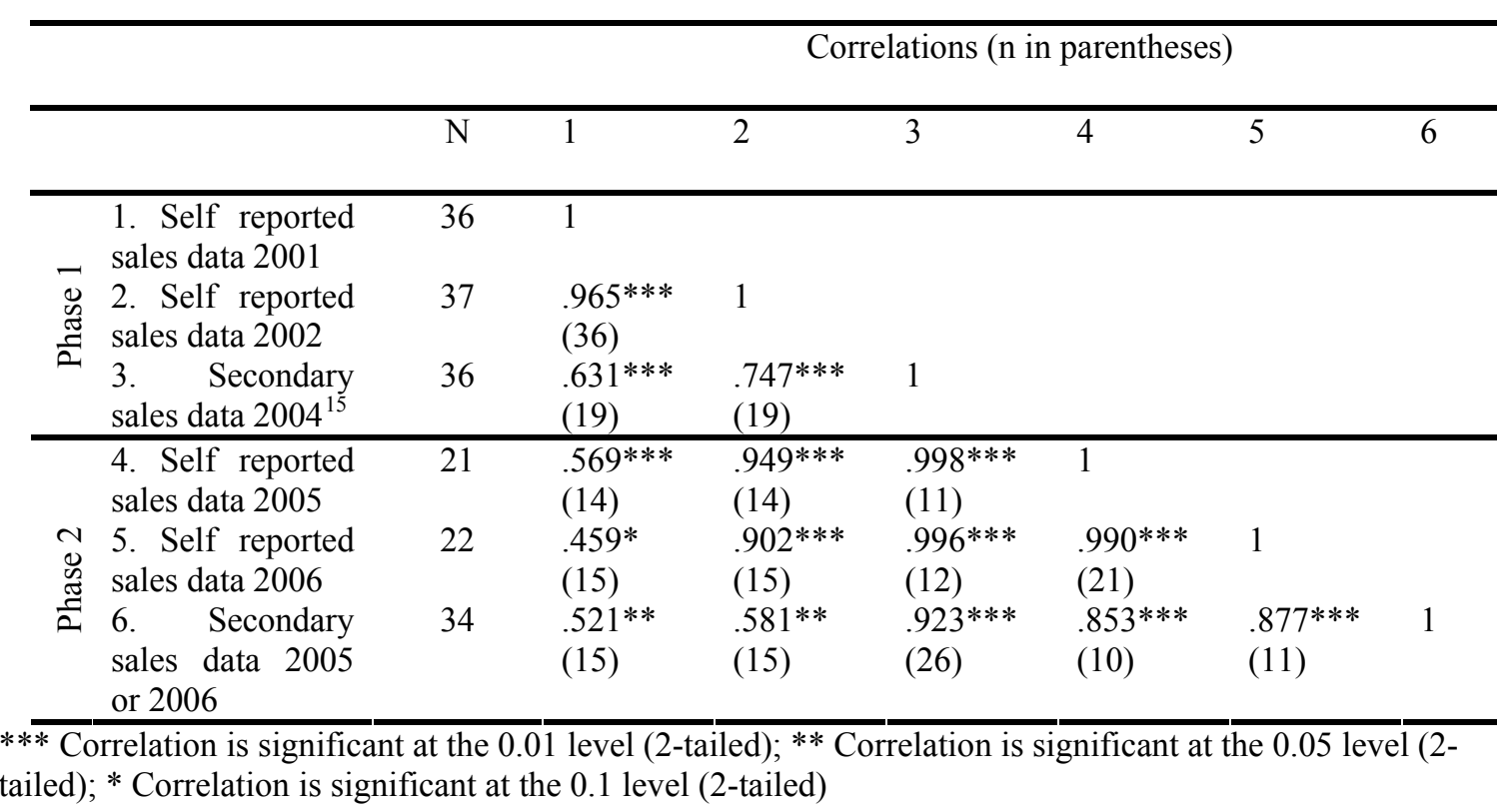

Equity investments. Limited internal funds and lack of sales income typical of young firms in markets for technology combined with the imperfections of capital markets suggest that external equity financing is crucially important for these firms (Carpenter and Petersen 2002). In the venture capitalists' view, the expectation of high financial returns is mainly correlated with the size and growth of markets targeted by the young innovative firm, and the radical nature of innovation (Tyebjee and Bruno 1984). In the US in particular, the role of venture capitalists in backing up promising technology ventures is a phenomenon that has received a wealth of attention in research studies of these firms (See e.g. Amit, Brander and Zott 1998; Gompers and Lerner 2001; Hellmann and Puri 2002). A recent study of German biotechnology firms by Champenois, Engel and Heneric (2006) emphasizes the importance

\footnotetext{
${ }^{15}$ Very few data points would have been available from secondary sources for years prior to 2004. This is probably due to the very young age of most firms when interviewed for phase 1 data collection.
} 
of venture capital finance as a source of funding for biotechnology firms developing new products and technologies in the therapeutic and diagnostic fields. Forty-two per cent of the "high risk" sample firms of Champenois et al. (2006) received early stage venture capital. Remembering that only a proportion of startup firms that search for venture capital investments actually receive funds, it is clear that venture capital is a crucially important phenomenon for biotechnology startups.

In the interviews conducted for the phase 1 as well as in the phase 2 questionnaire the respondents were asked to provide information on the capital invested in their firm up to the time of the interview. Seventy interviewees actually provided this information in phase 1 and thirty three in phase 2 . The Pearson correlation coefficient between phase 1 and phase 2 data is .905 (Significant at $\mathrm{p}<.01$ ). Since these young companies are not required to provide information about their sources of capital to the public, secondary data to confirm these numbers are not readily available. For currency conversions in phase 1 , USD $1=$ EUR $0.9=$ SEK 8. For currency conversions in phase 2, USD $1=$ EUR $0.74=$ SEK $6.8^{16}$. In the analyses, the amount of capital invested in the firm divided by firm age is used.

Outlicensing. A third proxy used to signal profit potential in this study is the number of technologies the firm has licensed out. The number of product candidates licensed out to other companies tells about the future profit potential of these products. Small, young biotechnology firms may adopt different commercialization routes for their product opportunities: either take their technology direct to the market as a final product or channel it through large established companies that will then apply their know-how and resources to commercialize it (Pfirrmann 1999; Costa, Fontes and Heitor 2004). The deals between smaller, upstream inventors and larger, downstream marketers are typically structured as licensing agreements, and profit potential together with functional complementarity are the

\footnotetext{
${ }^{16}$ This conversion rate was used for all financial information gathered in phase 2 primary data collection.
} 
driving forces behind such agreements (McCutchen and Swamidass 2004). In comparison with other industries, biotechnology has the highest absolute number of strategic alliances (Hagedoorn, 1993), involving mainly licensing agreements. Using a secondary database, Kollmer \& Dowling (2004) identify 360 North American biopharmaceutical firms as licensors out of a total population of 421 biopharmaceutical firms in the North America in $1999^{17}(86 \%)$. In this study, the questions about the number of technologies the firm had sold or licensed out to other companies were added between phases 1 and 2, so licensing data is only available at phase 2 . Out of the 42 companies for which data were obtained in phase 2, twenty-two had licensed out or sold at least one technology during the firm's existence. Out of the 14 biopharmaceutical companies from which data were collected in phase 2, eleven had been involved in such technology transfer as a seller / licensor (79\%). A sum of the number of technologies the firm has licensed out or sold out since the beginning of 2004 is used in the analyses.

Control variables. The use of control variables is limited by the small number of cases $(n=42)$ from which data were obtained in phase 2 . Introducing many control variables to the dependence models would bring down the degrees of freedom. It might be that the results of the tests are somewhat different for different types of biotechnology firms (medical device / technological platforms/ diagnostics / drug discovery \& development), for example. However, introducing dummy industry sector controls to the models would be detrimental for the degrees of freedom in the models. Three control variables have been selected for all the models. First, firm location is used as a control variable. The dummy variable for location $(1=$ USA, $0=$ Finland or Sweden $)$ is used as a control variable in all statistical analyses. In addition, firm age and firm size (number of employees) are used as controls. The

\footnotetext{
${ }^{17}$ Number based on the Biotechnology Guide USA.
} 
age of the firm is measured as the number of years between the year of the firm's formation (self-reported) and the year of phase 1 data collection.

\section{Design of the survey process}

The primary empirical data for this study have been collected from young, independent biotechnology ventures in Finland, Sweden, Pennsylvania, Florida and California. Different institutional systems for new venture finance and innovation commercialization (US vs. Scandinavia) may account for variation in the profit potential and innovativeness of new firms. However, even though attention will be paid to differences rising across the various geographic regions when conducting the analyses, comparisons and finding similarities / differences between areas is not the purpose of this research.

Market knowledge in a science driven field. Sheen $(2003,268)$ has not been the only one to state that "success in the pharmaceutical industry depends, perhaps more than in any other industry sector, on scientific research". However, even though the development process of a new drug or other kind of medical product is extremely long, knowledge intensive and costly, in the end the process aims at selling the output to end users. The deliberate decision to focus on medical biotechnology companies in this research - hence, mostly on pharmaceutical firms - is based on the understanding of the specific, science-driven nature of the industry. Biotechnology is a representative field of the functioning of markets for technology (Arora, Fosfuri and Gambardella 2001). The research results revealed by the study on the market knowledge of small biotechnology firms illustrate this phenomenon in a field that is considered extremely science and technology driven.

Primary data collection. The basic difficulty with quantitative research approaches to the biotechnology field lies in the fact that biotechnology is not an industrial sector but a 
technological area. Modern biotechnology has many product dimensions, different underlying knowledge bases and wide fields of application. According to Brink et al. (2004, 31-32), the main data sources for existing economic research in the field of biotechnology include:

- trade data classified by product group;

- $\quad$ specialized surveys of firms engaged in some form of biotechnology production

- surveys of 'technology use' at the firm level;

- scientific publications' data;

- patent data, either United States Patent and Trademark Office or European Patent Office;

- $\quad \mathrm{R} \& \mathrm{D}$ data covering expenditure and personnel;

- databases on specific topics, such as alliances, venture capital, firms and so on.

Market knowledge, technology knowledge, entrepreneurial orientation and entrepreneurial opportunities are organizational phenomena To study these phenomena based on secondary data would certainly not capture the essence of them. Even though secondary data on, e.g., market intelligence generation through firms' subscription to various databases could be available, the only way to collect firm level data on the independent variables altogether is either through empirical observation of firms, or through interviewing / surveying key individuals. In this empirical study, the latter approach is put into action.

Biotechnology in Finland and Sweden. In both Finland and Sweden the private capital market has undergone a change during the last decade. More venture capital has become available for innovative firms in their early development phase, especially for firms within biotechnology or information technology (Nilsson 2001). This has been an important driver 
for new firm formation; numerous new biotechnology firms have been formed in both Finland and Sweden since the beginning of the 1990s (Renko et al. 2005; Renko 2006a). However, public funding also plays an important role in the early stages of a firm, especially because it is "soft" money and the inventor still owns his/her idea. There are several public actors in both Finland and Sweden that provide funding to early-stage high-technology firms. Both the Swedish and the Finnish system are characterized by close cooperation between academia, clinical practice and basic, pre-clinical and clinical fields. (Renko 2006a)

Biotechnology in the US. USA provides a good environment for biotechnology firms to flourish, which is clearly illustrated by the funds invested in biotechnology R\&D; 70 per cent of biotechnology R\&D takes place in the US. In 1992 there were 1,231 companies in the biotechnology business in the US, in 2001 1,457 companies, and in 20061,452 companies (Ernst\&Young 2002; Kermani and Bonacossa 2003; Ernst\&Young 2007) In 2006, these 1,452 companies combined raised over USD 20,300 million from the financing community, out of which USD 944 million came from initial public offerings (an increase of 51\% over 2005) (Ernst\&Young 2007). US-based biotechnology companies like Genentech, Amgen, Biogen, Chiron and Genzyme have brought biotechnology-based drugs to markets over the past twenty years.

51 US metropolitan areas have been identified as biotechnology areas, and they can be further grouped into four general categories based on the relative amount of biotechnology activity in each. Nine metropolitan areas (Boston, Los Angeles, New York, Philadelphia, Raleigh-Durham, San Diego, San Francisco, Seattle and Washington/Baltimore) stand out as biotechnology centers because they have above-average levels of biotechnology research activity and biotechnology commercialization. Four metro areas can be characterized as biotech research centers with limited commercial activity. Twenty-eight metro areas have median levels of biotech research and commercialization, and within this group there are two 
metropolitan areas from the state of Florida, namely Miami-Fort Lauderdale, FL, and Tampa-St. Petersburg-Clearwater, FL. Ten metro areas have no significant biotech activities taking place (Cortright and Mayer 2002).

The US data collected for this research comes from companies in South Florida, Pennsylvania (Philadelphia area), and the Bay Area in California. The key aspects of biotechnology in each area are briefly highlighted in the following.

Florida. In terms of population, Florida is the fourth largest US state and it is third in consumption of pharmaceutical products. A boost to biotechnology in Florida has been on the way ever since the beginning of the new century. A California-based non-profit research institute, the Scripps Research Institute, has fueled growth by opening its second facility in Jupiter, FL (Abrams 2004). According to data compiled by the University of Florida's Sid Martin Biotechnology Incubator, more than half of Florida's current 134 biotech and biomedical device companies have been founded in 2001-2007. Within Florida, the top three regions with the greatest concentration of biotech and bio-medical device companies are: The Southeastern region with 46, the North Central Region with 37, and the Tampa Bay region with 30 companies. Most companies are privately owned with fewer than 20 employees. (BiotechBusinessWeek 2007).

Philadelphia Area. The Philadelphia medical district, with its large pharmaceutical firms, was established by the mid-1950s. Over the past two decades, the area has experienced a shift from a traditional drug and pharmaceutical base into biotechnology as a result of several interrelated elements, such as the concentration of academic, medical and researchoriented institutions; the presence of large pharmaceutical companies; the availability of capital; and the coordinated support of government and private organizations. The three-state area around Philadelphia, including eastern Pennsylvania, New Jersey and Delaware, accounts for about 80 per cent of the production of pharmaceuticals in the US (Llobrera, 
Meyer and Nammacher 2000; Santomero 2002). At the same time, biotechnology has a strong foothold: Investments in biotechnology in the Philadelphia area more than doubled in 2006, to \$349.2 million (Loyd 2007).

San Francisco Bay Area. The San Francisco Bay Area is an intellectual center with three world-class universities - the University of California, Berkley; the University of California, San Francisco; and Stanford University, Palo Alto - fueling biotech innovation. Many of the first biotech companies in the United States emerged in the Bay Area in the early 1980s, including Genentech, Chiron and Cetus. The area also benefits from a permissive regulatory infrastructure. For example, Stanford University announced the formation of an institute to study stem cells and human cloning in 2002 despite national pressure against the exploration or use of the technologies. In per capita concentration of life scientists, San Francisco ranks second in the world (after Boston) with about 3,100 life scientists. In terms of biotech patents, the San Francisco area is clearly a hotbed of activity, with almost 1,300 patent registrations in 2000 compared with less than 850 in Boston (Bergeron and Chan 2004).

Sample

The sample of this study includes a total of 85 biotechnology firms in the USA, Finland and Sweden in phase 1 (2003-2004). Forty-two (42) of these firms also participated in phase $2(2007)$

Population. The target population of the survey is the small and medium-sized independent medical biotechnology companies in Finland, Sweden, San Francisco Bay Area, Philadelphia area and South Florida. These areas were chosen so that firms from different institutional environments (Nordic and American) would be included. Furthermore, some areas have long roots in biotechnology (like Bay Area and Pennsylvania), others have 
experienced a dominance of large pharmaceutical companies in the past (Sweden), and some areas have only witnessed rapid growth in the biotechnology field over the past decade (Finland and South Florida).

Sampling method. Random sampling ensures that the answers from a sample approximate to what we would have got had we asked everyone in the population (Shadish et al. 2002). Random sampling was used in this study to make the sample similar to the population.

Sampling criteria. The sample was stratified using the following criteria: (a) corporate governance (independent firms), (b) employment size class maximum of 250 people following the European Union's cutoff for small and medium-sized enterprises, (c) industrial sector: active in $R \& D$ in human therapeutics (drug discovery \& development), diagnostics, medical devices, and / or technology research that helps in developing the aforementioned classes of products, and (d) product-orientedness (i.e. even if firms provide services as a part of their business model, their main lines of business are about researching and developing physical products).

Sampling frame. The random sample of companies included in this research was derived from the industry databases of BioFlorida (www.bioflorida.org), Pennsylvania Biotechnology Association (www.pabiotech.org), Biotechnology Industry Organization (www.bio.org) member directory of Californian companies, Directory of Finnish biotechnology companies (www.finbio.net), and "The Swedish Biotech Industry Guide" (http://biotech.idg.se/industryguide/).

Data collection method, phase 1. In order to collect valid and comprehensive data from the sample firms face-to-face interviews were conducted with the CEO (in some cases the business development manager or founder) of each sample firm in phase 1. This was important for a number of reasons. First, in addition to a structured questionnaire, the phase 1 survey instrument included questions that were open ended and the analysis of which 
would be qualitative. Second, face-to-face contact gave the respondents a possibility to ask for clarification if they did not understand some questions. Third, a personal visit and data collection minimized the amount of missing data.

The interviewees were told about the general purpose of the research before the interviews, but they were not shown the questionnaires. In the actual interview the session started with questions about company demographics, after which open-ended questions were presented. It was important to ask the open-ended questions before the interviewees filled in the standardized scales so that the answers to the open-ended questions would not be biased by the scale items. Overall, the questionnaire worked well and the personal interview approach resulted in a minimal amount of missing data. Table 11 below summarizes the positions of phase 1 interviewees $(n=85)$. More detailed response patterns by region will be described shortly.

Table 11: Position of interviewees, phase 1

\begin{tabular}{lll}
\hline Position & N & Percentage \\
\hline CEO & 48 & 57 \\
Founder & 2 & 2 \\
CEO and Founder & 19 & 22 \\
Vice President, Bus. Dev. & 16 & 19 \\
Total & $\mathbf{8 5}$ & $\mathbf{1 0 0}$
\end{tabular}

Phase 1 data collection with the survey instrument took place between October 2003 and June 2004. In 2003 and 2004 the biotechnology industry worldwide rebounded from the depressed stock market conditions of 2001 and 2002. Increasingly, pharmaceutical and medical device companies were converging with health care providers. The number of publicly traded biotech companies declined slightly in 2003 to 611 from 619 in 2002, but these companies earned $17 \%$ more in revenues and hired more workers, boosting 
employment by $9 \%$ while reducing R\&D spending by $16 \%$ and improving their net loss by 65\% (Ernst\&Young 2004).

Data collection method, phase 2. The purpose of the phase 2 data collection effort was to follow up with the firms first interviewed in phase 1. Phase 2 data collection started in May 2007 by secondary data collection from online sources to determine the status of each firm and original respondent. Sixty of the original 85 firms were still operating as independent businesses. In 43 of these 60 firms the interviewee from phase 1 was still in the same position as in 2003-2004 or had even been promoted. In these 43 cases, phase 2 questionnaire was mailed to this individual. In the remaining 17 cases the new company CEO received the questionnaire. Mail survey was employed in phase 2 data collection because it allowed a maximum amount of information to be collected from a maximum number of geographically dispersed firms in a minimum amount of time. The survey questionnaire was identical to the structured interview guide that had been used in phase 1 except that items on technology licensing were added for phase 2 and some questions were re-organized.

Before sending out the survey questionnaire, an executive summary of phase 1 research results was mailed to all respondents. The actual questionnaire with an introductory letter followed two weeks after the executive summary. To increase the response rate of the mail survey, a postcard reminder as well as two additional copies of the mail questionnaire were mailed to the respondents within specified time intervals after the initial mailing of the questionnaire as suggested by Dillman (1991). Dillman (1991) also summarizes a number of other techniques that have been proven to increase response rates in mail surveys. The following techniques were employed in phase 2 to increase the mail survey response rate: (1) ordering questions to assure that interesting ones related to the topic described in the cover letter come first; (2) printing the questionnaire in a booklet format with a topically neutral 
cover; (3) use of four carefully spaced mailings, including a postcard follow-up one week after the original mailing, a replacement questionnaire and cover letter informing the recipient the questionnaire has not yet been received four weeks after the original mailing, and a second replacement questionnaire and cover letter approximately seven weeks after the first mailing; (4) individually printed, addressed, and signed letters; (5) addresses printed onto envelopes rather than on address labels; (6) use of smaller than usual business stationery to reduce costs and make the entire request appear smaller and easier to comply with; (7) cover letter content that includes descriptions of the study's social usefulness and why the respondent is important; (8) explanation of how respondent confidentiality is protected, and (9) folding of outgoing materials in a way that contrasts with advertising mail. (Dillman 1991)

Phase 2 data collection with the survey instrument took place between May and October 2007. Over the past years the product pipelines of the global biotechnology companies have been strengthening, their financial performance improving, and the field has seen consolidation between companies with complementary product pipelines. The number of publicly traded biotech companies in the world reached 710 in 2006 (compared to 611 in 2003) and these - as well as private biotechnology companies - are increasingly profitable, indicating the increasing maturity of the biotechnology sector. In 2006 the global biotechnology industry registered strong revenue growth across all leading biotechnology regions of the world; $13 \%$ in the US and in Europe and $22 \%$ in Canada, and the industry also made some advances toward overall profitability (Ernst\&Young 2007).

Response patterns. BioFlorida is an organization that promotes the biotechnology industry in the state. Its goals include providing an infrastructure for companies, research community - both private and governmental - and others to exchange information and ideas (networking), providing and promoting education and other programs to assist biotechnology 
companies and attracting financial resources for BioFlorida members. At the start of phase 1 data collection in 2003, BioFlorida listed 160 companies active in biotechnology in Florida. The companies were assessed for the sampling criteria, and the $\mathrm{CEOs}^{18}$ of the firms (28) that fulfilled the sampling criteria of this research were sent an e-mail and asked about their interest to be included in phase 1 research (personal interview). Twenty-two managers answered and with 19 of them it was possible to set a time for a face-to-face interview. All these interviews were conducted in the end of 2003. By May 2007, beginning of phase 2 data collection, seven of the firms interviewed for phase 1 had either been acquired or merged (4 firms) or had ceased to exist without information on what happened to the firm (3 firms) ${ }^{19}$. Out of the twelve firms that were still in operation as independent firms in May 2007, phase 2 survey data were received from five firms. In all five firms the respondent was the same person as in phase 1 data collection.

In a similar way, the Pennsylvania Biotechnology Association listed 170 firms in May 2003. Again, these companies were assessed for their characteristics and those that fulfilled the criteria of this research were approached by e-mail (43 companies). In Pennsylvania it was possible to set times for 14 interviews with managers of firms in the Delaware Valley area. One of these interviews turned out to be unusable because the interviewee - even though very willing to discuss trends in biotechnology in general - was not able to answer the questions presented. He kept on talking about issues related to the questions presented, but within the one-and-a-half hours spent with him, only about 5 per cent of the whole questionnaire got filled in. Thus, the phase 1 sample from Pennsylvania comprises 13 firms.

\footnotetext{
${ }^{18}$ Company CEO was always approached first and in most cases he / she also served as the respondent. Because the firms are young and small, often this CEO had also started the firm. In some cases (larger firms) the CEO appointed a business development manager to be interviewed for the study.

${ }^{19}$ Assessment of company status in May 2007 was based on data available on companies' websites, from their operators, from interviewees of phase 1 whenever they could be reached, and from online press archives, such as LexisNexis.
} 
By May 2007, one of these firms had disappeared and 2 had been acquired. From the 10 Philadelphia-area based firms approached in phase 2 data collection, nine provided data. Eight phase 2 respondents here were the same individuals as in phase 1 interviews. In one company the CEO had changed and the new CEO filled in the questionnaire in phase 2.

Of the 256 firms listed by the Biotechnology Industry Organization in California in early 2004, 78 were evaluated as suitable for the study based on sampling criteria, and they were contacted. Of these firms, phase 1 interviews were conducted in 26 Bay Area firms. By May 2007, six of these firms had gone through a merger or had been acquired and two firms had ceased to exist altogether. Of the remaining 18 Bay Area firms that were approached for data collection in phase 2, ten firms participated. In all ten firms phase 2 respondents were the same individuals as the phase 1 interviewees.

In Finland the Finnish Biotechnology Industry Association listed a total of 128 firms in the country in the beginning of 2004. Of these, 28 firms were evaluated as suitable for this study. They were approached either by phone or by e-mail in January - February 2004, and 20 managers agreed to a phase 1 face-to-face interview. In May 200714 of these firms still existed as independent companies; four had been acquired / merged and two had closed their operations. In Finland, phase 2 data were received from thirteen firms. In five firms the respondent had changed form phase 1.

Finally, in Sweden phase 1 data collection was completed within a five-day period in the Gothenburg - Linköping area. Based on the directory used, 34 biotechnology companies were active in the area at the time of the phase 1 interviews, and of them, 16 were deemed suitable for this study. Of these 16 firms approached, interviews were conducted in seven firms in phase 1. Six of these firms were still in operation in May 2007; one firm had been acquired. Phase 2 data were received from five Swedish respondents, four of whom had also been informants in phase 1. 
It should be pointed out that the phase 1 data collection in Sweden as well as in Pennsylvania was carried out within a very short period of time (five days in Sweden in February 2004, seven days in Philadelphia area in Pennsylvania in October 2003). Consequently, because of the busy schedules of the managers, some of those willing to be interviewed could not be included in the sample. In Finland the data collection was completed over the months of January and February 2004, in South Florida in NovemberDecember 2003, and in the San Francisco Bay Area in April-June 2004.

Description of the survey response

Non-response bias is a potential problem in any sample survey; non-response error represents a failure to obtain information from some parts of the population. Specifically, non-response is a problem if those included in the sample differ systematically from those who did not respond (Armstrong and Overton 1977). Figure 10 presents the response analysis of the study. 


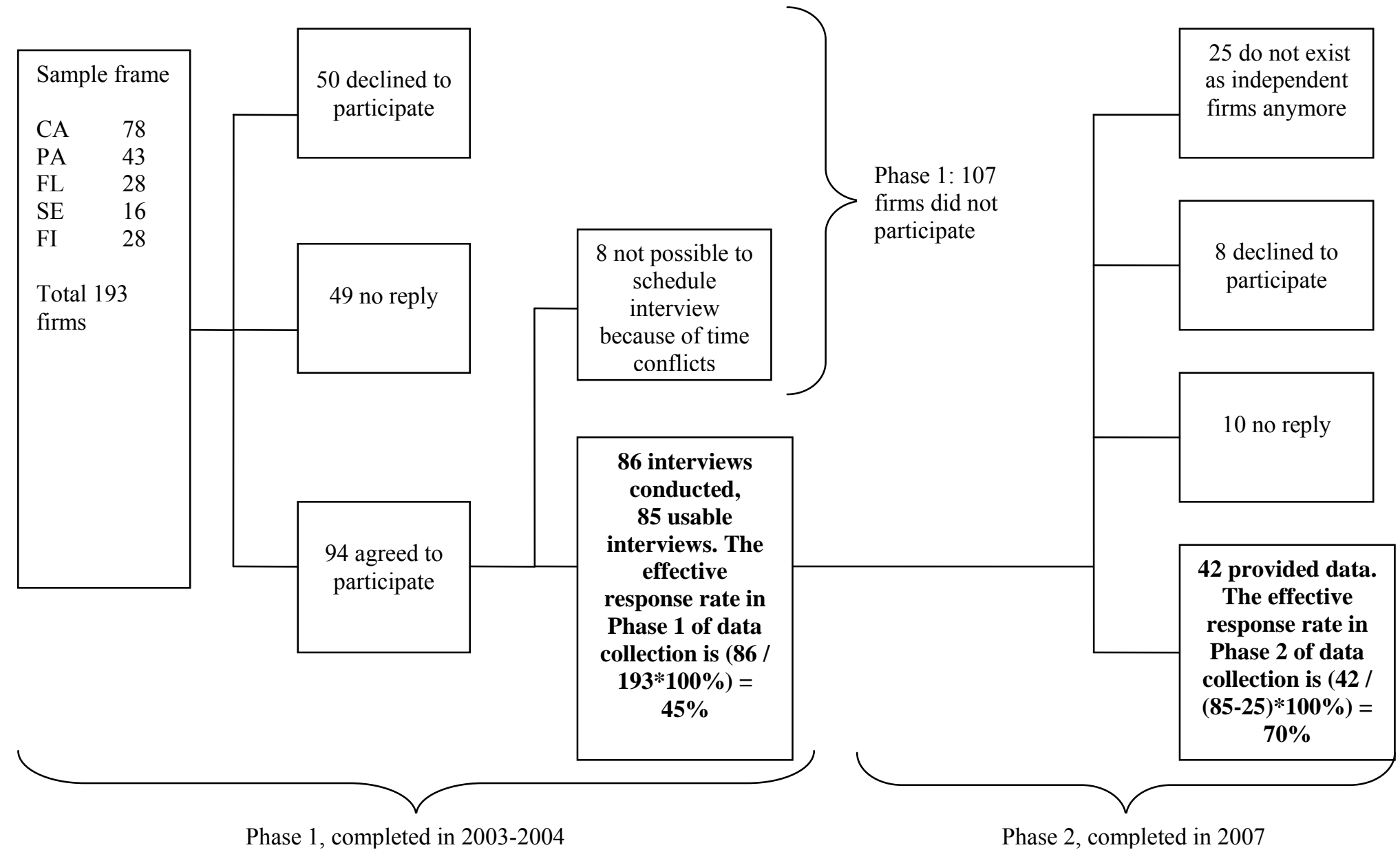

Figure 10: Response patterns in the empirical study 
The phase 1 response rate of $45 \%$ is rather good, especially considering that a onehour commitment was needed from the CEO of the company. The only incentive given for participation was access to research results. The actual length of the phase 1 interviews varied between 40 minutes and a bit over two hours. Most interviews, however, lasted for about one hour.

In some of the 49 firms that did not respond the interview request possibly never reached the CEO of the firm. Often, the e-mail addresses of CEOs were not available and e-mails to the general company addresses (info@company.com) seldom resulted in replies. Telephone calls reached the managers' secretaries, and despite their promises, the managers seldom called back.

The phase 2 response rate of $70 \%$ is in line with the response rates summarizes in Dillman (1991) for other mail surveys that have employed similar steps in carrying out a survey. The response rate of $70 \%$ was only achieved after multiple rounds of mailings as described earlier. In many cases, the respondents were also contacted by phone and encouraged to respond. Those managers who said they couldn't answer because of the length of the questionnaire were encouraged to fill in at least those parts of the questionnaire that collect data for the dependent variables of the study. Because of this, phase 2 data contain many more missing values than phase 1 data. For example, values for entrepreneurial opportunity recognition in phase 2 are available from all 42 respondents, but market knowledge in phase 2 is only available for 36 cases ( 85 cases in phase 1) and entrepreneurial orientation in phase 2 for 35 cases.

One method for estimating non-response bias is to compare results from a survey with known values of the population (Armstrong and Overton 1977). To assess non- 
response bias, Table 12 describes the company age of the phase 1 sample firms $(\mathrm{n}=85)$ and non-respondents $(n=107)$ area by area. The purpose of the table is to show that respondents do not significantly differ from non-respondents. The data is based on the companies' websites; for firms in the sample, information provided on the website was confirmed in the interview, whereas for non-respondents, the data is based on website information only. All of these firms in each area were contacted, and those who did not respond to the inquiry about their willingness to be interviewed for the research or responded negatively are classified as non-respondents.

Table 12 reveals that in South Florida and Finland the sample firms are, on average, older than the non-respondents. In the three other locations the sample firms are younger than the non-respondents. However, only in the Bay Area of California does the difference in age between the two groups turn out to be significant (t-test p-value $<$ 0.05). There are two possible explanations for this. First, it may be that in some cases despite numerous trials - attempts to contact the CEOs of larger firms did not go through. For example, in larger firms the managers' secretaries may scan the managers' e-mails, in which case interview invitations could have been deleted without the actual managers ever seeing them. Furthermore, when contacting companies by phone, in larger firms managers' secretaries - instead of the managers themselves - typically answered. Even though the secretaries often promised to forward the interview request to the manager in question, this may not always have been the reality. In smaller firms the manager herself was often reached by phone. Another possible explanation is that larger firm managers are busier and do not have time for research interviews. In fact, many of those who turned down the interview invitation said that they were too busy to 
devote time to the study. One more speculation is that larger firms often have "professional" managers, whereas smaller firms are typically run by scientists who have been $\mathrm{PhD}$ students themselves. It may be that these ex-PhD students sympathized with a $\mathrm{PhD}$ student and were more willing to agree to be interviewed.

Table 12: Age of sample firms and non-respondents ${ }^{20}$

\section{Firm Age}

\begin{tabular}{lllll} 
& \multicolumn{2}{c}{ Sample firms } & \multicolumn{2}{c}{ Non-respondents ${ }^{21}$} \\
\hline & Mean & S.D. & Mean & S.D \\
South Florida, USA & $7.47(\mathrm{n}=19)$ & 5.40 & $7.00(\mathrm{n}=9)$ & 7.38 \\
$\begin{array}{l}\text { Pennsylvania, USA } \\
\text { Bay Area, Northern }\end{array}$ & $5.61(\mathrm{n}=13)$ & 4.39 & $7.41(\mathrm{n}=29)$ & 6.68 \\
$\begin{array}{l}\text { California, USA } \\
\text { Sweden, Gothenburg }\end{array}$ & $3.50^{* *}(\mathrm{n}=26)$ & 2.94 & $5.38^{* *}(\mathrm{n}=52)$ & 4.02 \\
$\begin{array}{l}\text { Area } \\
\text { Finland }\end{array}$ & $5.14(\mathrm{n}=7)$ & 1.86 & $7.00(\mathrm{n}=9)$ & 8.46 \\
& $6.45(\mathrm{n}=20)$ & 3.78 & $4.75(\mathrm{n}=8)$ & 3.70
\end{tabular}

$* *=$ Significant at $\mathrm{p}<.05$

Chi-square tests were conducted to analyze if there were significant differences between respondents and non-respondents in terms of industry sectors. The only significant difference between the sample firms and the non-respondents can be observed for diagnostics firms in Pennsylvania. There, the count for diagnostic firms in

\footnotetext{
${ }^{20}$ Because of the small $\mathrm{n}$ in many categories the results should be interpreted with caution.

${ }^{21}$ Non-respondent here means that the company was determined to fulfill the criteria to be included in the sample and the company was contacted to ask for interview appointment, but either the company never responded or the response was negative.
} 
the sample is zero, whereas there are four non-respondents that are diagnostics firms. Even though the difference is significant $(\mathrm{p}<0.05)$, the overall count of diagnostics firms is very small and selection bias is hard to prove.

Finally, companies that participated in both phase 1 and phase 2 data collection $(n=42)$ were compared to those that participated in phase 1 but were non-respondents in $2007(\mathrm{n}=18)$. An independent samples t-test revealed that the two groups of companies are not significantly different from each other with regard to any of the variables chosen for the analysis (firm age, number of employees, amount of sales, number of patents, and level of market knowledge).

\section{Quality of the study - testing, checking and validation procedures}

The first ten interviews in phase 1 also served as a pilot test for the questionnaire that was later also used in phase 2. Because the final questionnaire was developed based on a preliminary, qualitative study as well as the extant literature, it was expected that not many changes would be necessary after the pilot testing. In the pilot testing stage, i.e. during the first ten interviews, the respondents were asked to pay extra careful attention to the formulation of the questions and give feedback on any possible problems or challenges. The feedback and the actions taken are summarized in Appendix 2.

Even though minor changes were made to the questionnaire based on the pilot testing (see Appendix 2), the changes were not of such dramatic nature that they would have justified dropping all or some of the first ten interviews (pilot testing) from the sample. 
Consequently, the interviews that served as pilot tests for the questionnaire remained in the final sample.

\section{Single-respondent bias}

There is considerable debate concerning the effect of leaders on organizational outcomes. At one extreme, Perrow (1970) argued that "leadership" approaches to organizational analysis represent a form of psychological reductionism and understate the effect of systemic influences on organizational outcomes. At the other end, however, there is evidence that suggests that the characteristics of key organizational actors cannot be ignored when studying organizations. For example, those who allocate organizational resources also influence innovation adoption (Hage and Dewar 1973). Especially in small firms, the characteristics and skills of the entrepreneur-manager influence all aspects of business.

A common problem in researching small firms is that secondary, objective data on these firms is not readily available. Most firms in the current sample are very small and they do not publish their financial information. Thus, the only way to assess company financials, for example, is to ask the managers. Controlling the accuracy of the information they provide is difficult. In this study, in addition to asking the managers about their firms' performance, multiple company databases were searched through in order to find objective numbers that could be compared to those given by the managers. Demographic data is readily available from multiple sources for the public companies in the sample ( $\mathrm{n}=12$ in phase 1), and it matches very well the numbers given by the 
interviewees. However, only scarce data is provided by secondary sources for the private biotechnology companies; sales information is the piece of information most commonly available. Thus sales data were collected from secondary databases for as many sample firms as possible. The correlations between these secondary data and the data provided by the respondents were reported earlier in Table 10. Overall, the positive correlations between primary and secondary sales data were comfortably high. Consequently, based on the sales data there seems to be no reason to suspect that the respondents have been giving biased information. The Wilcoxon Signed-Rank test was also employed to detect differences in the distributions of sales as reported by the interviewees and the sales data obtained from secondary sources. The 2-tailed p-value for this test was non-significant $(\mathrm{p}=0.121)$; the distribution of sales obtained from secondary sources is not different from the sales data provided by the respondents.

In research where measurements of different variables are collected from the same respondents and an attempt is made to interpret any correlations between those variables, common method variance can be a problem that biases the research results (Campbell and Fiske 1959). Because the measurements come from the same source, any "defect" in that source contaminates both measurements, presumably in the same fashion and in the same direction. Because the variables of this study were obtained from a single key informant per firm, a possible common method bias was assessed using the Harman one-factor test (Podsakoff and Organ 1986). Because of the relatively small number of cases in the dataset $(n=85)$, the factor analysis had to be limited to selected sets of variables at a time. Hence I selected eight variables at a time for factor analysis. The variables were selected from different constructs that the questionnaire 
was desired to tap in order to detect possible common method bias. Altogether, three sets of eight variables were chosen for factor analysis. For each set of variables analyzed, the results of the principal components analysis revealed three factors with eigenvalues greater than 1.0. These results (even with limited sets of variables at a time) seem to indicate that there is no one general factor in the unrotated factor structure. Hence common method bias should not be a great concern.

In seven firms the phase 2 respondent is a different person than phase 1 respondent. If the respondents' answers to the survey questions reflected their own personal attributes rather than those of their organizations, the estimates obtained from these different respondents for constructs like market knowledge and entrepreneurial orientation would be more dissimilar to phase 1 estimates than in the case of the same respondent in both phases. An independent samples t-test was used to analyze whether these differences were significant. For the same respondent in phase 1 and phase 2 , the average absolute difference in market knowledge mean between phase 1 and phase 2 is $.489(\mathrm{n}=30)$. This is not significantly different $(\mathrm{p}=.628)$ from companies where phase 2 respondent was different from phase 1 respondent: Average difference in market knowledge mean $.560(n=6)$. Similarly, for the same respondent in phase 1 and phase 2, the average absolute difference in entrepreneurial orientation mean between phase 1 and phase 2 is $.440(n=29)$. This is not significantly different $(p=.760)$ from companies where phase 2 respondent was different from phase 1 respondent: Average difference in entrepreneurial orientation mean $.405(n=6)$. Even if the small number of cases in the group where the respondent of phase 2 is different from phase 1 respondent makes the $t$ - 
test results somewhat unreliable, these findings still provide some comforting evidence about the absence of single respondent bias.

\section{Validity and reliability of the measurements}

Valid measurement is a prerequisite for the successful study of concepts. Constructs such as knowledge, attitudes and behavior cannot be directly and perfectly measured with one item. Validity refers to the degree to which an instrument is truly measuring the construct it is supposed to measure (Peter 1981).

Cook and Campbell (1979) divide validity into four related components: statistical conclusion validity, internal validity, construct validity and external validity. Each one of these is discussed in the following.

\section{Statistical conclusion validity}

Statistical conclusion validity refers to the appropriate use of statistics to infer whether the presumed independent and dependent variables co-vary and - if they do how strongly do they co-vary. We can incorrectly conclude that cause and effect covary when they do not (type I error) or incorrectly conclude that they do not co-vary when they actually do (type II error) (Shadish et al. 2002). In this study, the most severe threat to statistical conclusion validity arises from the use of a rather small sample $(n=42)$ of firms. However, it is worthwhile mentioning that a number of important contributions to literature on the effects of market knowledge and market orientation 
have been based on similarly small samples. The sample of Appiah-Adu (1998) included 74 firms, Caruana, Ramaseshan and Ewing (1998) 84 organizations, Dawes (2000) 93 organizations, Deshpandé and Farley (1998) 82 organizations, Langerak (2001) 72 firms, Ngai and Ellis (1998) 73 firms, Pelham and Wilson (1996) 68 organizations, and that of Slater and Narver (2000) 53 firms.

Despite the small dataset, longitudinal research design improves the validity of the study. A small sample size would be very problematic in a study where new scales would be developed for the measurement of various constructs. However, in this study established scales are used for the measurement of latent constructs as described earlier to avoid this problem. What is more, the phase 1 face-to-face data collection increased the internal as well as the construct validity of the research as will be described below. Given the limited resources of one researcher, using such a personal data collection method to access more than 85 firms in phase 1 would have required more time and money than was available. Thus, the sample size was partly compromised in order to be able to collect data that would satisfy the internal validity and construct validity requirements.

Shadish et al. (2002) suggest a number of strategies to increase the statistical validity of a research. In this study, as reliable measurements as possible were chosen for the variables of interest. Whenever possible, measurements were chosen that had shown high reliability in previous studies, because a conclusion about co-variation may be inaccurate if either variable is measured unreliably (Nunnally and Bernstein 1994). Also, restricting variables to a narrow range was avoided; in the statistical analyses continuous variables were not dichotomized. What is more, the fact that the units of 
analysis, and, more importantly, respondents, represent a relatively homogenous group of companies in terms of firm demographics should increase the statistical conclusion validity. The more the units in a study are heterogeneous within conditions on a variable, the greater will be the standard deviations on that variable (and on any others correlated with it). With regard to statistical conclusion validity, Bouckenooghe, De Clercq, Willem, \& Buelens (2007) note that 40 per cent of the published entrepreneurship research in recent years has used only one dependent variable in a study. In the current study, statistical conclusion validity should be improved through the use of multiple dependent variables. Finally, to increase statistical conclusion validity as accurate effect size estimation as possible is sought. Before conducting the statistical analyses the data were scanned for potential outliers that would cause the distribution to depart from normality.

Internal validity

Internal validity refers to inferences about whether observed co-variation between A and $\mathrm{B}$ reflects a causal relationship between $\mathrm{A}$ and $\mathrm{B}$ in the form in which the variables were measured (Shadish et al. 2002). In a cross sectional study, we should be concerned about ambiguous temporal precedence. Current research in the field of entrepreneurship is mostly cross-sectional in nature, which should raise concerns about potential reverse causality between variables (Bouckenooghe et al. 2007). In this research, careful attention was paid to the research design in order to ensure that the observed relationships reflect the directionality of the co-variation between the variables under 
study. Data on independent variables were collected about 3.5 years before the data on dependent variables.

Systematic differences in respondent characteristics from those of the population of interest can also cause the observed effect. The key feature of such a selection bias is a confounding of observed effects with population differences (Shadish et al. 2002). For example, if the market knowledge in a young biotechnology firm is largely determined by the quality of the management team, and if the firms included in the current sample systematically represent firms that were established by teams of $\mathrm{PhDs}$ and serial entrepreneurs (high quality teams), we should be concerned about the internal validity of the results. In this case it would be possible that significant relationships between, for example, a firm's level of market knowledge and the money invested in the firm could be a result of a confound effect of the firm's management team.

Comparing sample characteristics to population characteristics was carried out when discussing the non-response bias above. Overall, the sample seems to be representative of the population, i.e. medical biotechnology SMEs in Finland, Sweden, South Florida, Pennsylvania and San Francisco Bay Area. However, one more important concern related to internal validity is the operationalization of variables of interest; do the measurements employed in the empirical study really reflect the underlying constructs, like market orientation? This question also relates to construct validity and is discussed in the following. 


\section{Construct validity}

Construct validity is the most salient indicator of measurement validity. It is commonly regarded as consisting of two aspects: convergent and discriminant validity. Convergent validity is the degree to which multiple independent attempts to measure the same construct are in agreement. Hence, it is also related to scale reliability, which will be discussed later. Discriminant validity is the extent to which measurements of two or more different constructs are distinct (Peter 1981; Bagozzi, Yi and Phillips 1991). Exploratory factor analysis and principal component analysis (PCA) are typical ways to analyze the initial construct validity and underlying dimensions of scales. However, these analyses are extremely sensitive to small sample sizes like the one in this study. Hence construct validity is assessed via means other than PCA and factor analysis.

The measurements of market intelligence generation and dissemination (used here as a proxy for market knowledge) were originally developed by Kohli et al. (1993) based on previous, qualitative work by Kohli \& Jaworski (1990). Since then, the scale has been used and its reliability tested in numerous empirical studies and various industry contexts (Siguaw et al. 1998; Matsuno et al. 2002; Perry and Shao 2002; Kyriakopoulos and Moorman 2004; Kara et al. 2005). Similarly, the entrepreneurial orientation scale used here was originally developed and tested by Knight (1997) based on Covin \& Slevin (1989). Patents and R\&D intensity as well as outcome measures such as sales and capital invested are widely used measures as well. The only measurement employed in this study that has few predecessors in existing research is the measurement for 
entrepreneurial opportunities recognized. As described earlier, this measurement in the current study was developed keeping the industry context in mind. Conceptually, exploited and recognized opportunities are two separate constructs and, hence, they should not share variance. To check this in the empirical dataset, a measurement for exploited opportunities was developed. Table 13 below shows the correlation coefficients between exploited and recognized opportunity measures in this study for both phase 1 and phase 2 data. High positive correlations in the dark-shaded areas provide evidence of convergent validity; measurements of the same construct with the same instrument at two points of time (approximately 3.5 years apart) indicate consistency. Non-significant correlations in the lighter shaded areas, again, should provide evidence of discriminant validity. With the exception of highly significant positive correlation between items 1 and 3 (Table 13) they do.

Table 13: Correlations between recognized and exploited opportunities

\begin{tabular}{|c|c|c|c|c|c|c|}
\hline Variables & Mean & SD & 1 & 2 & 3 & 4 \\
\hline $\begin{array}{l}\text { 1. Entrepreneurial } \\
\text { opportunities recognized, } \\
\text { phase } 1(\log )\end{array}$ & 1.92 & 1.26 & 1 & & & \\
\hline $\begin{array}{l}\text { 2. Entrepreneurial } \\
\text { opportunities recognized, } \\
\text { phase } 2(\log )\end{array}$ & 1.54 & 1.28 & $.753 * * *$ & 1 & & \\
\hline $\begin{array}{l}\text { 3. Entrepreneurial } \\
\text { opportunities exploited, phase } \\
1 \text { (log) }\end{array}$ & 2.07 & .91 & $.354^{* * *}$ & .232 & 1 & \\
\hline $\begin{array}{l}\text { 4. Entrepreneurial } \\
\text { opportunities exploited, phase } \\
2 \text { (log) }\end{array}$ & 2.16 & 1.18 & .233 & .237 & $.317^{*}$ & 1 \\
\hline
\end{tabular}


In the current study, business philosophy items, used by Harris $(2001 ; 2002)$ and adapted from Deng and Dart (1994) and Peterson (1989), were used to check the construct validity of the market knowledge scale. These items are supposed to measure the sales, production, customer, stakeholder, and technology focus ${ }^{22}$ of the organization (for actual items, see questionnaire in Appendix 1). Table 14 lists the correlations (Pearson) between business philosophy and the composite market knowledge measurement (mean) calculated for each firm. As expected, there is a significant positive correlation between the market knowledge measurement and customer focus (0.244) (evidence of convergent validity). Correlations between market knowledge and business philosophy items other than customer focus turned out to be insignificant (evidence of discriminant validity).

Table 14: Correlations between market knowledge and business philosophy

\begin{tabular}{|c|c|c|c|c|c|c|c|c|}
\hline Variables & Mean & $\mathrm{SD}$ & 1 & 2 & 3 & 4 & 5 & 6 \\
\hline $\begin{array}{l}\text { 1. Business philosophy, } \\
\text { production focus }\end{array}$ & 2.95 & 1.30 & 1 & & & & & \\
\hline $\begin{array}{l}\text { 2. Business philosophy, } \\
\text { sales focus }\end{array}$ & 3.87 & 1.14 & $.355^{* * *}$ & 1 & & & & \\
\hline $\begin{array}{l}\text { 3. Business philosophy, } \\
\text { customer focus }\end{array}$ & 4.01 & .963 & .039 & $.309 * * *$ & 1 & & & \\
\hline $\begin{array}{l}\text { 4. Business philosophy, } \\
\text { stakeholder focus }\end{array}$ & 3.62 & 1.06 & $.231 * *$ & $.257 * *$ & .146 & 1 & & \\
\hline $\begin{array}{l}\text { 5. Business philosophy, } \\
\text { technology focus }\end{array}$ & 4.37 & .889 & $.193^{*}$ & $.275^{* *}$ & .051 & $.327 * * *$ & 1 & \\
\hline 6. Market knowledge & 3.79 & .462 & -.172 & -.025 & $.244 * *$ & .089 & -.097 & 1 \\
\hline
\end{tabular}

${ }^{22}$ Items for production, sales, customer and stakeholder focus were formulated similarly to previous studies, and the item for technology focus was formulated specifically for this study. 
As a conclusion, the construct validity of the key measurements of the empirical study appears to be solid.

\section{External validity}

External validity concerns inferences about the extent a causal relationship holds over varying conditions, like variations in people, settings and outcomes (Shadish et al. 2002 , 83). Thus the question of external validity is essentially a question of generalizability. Shadish et al. (2002, 87-90) distinguish between five different threats to external validity. Of those five, the relevant threats in this study concern the interaction of the causal relationships with units (i.e. firms being studied), with outcomes (i.e. the kinds of performance measurements employed in this study) and with settings (e.g. medical biotechnology industry).

The threat of interaction of the observed causal relationship(s) with the units of the study can be avoided through random sampling. The sampling procedures of this study were described in detail earlier, and they aimed at guaranteeing a random sample of the population, i.e. of the small and medium-sized independent medical biotechnology companies in Finland, Sweden, San Francisco Bay Area, Philadelphia area and South Florida. Random sampling - within the limits of sampling error - guarantees that the average relationships observed in the sample are the same as (1) the average relationships that would have been observed in any other random sample of companies from the same population, and (2) the average relationships that would have been observed across all other firms in that population which were not in the original random 
sample. Thus random sampling should eliminate possible interactions between the causal relationship(s) observed and the class of firms who are studied versus the class of firms who are not studied.

As described earlier, markets for biotechnology are global in nature. However, because of the different institutional settings in, e.g., the USA versus Europe, companies' approach to stakeholders such as venture capitalists or governmental organizations may vary. It is possible that in differing country settings types of knowledge manifest differently in young biotechnology firms and, furthermore, their consequences on entrepreneurial opportunities and profit potential could differ. This potential importance of physical location led to the deliberate decision to sample firms in five locations on two continents. This has benefits for external validity. It allows tests of the interaction between the relationships observed between the variables of interest and firm location in the study data. If an interaction is detected (i.e. if firm location moderates the firms' knowledge levels and their contribution to opportunity recognition or profit potential), this is prima facie evidence of limited external validity across geographical locations (Shadish et al. 2002).

The careful selection of dependent variables that was described earlier should reduce the possible threat that the detected causal relationships actually interact with the outcomes (i.e. the kinds of dependent variables employed in this study). Also, a number of different measurements are used to capture profit potential, and entrepreneurial opportunity recognition is measured with a scale of multiple items. These actions should further reduce the threat of interaction of study findings with the chosen dependent variables. 
Generalizations to other firms should - as always - be made cautiously, but there is no reason to suspect that the findings of the study are systematically biased and / or non-representative of the target population.

\section{Face validity}

An instrument is said to have face validity if it "looks like" it is going to measure what it is supposed to measure. At the end of each phase 1 interview the interviewee was asked to comment on the interview; what did he / she think about the relevance of the questions asked? Was there something that was not asked even though he / she thought it was an important aspect of market orientation? Overall, the interviewees were satisfied with the interview experience and many of them commented that the issues covered in the questions were very important in their everyday work. However, some of the interviewees mentioned that rather than business issues they were more preoccupied with advancing technological development. Some of the most insightful comments by the interviewees about the relevance and quality of the questions asked are listed below:

"Marketing being commonsense, a lot of questions here are about reacting quickly."

"Answers to your questions are different for different products. When I was answering I had this one specific product in mind, but if I had thought of another product my answers would have been different."

"Why do you need to have a scale from 1 to 5 for questions that are clearly yes / no questions?"

"What does this word "periodically" mean really? I don't think it matches the thinking of a dynamic company." 
"Cultural desires. They are missing from the questions. In some countries doctors want something that is not acceptable in other markets. Country-based changes in products."

"Very few early stage companies are interacting directly with patients, it is a stepwise process. But the data is already important in the early stages. We picked small indications because they require smaller clinical trials."

Based on the feedback received from interviewees in phase 1 as well as the few comments written on the questionnaires by phase 2 respondents it can be concluded that most respondents felt that the questions asked were relevant for their firms' strategies and operations.

\section{Reliability}

Reliability is a matter of internal consistency; the degree to which the instruments are free from error and thereby yield consistently accurate measurements of the construct of interest (Churchill 1979; Peter 1979). The most popular method for assessing measurement reliability in cross sectional research is Cronbach's alpha (Cronbach 1951). Cronbach's alpha summarizes the extent to which a set of items are interrelated with each other (Churchill 1979; Peter 1979). Cronbach's alpha is formulated as:

$$
\alpha=\left(\frac{k}{k-1}\right)\left(1-\frac{\sum_{i}^{k} \delta_{i}^{2}}{\delta_{t}^{2}}\right)
$$

where $\mathrm{k}=$ number of items in the scale; $\delta_{t}^{2}=$ total variance of the scale, and $\delta_{i}^{2}=$ variance of item $i$. 
Table 15 shows the values of Cronbach's alpha for the scales used in the empirical study for both phases of data collection. Only values from the phases on grey backgrounds in Table 15 were used in analyses. Naturally, no reliability coefficients can be computed for variables measured on a unidimensional scale consisting of a single question. Skewed distribution toward socially desirable responses is a common problem with self-response measurements. Since the distribution is skewed for practically all items on the scales, it was not possible to eliminate a subset of them. Because these variables are important for the analyses, they were retained and used in further statistical analyses. Because the original distribution of the "entrepreneurial opportunities recognized" scale was not normal, a log-transformed value of the scale was used in analyses.

Table 15: Scale reliabilities

\begin{tabular}{|c|c|c|c|c|c|c|}
\hline & \multicolumn{3}{|c|}{ Phase $1(n=85)$} & \multicolumn{3}{|c|}{ Phase $2(n=42)$} \\
\hline $\begin{array}{l}\text { Scale (number of } \\
\text { items) }\end{array}$ & Mean & $S D$ & Cronbach's $\alpha$ & Mean & $S D$ & Cronbach's $\alpha$ \\
\hline Market knowledge (22) & 3.79 & .462 & .753 & 3.60 & .581 & .877 \\
\hline $\begin{array}{l}\text { Entrepreneurial } \\
\text { orientation (7) }\end{array}$ & 3.86 & .608 & .719 & 3.88 & .547 & .633 \\
\hline $\begin{array}{l}\text { Entrepreneurial } \\
\text { opportunities } \\
\text { recognized (4), mean }\end{array}$ & 15.77 & 33.95 & .664 & 10.13 & 15.69 & .882 \\
\hline
\end{tabular}

Nunnally (1978) and Churchill (1979) suggest that for a reliable scale, Cronbach's alpha should be over 0.7. Here, the alpha coefficients range from 0.664 to 0.877 , 
indicating sufficient reliabilities. Since data from 42 companies are available at two points of time (phase 1 and phase 2), reliability of measures was also assessed using test-retest analysis. These results are reported below in Table 16 .

Table 16: Test-retest correlations and mean differences

\begin{tabular}{|c|c|c|c|c|c|c|c|c|c|}
\hline & \multicolumn{4}{|c|}{ Correlations } & \multicolumn{4}{|c|}{ Paired differences } \\
\hline & & $\mathrm{N}$ & $\mathrm{r}$ & $r^{2}$ & Sig. & Mean & $\mathrm{t}$ & $\mathrm{df}$ & $\begin{array}{l}\text { Sig.(2- } \\
\text { tailed) }\end{array}$ \\
\hline Pair 1 & $\begin{array}{l}\text { Market } \\
\text { knowledge }\end{array}$ & 36 & .426 & 0.181 & .010 & .168 & 1.75 & 35 & .089 \\
\hline Pair 2 & $\begin{array}{l}\text { Entrepreneurial } \\
\text { orientation }\end{array}$ & 35 & .486 & 0.236 & .003 & .024 & .286 & 34 & .777 \\
\hline Pair 3 & $\begin{array}{l}\text { Entrepreneurial } \\
\text { opportunities } \\
\text { recognized (log } \\
\text { transformed) }\end{array}$ & 39 & .753 & 0.567 & .000 & -.241 & -1.77 & 38 & .085 \\
\hline
\end{tabular}

Results of the test-retest study are presented in Table 16. Considering all three scales, the lower R-square (for market knowledge) is .181, the highest one (for entrepreneurial opportunities recognized) reaches .567 . None of the t-tests are significant at $p<0.05$, but two are significant at $\mathrm{p}<0.10$, indicating that the distribution of values for market knowledge and entrepreneurial opportunities recognized are somewhat different for phase 1 vs. phase 2 data. In summary, the significant positive correlations (all at $p=$ 0.01 or lower) and non-significant or only marginally significant (at $\mathrm{p}<0.085$ or higher) paired t-test values for the four scales are comforting. 


\section{Data analysis}

\section{Multiple linear regression}

Multiple linear regression analysis is a tool for assessing the relationship between one dependent variable and a number of independent variables. The technique is used to test models that help to predict the dependent variable based on the (known) values of the independent variables (Hair, Anderson, Tatham and Black 1995). The resulting model indicates the relative contribution (weight) of each independent variable on the dependent variable. Multiple linear regression is used to test Hypotheses 1-4. The basic multiple regression model has the following form:

$\hat{Y}=b_{0} x_{0}+b_{1} x_{1}+\ldots+b_{n} x_{n}$

In the equation above, $\mathrm{Y}$ is the dependent variable (for example, entrepreneurial opportunities recognized), $b_{0}$ a constant, $x_{n}$ an independent variable and $b_{n}$ the relative weight of that variable. The main assumptions for using multiple linear regression are normality of the variables, homoscedasticity (i.e. equality of variance) and independence of the independent variables.

Given the moderating relationships within the research models, a second analysis technique that was initially considered was structural equation modeling. However, this technique was ruled out due to the sample size of the database. 
Normality and homoscedasticity in regression analysis

In this research the normality of the variables was tested by assessing the normality of distribution graphically with the help of normal probability plots. This procedure is widely used and recommended by experts (Hair et al. 1995). The findings of each assessment were additionally verified by means of the Kolmogorov-Smirnov test for normality.

The homoscedasticity of the variables is tested using Levene's test. This test is robust against departures from normality and thus particularly recommended (Hair et al. 1995). Variance-stabilizing transformations were applied in order to achieve equal variances in cases where heteroscedasticity was present.

\section{Independence of predictor variables}

In true experiments, typical for the natural sciences, it is often possible to control the introduction of independent variables. In such a case the overall importance of each factor (for example, the proportion of the $\mathrm{Y}$ variance it accounts for) can be unambiguously determined since its orthogonality with the other factors assures that its effects on Y cannot overlap with the effects of the others (Cohen and Cohen 1983). This is seldom the case in behavioral research and the social sciences. The presence of multicollinearity between independent variables has a substantial effect on the results of a regression analysis; it complicates determining the contribution of each single variable. A common strategy for detecting multicollinearity is the calculation of the tolerance value or its inverse, the variance inflation factor (VIF). The smaller the 
tolerance value, the higher the multicollinearity. When running the regression analyses, VIF values are calculated to assess multicollinearity.

In addition to the assumptions mentioned above, the existence of outliers - cases that have large residual values - influences the result of the regression analysis (Belsey, Kuh and Welsch 1980). When residuals are standardized by dividing them by their standard deviation, a residual that is as much as three (or, certainly, four) of these units in absolute size is reasonably considered an outlier (Cohen and Cohen 1983). As a regression equation minimizes the squared residuals, an outlier not only makes a relatively large contribution to the variance (thus reducing $\mathrm{R}^{2}$ of the model) but also exerts a disproportionately strong pull on the regression. Outliers are, therefore, particularly bothersome when they are all or predominantly of the same sign.

Outliers can incur the suspicion that they arose from some causal process different from that operating on the bulk of the data, usually an error in recording or data input. In the case of outliers in the dataset used in this dataset study, multiple checks of original data documentations were made to confirm that the outliers did not result from mistakes in data input. Typically, this was not the case. There were a few outlier values for some of the variables (See Table 17) but, as suggested by Cohen \& Cohen (1983), these outliers were left alone because they were few and no error could be assumed.

Table 17 summarizes the key characteristics of original data. To test normality, Kolmogorov-Smirnov tests were completed, and skewness values were computed for each variable. Box plots were analyzed in order to detect outliers. 
Table 17: Data characteristics (original data)

\begin{tabular}{|c|c|c|c|c|c|c|c|c|}
\hline & Variable & $\mathrm{n}$ & Mean & $\begin{array}{l}\text { Min/ } \\
\text { Max values }\end{array}$ & S.D. & $\begin{array}{l}\text { Number of } \\
\text { moderate / } \\
\text { extreme outliers }\end{array}$ & Skewness & $\begin{array}{l}\text { Kolmogorov- } \\
\text { Smirnov test } \\
\text { for normality } \\
(* * \text { significant } \\
\text { at } p<.05)\end{array}$ \\
\hline \multirow{8}{*}{ 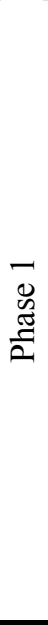 } & $\begin{array}{l}\text { Patents, mean of USPTO and reported } \\
\text { domestic approved patents }\end{array}$ & 85 & 6.07 & $0 / 57$ & 9.68 & $1 / 2$ & 2.672 & $* *$ \\
\hline & $\begin{array}{l}\text { Share of R\&D expenses (\%) of all the } \\
\text { expenses of the firm }\end{array}$ & 80 & 60.46 & $0 / 100$ & 30.10 & $0 / 0$ & -.553 & ns \\
\hline & Market knowledge (scale mean) & 85 & 3.792 & $2.7 / 4.8$ & .462 & $0 / 0$ & -.341 & ns \\
\hline & Entrepreneurial orientation (scale mean) & 85 & 3.863 & $1.71 / 5$ & .608 & $2 / 0$ & -.655 & ns \\
\hline & USA vs Scandinavia & 85 & .68 & $0 / 1$ & .468 & -- & -.798 & ns \\
\hline & Firm age (years) & 85 & 6.09 & $0 / 17$ & 3.841 & $0 / 0$ & .898 & ns \\
\hline & Number of employees & 85 & 37.62 & $1 / 250$ & 50.57 & $1 / 1$ & 2.822 & $* *$ \\
\hline & $\begin{array}{l}\text { Entrepreneurial opportunities recognized } \\
\text { (mean of } 4 \text { item scale) }\end{array}$ & 83 & 15.77 & $0 / 257$ & 33.95 & $5 / 2$ & 5.229 & $* *$ \\
\hline \multirow{5}{*}{$\begin{array}{l}N \\
0 \\
\mathscr{\sigma} \\
\frac{\pi}{2}\end{array}$} & $\begin{array}{l}\text { Entrepreneurial opportunities recognized } \\
\text { (mean of } 4 \text { item scale) }\end{array}$ & 42 & 10.13 & $0 / 76.25$ & 15.7 & $0 / 2$ & 3.289 & $* *$ \\
\hline & $\begin{array}{l}\text { Capital raised by the firm, USD thousands per } \\
\text { year }\end{array}$ & 33 & 5489 & $0 / 38875$ & 8202 & $0 / 1$ & 2.456 & $* *$ \\
\hline & Annual sales turnover 2006, USD thousands & 44 & 13819 & $0 / 250000$ & 45041 & $2 / 3$ & 4.643 & $* *$ \\
\hline & Sales growth between phase 1 and phase 2 & 31 & 4070 & $-100 / 58000$ & 11430 & $0 / 4$ & 3.956 & $* *$ \\
\hline & Technology licensing \& sales & 40 & 1.45 & $0 / 14$ & 2.552 & $1 / 1$ & 3.386 & $* *$ \\
\hline
\end{tabular}


Based on tests for normality (Table 17) and the skewness values, the following transformations were completed for the variables in the analysis to assure normality (Table 18).

Table 18: Data transformations

\begin{tabular}{|c|c|c|c|c|}
\hline & & $\begin{array}{l}\text { Skewness of the } \\
\text { original variable }\end{array}$ & Transformation & $\begin{array}{l}\text { Skewness after } \\
\text { transformation }\end{array}$ \\
\hline \multirow{3}{*}{ 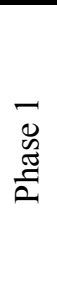 } & Number of employees, current & 2.822 & $\begin{array}{l}\text { Logarithm } \\
\text { LG10(X) }\end{array}$ & .019 \\
\hline & $\begin{array}{l}\text { Patents, mean of USPTO and } \\
\text { reported domestic approved patents }\end{array}$ & 2.672 & $\begin{array}{l}\text { Logarithm } \\
\text { LG10(X) }\end{array}$ & .155 \\
\hline & $\begin{array}{l}\text { Entrepreneurial opportunities } \\
\text { recognized (mean of } 4 \text { item scale) }\end{array}$ & 5.229 & $\begin{array}{l}\text { Logarithm } \\
\text { LG10(X) }\end{array}$ & .239 \\
\hline \multirow{5}{*}{ 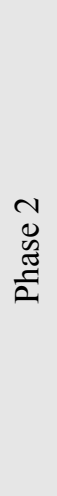 } & $\begin{array}{l}\text { Entrepreneurial opportunities } \\
\text { recognized (mean of } 4 \text { item scale) }\end{array}$ & 3.289 & $\begin{array}{l}\text { Logarithm } \\
\text { LG10(X) }\end{array}$ & .135 \\
\hline & $\begin{array}{l}\text { Capital raised by the firm, USD } \\
\text { thousands per year }\end{array}$ & 2.456 & $\begin{array}{l}\text { Logarithm } \\
\text { LG10(X) }\end{array}$ & -.501 \\
\hline & $\begin{array}{l}\text { Annual sales turnover 2006, USD } \\
\text { thousands }\end{array}$ & 4.643 & $\begin{array}{l}\text { Logarithm } \\
\text { LG10(X) }\end{array}$ & .799 \\
\hline & $\begin{array}{l}\text { Sales growth between phase } 1 \text { and } \\
\text { phase } 2\end{array}$ & 3.956 & $\begin{array}{l}\text { Logarithm } \\
\text { LG10(X) }\end{array}$ & .313 \\
\hline & Technology licensing \& sales & 3.386 & $\begin{array}{l}\text { Logarithm } \\
\text { LG10(X) }\end{array}$ & .754 \\
\hline
\end{tabular}

After these transformations the variables were tested for normality and linearity again. High significance values $(p>.05)$ of the tests for normality indicate that the distribution of the data does not differ significantly from a normal distribution after the transformations. 


\section{RESULTS}

The results of the empirical study are presented in the following. These results are based on the data collected on the independent variables in phase $1(2003-2004)$ and data collected on dependent variables in phase 2 (2007). Since the instrument employed in this study has been used before (Renko 2006a, b), parts of the description of sample firms reported in the following can also be found in Renko (2006a).

Description of sample firms

Of the total of 85 interviews in phase 1, 58 were conducted in the US. The remaining 27 were divided between Finnish $(\mathrm{n}=20)$ and Swedish $(\mathrm{n}=7)$ companies. In Finland, the sample companies are located in the three major cities, namely Helsinki, Turku and Tampere. In Sweden, all seven companies are located in the Gothenburg area. Table 19 below illustrates the distribution of survey responses in phase 1 and phase 2 by geographic region. The lowest follow-up (phase 2) response rate was obtained in South Florida (42\%) and the highest in Finland (93\%). This partly reflects the differing levels of success in reaching managers by phone. Scandinavian managers typically answered their phones themselves, whereas US- based managers did not. Once reached by phone, many were willing to help and respond. However, in those (numerous) US companies where 
the assistant / secretary of the manager in question decided that the survey was not worth the manager's time, it was impossible to get a response.

Table 19: Survey response by geographic region

\begin{tabular}{lccc|cccc}
\hline & \multicolumn{3}{c|}{ Phase 1 } & \multicolumn{2}{c|}{$\begin{array}{c}\text { Between phase 1 } \\
\text { and phase 2 }\end{array}$} & \multicolumn{3}{c}{ Phase 2 } \\
\cline { 2 - 8 } & \multicolumn{3}{c}{$\begin{array}{c}\text { Quit or } \\
\text { no }\end{array}$} & Merged I & Effective \\
Firm location & in phase 1 & record & $\begin{array}{c}\text { Reply } \\
\text { acquired }\end{array}$ & $\begin{array}{c}\text { Reply } \\
\text { after } \\
\text { phone } \\
\text { inquiry }\end{array}$ & $\begin{array}{c}\text { Effective } \\
\text { response } \\
\text { rate phase 2 }\end{array}$ \\
\hline Finland & 20 & 2 & 4 & 14 & 4 & 9 & $93 \%$ \\
Sweden & 7 & 0 & 1 & 6 & 4 & 1 & $83 \%$ \\
Bay area, CA & 26 & 2 & 6 & 18 & 3 & 7 & $56 \%$ \\
Pennsylvania & 13 & 1 & 2 & 10 & 7 & 2 & $90 \%$ \\
South Florida & 19 & 3 & 4 & 12 & 5 & 0 & $42 \%$ \\
\hline TOTAL & $\mathbf{8 5}$ & $\mathbf{8}$ & $\mathbf{1 7}$ & $\mathbf{6 0}$ & $\mathbf{2 3}$ & $\mathbf{1 9}$ & $\mathbf{7 0 \%}$ \\
\hline
\end{tabular}

Using company status in phase 2 as a "dependent variable", an attempt was made to distinguish those companies that were still in operation from those that had ceased to exist or had merged or been acquired by other firms. Even though specific hypotheses were not formulated with regard to the expectations of company status, it would be logical to assume, based on existing literature in entrepreneurship as well as marketing, that firms that had initially recognized more opportunities and had higher levels of market knowledge, technology knowledge, as well as entrepreneurial orientation would be the ones that survive. Also, based on the literature on liabilities of newness (Stinchcombe 1965), one would assume older organizations to have better chances of survival than new ones.

Table 20 lists the correlations between the three company status variables in phase 2 and selected independent variables in phase 1 . The number of cases in each status 
category is as follows: Ongoing business $=60$; merged or acquired $(M \& A)=17$; quit/no records $=8$. The strongest correlation is between market knowledge at phase 1 and the M\&A outcome in phase 2 (correlation coefficient .347 , significant at $\mathrm{p}<.01$ ). Market knowledge is also significantly but negatively $(\mathrm{p}<.05)$ related to subsequent "quit/ no records" category. This negative effect could have been expected based on the marketing literature that emphasizes the positive performance and survival effects of market knowledge and market oriented company culture (Kohli et al. 1993; Narver, Slater and MacLachlan 2004; Mavondo, Chimhanzi and Stewart 2005), but the positive association between market knowledge and ending up acquired or merged is not captured in the existing empirical literature on market orientation or market knowledge. In the current biotechnology environment, where opportunities for investors' successful exit through an initial public offering are few (Ernst\&Young 2007), M\&As offer an alternative exit strategy and improved liquidity. Other financial objectives that can be achieved through a M\&A are increased shareholder base as well as improved opportunities to access new sources of capital. The funds of larger institutional investors are only available to those companies that first fulfill the sizable requirements for "minimum" market capitalization. (McBeath and Bacha 2001) Assuming that involvement in a merger or acquisition is a positive development, the marketing literature that has linked market knowledge to positive firm level outcomes could explain this relationship. However, if the acquisition or merger is a result of the firm losing its viability as a standalone business, the relationship becomes harder to explain. 
Table 20: Correlations for selected phase 1 variables and company status in phase 2

\begin{tabular}{|c|c|c|c|c|c|c|c|c|c|c|c|c|}
\hline & & \multicolumn{8}{|c|}{ Phase 1} & \multicolumn{3}{|c|}{ Phase 2} \\
\hline & Variables & Patents & $\begin{array}{l}\mathrm{R} \& \mathrm{D} \\
\text { intensity }\end{array}$ & $\begin{array}{l}\text { Market } \\
\text { knowledge }\end{array}$ & $\begin{array}{l}\text { Entrepren. } \\
\text { orientation }\end{array}$ & $\begin{array}{l}\text { Location, } \\
\text { USA }\end{array}$ & Age & Size & $\begin{array}{l}\text { Entrepreneurial } \\
\text { opp. recognized }\end{array}$ & $\begin{array}{l}\text { Ongoing } \\
\text { business } \\
\end{array}$ & $\begin{array}{l}\text { Merged / } \\
\text { acquired }\end{array}$ & $\begin{array}{l}\text { Quit /No } \\
\text { records }\end{array}$ \\
\hline \multirow{3}{*}{ 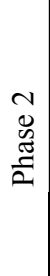 } & $\begin{array}{l}\text { Ongoing } \\
\text { business }\end{array}$ & $\begin{array}{l}-.122 \\
(69)\end{array}$ & $-.061(80)$ & $-.146(85)$ & $.134(85)$ & $-.052(85)$ & $\begin{array}{l}.036 \\
(85)\end{array}$ & $\begin{array}{l}-.028 \\
(85)\end{array}$ & $-.053(80)$ & 1 & & \\
\hline & $\begin{array}{l}\text { Company } \\
\text { merged or } \\
\text { acquired }\end{array}$ & $\begin{array}{l}.138 \\
(69)\end{array}$ & $.081(80)$ & $.347 * *(85)$ & $-.047(85)$ & $.025(85)$ & $\begin{array}{l}- \\
.097 \\
(85)\end{array}$ & $\begin{array}{l}.219^{*} \\
(85)\end{array}$ & $.241 *(80)$ & $\begin{array}{l}-.775 * * \\
(85)\end{array}$ & 1 & \\
\hline & Quit / No records & $\begin{array}{l}-.004 \\
(69)\end{array}$ & $-.016(80)$ & $-.248 *(85)$ & $-.146(85)$ & $.047(85)$ & $\begin{array}{l}.076 \\
(85)\end{array}$ & $\begin{array}{l}-.256^{*} \\
(85)\end{array}$ & $-.240 *(80)$ & $\begin{array}{l}-.499^{* *} \\
(85)\end{array}$ & $-.161(85)$ & 1 \\
\hline
\end{tabular}

*Correlation is significant at the 0.05 level (2-tailed). $* *$ Correlation is significant at the 0.01 level (2-tailed). $\mathrm{N}$ in parentheses.

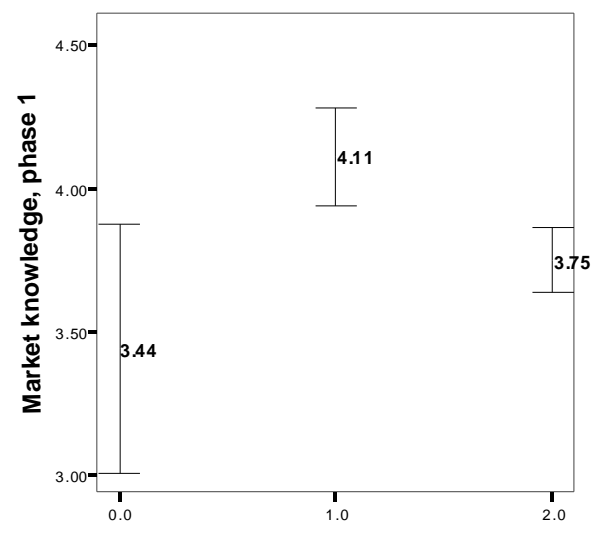

Company status, phase 2

Figure 11: Error bars showing 95\% confidence interval of mean for market knowledge by phase 2 status category

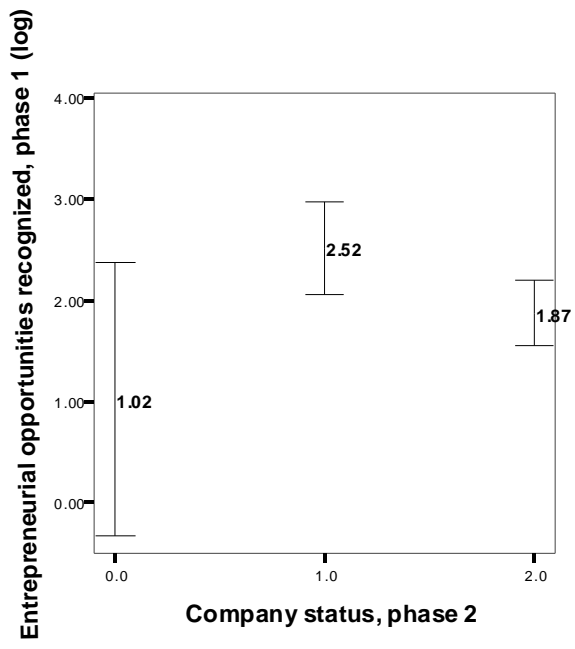

Figure 12: Error bars showing 95\% confidence interval of mean for opportunities recognized by phase 2 status category 
Table 20 also shows how entrepreneurial opportunity recognition is related to the outcome statuses in a way that is similar to market knowledge. However, even if these correlations are significant at $\mathrm{p}<.05$, they are not as substantial as the market knowledge - status correlations. Figure 11 and Figure 12 further illustrate the differences between the three status groups at phase 2 with regard to market knowledge and entrepreneurial opportunities recognized at phase 1 ( $0=$ quit, $1=\mathrm{M} \& \mathrm{~A}, 2=$ ongoing business). Figure 11 shows how the middle category (M\&A) is significantly different from the two other categories using the $95 \%$ confidence intervals of market knowledge mean. Figure 12, again, shows how the status categories with regard to opportunities recognized have different means but still overlapping confidence intervals. Thus, evidence for the discriminating power of market knowledge is quite convincing, whereas the relationship between opportunities recognized and subsequent firm status remains inconclusive. The non-significant correlations between firm age and outcome statuses suggest that there is no evidence of liability of newness in this sample. The correlations between firm size and M\&A (correlation coefficient .219 , significant at $\mathrm{p}<.05$ ) and firm size and firm death (correlation coefficient -.256 , significant at $\mathrm{p}<.05$ ) suggest that there is some evidence of the liability of smallness in this sample. The latter (negative) correlation clearly points towards the liability of smallness argument: Disadvantages of scale or a generally lower talent of the management in small firms may contribute to their disproportionately high dissolution rate (Strotmann 2007). However, the lack of a link between firm survival and larger firm size somewhat dilutes the strength of this argument. Again, the positive and significant relationship between M\&A and firm size is somewhat surprising, but may be indicative of a certain critical mass required for a firm to be an interesting acquisition 
target or a potential merger partner. Even if not the main focus of this study, these relationships between firm-level attributes and subsequent survival of the firm provide some interesting speculations for future research.

Next, some characteristics of those firms that participated in both data collection phases are described. Tables that illustrate the descriptive statistics of the sample firms are provided in Appendix 3. Some key features of these Tables as well as descriptive numbers presented earlier in Table 17 are discussed in the following.

With regard to the positions of the interviewees in their respective organizations, 69 of the 85 phase 1 interviewees were CEOs or founders, or both CEOs and founders of their respective firms. The remaining 16 interviewees held managerial positions in business development. These interviewees typically represent larger firms in the sample. The distribution of respondent positions remained very similar in phase 2 data.

In terms of business focus, most of the sample firms ( $\mathrm{n}=33$ in phase 1) provide technological tools and platforms in biotechnology. Some of these firms have a secondary line of business where they develop their own proprietary drugs or devices; 29 firms indicated drug discovery and development as their main activity and 16 firms represent the field of medical devices. One firm was categorized as a "fully integrated pharmaceutical company", but in the following analyses that include "field of business" as a variable this one firm is included in the "drug discovery and development" category. Finally, six of the sample firms indicated "diagnostics" as their main field of business.

About half of the phase 1 sample firms, i.e. 42 companies, did not have sales income at the time of the interview. Nineteen of these firms had their most advanced product at the preclinical development stage, for six firms this lead product was in early stage 
clinical development, and 16 firms had no sales yet but had a product in late stage clinical development ${ }^{23}$. Of the 43 firms that were selling their product(s) at the time of the phase 1 interview, 24 marketed the product(s) themselves and 16 firms had their products on markets through some kind of a licensing or third-party distribution agreement. Four firms could not provide information on the development phase of their most advanced product. One could assume that over the study time lag period (between phase 1 and phase 2, approximately 3.5 years) more companies would move to stages that indicate product launch. Somewhat surprisingly, this is not the case; the distribution of firms in each stage of lead product development remained unchanged between phases 1 and 2 . There are two likely explanations for this. First, biotechnology product development is a long process that takes even decades. Even the 3.5 year time lag may be too short for companies to make significant progress from one stage of clinical trials to another, for example. Second, a more plausible explanation can be that as firms make progress towards markets and grow, they also become more bureaucratic. Getting survey responses in phase 2 was especially challenging in larger organizations, which may be reflected in the fact that the distribution of firms in each stage of product development remained unchanged between phases 1 and 2 . However, the mean firm size of the sample firms (number of employees reported by respondents) grew from 38 in phase 1 to 51 in phase 2.

The average sample firm was six years old at phase 1, and most firms were very young at that time; 88 per cent of the sample firms were 10 years old or younger when first

\footnotetext{
${ }^{23}$ Not all sample firms follow the standard clinical development path in the product development. However, the respondent of firms that do not follow this standard path to FDA approval and marketing typically had no difficulties in assessing and placing their firms' lead product at a relevant stage along this standard pharmaceutical product development timeline.
} 
interviewed. On average, 60 per cent of all company expenses were categorized under the umbrella of "R\&D expenses". However, for 40 per cent of the sample firms this figure (i.e. the share of R\&D expenses out of total expenses of the firm) was 80 per cent or more.

Even though the average for capital raised by sample firms is 5.5 million USD per firm per year, this figure varies remarkably from one firm to another; 45.5 per cent of the firms had - by 2007 - only attracted USD one million /year or less, whereas 8 of the thirty-three phase 2 study firms that reported capital investments had gathered more than USD 10 million per year.

The majority $(\mathrm{n}=59)$ of the sample firms in phase 1 (85) have been started by teams rather than individuals. Forty-one firms have started as independent ventures, 25 interviewees categorized their firms as university spin-offs, and 17 as industrial spin-offs from another company. Altogether, 12 sample firms (14\%) were publicly traded at the time of the phase 1 interviews, and 5 firms (12\%) were publicly held at the time of phase 2 data collection. Finally, 30 firms out of 85 - 26 in the US and four in Finland or Sweden - have been started by a serial entrepreneur. These data (a dummy variable of yes / no for previous start-up by the same entrepreneur) are not self-reported by the respondents but were gathered based on publicly available information, mostly online. This information was available for 79 firms. Most firms report their managers' biographies on their website, and if an entrepreneur has previously started another technology firm, this information would be mentioned in the biography.

A test of means for the key firm demographic variables and the variables used in the regression analyses in the USA-based and Finland- or Sweden-based sample firms was 
conducted and the results are depicted in Table 21. The null (H0) and alternate (Ha) hypotheses are as follows:

H0: $\mathrm{M}_{\mathrm{USA}}=\mathrm{M}_{\mathrm{NOR}}$

Ha: $\mathrm{M}_{\mathrm{USA}} \neq \mathrm{M}_{\mathrm{NOR}}$

Where $\mathrm{M}_{\mathrm{USA}}$ : Mean score for a given factor in the USA-based firms and $\mathrm{M}_{\mathrm{NOR}}$ : Mean score for a given factor in the Nordic (Finland \& Sweden) firms.

Table 21: T-test for differences in variables, USA vs. Nordic firms

\begin{tabular}{|c|c|c|c|c|c|c|}
\hline & & \multicolumn{2}{|c|}{ USA firms } & \multicolumn{3}{|c|}{ Nordic firms } \\
\hline & Variable & Mean & s.d. & Mean & s.d. & $\begin{array}{l}\text { t-Values for } \\
\text { Differences } \\
\text { in Means }\end{array}$ \\
\hline \multirow{7}{*}{ 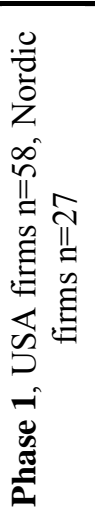 } & $\begin{array}{l}\text { Patents, mean of USPTO and reported } \\
\text { domestic approved patents (log) }\end{array}$ & 1.35 & 1.36 & .853 & 1.29 & \\
\hline & $\begin{array}{l}\text { Share of R\&D expenses }(\%) \text { of all the } \\
\text { expenses of the firm }\end{array}$ & 63.3 & 28.4 & 54.8 & 32.9 & \\
\hline & Market knowledge (scale mean) & 3.80 & .480 & 3.77 & .433 & \\
\hline & Entrepreneurial orientation (scale mean) & 3.97 & .612 & 3.63 & .538 & $* *$ \\
\hline & Firm age (years) & 5.62 & 3.97 & 7.11 & 3.40 & $*$ \\
\hline & Number of employees (log) & 3.10 & 1.27 & 2.82 & .842 & \\
\hline & $\begin{array}{l}\text { Entrepreneurial opportunities recognized } \\
\text { (mean of } 4 \text { item scale) }(\log )\end{array}$ & 2.10 & 1.30 & 1.55 & 1.11 & $*$ \\
\hline \multirow{5}{*}{ 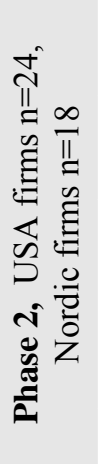 } & $\begin{array}{l}\text { Entrepreneurial opportunities recognized } \\
\text { (mean of } 4 \text { item scale) }(\log )\end{array}$ & 2.03 & 1.20 & .889 & 1.09 & $* * *$ \\
\hline & $\begin{array}{l}\text { Capital raised by the firm, USD thousands } \\
\text { per year }(\log )\end{array}$ & 7.89 & 1.93 & 7.23 & 1.58 & \\
\hline & $\begin{array}{l}\text { Annual sales turnover 2006, USD thousands } \\
(\log )\end{array}$ & 8.19 & 1.66 & 7.62 & 1.32 & \\
\hline & $\begin{array}{l}\text { Sales growth between phase } 1 \text { and phase } 2 \\
(\log )\end{array}$ & 6.96 & 2.65 & 4.18 & 1.30 & $* * *$ \\
\hline & Technology licensing \& sales $(\log )$ & .774 & .838 & .701 & .686 & \\
\hline
\end{tabular}

*** Significant at the 0.01 level; ** Significant at the 0.05 level; * Significant at the 0.10 level 
As indicated by Table 21, the null hypothesis is rejected for entrepreneurial orientation and marginally for firm age and "entrepreneurial opportunities recognized" in phase 1 data. The US-based firms exhibit higher levels of entrepreneurial orientation, whereas the Nordic sample firms are, on average, somewhat older and have recognized fewer entrepreneurial opportunities than American firms. In phase 2 data the null hypothesis is rejected for "entrepreneurial opportunities recognized" and sales growth. US-based firms have higher means both for sales growth and entrepreneurial opportunity recognition than their Nordic counterparts. However, especially in phase 2 data the group sizes are rather small (24 US-based firms and 18 Nordic firms), so the results should be interpreted with some caution.

\section{Tests of hypotheses}

The characteristics of the variables used in the tests of hypotheses are in Table 22. The correlations between study variables are presented in Table 23. It is interesting to note that out of the two technology knowledge variables, R\&D intensity shares a significant positive correlation with entrepreneurial opportunities recognized at phase 2 , whereas the correlation between patents and opportunity recognition is not significant at $p<.05$. Also market knowledge and entrepreneurial orientation at phase 1 are significantly and positively related to opportunity recognition in phase 2 . With regard to the variables that measure profit potential, capital investments in a firm correlate significantly and positively with the firm's earlier patent count, market knowledge as well as the number of opportunities recognized. For sales-related variables there is only one interesting 
correlation to report, namely that between market knowledge in phase 1 and sales turnover in 2006. Patents as well as market knowledge also correlate positively and significantly with subsequent technology licensing \& technology sales.

The correlations between independent variables in Table 23 do not raise much concern about multicollinearity. However, the VIF multicollinearity statistic is calculated for each variable in each model. All of these values were far below the cut-off value of ten (Freund and Wilson 1998), indicating no multicollinearity problems.

Table 22: Data characteristics

\begin{tabular}{|c|c|c|c|c|c|}
\hline & Variable & $\mathrm{n}$ & Mean & $\begin{array}{l}\text { Min/ } \\
\text { Max values }\end{array}$ & S.D. \\
\hline \multirow{8}{*}{$\begin{array}{l}\overline{0} \\
\tilde{d} \\
\bar{E}\end{array}$} & $\begin{array}{l}\text { Patents, mean of USPTO and reported } \\
\text { domestic approved patents (log) }\end{array}$ & 69 & 1.18 & $-.69 / 4.04$ & 1.35 \\
\hline & $\begin{array}{l}\text { Share of R\&D expenses (\%) of all the } \\
\text { expenses of the firm }\end{array}$ & 80 & 60.46 & $0 / 100$ & 30.10 \\
\hline & Market knowledge (scale mean) & 85 & 3.792 & $2.7 / 4.8$ & .462 \\
\hline & Entrepreneurial orientation (scale mean) & 85 & 3.863 & $1.71 / 5$ & .608 \\
\hline & Location, USA & 85 & .68 & $0 / 1$ & .468 \\
\hline & Firm age (years) & 85 & 6.09 & $0 / 17$ & 3.841 \\
\hline & Number of employees (log) & 85 & 2.99 & $0 / 5.52$ & 1.15 \\
\hline & $\begin{array}{l}\text { Entrepreneurial opportunities recognized } \\
\text { (mean of } 4 \text { item scale) }(\log )\end{array}$ & 80 & 1.92 & $-1.39 / 5.55$ & 1.26 \\
\hline \multirow{5}{*}{ 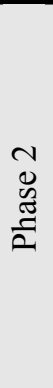 } & $\begin{array}{l}\text { Entrepreneurial opportunities recognized } \\
\text { (mean of } 4 \text { item scale) }(\log )\end{array}$ & 42 & 1.54 & $-.70 / 4.33$ & 1.28 \\
\hline & $\begin{array}{l}\text { Capital raised by the firm, USD thousands per } \\
\text { year }(\log )\end{array}$ & 29 & 7.64 & $3.22 / 10.57$ & 1.80 \\
\hline & $\begin{array}{l}\text { Annual sales turnover 2006, USD thousands } \\
(\log )\end{array}$ & 42 & 7.97 & $5.3 / 12.43$ & 1.54 \\
\hline & $\begin{array}{l}\text { Sales growth between phase } 1 \text { and phase } 2 \\
(\log )\end{array}$ & 24 & 5.92 & $1.93 / 10.97$ & 2.60 \\
\hline & Technology licensing \& sales $(\log )$ & 20 & .747 & $0 / 2.46$ & .762 \\
\hline
\end{tabular}


Table 23: Pearson correlations for dependent and independent variables in the regression analysis

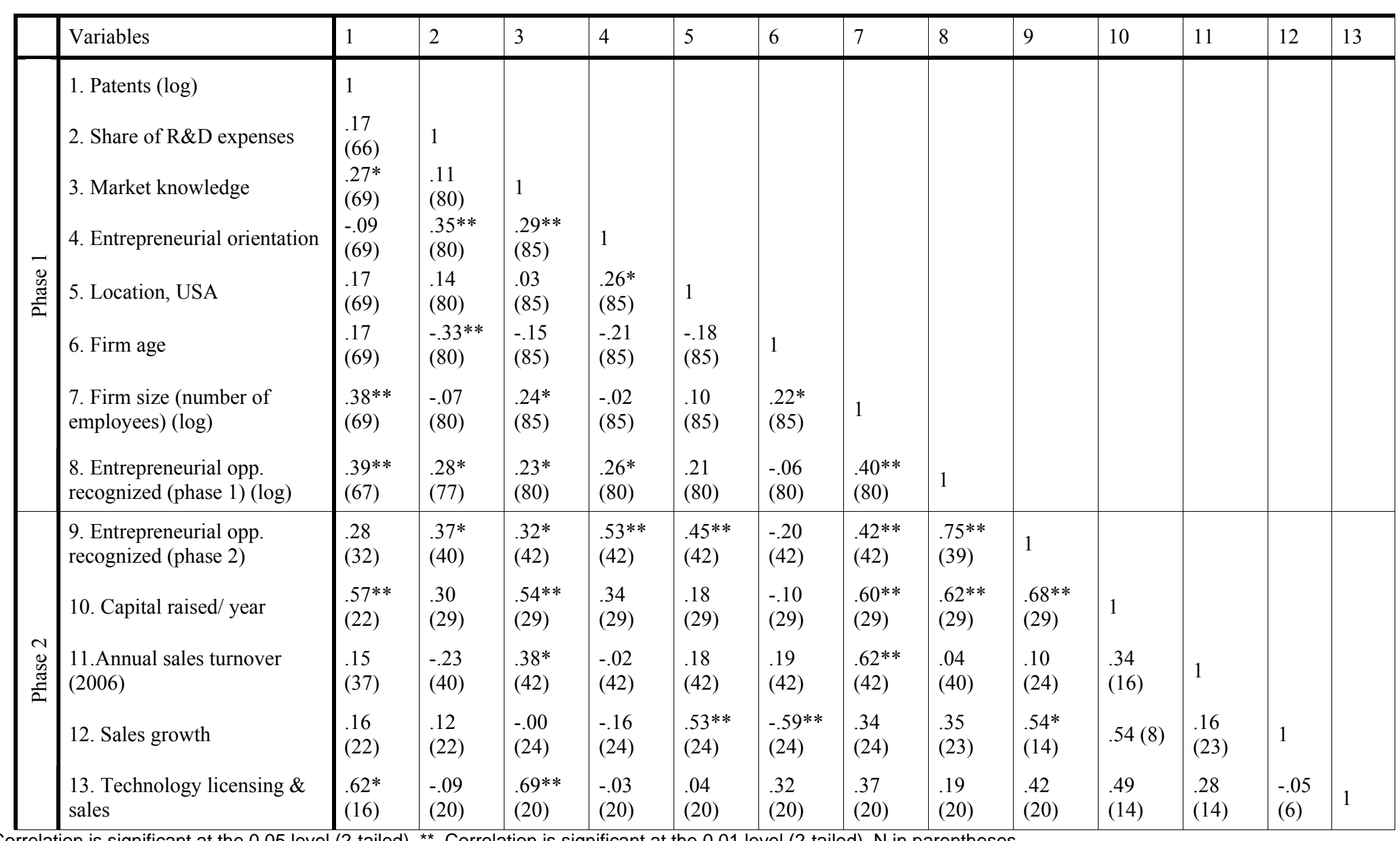

* Correlation is significant at the 0.05 level (2-tailed). ${ }^{* *}$ Correlation is significant at the 0.01 level (2-tailed). $\mathrm{N}$ in parentheses. 


\section{Factors behind entrepreneurial opportunity recognition}

The relationships predicted in study hypotheses are assessed through a regression analysis. At the first step, control variables for firm location, size and age are introduced to the models. At the following steps, the factors predicted to influence the outcome variable are introduced to the models one at a time. Standardized beta-coefficients are reported in the regression tables that follow. The models also include constant terms not included in the tables.

The analysis started by investigating the relationship between technology knowledge, market knowledge, and subsequent opportunities recognized in a biotechnology venture as proposed in Hypotheses 1 and $1 \mathrm{a}-1 \mathrm{c}$. All independent variables come from phase 1 data (2003-2004) and the dependent variable was measured at phase 2 (2007). In Model A1 (Table 24), only control variables of firm location, size and age are introduced to the analysis. Model A1 shows that 37 per cent (Adjusted R-square) of the variance in entrepreneurial opportunities recognized is explained. The importance of firm size as a predictor of entrepreneurial opportunities recognized is logical, since larger organizations have more resources, brains, and capabilities that aid in opportunity recognition.

At the next step after the control model, the technology knowledge variables of patent count and R\&D investment intensity were separately added to the model (Models A2 and A3). Patent count turned out to be a marginally significant predictor of subsequent opportunity recognition, and the model has an adjusted R-square value of 0.44 . R\&D intensity is not significant. As a conclusion, partial support (in the case of patents as a proxy for technology knowledge) is found for Hypothesis 1: If all other factors are 
constant, the greater the degree of technology knowledge in a new venture the larger the number of entrepreneurial opportunities that will be recognized.

Table 24: Regression results. Dependent variable: Entrepreneurial opportunities recognized (phase $2, \log$ ).

\begin{tabular}{|c|c|c|c|c|c|c|}
\hline & $\begin{array}{l}\text { Control } \\
\text { variable }\end{array}$ & \multicolumn{4}{|c|}{ Main effect variables } & \multirow{2}{*}{$\begin{array}{l}\text { Interaction } \\
\text { Model } \\
\text { A6 }\end{array}$} \\
\hline & $\begin{array}{l}\text { Model } \\
\text { A1 }\end{array}$ & $\begin{array}{l}\text { Model } \\
\text { A2 }\end{array}$ & $\begin{array}{l}\text { Model } \\
\text { A3 }\end{array}$ & $\begin{array}{l}\text { Model } \\
\text { A4 }\end{array}$ & $\begin{array}{l}\text { Model } \\
\text { A5 }\end{array}$ & \\
\hline $\begin{array}{l}\text { Location, } \\
\text { USA }\end{array}$ & $.451 * * *$ & $.467 * * *$ & $.451 * * *$ & $.467 * * *$ & $.473 * * *$ & $.453 * * *$ \\
\hline Firm age & -.219 & -.235 & -.132 & -.235 & $-.251 *$ & -.232 \\
\hline $\begin{array}{l}\text { Firm size } \\
(\log )\end{array}$ & $.347 * *$ & $.299 * *$ & $.394 * * *$ & $.299 * *$ & $.270^{*}$ & $.293 * *$ \\
\hline Patents $(\log )$ & & $.278^{*}$ & & & .223 & \\
\hline $\begin{array}{l}\text { Share of } \\
\text { R\&D } \\
\text { expenses (\%) }\end{array}$ & & & .162 & & & \\
\hline $\begin{array}{l}\text { Market } \\
\text { knowledge }\end{array}$ & & & & $.278^{*}$ & .175 & \\
\hline $\begin{array}{l}\text { Patents x } \\
\text { market } \\
\text { knowledge }\end{array}$ & & & & & & $.287 * *$ \\
\hline R-square & .434 & .508 & .484 & .493 & .534 & .513 \\
\hline $\begin{array}{l}\text { Adjusted R- } \\
\text { square }\end{array}$ & .373 & .435 & .425 & .432 & .444 & .441 \\
\hline $\begin{array}{l}\text { Change in R- } \\
\text { square }\end{array}$ & & $\begin{array}{l}\text { (A2-A1) } \\
.074^{*}\end{array}$ & $\begin{array}{l}\text { (A3-A1) } \\
.050\end{array}$ & $\begin{array}{l}\text { (A4-A1) } \\
.061 *\end{array}$ & $\begin{array}{l}\text { (A5-A1) } \\
.100^{*}\end{array}$ & $\begin{array}{l}\text { (A6-A5) } \\
-.021\end{array}$ \\
\hline F-value & $7.143^{* * *}$ & $6.970 * * *$ & $8.207 * * *$ & $6.970 * * *$ & $5.955^{* * *}$ & $7.104 * * *$ \\
\hline Durbin-Watson & 2.150 & 2.056 & 2.007 & 2.056 & 1.966 & 2.059 \\
\hline
\end{tabular}

$* * *$ Significance $\mathrm{p}<0.01,{ }^{* *}$ Significance $\mathrm{p}<0.05, *$ Significance $\mathrm{p}<0.1$ 
Hypotheses 1a-1c predict that the relationship between technology knowledge and entrepreneurial opportunity recognition is contingent upon the amount of market knowledge that the organization has. To examine this moderation effect, the plan was to divide the sample into three groups according to market knowledge scores using a threeway split into groups of equal size and to then run separate regressions for the three groups. Unfortunately, only 42 cases in total are available for regression analysis, and dividing this sample into smaller categories would jeopardize the statistical power of any quantitative analysis.

To assess the moderation, a product term (patents $\mathrm{x}$ market knowledge) was computed. R\&D intensity was omitted at this stage since it did not show significant effects (Model A3). A moderation (an interaction effect) only exists if the interaction term gives a significant contribution over and above the direct effects of the independent variables (here, technology knowledge and market knowledge).A hierarchical regression analysis (Table 24) reveals that strictly speaking, market knowledge does not moderate the relationship between technology knowledge and opportunity recognition since model A6 (with the product term) actually has a lower R-square value than model A5 (with the main effects from market knowledge and technology knowledge). However, given the low number of cases (only 32 in models A5 and A6) it is hard to draw conclusions form these models, especially model A5 with five independent variables. The facts that the product term (standardized $\beta .287$ ) in model A6 is significant at $\mathrm{p}<.05$ and the model has a significantly higher R-square value than the control model (A1) can be interpreted as weak evidence of a moderated relationship. 
To assess this interaction in more detail, sample firms were divided into three groups of equal size (low, medium \& high) both based on their market knowledge scores and patent scores. An interaction plot (Figure 13) illustrates the nature of the relationship between patents and market knowledge in influencing entrepreneurial opportunities recognized.

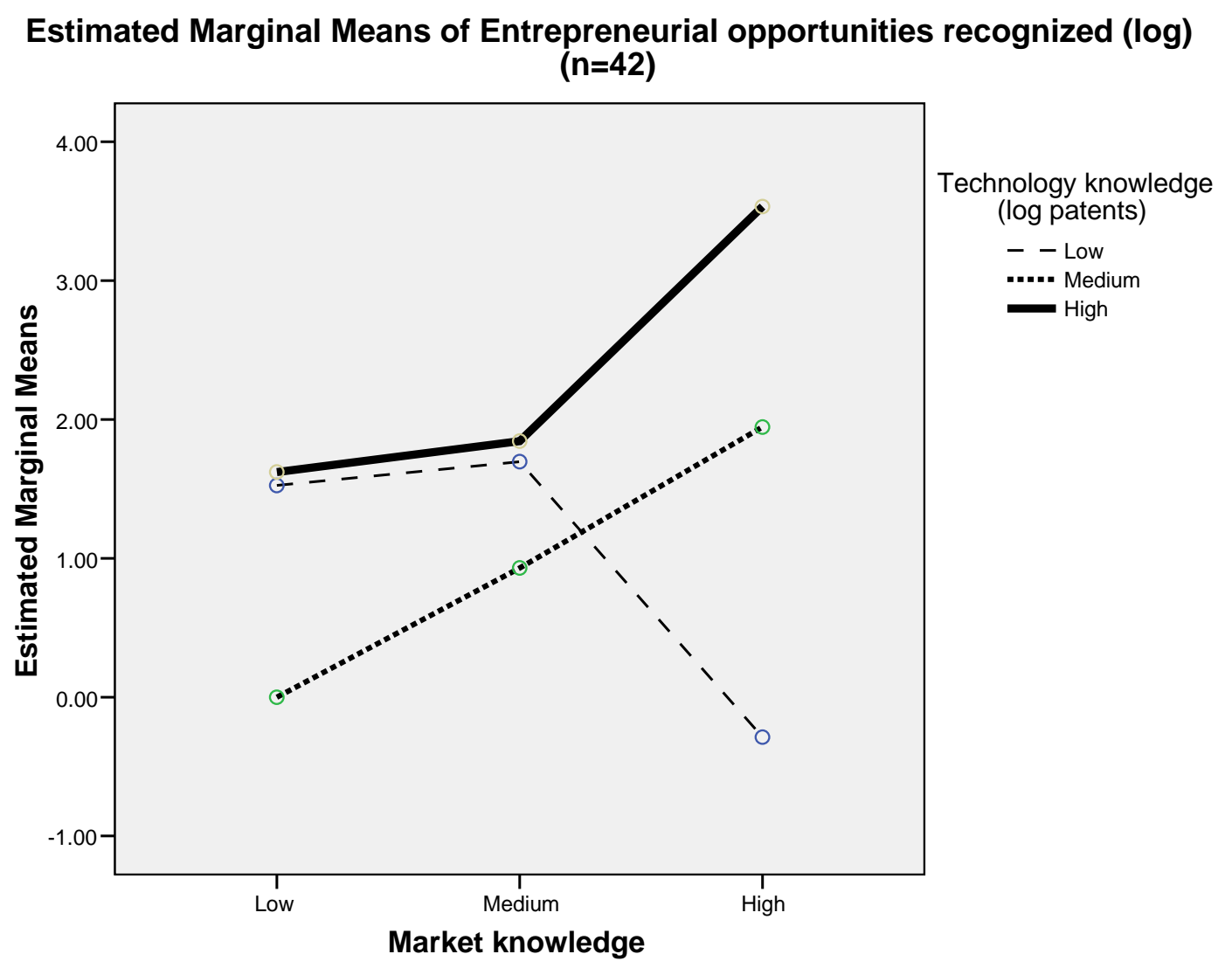

Figure 13: The interaction of market knowledge and technology knowledge (patents) in influencing entrepreneurial opportunities recognized. 
Hypotheses 1a-1c predicted that the relationship between technology knowledge and entrepreneurial opportunity recognition would be strongest at moderate levels of market knowledge and weaker at very high or very low levels of market knowledge. Based on Figure 13, however, this is not the case. The clearly defined relationship of low levels of technology knowledge leading to low numbers of opportunities recognized, medium levels of technology knowledge leading to medium numbers of opportunities recognized, and high levels of technology knowledge leading to high number of opportunities recognized is only present when the amount of market knowledge is high (right hand side of Figure 13). Hence, no support is found for hypotheses 1a-1c. However, a moderating effect of market knowledge on the relationship between technology knowledge and entrepreneurial opportunity recognition is detected (See Table 24 and Figure 13). Based on the detected relationship a proposition for future research suggests that a positive linear relationship between technology knowledge and entrepreneurial opportunity recognition only exists when a firm also has a high level of market knowledge.

Despite the low number of cases, the models presented in Table 24 seem to be robust; the directions of effects (negative / positive) and relative magnitudes of independent variables' effects remain similar in Models A1 through A6 (Table 24). When the number of observations is small $(\mathrm{n}=42)$ and the number of predictors is large, it is expected that there will be a greater difference between R-square and adjusted R-square compared with a situation when the number of observations is larger compared with the number of predictors.

Based on model A4 in Table 24 it can be concluded that there is evidence that supports hypothesis 2: If all other factors are constant, the greater the degree of market 
knowledge in a new venture the greater the recognition of entrepreneurial opportunities. Hypothesis 2a predicts that if all other factors are constant, when a new venture has a higher level of entrepreneurial orientation, the relationship between the degree of market knowledge and the recognition of entrepreneurial opportunities will be enhanced. The test of this hypothesis is presented in Table 25.

Table 25: Regression results, part 2. Dependent variable: Entrepreneurial opportunities recognized (phase $2, \log$ ).

\begin{tabular}{|c|c|c|c|c|c|}
\hline & $\begin{array}{l}\text { Control } \\
\text { variable }\end{array}$ & \multicolumn{3}{|c|}{ Main effect variables } & Interaction \\
\hline & $\begin{array}{l}\text { Model } \\
\text { B1 }\end{array}$ & $\begin{array}{l}\text { Model } \\
\text { B2 }\end{array}$ & $\begin{array}{l}\text { Model } \\
\text { B3 }\end{array}$ & $\begin{array}{l}\text { Model } \\
\text { B4 }\end{array}$ & $\begin{array}{l}\text { Model } \\
\text { B5 }\end{array}$ \\
\hline Location, USA & $.451 * * *$ & $.467 * * *$ & $.277 * *$ & $.301 * *$ & $.318 * *$ \\
\hline Firm age & -.219 & -.235 & -.137 & -.154 & -.161 \\
\hline Firm size $(\log )$ & $.347 * *$ & $.299 * *$ & $.420 * * *$ & $.383 * * *$ & $.384 * * *$ \\
\hline $\begin{array}{l}\text { Market } \\
\text { knowledge }\end{array}$ & & $.278^{*}$ & & .175 & \\
\hline $\begin{array}{l}\text { Entrepreneurial } \\
\text { orientation }\end{array}$ & & & $.320 * *$ & $.268^{*}$ & \\
\hline $\begin{array}{l}\text { Market } \\
\text { knowledge } \mathrm{x} \\
\text { Entrepreneurial } \\
\text { orientation }\end{array}$ & & & & & $.345^{* * *}$ \\
\hline R-square & .434 & .493 & .509 & .524 & .523 \\
\hline $\begin{array}{l}\text { Adjusted R- } \\
\text { square }\end{array}$ & .373 & .432 & .443 & .459 & .472 \\
\hline $\begin{array}{l}\text { Change in R- } \\
\text { square }\end{array}$ & & $\begin{array}{l}\text { (B2-B1) } \\
.061 *\end{array}$ & $\begin{array}{l}\text { (B3-B1) } \\
.075^{* *}\end{array}$ & $\begin{array}{l}\text { (B4-B1) } \\
.09 * *\end{array}$ & $\begin{array}{l}\text { (B5-B4) } \\
-.01\end{array}$ \\
\hline F-value & $7.143^{* * *}$ & $6.970 * * *$ & $9.160 * * *$ & $7.917 * * *$ & $10.151^{* * *}$ \\
\hline Durbin-Watson & 2.150 & 2.056 & 2.155 & 2.000 & 1.975 \\
\hline
\end{tabular}


Both market knowledge and entrepreneurial orientation have independent, significant effects on subsequent entrepreneurial opportunities recognized, as revealed by models B2-B4 in Table 25. The product of market knowledge and entrepreneurial orientation is used to assess the interactive relationship. Again, looking at the interaction model B5, strictly speaking, entrepreneurial orientation does not moderate the relationship between market knowledge and opportunity recognition since model B5 (with the product term) actually has a lower R-square value than model B4 (with the main effects from market knowledge and entrepreneurial orientation). However, the adjusted R-square of the interaction model is higher than that of any of the other models in Table 25. The facts that the product term (standardized $\beta .345$ ) in model B5 is significant at $\mathrm{p}<.01$ and the model has a significantly higher R-square value than the control model (B1) can, again, be interpreted as weak evidence of a moderated relationship.

Again, to assess this interaction in more detail, sample firms were divided into three groups of equal size (low, medium \& high) both based on their market knowledge scores and entrepreneurial orientation scores. Figure 14 below illustrates the interactive relationship. According to hypothesis $2 \mathrm{a}$ we would expect to see that the positive linear relationship between market knowledge and opportunity recognition should be stronger at higher levels of entrepreneurial orientation. This is true for those firms that have high or low levels of market knowledge; the slope of the regression line gets steeper when moving from low-medium entrepreneurial orientation to medium-high entrepreneurial orientation. Hence, there is some support for hypothesis 2a. However, a more striking feature in Figure 14 is the importance of entrepreneurial orientation especially for those firms who have medium levels of market knowledge. A firm that is about average in 
terms of its market knowledge scores poorly in opportunity recognition when its entrepreneurial orientation is low. Nevertheless, Figure 14 suggests that under a high level of entrepreneurial orientation the same firm recognizes more entrepreneurial opportunities than other firms who have higher levels of market knowledge. This is an interesting finding and will be further discussed in the "Discussion" section.

\section{Estimated Marginal Means of Entrepreneurial opportunities recognized (log) $(n=42)$}

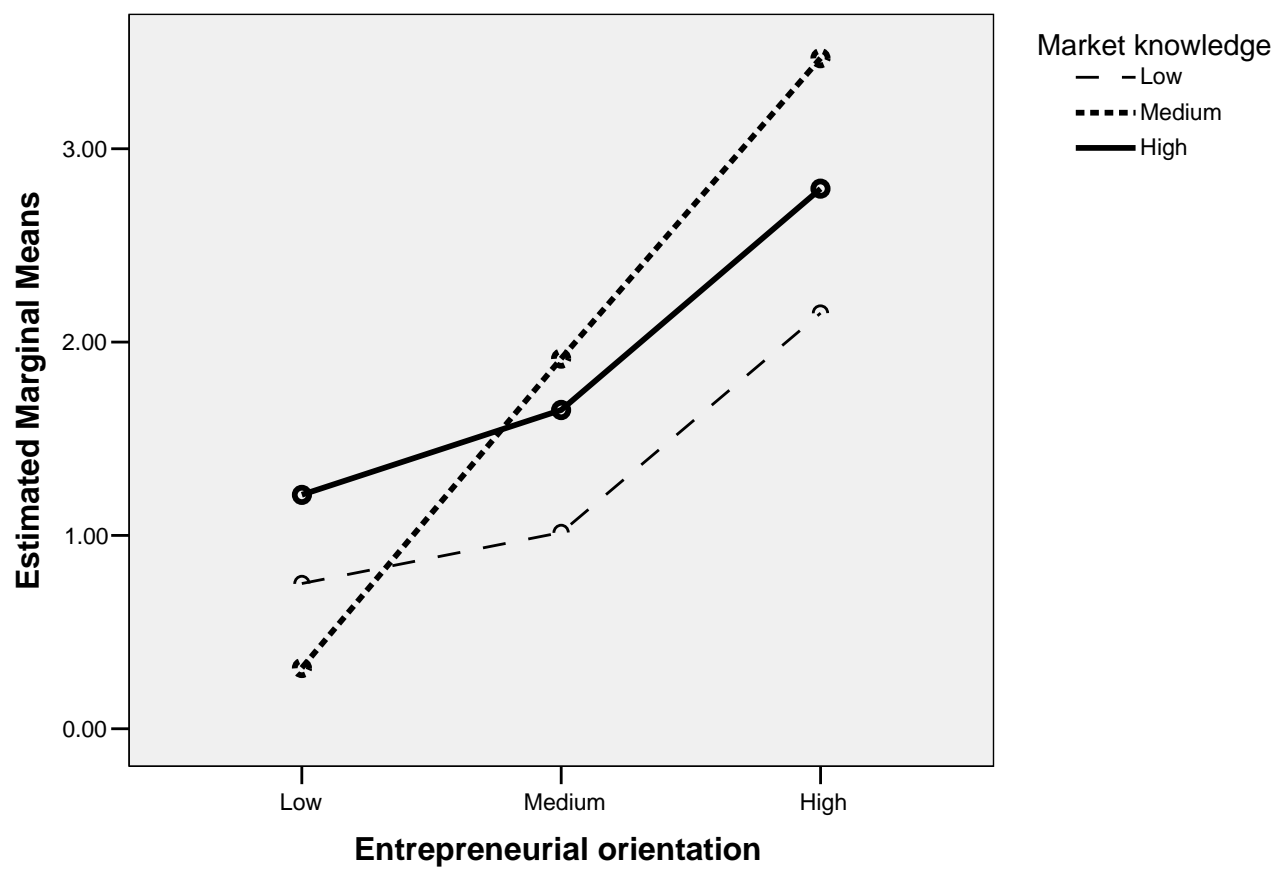

Figure 14: The interaction of entrepreneurial orientation and market knowledge in influencing entrepreneurial opportunities recognized. 


\section{Factors behind profit potential}

An attempt to measure a young firm's profit potential is, indeed, a challenging task. As mentioned earlier, in this study the proxies adopted for a firm's profit potential include (1) sales growth; (2) sales turnover in 2006; (3) equity investments in the firm; and (4) selling and licensing out technologies. In the following, each one of these dependent variables is analyzed separately.

Similar to the regression models presented above, each analysis starts with a model (C1, D1, E1, and F1) that only includes the three control variables. At the next stages (24) main effects of entrepreneurial opportunities recognized and market knowledge (phase 1 data) are included in the models. Finally, at the last (5th) stage, an interaction term is introduced to the models as a test of hypothesis $3 \mathrm{a}$, which predicts that if all other factors are constant, when a new venture has a high level of market knowledge the relationship between recognition of entrepreneurial opportunities and subsequent profit potential will be enhanced.

The adjusted $\mathrm{R}$ square values in these models vary from less than ten per cent (for technology licensing and sales as a dependent variable) to over fifty per cent. The results are discussed in more detail in the following. 
Table 26: Regression results for firm profit potential (phase 2).

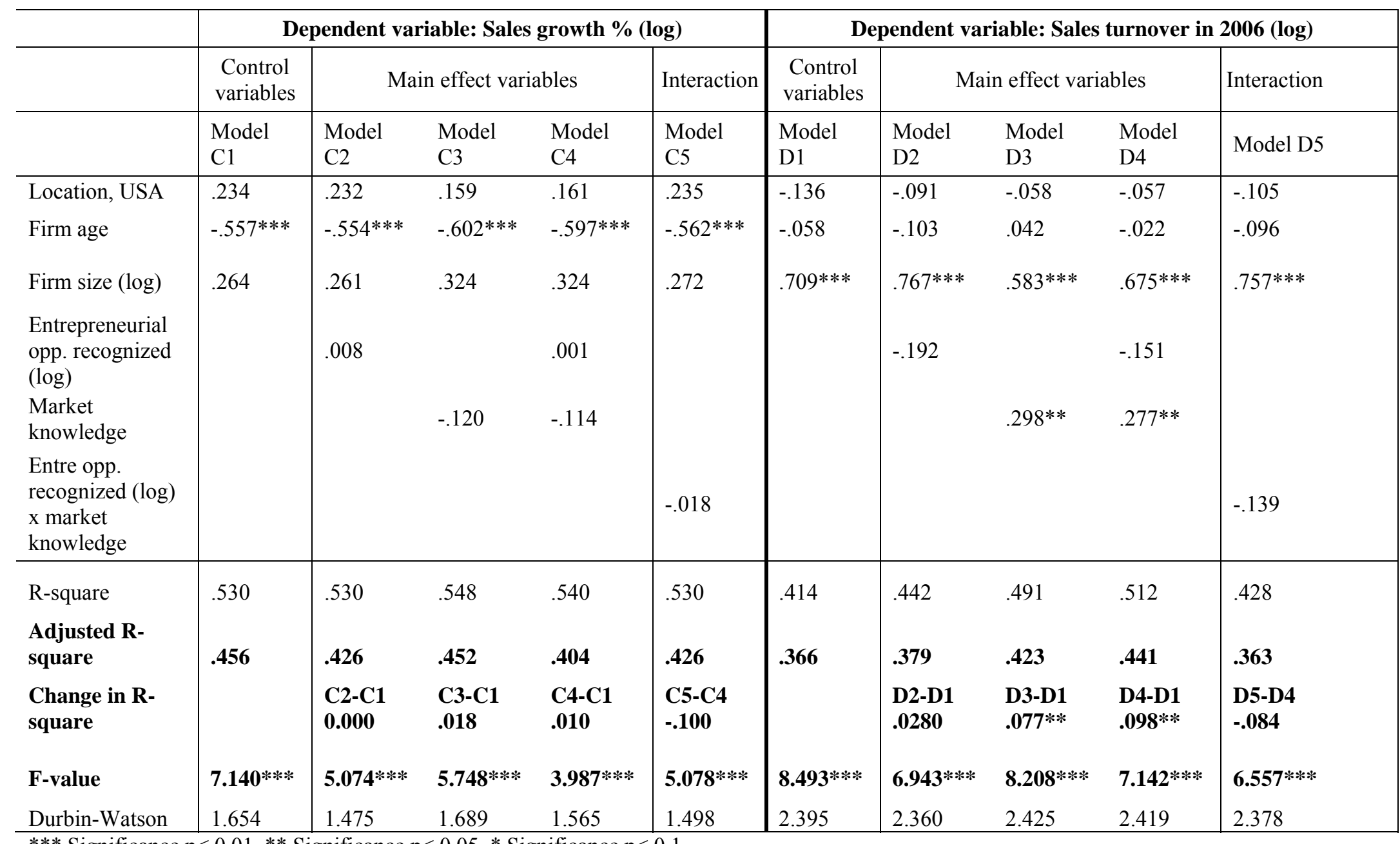

$* * *$ Significance $\mathrm{p}<0.01, * *$ Significance $\mathrm{p}<0.05, *$ Significance $\mathrm{p}<0.1$ 
Table 27: Regression results for firm profit potential (phase 2) continued

\begin{tabular}{|c|c|c|c|c|c|c|c|c|c|c|}
\hline & \multicolumn{5}{|c|}{ Dependent variable: Equity investments in the firm (log) } & \multicolumn{5}{|c|}{ Dependent variable: Technology licensing and sales (log) } \\
\hline & \multirow{2}{*}{$\begin{array}{c}\begin{array}{c}\text { Control } \\
\text { variables }\end{array} \\
\text { Model E1 }\end{array}$} & \multicolumn{3}{|c|}{ Main effect variables } & \multirow{2}{*}{\begin{tabular}{|l|} 
Interaction \\
Model E5
\end{tabular}} & \multirow{2}{*}{$\begin{array}{c}\begin{array}{c}\text { Control } \\
\text { variables }\end{array} \\
\text { Model F1 }\end{array}$} & \multicolumn{3}{|c|}{ Main effect variables } & \multirow{2}{*}{$\begin{array}{l}\text { Interaction } \\
\text { Model F5 }\end{array}$} \\
\hline & & Model E2 & $\begin{array}{l}\text { Model } \\
\text { E3 }\end{array}$ & Model E4 & & & Model F2 & Model F3 & Model F4 & \\
\hline Location, USA & .086 & -.018 & .077 & -.014 & -.041 & .129 & .144 & -.021 & .000 & .100 \\
\hline Firm age & -.151 & -.151 & -.158 & -.158 & -.147 & .252 & .247 & .105 & .097 & .259 \\
\hline Firm size $(\log )$ & $.619^{* * *}$ & $.416^{* *}$ & $.519 * * *$ & $.346^{* *}$ & $.387 * *$ & .290 & .334 & .018 & .079 & .216 \\
\hline $\begin{array}{l}\text { Entrepreneurial } \\
\text { opp. recognized } \\
\text { (log) }\end{array}$ & & $.400^{* *}$ & & $.357^{* *}$ & & & -.067 & & -.094 & \\
\hline $\begin{array}{l}\text { Market } \\
\text { knowledge }\end{array}$ & & & $.414 * * *$ & $.385^{* * *}$ & & & & $.653 * * *$ & $.657 * *$ & \\
\hline $\begin{array}{l}\text { Entre opp. } \\
\text { recognized (log) } \\
\text { x market } \\
\text { knowledge }\end{array}$ & & & & & $.463 * *$ & & & & & .108 \\
\hline R-square & .400 & .507 & .561 & .645 & .542 & .192 & .194 & .491 & .496 & .198 \\
\hline $\begin{array}{l}\text { Adjusted R- } \\
\text { square }\end{array}$ & .328 & .425 & .488 & .568 & .466 & .04 & .02 & .355 & .316 & .04 \\
\hline $\begin{array}{l}\text { Change in R- } \\
\text { square }\end{array}$ & & $\begin{array}{l}\text { E2-E1 } \\
.107 * *\end{array}$ & $\begin{array}{l}\text { E3-E1 } \\
.161^{* * *}\end{array}$ & $\begin{array}{l}\text { E4-E1 } \\
.245^{* * *}\end{array}$ & $\begin{array}{l}\text { E5-E4 } \\
-.103\end{array}$ & & $\begin{array}{l}\text { F2-F1 } \\
.002\end{array}$ & $\begin{array}{l}\text { F3-F1 } \\
.299 * * *\end{array}$ & $\begin{array}{l}\text { F4-F1 } \\
.304 * *\end{array}$ & $\begin{array}{l}\text { F5-F4 } \\
-.298\end{array}$ \\
\hline F-value & $5.565 * * *$ & $6.180 * * *$ & $7.673 * * *$ & $8.369 * * *$ & $7.103^{* * *}$ & 1.265 & .904 & $3.617^{* *}$ & $2.753^{*}$ & .924 \\
\hline Durbin-Watson & 2.023 & 1.796 & 2.120 & 1.909 & 1.756 & 1.605 & 1.572 & 1.191 & 1.151 & 1.638 \\
\hline
\end{tabular}

*** Significance $\mathrm{p}<0.01,{ }^{* *}$ Significance $\mathrm{p}<0.05,{ }^{*}$ Significance $\mathrm{p}<0.1$ 
Hypothesis 3 predicts that if all other factors are constant, the greater the number of entrepreneurial opportunities recognized in a new venture the greater the subsequent profit potential. Out of the four profit potential measurements used (See Table 26 and Table 27), hypothesis three is only supported in the case of equity investments in the firm. Hence, hypothesis three only receives partial support from the empirical data.

The only variable that has a significant (negative) effect of sales growth is firm age; the younger the firm, the faster its sales growth. This makes sense since many of the younger sample firms started from non-existent or very low sales at the time of the first data collection. With regard to predictors of sales turnover in 2006 (models D1-D5), larger firms obviously have higher sales turnover. Interestingly, also market knowledge contributes significantly and positively to higher sales turnover. This should be expected in the light of existing marketing literature, where understanding of markets and customers has been linked to superior firm performance (Jaworski and Kohli 1993; Appiah-Adu and Ranchhod 1998; Matsuno et al. 2002). The (non)-finding that the variable "entrepreneurial opportunities recognized" does not influence either one of the selected sales measures is most likely a consequence of the fact that the biotechnology product development cycles expand years, even decades. Even the 3.5 year time lag of this study is too short for ideas to make their ways to markets. For many firms current sales turnover is created by products and services that have been launched while the company is still waiting for its most promising products to reach the markets.

The only variable that is significantly related to a firm's technology sales \& licensing in the regression models (F3-F4) is market knowledge. As far as technology licensing and sales are considered another form of bringing a firm's products to markets, the 
importance of market knowledge in this process should not be surprising. Instead of aiming at developing ideas all the way to complete products, many biotechnology firms choose to license out or sell rights to their inventions, and in this process the understanding of potential licensees, end markets and as well as end customers is important. One would expect the number of opportunities recognized to be positively related to the number of technologies the firm licenses out in the following years. There are two possible reasons for why this is not the case. First, it is likely that out of all the opportunities recognized, only some have potential to generate significant revenues in the marketplace. Given the transaction costs and principal-agent problems associated with technology transfer (Caves, Crookell and Killing 1983; Gallini and Wright 1990), it can be assumed that only the most promising new product ideas can be licensed out or sold to other companies. Hence, establishing a link between opportunities recognized and technology licensing may require a set of observations much larger than the current dataset, and even then the linkage might be weak in statistical terms. Alternatively, we would need a way to measure the value of each recognized opportunity, after which we could hypothesize that the link between opportunity recognition and technology licensing exists only in the case of the most valuable opportunities. Second, even though commonplace in biotechnology, technology licensing may still not be a preferred business model for many firms. This is evident in the respondents' answers to the questions about their business models: Out of those 23 sample firms that already had products on the markets in 2007 , licensing had been the primary method to bring products to the markets only in the case of one firm. Out of those nineteen firms that did not have products on the markets in 2007, half (eight) were hoping to be able to use 
licensing as a method for commercialization in the future. Hence, there are obviously many firms that opt for business models other than technology licensing or sales. The reasons vary, but may include the nature of the idea itself, difficulties in determining the scope of the license, the issue of derivatives and to what extent the material can be modified and still belong to the licensor, tricky and sometimes risky calculations of royalties, as well as government regulations, warranties and disclaimers (Fowlston 1988).

The results with regard to capital investments (models E1-E5 in Table 27) are quite interesting. In control model E1 firm size is the only significant predictor of capital investments. This is logical since the larger firms need sizable investments to keep their research and development moving forward. In a cross-section of data from phase 1 only, US-based firms seemed to attract significantly more capital than Scandinavian firms (Renko 2006a), which was supported by empirical evidence from other sources. For example, the average biotechnology deal size in Europe in 2003 was $€ 1.04$ Million, whereas in the U.S. it was $€ 9.55$ Million (PriceWaterhouseCoopers 2005). However, in the longitudinal dataset reported in Table 27 firm location (US vs. Northern Europe) is not a significant predictor of capital investments, which is somewhat surprising given the common assumption that risk capital is easier to access in the US. It looks like over time, those firms that survive the early years do have equal access to outside equity regardless of their location. The fact that the early finding about the importance of location (Renko 2006a) is not repeated in the longitudinal dataset may also be a reflection of the institutional environments that are different in the US vs. Scandinavia. US-based startups are heavily dependent on angel- and venture capital investments from early on, whereas 
in Scandinavia governments have created funding opportunities (such as TEKES ${ }^{24}$ in Finland and VINNOVA ${ }^{25}$ in Sweden) for innovative new ventures that spare them form having to access private investors at the earliest stages of firm development. Hence, a snapshot of very young biotechnology firms (Renko 2006a) reflects how the US-based ventures have been gathering more equity capital, whereas over time the difference between Nordic and American firms levels off as also Nordic firms move from the domain of government sponsored product development to dependence on venture capital.

Both entrepreneurial opportunities recognized and market knowledge turned out to be significant predictors of capital invested in a firm per year (Table 27) in the main effects models, and the models have adjusted R-square values ranging from .425 to .568 . The interaction model (E5) has a lower R-square value than the model with the main effects, which suggests that the interaction does not explain additional variance over and above what is being explained by the main effects. However, the interaction was plotted in a way similar to Figure 13 and Figure 14. The patterns of interaction were very subtle. Given the limited number of cases (only 29 cases for the regression analysis on capital investments) as well as the fact that the main effects together produced a stronger model (E5) the interaction is not discussed further. Thus, even if the data supports hypothesis 3 in the case of capital investments as a proxy for profit potential, there is no support for hypothesis 3a, which predicted that a high level of market knowledge would enhance the relationship between recognition of entrepreneurial opportunities and subsequent profit potential.

\footnotetext{
${ }^{24}$ Tekes, the Finnish Funding Agency for Technology and Innovation, www.tekes.fi

${ }^{25}$ Swedish Governmental Agency for Innovation Systems, www.vinnova.se
} 
Tyebjee and Bruno (1984) analyzed the investment decisions of venture capitalists and came to the conclusion that the two constructs of "market attractiveness" and "product differentiation" determined the returns expected by the investors. Market attractiveness consists of market size, growth and access to customers, and product differentiation includes uniqueness, patents, technical edge and profit margin. In light of this, it is not surprising that both the opportunity recognition and market knowledge variables turned out to be significant predictors of capital invested.

Overall, all the models produced in the regression analysis seem to be robust; the directions of effects (negative / positive) and relative magnitudes of independent variables' effects remain similar in Models A1 through F5.

\section{Summary of results}

Table 28 summarizes the results of the empirical study as far as the hypotheses are concerned. These results will be reflected in light of the existing literature in the final chapter of this thesis. As Table 28 indicates, of the total of 8 hypotheses, the empirical data supported four (including partial support for some hypotheses). None of the three moderation hypotheses for entrepreneurial opportunity recognition are supported (H1a-c), but in the case of H1c there is evidence that supports the opposite hypothesis. Furthermore, even if H3a is not supported, market knowledge does influence profit potential. This effect is not a moderating effect but an independent main effect instead. The implications of these findings are discussed in the following section. 
Table 28: Results by hypothesis

Hypotheses
Hypothesis 1: If all other factors are constant, the greater the
degree of technology knowledge in a new venture the larger the
number of entrepreneurial opportunities that will be recognized.

Hypothesis 1a: If all other factors are constant, when a new venture has a moderate level of market knowledge, there will be a strong positive relationship between the level of technological knowledge in the new venture and the recognition of entrepreneurial opportunities.

Hypothesis 1b: If all other factors are constant, when a new venture has a low level of market knowledge, there will be a weak positive relationship between the level of technological knowledge in the new venture and the recognition of entrepreneurial opportunities.

Hypothesis 1c: If all other factors are constant, when a new venture has a high level of market knowledge, there will be a weak positive relationship between the level of technological knowledge in the new venture and the recognition of entrepreneurial opportunities.

Hypothesis 2: If all other factors are constant, the greater the degree of market knowledge in a new venture the greater the recognition of entrepreneurial opportunities.

Hypothesis 2a: If all other factors are constant, when a new venture has a higher level of entrepreneurial orientation, the relationship between the degree of market knowledge and the recognition of entrepreneurial opportunities will be enhanced.

Hypothesis 3: If all other factors are constant, the greater the number of entrepreneurial opportunities recognized in a new venture the greater the subsequent profit potential.

Hypothesis 3a: If all other factors are constant, when a new venture has a high level of market knowledge the relationship between recognition of entrepreneurial opportunities and subsequent profit potential will be enhanced.

\section{Support}

\section{Partial support (marginal).} Support for patents as a proxy for technology knowledge, not for $R \& D$ expenditure.

\section{Not supported.}

\section{Not supported.}

\author{
Support for the opposite \\ hypothesis. When a new venture \\ has a high level of market \\ knowledge, there is a strong \\ positive relationship between the \\ level of technological knowledge in \\ the new venture and the recognition \\ of entrepreneurial opportunities.
}

Marginal support (at $\mathrm{p}<.10$ )

\section{Supported.}

Partial support. Supported for one out of four profit potential measures.

Not supported. Market knowledge influences capital investments, sales turnover, and technology licensing but the effect is independent of opportunities recognized. 


\section{DISCUSSION AND CONCLUSIONS}

This study was designed to answer two critical questions about the nature and origins of entrepreneurial opportunities: What is the role of idiosyncratic market knowledge and new scientific knowledge in the creation and discovery of technology based entrepreneurial opportunities? And how does market knowledge contribute to the exploitation of technology based entrepreneurial opportunities? Following a literature review, specific hypotheses (refutable assertions) were developed regarding the role of market knowledge in entrepreneurial opportunity recognition and exploitation. These hypotheses specify three different mechanisms through which market knowledge was expected to influence entrepreneurial opportunity recognition and exploitation. The mechanisms suggested are (1) the moderating role of market knowledge in the relationship between technology knowledge and entrepreneurial opportunities recognized in a young venture, (2) the direct positive effects of market knowledge on the entrepreneurial opportunities recognized in a young venture, and (3) the positive moderation of market knowledge in the relationship between entrepreneurial opportunities recognized in a young venture and the subsequent profit potential of the venture.

The research questions have now been addressed in the light of the established literature on entrepreneurial opportunities. Also, 85 biotechnology ventures have been consulted in the process of answering the questions, and 42 of these firms have provided 
longitudinal data that has been used to empirically test the hypotheses. The purpose of this final chapter is to discuss the main findings of the study and make the theoretical and managerial contributions of the research explicit. The section starts with a summary of the answers to the two research questions, after which the theoretical and managerial contributions of the research are assessed in more detail.

The role of market knowledge and technology knowledge in the recognition of entrepreneurial opportunities

To understand the knowledge-based antecedents of opportunity recognition in a technology intensive environment, a quantitative, hypothetico-deductive research approach was adopted. This approach is different from a bulk of entrepreneurial opportunity recognition literature, which has been either conceptual (Christensen et al. 1994; Busenitz 1996; Gaglio and Katz 2001; Eckhardt and Shane 2003; Baron 2004; Gaglio 2004; De Carolis and Saparito 2006; Buenstorf 2007; Casson and Wadeson 2007) or qualitative (Shane 2000; McKelvie and Wiklund 2004; Park 2005; Sanz-Velasco 2006) in nature.

Based on a review of previous literature, three key components were identified behind entrepreneurial opportunity recognition. First, according to the followers of the Kirznerian tradition, idiosyncratic market knowledge enables opportunity recognition. Second, according to the Schumpeterian tradition, new combinations emerge from new knowledge. In technology intensive markets this new knowledge is typically of a scientific or technological nature. Third, previous research that was summarized in the 
literature review section has emphasized the importance of entrepreneurial alertness in opportunity recognition. In the context of existing organizations, the construct of entrepreneurial orientation captures the essence of this alertness.

To summarize the findings of the empirical study with regard to the antecedents of opportunity recognition, technology knowledge that is captured in the form of patents does, indeed, contribute to subsequent opportunity recognition. In addition to being evidence of the importance of Schumpeterian-type "new knowledge" in opportunity recognition process, this finding can also be regarded as evidence of the existence of absorptive capacity in these firms. Based on Cohen and Levinthal's (1990) definition, "absorptive capacity is the ability to recognize external information, assimilate this information, and apply it to commercial ends" (p. 128). Research activity in a firm has a dual role of generating new knowledge and enhancing a firm's ability to absorb new knowledge generated by others (Cohen and Levinthal 1989, 1990). The more entrepreneurs and their firms have previously absorbed in terms of technology knowledge, the greater their absorptive capacity. Hence, also absorptive capacity hypotheses would expect to see a link between a firm's patenting activity (as a proxy for technology knowledge) and its subsequent capability to recognize entrepreneurial opportunities (See also Alvarez and Busenitz 2001).

Outside of opportunity recognition literature, the influence that a firm's past patenting activity has on its subsequent opportunity recognition can also be reflected in the light of organizational path dependency arguments. Technological path dependencies, caused by technological choices, lock the firm in or out of certain technological trajectories (Dosi 1988). Since no information was obtained with regard to the specific technological details 
of sample firms' patents, it is not possible to conclude anything about the exact technological paths followed by the firms. However, what can be said is that the past amount of technology knowledge has an impact on future inventions originating from the firm; more technology knowledge in the firm leads to more numerous new inventions. Even a young firm's history seems to be an antecedent to its current capabilities (Helfat and Raubitschek 2000).

The data analysis has shown that the influence of technology knowledge on opportunity recognition is moderated by market knowledge in that the positive linear relationship between technology knowledge and entrepreneurial opportunity recognition only exists when a firm also has a high level of market knowledge. This finding contradicts much of the previous literature, which has suggested that when dealing with radically new technology knowledge and developing radically new products - like the sample ventures are doing - conventional market knowledge would be of limited utility; customers have limited domains of expertise and may be unable to articulate their underlying needs (Hamel and Prahalad 1991; Leonard-Barton 1995; Leonard-Barton and Rayport 1997; Adams et al. 1998; O'Connor 1998; Takayama and Watanabe 2002; Im and Workman 2004). Instead, the finding about the interaction of market knowledge and technology knowledge emphasizes that a mere understanding of technology and science is not enough for entrepreneurial opportunity recognition. In order for entrepreneurs or entrepreneurial firms to recognize business opportunities they need to understand markets and customers in addition to technology (Shane 2003). New product opportunities are predominantly recognized by firms who stay close to their customers and markets (Athuene-Gima 1995, 1996; Hurley and Hult 1998) and possess high levels of technology 
knowledge. It should be pointed out that even if this importance of market knowledge for opportunity recognition has been established in previous conceptual and qualitative studies, the current study is the first more quantitative analysis of the moderating effect of technology- and market knowledge on entrepreneurial opportunity recognition.

In addition to its moderating effect, market knowledge also has an independent, direct positive effect on opportunities recognized. Since market knowledge has been proposed as an antecedent of opportunity recognition especially in the case of discovery of an external opportunity (Kirzner 1997; Shane 2003) rather than creation of a new opportunity (Ardichvili et al. 2003; Sarasvathy et al. 2003; Alvarez and Barney 2007), this significant but weaker relationship is not unexpected. Rather than simply discovering opportunities, biotechnology ventures often face considerably ambiguity in both markets and technologies, and create (or develop) the opportunities they pursue (Sarasvathy et al. 2003).

Because of the growing presence of perceptual processes and entrepreneurial alertness in entrepreneurship research, entrepreneurial orientation was tested as a moderator between market knowledge and opportunities recognized. Kirzner $(1979 ; 1980)$ maintains that the crucial difference between opportunity finders and non-finders can be found in their relative assessment of the market event or situation. Entrepreneurs, being more alert, perceive reality more accurately and are better at inferring the likely implications and consequences. Based on a review of Kirzner's contributions, Gaglio \& Katz (2001) suggest that an entrepreneurially alert individual or entrepreneur must perceive the market environment correctly (veridical perception); identify the true driving forces and critical factors; and infer the real relational dynamics among these elements (veridical 
interpretation) (p. 97). In the context of existing firms, entrepreneurial orientation captures the essence of a firm's alertness to new opportunities in the environment. Entrepreneurial orientation stands for a company culture and behavior that emphasizes innovativeness, proactiveness and risk-taking (Covin and Slevin 1991). Innovativeness reflects a tendency to support new ideas, novelty, experimentation, and creative processes (Lumpkin and Dess 1996). Proactiveness refers to a posture of anticipating and acting on future wants and needs in the marketplace before competitors do (Lumpkin and Dess 1996). With such a forward-looking perspective, proactive firms are expected to capitalize on emerging opportunities (Wiklund and Shepherd 2003). Risk-taking is associated with a willingness to commit large amounts of resources to projects where the cost of failure may be high or where the outcomes are unknown (Wiklund and Shepherd 2003). Using entrepreneurial opportunity as a substitute for alertness in the organizational context and following Wiklund \& Shepherd (2003), it was expected that organizations that have a high level of entrepreneurial orientation are more prone to focus attention and effort towards opportunities. Indeed, the empirical tests revealed that entrepreneurial orientation is not only a strong moderator in the market knowledge - opportunity recognition relationship, but it also has an independent, direct positive effect on opportunities recognized.

Regardless of whether a firm's level of market knowledge is low, medium, or high, a high level of entrepreneurial orientation enhances a firm's capability to recognize opportunities. As a conclusion, firms that have a tendency to support new ideas and creative processes (innovativeness), act on future wants and needs in the marketplace before competitors do (proactiveness), and are willing to commit large amounts of 
resources to projects where the outcomes are unknown (risk taking) recognize more opportunities than firms that lack these qualities.

Interestingly, the detected interaction of market knowledge and entrepreneurial orientation suggests that the largest numbers of opportunities are recognized by firms that have high levels of entrepreneurial orientation but only medium levels of market knowledge. This is an unexpected finding, since entrepreneurial orientation was hypothesized to further enhance the positive effects of high levels of market knowledge. An ex post explanation for this finding might hold that entrepreneurial orientation can actually, under some circumstances, compensate for a lack of elaborate market knowledge. Firms that possess moderate levels of market knowledge can recognize numerous opportunities provided that their postures and behaviors are entrepreneurially oriented. When coupled with a high level of market knowledge, high entrepreneurial orientation actually results in fewer opportunities recognized than when coupled with only a moderate level of market knowledge (Figure 14). This unexpected finding can be explained if we view discovering an opportunity as a combination of two distinct activities: (1) Effective entrepreneurs identify problems which, if solved, would create value, and (2) create efficient solutions to these problems (Hsieh, Nickerson and Zenger 2007). It may be that knowledge, including market knowledge, is particularly helpful when in comes to finding solutions to the identified problems. However, in finding the "right questions to ask" prior knowledge may be of lesser importance. As explained in the literature review earlier, when dealing with radically new technology knowledge and developing radically new products, conventional market knowledge is often of limited utility. Customers have limited domains of expertise and they may be unable to articulate 
their underlying needs, resulting in user-developed problems that are not innovative or creative. Instead of prompting entrepreneurs to ask revolutionary questions, understanding the existing customers very well can lead entrepreneurs to recognize problems that are of incremental or even trivial nature in the larger marketplace. Hence, for a firm that has an innovative, proactive and risk-prone posture, medium levels of market knowledge are enough to identify problems that are worth solving and to find solutions to these problems. A high level of market knowledge in an entrepreneurially oriented firm can actually take away from the firm's willingness or capability to ask revolutionary kinds of questions that could lead to recognizing multiple new opportunities.

Taken together, the findings about the factors affecting entrepreneurial opportunity recognition in the technology intensive environment of biotechnology ventures suggest that market knowledge does, indeed, influence opportunity recognition through multiple mechanisms. First, it has a somewhat significant positive role in contributing directly to the numbers of opportunities recognized. Second, more importantly, its interaction with technology knowledge (measured with the number of patents) has implications for opportunity recognition. When a high level of market knowledge is combined with a high level of technology knowledge in a firm, the firm's subsequent opportunity recognition is greatly enhanced. However, for those firms that have only low levels of technology knowledge, high levels of market knowledge cannot compensate for the lack of technology knowledge: High level of market knowledge combined with a low level of technology knowledge results in low numbers of subsequent opportunities recognized (See Figure 13). Third, market knowledge also interacts with a firm's entrepreneurial 
orientation in influencing subsequent opportunity recognition. When a firm's level of entrepreneurial orientation is elevated, it recognizes more opportunities. Entrepreneurial orientation can also compensate for a lack of elaborate market knowledge. Firms that possess moderate levels of market knowledge recognize numerous opportunities provided that their postures and behaviors are entrepreneurially oriented. These relationships detected in empirical tests of hypotheses are illustrated in Figure 15 below. A solid arrow indicates a relationship that is significant at $\mathrm{p}<.05$, a dotted arrow stands for a relationship significant at $\mathrm{p}<.10$.

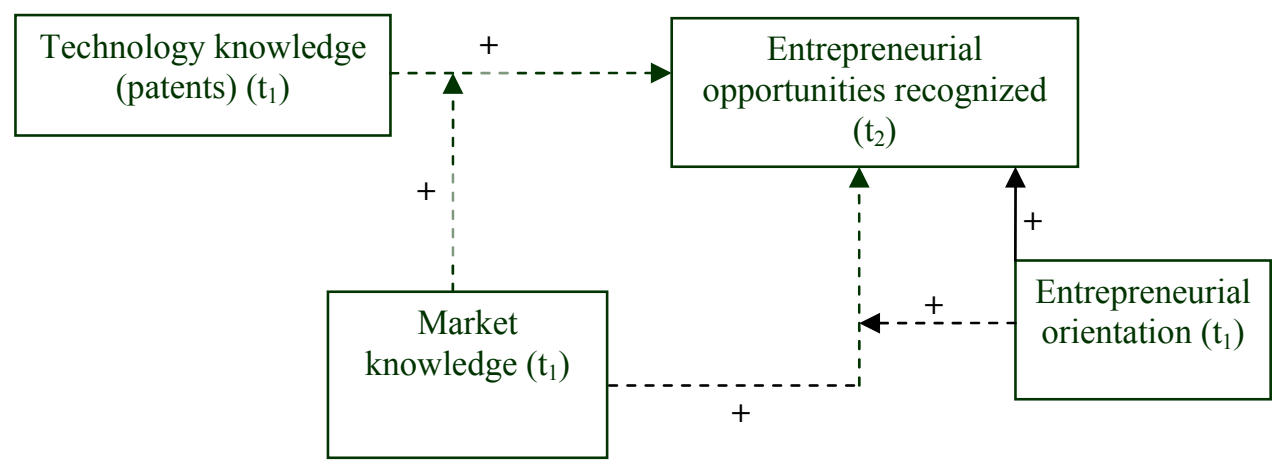

Figure 15: The direct and moderating effects of market knowledge on entrepreneurial opportunity recognition. Ex post model.

Obviously, the simple "more market knowledge - more opportunities recognized" kind of thinking that is currently prevalent in studies of entrepreneurial opportunities seems naïve in the light of the above-presented findings. The mechanisms through which entrepreneurial opportunities are recognized vary from a discovery of an arbitrage to the creation of a radical opportunity, and the knowledge foundations of the different OpR mechanisms are different. As far as the opportunities that are based on novel 
technological knowledge come into being through "creation" rather than discovery, it can be concluded that in a "creation context" (Alvarez and Barney 2007) market knowledge is only beneficial for opportunity recognition when it is coupled with a moderate or high level of technology knowledge ${ }^{26}$. As far as market knowledge itself is a basis for opportunity discovery (discovery context of Alvarez \& Barney, 2007) more market knowledge is not always better. When taking into account a firm's entrepreneurial orientation, the largest numbers of opportunities are recognized by those firms that have high levels of entrepreneurial orientation but only moderate (not high) levels of market knowledge.

The role of market knowledge in the exploitation of technology based entrepreneurial opportunities

Once opportunities have been recognized, they also need to be exploited for rent appropriation. Because of the long development time spans of biotechnology products from laboratory to market launch and because of the concept of profit potential being central in definitions of entrepreneurial opportunities (Singh 2000; Sarasvathy et al. 2003; Shane 2003; Sanz-Velasco 2006; Companys and McMullen 2007; Goss 2007), hypotheses were formulated to test the impact of opportunity recognition and market knowledge on firm's profit potential. Profit potential was measured through equity investments in the firm, sales growth, sales turnover, and technology licensing \& sales.

\footnotetext{
${ }^{26}$ This finding is obviously specific to a context where technology knowledge is a relevant basis for economic development.
} 
The only hypothesized relationship that was confirmed in empirical tests is entrepreneurial opportunities' influence on equity investments in the firm. Market knowledge did not significantly moderate this relationship over and beyond the independent main effects of opportunities recognized and market knowledge. Rather than having the hypothesized moderating effect on the opportunity recognition - profit potential relationship, market knowledge turned out to have a direct and positive effect on sales turnover, technology licensing \& sales, and equity investments. The significant relationships are illustrated in Figure 16. All relationships are significant at $\mathrm{p}<.05$.

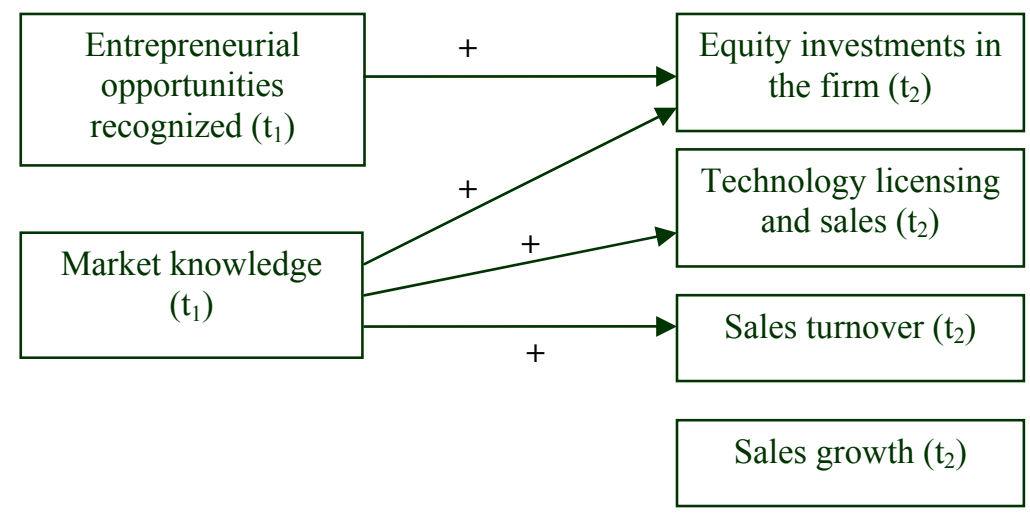

Figure 16: The relationships between market knowledge, entrepreneurial opportunities recognized, and profit potential. Ex post model.

The positive findings with regard to the influence of market knowledge are in line with the bulk of the literature on market orientation that has established a link between market knowledge generation, dissemination and responsiveness on one hand and firm performance on the other hand (See Rodriguez Cano et al. 2004 for a meta-analysis). Better understanding of a firm's current and future customers contributes to investor's 
increased belief in the firm's ability to break through in the markets. Previous literature has suggested that investors evaluate both the technology/product aspects of the firm as well as its market potential when making investment decisions (See for example Tyebjee and Bruno 1984; Shepherd and Zacharakis 1999; Mason and Stark 2004).

Better understanding of a firm's current and future customers also contributes to potential partners' increased willingness to buy into the firm's technology base (positive effect on technology licensing and sales). This finding adds to the increasing body of literature on technology licensing which has, regardless of its recent growth, remained focused on large corporations, universities, and macro-level drivers of efficiency in the markets for technology (Arora et al. 2001). Previous empirical research on technology transfer has focused on the factors that determine a firm's choices among various organizational forms (Teece 1986), especially its foreign market entry choices (e.g. Kogut and Singh 1988). However, there is a lack of studies investigating the factors underpinning the rate of technology licensing among firms, especially smaller and younger firms that typically operate on the supplier-side of markets for technology (Fosfuri 2006). Gans, Hsu, and Stern (2002) who do study the determinants of commercialization strategy for start-up innovators only focus on the strength of intellectual property protection, the cost of contracting, and the importance and effectiveness of complementary-asset ownership as drivers of licensing activity by startup firms. The link established in this study between a young firm's market knowledge and its subsequent ability to license out technologies is unique in the current literature. The mechanism behind this effect is open to speculation, but it is likely that a young firm that knows about its markets and customers is better able to convince potential licensees 
of the value of its technologies. This finding opens up interesting questions for future research with regard to the motivations of licensors and licensees as well as rent appropriation in these collaborative arrangements. Market knowledge contributes to the number of licensing deals that a start-up firm is able to complete, but what are the terms of these agreements? One could assume that if the licensor is able to convince the licensee about the value of the invention in the marketplace because of a good understanding of markets and customers, the licensor should also be able to negotiate favorable terms for the licensing deal. The current dataset does not contain information on the value or terms of the individual licensing deals, but this could be an interesting topic for future research. Also, technology licensing literature would benefit from a deeper understanding of other firm-level attributes that contribute to licensing success in young ventures. In addition to market knowledge the attributes of the technology itself, connectedness of the firm, its legitimacy and reputation in the eyes of external stakeholders, as well as the quality of its management team could be tested as antecedents of licensing success. An improved understanding of the factors that contribute to licensing success would benefit the managers in that growing number of firms that are involved in these deals. In the United States alone, technology licensing revenues are estimated to account for U.S. $\$ 45$ billion annually; worldwide, the figure is around U.S. $\$ 100$ billion (Fosfuri 2006) ${ }^{27}$.

The positive relationship between market knowledge and subsequent sales turnover established in this research is in line with those numerous studies in the marketing domain that have established a link between market knowledge / market orientation and

\footnotetext{
${ }^{27}$ Original source: The Economist. 2005. A market for ideas. 20 October: 48-51.
} 
sales (See Rodriguez Cano et al. 2004 for a meta-analysis). The lack of relationship between market knowledge and sales growth is probably due to the nature of this growth in the sample firms. For many firms, this percentage is very high since their initial sales levels were minimal. In cases where sales growth during first years or months of firm sales ever is captured, this measure is a biased estimator of the longer term sales potential of the firm.

The lack of relationships between entrepreneurial opportunities recognized and the subsequent profit potential measurements (with the exception of equity investments) is most likely due to the time needed to convert opportunities recognized into actual dollars or euros. Investors, who base their decisions on the future potential of a venture, are, indeed, influenced by the amount of opportunities the firm has recognized. However, more time than the 3.5 years allowed in this research design will need to elapse before these opportunities are turned into concrete sales or even licensing deals.

\section{Theoretical contribution of the research}

This study makes numerous contributions to the literature that addresses entrepreneurial opportunities and their origins. Contributions to establishing the domain of entrepreneurial opportunities are reviewed first, after which contribution to understanding the sources of these opportunities is discussed.

In the current literature on entrepreneurial opportunities there is no consensus concerning the exact meaning of the entrepreneurial opportunity concept. However, based on the definitions offered in existing literature this study concludes that some 
unifying themes exist; many researchers share the innovation-emphasis evident initially in the writings of Kirzner (1979) and Schumpeter (1934b) (See also McMullen et al. 2007). To distinguish from "non-entrepreneurial" opportunities, some researchers have also added the element of starting a firm. Ultimately, however, the firm is started with the purpose of introducing a new good or service (McMullen et al. 2007). For the purposes of this study, entrepreneurial opportunity has been defined as the possibility to introduce innovative (rather than imitative) goods or services to a marketplace through starting a firm or through the significant improvement of an existing venture (Inspired especially by the definitions of Gaglio 2004, 534, Singh 2000, 23, and Mueller 2007, 356). This definition is specific enough to distinguish entrepreneurial opportunities from the rest of business opportunities, but it is also wide enough to include multiple contexts (new or existing firms) where OpR can take place.

There are few attempts in the existing research to quantitatively measure entrepreneurial opportunities. Those existing studies that have operationalized entrepreneurial opportunities have made a wealth of implicit assumptions about the nature of these opportunities but have seldom clearly communicated these assumptions. For example, a new venture idea that leads to a business startup seems to be the operationalization of a business opportunity for Baron \& Ensley (2006), but the reader has to infer this from their research design. Busenitz (1996) does not explicitly state what entrepreneurial opportunities are, but since his empirical research compares managers in publicly traded large corporations to founders of new ventures it can be assumed that founders of new ventures have recognized entrepreneurial opportunities whereas managers in large corporations have not. Young firms are also the incarnation of 
opportunities in the Saemundsson and Dahlstrand (2005) study. Shane's (2000) opportunities are startup activities geared at commercialization of a patented technology. In some studies, the interpretation of what constitutes an opportunity seems to be left to the respondents of an empirical study (Brown et al. 2001; Ozgen and Baron 2007).

Given the ambiguity in definitions and operationalizations of entrepreneurial opportunities in previous research, one of the contributions of this study is definitional clarity. Following the definition of entrepreneurial opportunity for the study, entrepreneurial opportunity recognition has been separated from opportunity exploitation, and both constructs have been operationalized after a thorough review of the empirical context of the study. Even if the general definition of entrepreneurial opportunity suggested in this study as well as the distinction between recognition and exploitation are generalizable across time and industries, operationalizations are specific to the context of biotechnology. To quantify the opportunities recognized by the sample firms we looked into their product development pipelines to count the number of opportunities. One aspect related to the complexity of the biotechnology innovation process is that there is not normally a one-to-one relationship between a specific scientific discovery and a certain industrial application. Any given biotechnology invention may be used in a variety of applications and industries (McKelvey et al. 2004), and often firms have to select which one of the many potential commercialization avenues they want to pursue for any one invention. Industry-specific issues like this mean that researchers who operationalize entrepreneurial opportunities in the future should be extremely cautious of the influence of empirical research context on relevant operationalizations. The operationalization of "entrepreneurial opportunities recognized" in this study was shown 
to have convergent validity (measurements at two points of time) as well as discriminant validity (different from “entrepreneurial opportunities exploited”).

The hottest potato in today's entrepreneurship research is the process of opportunity recognition. The fresh first issue of Strategic Entrepreneurial Journal includes articles by leading scholars in the field, and nearly all of them focus, in a way or another, on opportunity recognition. Many of these contributions center on the question of whether or under what circumstances - opportunities are recognized, discovered, or created (Alvarez and Barney 2007; Baron 2007; Miller 2007; Shepherd et al. 2007) and even articles that focus on firm internationalization (Bingham, Eisenhardt and Furr 2007) or users of juvenile products as entrepreneurs (Shah and Tripsas 2007) claim they are making contributions to opportunity recognition literature. A clear juxtaposition of the creation vs. discovery view of opportunity recognition (Alvarez and Barney 2007) may be beneficial for illustrating the conceptual differences between the two approaches, but in reality one can identify elements of creation, discovery, as well as effectuation (Sarasvathy 2001b) in most new firm startups. This study concurs with the view that entrepreneurial opportunities can be discovered based on a technological innovation (Schumpeter 1934b; Drucker 1985), in which case the supply of technology is known and demand is unknown (Sarasvathy et al. 2003) and / or they can be discovered because different market participants have unequal access to information about the market conditions (customers, markets, and ways to serve markets) (Kirzner 1997; Shane 2000, 2003), in which case the demand in the market is known to some, but the supply has to be developed. 
Following this logic the findings of the empirical study have shown that both technology knowledge and market knowledge do contribute to opportunity recognition in young technology ventures. Firms that come up with most entrepreneurial opportunities have high levels of both market knowledge and technology knowledge. This finding is in line with, for example, the suggestions of Amabile (1999), who stressed the importance of combining market knowledge and technology knowledge in the development of new ideas. Numerous research insights from the new product development literature also emphasize the role of divergent knowledge types in recognizing and developing opportunities (Holt et al. 1984; Rothwell 1992; Cooper 1993; O'Connor and Veryzer 2001). However, there are also studies that have questioned the importance of marketand customer knowledge in the context of radically new innovations (Hamel and Prahalad 1991; Leonard-Barton 1995; Leonard-Barton and Rayport 1997; Adams et al. 1998; O’Connor 1998; Takayama and Watanabe 2002; Im and Workman 2004; Marvel and Lumpkin 2007). In the light of the findings of the current study, this body of literature has underestimated the role of market knowledge in innovative and entrepreneurial activities.

This study has employed entrepreneurial orientation (firm level construct) as a substitute of entrepreneurial alertness (individual level construct) in opportunity recognition. In the discovery-view of entrepreneurial opportunity recognition, where idiosyncratic market knowledge plays a central role, alertness has been suggested as a critical antecedent of opportunity recognition (Gaglio and Katz 2001). Supporting this line of theory, the current study found that a firm's entrepreneurial orientation enhances the positive effects that market knowledge has on the number of opportunities 
recognized. Entrepreneurially oriented firms have the methods, practices, and managers with a decision-making style that promote a willingness to use market knowledge by engaging in entrepreneurial activities. This finding about the moderating role of entrepreneurial orientation in the market knowledge - opportunity recognition relationship has similarities with the findings of Wiklund \& Shepherd (2003), who found that entrepreneurial orientation moderates the relationship between knowledge based resources and firm performance among Swedish SMEs. Firms with market knowledge know where to look for opportunities and can more accurately assess the value of potential opportunities, but unless the firm is willing to take a risk and proactively pursue these opportunities, its market knowledge is likely to be underutilized. This finding of the current study can also be interpreted as support for dynamic capabilities arguments; over and above a firm's stock of valuable and rare resources - like idiosyncratic market knowledge - it is how management utilizes those resources that is important in explaining opportunity recognition. Dynamic capabilities include difficult-to-replicate enterprise capabilities required to adapt to changing customer and technological opportunities (Teece 2007). Entrepreneurial orientation is a dynamic capability (Wiklund and Shepherd 2003) in a sense that it tells about a firm's capacity to sense and shape opportunities and threats, as well as its capacity to seize opportunities (Teece 2007).

Even if the contribution of market knowledge to opportunity recognition has been widely discussed, researchers yet have to focus their attention on opportunity exploitation in addition to opportunity recognition. Depending on the industry context, the paths from opportunity recognition to opportunity exploitation vary, and in biotechnology that path is particularly long and risky. The results of the empirical study have shown that market 
knowledge significantly and positively contributes to three out of four profit potential measures, which illustrate a firm's decision to exploit opportunities. This finding concerning the importance of market knowledge in opportunity exploitation is in line with Choi \& Shepherd (2004). They find that entrepreneurs who believe that customers will value their new product(s) are more likely to proceed with exploitation. Entrepreneurs will need to resolve some of the uncertainty surrounding market demand before they can determine whether their new product is sufficiently valuable to commit to its full-scale exploitation (Choi and Shepherd 2004). A main mechanism for lowering such demand uncertainty is increased market knowledge, achieved through market research.

\section{Managerial contribution}

The managerial advice that can be derived from these research results applies to young technology intensive firms operating - obviously - in the field of biotechnology, but also in other technology intensive fields. Opportunity recognition is important for firm renewal and continued success. Essentially, the study results show that there is no one way to success in opportunity recognition. Firms that want to stay in the forefront of innovation have to invest in technology knowledge as well as market knowledge. In addition, they have to ensure that the firm stays alert to opportunities arising from the environment. Hence, an organizational posture that emphasizes innovativeness, proactiveness, and risk taking is beneficial when it comes to opportunity recognition. 
In a science driven field like biotechnology, investments in the development of market knowledge base are often forgotten. Even though low hierarchies and centralization of small organizations usually make firms' internal communication easier, managers should still pay special attention to the challenges of bridging boundaries between the scientific and business personnel. At best, everyone in the firm is aware of the customer- and competitor-related aspects, and can channel market information from the environment to the firm whenever possible.

As far as acquisition is a preferred exit strategy for a young technology firm, investments in market knowledge should be especially beneficial. Even if the current study can only speculate about the mechanisms through which market knowledge of a young venture has a positive effect on its subsequent likelihood to be involved in a merger or acquisition, a significant relationship was detected between market knowledge and subsequent M\&A.

This study has also shown that market knowledge has positive effects on sales, technology licensing, and capital invested in the firm. Because biotechnology start-ups are often early entrants to their respective fields, they may be compelled by the scientific advances and demonstrate low levels of market knowledge and orientation in the absence of direct market competition. However, the positive linkages detected here between market knowledge and the three important aspects of a young venture's profit potential should urge managers to invest in market intelligence generation and efficient dissemination within their respective organizations. 


\section{Limitations of the study}

Empirical estimation of knowledge and its production and transfer is challenging. Research results concerning knowledge, innovation and technological change have been shaped by the nature of the data that has been available to scholars for analyses. Such data have always been incomplete (Acs and Audretsch 2005), and this research is no exception.

The main limitations of this study include single informant bias and limited statistical conclusion validity as a result of the small sample size. The single informant problem is typical for studies conducted in small firm settings. In this study, comparisons of patent figures as well as sales turnover reported by the interviewees with data from secondary sources were completed to ensure the reliability of the data. These comparisons indicate that even though the self-reported numbers are not exactly similar to those available from the secondary sources, there is no evidence that the measurements used would be biased estimators. Also other tests that were reported under "Single respondent bias" provided comforting evidence confirming the absence of this problem.

Most of the limitations of this study result from time and resource constraints in the data collection. Had the initial sample size of firms interviewed in 2003-2004 been larger, the final longitudinal sample could also have been more sizeable than the current 42 firms. Regardless of the small sample size, however, a longitudinal study provides a better understanding of the nature of the relationships between market- and technologyrelated variables, opportunity recognition, and profit potential than what a cross sectional 
study would. Within a longitudinal sample of young ventures the amount of company exits between data collection efforts is, unfortunately, bound to be substantial.

An additional limitation of this research - like many other studies - is the reliance on self-reported judgments. While appropriate to the design, future research might combine internal self-report measurements with other internal and external measurements, which would enhance the generalizability of the findings.

The empirical data in this study was collected from a single industry, namely medical biotechnology. Biotechnology markets are a prime example of markets for technology (Arora et al. 2001). In addition to biotechnology there are numerous fields of business that share similar market features typical of markets for technology. The results of this study can and should be applicable within the context of a number of other knowledgeintensive, high-technology industries. As examples of markets for technology, Arora et al. (2001) discuss, for example, the growing market for chip design modules in the semiconductor business as well as the software, biotechnology and chemical processing markets. All these industries rely heavily on science and technology, and are dynamic fields where companies constantly need to reinvent themselves to stay in the forefront of competition. What is more, in all these industries specialization relies heavily on patents and intellectual property rights. Patents are increasingly being used as a means to define the property rights on inventions to facilitate the trade of these property rights; the creation and enforcement of intellectual property is extremely important. These similarities described here lead to the conclusion that even though biotechnology is, in many respects, a special kind of industry, the relationships detected in the empirical study should be applicable in some other contexts as well. 
The empirical study firms come from five locations on two continents. This has benefits for external validity. Even though firms in the US differ from those in Finland and Sweden along some criteria (most importantly, US-based firms have recognized more opportunities than the Nordic firms), there were no major differences between US vs. Nordic firms as far as the profit potential of the ventures, their market knowledge, or their technology knowledge are concerned. This is strong evidence of the external validity of the research results across geographical locations.

The final limitation of the study is the nature of the main dependent variable of the study, namely "entrepreneurial opportunities recognized". Even if the number of therapeutic areas where an invention can be applied is a part of this measure, it is still largely a measure of quantity rather than quality. Hence, even if the measure tells about the amount of opportunities recognized in a firm, it is a poor measure of the market potential of these opportunities. This may be another ${ }^{28}$ reason why opportunities recognized by a firm in phase 1 of the study were only related to one out of four profit potential measures in phase 2. A firm can invent and patent endlessly, but unless those inventions actually have market potential they will not lead to positive commercial outcomes.

\footnotetext{
${ }^{28}$ The reason for the lack of these relationships identified earlier is the short (relatively speaking, in the context of biotechnology R\&D) time lag of approximately 3.5 years between the two data collection efforts.
} 


\section{Future research directions}

In addition to the "usual suspects" for future research directions (need for a longer time lag between he measurement of opportunity recognition and exploitation, need to collect more objective data about young, small firms, and the need to expand the geographic scope of this study to further increase external validity), I would like to mention some not-so-obvious ideas for future research in addition to the ideas that have already been expressed earlier.

First and foremost, clear definitions of constructs employed in entrepreneurial opportunity research would greatly advance the development of the field, regardless of the specific research questions asked. Currently, too many researchers are not specific enough about what they really mean by entrepreneurial opportunities.

Even if such relationship was not hypothesized, a significant positive association was discovered in the current study between market knowledge and ending up acquired or merged. This insight is not captured in the existing empirical literature on market orientation or market knowledge. An interesting question for future research is why is there such a relationship? In the current biotechnology environment, where opportunities for investors' successful exit through an initial public offering are few (Ernst\&Young 2007), M\&As offer an alternative exit strategy and improved liquidity. Are acquirers more interested in more market oriented small firms because these firms already have clear, market derived goals for their product development? Or are small firms that are knowledgeable of their markets better in identifying potential partners for merger / acquisitions? Research into the factors that contribute to a successful M\&A as an exit 
strategy could provide valuable information not only for theory development in the area, but also for managerial purposes.

Future research in the field of opportunity recognition should boldly tackle the challenge of operationalizing concepts such as alertness, heuristics, knowledge based resources, entrepreneurial opportunity recognition, and exploitation in multiple contexts. A wealth of conceptual literature, including many conceptual models waiting to be tested empirically, already exists. The field would benefit from further empirical research, where operationalizations are context specific enough so that they actually measure the proposed constructs. Even the kinds of knowledge- measurements used in this study are not applicable to all kinds of contexts. Measurement of technology knowledge with patents assumes that patents are a primary way for protecting that knowledge. This is not the case in many industries (and countries). Even the market knowledge measure used in this study, which has been widely used before within marketing literature, had to undergo some transformations before it could be applied in the context of young biotechnology ventures.

Future scholarship should also develop our understanding of opportunity exploitation to complement recent works on opportunity discovery and recognition. All recognized opportunities are not exploited by entrepreneurial firms, and a fine-grained analysis of the attributes of the opportunities that end up exploited would be beneficial. Based on the current research we know that market knowledge does contribute to licensing out technologies, which can be considered one form of opportunity exploitation. However, what are the other firm- and opportunity related characteristics that contribute to an opportunity being exploited? We also know that market knowledge has a positive effect 
of investors' willingness to invest in the firm as well as firm sales, but there are certainly a wealth of other factors as well that contribute to opportunity exploitation and even interact with the effect of market knowledge. For example, opportunities produce new products that could be considered rare (Choi and Shepherd 2004). The level of this rarity may moderate the relationship between market knowledge and opportunity exploitation.

In conclusion, this dissertation shows the value and importance of market knowledge and technology knowledge as well as an entrepreneurial company posture for opportunity recognition in young high technology ventures. Furthermore, it has shown that new ventures with more market knowledge are able to gather more equity investments, license out more technologies, and achieve higher sales than new ventures with lower levels of market knowledge. Equity investments are also affected by the firm's historical record in opportunity recognition. Most likely, a future research with an extended time lag between the measurement of opportunity recognition and sales /technology licensing will show that also these outcomes are influenced by firm's record in opportunity recognition. Overall, the findings of this dissertation help further our understanding of the sources of entrepreneurial opportunities, and should encourage further research in this area. 


\section{LIST OF REFERENCES}

Abrams, S. L. (2004). How to build a biotech center. Investment Dealers' Digest 70(28): 24-26.

Acs, Z. J. and Audretsch, D. B., Eds. (2005). Handbook of entrepreneurship research. An interdisciplinary survey and introduction. . New York, Springer.

Adams, M. E., Day, G. S. and Dougherty, D. (1998). Enhancing new product development performance: an organizational learning perspective. Journal of Product Innovation Management 15: 403-422.

Aldrich, H. and Wiedenmayer, G. (1993). From traits to rates: An ecological perspective on organizational foundings. Advances in Entrepreneurship, Firm Emergence, and Growth. J. Katz. Greenwich, CT, JAI Press. 1.

Alvarez, S. A. and Barney, J. B. (2004). Organizing Rent Generation and Appropriation: Toward a Theory of the Entrepreneurial Firm. Journal of Business Venturing 19(5): 621.

Alvarez, S. A. and Barney, J. B. (2007). Discovery and creation: Alternative theories of entrepreneurial action. Strategic Entrepreneurship Journal 1(1): 11-26.

Alvarez, S. A. and Busenitz, L. W. (2001). The entrepreneurship of resource-based theory. Journal of Management 27(6): 755.

Amabile, T. (1999). How to kill creativity. Harvard Business Review on breakthrough thinking. Boston, Harvard Business School Press: 1-59.

Amit, R., Brander, J. and Zott, C. (1998). Why do venture capital firms exist? Theory and Canadian evidence. Journal of Business Venturing 13: 441-466.

Appiah-Adu, K. (1998). Marketing activities and business performance: Evidence from foreign and domestic manufacturing firms in a liberalized developing economy. Marketing Intelligence and Planning 16(7): 436-442.

Appiah-Adu, K. and Ranchhod, A. (1998). Market orientation and performance in the biotechnology industry: An exploratory empirical analysis. Technology Analysis \& Strategic Management 10(2): 197-210.

Ardichvili, A., Cardozo, R. and Ray, S. (2003). A theory of entrepreneurial opportunity identification and development. Journal of Business Venturing 18: 105-123. 
Armstrong, J. S. and Overton, T. S. (1977). Estimating nonresponse bias in mail surveys. Journal of Marketing Research 14(3): 396-402.

Arora, A., Fosfuri, A. and Gambardella, A. (2001). Markets for technology. The economics of innovation and corporate strategy. Cambridge, Mass., The MIT Press.

Athuene-Gima, K. (1995). An exploratory analysis of the impact of market orientation on new product performance. Journal of Product Innovation Management 12: 275-293.

Athuene-Gima, K. (1996). Market orientation and innovation. Journal of Business Research 25(2): 93-103.

Bagozzi, R. P., Yi, Y. and Phillips, L. W. (1991). Assessing construct validity in organizational research. Administrative Science Quarterly 36: 421-458.

Baker, W. and Sinkula, J. M. (1999). The synergistic effect of market orientation and learning orientation on organizational performance. Journal of the Academy of Marketing Science 27(4): 411-427.

Baron, R. A. (2004). Opportunity recognition: insights from a cognitive perspective. Research in Entrepreneurship and Management: Opportunity Identification and Entrepreneurial Behavior. J. A. Butler. Greenwich, CT, Information Age Publishing. 4: 47-74.

Baron, R. A. (2007). Behavioral and cognitive factors in entrepreneurship: entrepreneurs as the active element in new venture creation. Strategic Entrepreneurship Journal 1(1): $167-182$.

Baron, R. A. and Ensley, M. D. (2006). Opportunity Recognition as the Detection of Meaningful Patterns: Evidence from Comparisons of Novice and Experienced Entrepreneurs. Management Science 52(9): 1331-1344.

Begley, T. and Boyd, D. (1987). Psychological characteristics associated with performance in entrepreneurial firms and smaller businesses. Journal of Business Venturing 2: 79-93.

Belsey, D., Kuh, E. and Welsch, R. (1980). Regression diagnostics: Identifying influential data and sources of collinearity. New York, Wiley.

Bergeron, B. P. and Chan, P. (2004). Biotech industry: A global, economic, and financing overview. New York, John Wiley \& Sons, Inc. 
Bhave, M. P. (1994). A process model of entrepreneurial venture creation. Journal of Business Venturing 9(3): 223.

Bhide, A. (2000). The origin and evolution of new businesses. New York, US, Oxford University Press.

Bingham, C. B., Eisenhardt, K. M. and Furr, N. R. (2007). What makes a process a capability? Heuristics, strategy, and effective capture of opportunities. Strategic Entrepreneurship Journal 1(1): 27-47.

BiotechBusinessWeek (2007). According to UF's Sid Martin Florida BioDatabase, More Than Half of Florida's Biotech Companies Founded since 2001. Biotech Business Week: 143.

Blau, D. (1987). A time series analysis of self employment in the United States. Journal of Political Economy 95: 445-467.

Blaug, M. (2000). Entrepreneurship before and after Schumpeter. Entrepreneurship - the social science view. R. Swedberg. Oxford, UK, Oxford University Press: 76-88.

Blenker, P., Philipsen, K. and Damgaard, T. (2005). How do we talk about market creation? Towards a language of opportunity enactment. 2nd Symposium on the Entrepreneurship - Innovation - Marketing Interface. Karlsruhe, Germany.

Bouckenooghe, D., De Clercq, D., Willem, A. and Buelens, M. (2007). An Assessment of Validity in Entrepreneurship Research. The Journal of Entrepreneurship 16(2): 147-171.

Brink, J., McKelvey, M. and Smith, K. (2004). Conceptualizing and measuring modern biotechnology. The economic dynamics of modern biotechnology. M. McKelvey, A. Rickne and J. Laage-Hellman. Cheltenham, UK, Edward Elgar Publishing Limited: 2041.

Brown, T. E., Davidsson, P. and Wiklund, J. (2001). An operationalization od Stevenson's conceptualization of entrepreneurship as opportunity-based firm behavior. Strategic Management Journal 22: 953-968.

Buenstorf, G. (2007). Creation and Pursuit of Entrepreneurial Opportunities: An Evolutionary Economics Perspective. Small Business Economics 28(4): 323-337.

Burgelman, R. A. (1983). Corporate entrepreneurship and strategic management: Insights from a process study. Management Science 29(12): 1349-1364. 
Busenitz, L. W. (1996). Research on entrepreneurial alertness. Journal of Small Business Management 34(4): 35-44.

Busenitz, L. W. and Barney, J. B. (1997). Differences between entrepreneurs and managers in large organizations: Biases and heuristics in strategic decision-making. Journal of Business Venturing 12(1): 9.

Busenitz, L. W. and Lau, C.-M. (1996). A cross-cultural cognitive model of new venture creation. Entrepreneurship Theory and Practice 20(4): 25.

Campbell, D. T. and Fiske, D. W. (1959). Convergent and discriminant validation by the multitrait-multimethod matrix. Psychological Bulletin 56: 81-105.

Carpenter, R. and Petersen, B. (2002). Capital market imperfections, high-tech investment, and new equity financing. The Economic Journal 112: 54-72.

Caruana, A., Ramaseshan, B. and Ewing, M. T. (1998). The market orientationperformance link: Some evidence from the public sector and universities. Journal of Nonprofit and Public Sector Marketing 61(1): 63-82.

Casson, M. (1982). The entrepreneur: An economic theory. Totowa, NJ.

Casson, M. and Wadeson, N. (2007). The Discovery of Opportunities: Extending the Economic Theory of the Entrepreneur. Small Business Economics 28(4): 285-300.

Caves, R., Crookell, H. and Killing, P. J. (1983). The imperfect market for technology licenses. Oxford Bulletin of Economics and Statistics 45(3): 249-267.

Champenois, C., Engel, D. and Heneric, O. (2006). What kind of German biotechnology start-ups do venture capital companies and corporate investors prefer for equity investments? Applied Economics 38(5).

Choi, Y. R. and Shepherd, D. A. (2004). Entrepreneurs' decisions to exploit opportunities. Journal of Management 30(3): 377-395.

Chrisman, J. J. and McMullan, W. E. (2000). A preliminary assessment of outsider assistance as a knowledge resource: The longer-term impact of new venture counseling. Entrepreneurship Tlheory and Practice 24(3): 37-53.

Christensen, C. and Bower, J. (1996). Customer power, strategic investment, and the failure of leading firms. Strategic Management Journal 17: 197-218. 
Christensen, M. C. (1997). The innovator's dilemma. Boston, Harvard Business School Press.

Christensen, P. S., Madsen, O. O. and Peterson, R. (1994). Conceptualizing entrepreneurial opportunity recognition. Marketing and Entrepreneurship: Research Ideas and Opportunities G. E. Hills. Westport, CT, Quorum Books: 61-75.

Churchill, G. A. (1979). A paradigm for developing better measures of marketing constructs. Journal of Marketing Research 16: 64-73.

Clark, K. B. and Henderson, R. M. (1990). Architectural Innovation: The Reconfiguration of Existing Product Technologies and the Failure of Established Firms. Administrative Science Quarterly 35.

Cohen, B. and Winn, M. I. (2007). Market imperfections, opportunity and sustainable entrepreneurship. Journal of Business Venturing 22(1): 29-49.

Cohen, J. and Cohen, P. (1983). Applied multiple regression/correlation analysis for the behavioral sciences. Hillsdale, New Jersey, Lawrence Erlbaum Associates Publishers.

Cohen, W. M. and Levinthal, D. A. (1989). Innovation and learning: the two faces of R\&D. The Economic Journal 99(397): 569-596.

Cohen, W. M. and Levinthal, D. A. (1990). Absorptive capacity: A new perspective on learning and innovation. Administrative Science Quarterly 5: 128-152.

Companys, Y. E. and McMullen, J. S. (2007). Strategic Entrepreneurs at Work: The Nature, Discovery, and Exploitation of Entrepreneurial Opportunities. Small Business Economics 28(4): 301-322.

Cook, T. D. and Campbell, D. T. (1979). Quasi-experimentation: Design and analysis issues for field settings. Chicago, Rand-McNally.

Cooke, P. (2001). Regional innovation systems, clusters, and the knowledge economy. Industrial and Corporate Change 10(4): 945-974.

Coombs, J. E. and Bierly, P. E. (2001). Looking through the kalidescope: Measuring technological capability and performance. Academy of Management Proceedings B1-7.

Cooper, R. G. (1993). Winning at new products. Reading MA, Addison-Wesley. 
Cortright, J. and Mayer, H. (2002). Signs of life: The growth of biotechnology centers in the U.S. , Publications of The Brookings Institution, Center on Urban and Metropolitan Policy.

Costa, C., Fontes, M. and Heitor, M. V. (2004). A methodological approach to the marketing process in the biotechnology-based companies. Industrial Marketing Management 33: 403-418.

Covin, J. G. and Slevin, D. P. (1988). The Influence of Organization Structure on the Utility of an Entrepreneurial Top Management Style. The Journal of Management Studies 25(3): 217.

Covin, J. G. and Slevin, D. P. (1989). Strategic Management Of Small Firms In Hostile And Benign E. Strategic Management Journal 10(1): 75.

Covin, J. G. and Slevin, D. P. (1991). A Conceptual Model of Entrepreneurship As Firm Behavior. Entrepreneurship Theory and Practice 16(1): 7.

Cronbach, L. J. (1951). Coefficient alpha and the internal structure of tests. Psychometrika 16(3): 297-333.

Cumby, J. and Conrod, J. (2001). Non-financial performance measures in the Canadian biotechnology industry. Journal of Intellectual Capital 2(3): 261-272.

Cyert, R. M. and March, J. G. (1963). A Behavioral Theory of the Firm. Englewood Cliffs, NJ, Prentice Hall.

Dawes, J. (1999). The relationship between subjective and objective company performance measures in market orientation research: Further empirical evidence. Marketing Bulletin 10: 65-75.

Dawes, J. (2000). Market orientation and company profitability: Further evidence incorporating longitudinal data. Australian Journal of Management 25(2): 173-199.

De Carolis, D. M. and Saparito, P. (2006). Social Capital, Cognition, and Entrepreneurial Opportunities: A Theoretical Framework. Entrepreneurship Theory and Practice 30(1): 41-56.

DeCarolis, D. M. and Deeds, D. L. (1999). The impact of stocks and flows of organizational knowledge on firm performance: An empirical investigation of the biotechnology industry. Strategic Management Journal 20: 953-968. 
Deng, S. and Dart, J. (1994). Measuring market orientation: a multi-factor, multi-item approach. Journal of Marketing Management 10(8): 725-742.

Denrell, J., Fang, C. and Winter, S. G. (2003). The economics of strategic opportunity. Strategic Management Journal 24(10): 977-990.

Denzin, N. K. (1978). The research act: A theoretical introduction to sociological methods. New York, McGraw-Hill.

Deshpandé, R. and Farley, J. U. (1998). Measuring market orientation generalization and synthesis. Journal of Market-Focused Management 2(3): 213-232.

Dickson, P. R. (1992). Toward a General Theory of Competitive Rationality. Journal of Marketing 56(1): 69-83.

Dillman, D. A. (1991). The Design and Administration of Mail Surveys. Annual Review of Sociology 17: 225-249.

Dorf, R. C. and Byers, T. H. (2005). Technology ventures: From idea to enterprise. Boston, MA, McGrawHill Higher Education.

Dosi, G. (1988). Sources, procedures, and microeconomic effects of innovation. Journal of Economic Literature 26(3): 1120-1171.

Drucker, P. F. (1985). Innovation and entrepreneurship. New York, NY, Harper \& Row Publishers, Inc.

Dutta, D. K. and Crossan, M. M. (2005). The Nature of Entrepreneurial Opportunities: Understanding the Process Using the 4I Organizational Learning Framework. Entrepreneurship Theory and Practice 29(4): 425-449.

Eckhardt, J. T. and Shane, S. A. (2003). Opportunities and entrepreneurship. Journal of Management 29(3): 333-349.

Ernst\&Young (2002). Beyond borders. The global biotechnology report 2002. London, Ernst \& Young.

Ernst\&Young (2004). Ernst \& Young's 2004 Biotechnology Reports-Beyond Borders: A Global Perspective. London, Ernst \& Young.

Ernst\&Young (2007). Beyond Borders: The global perspective. London, Ernst \& Young. 
Fiet, J. O. (2002). The systematic search for entrepreneurial discoveries. Westport, Conn. , Quorum Books.

Fosfuri, A. (2006). The licensing dilemma: Understanding the determinants of the rate of technology licensing. Strategic Management Journal 27: 1141-1158.

Fowlston, B. (1988). Licensing Biotechnology. International Journal of Technology Management 3(1-2): 51-62.

Freeman, J. (1982). Organizational life cycles and the natural selection processes. Research in organizational behavior. B. M. Staw and L. L. Cummings. Greenwich, CT, JAI Press. 4: 1-32.

Freund, R. J. and Wilson, W. J. (1998). Regression Analysis, Academic Press.

Gaglio, C. M. (1997). Opportunity identification: Review, critique and suggested research directions. Advances in Entrepreneurship, Firm Emergence and Growth. J. A. Katz and R. H. Brockhaus. Greenwitch, CT, JAI Press. 3.

Gaglio, C. M. (2004). The Role of Mental Simulations and Counterfactual Thinking in the Opportunity Identification Process. Entrepreneurship Theory and Practice 28(6): 533552.

Gaglio, C. M. and Katz, J. A. (2001). The psychological basis of opportunity identification: Entrepreneurial alertnes. Small Business Economics 16(2): 95.

Gaglio, C. M. and Taub, R. P. (1992). Entrepreneurs and opportunity recognition. Frontiers of Entrepreneurship Research. Wellesley, MA, Babson College: 136-147.

Gallini, N. T. and Wright, B. D. (1990). Technology Transfer under Asymmetric Information The RAND Journal of Economics 21(1): 147-160.

Gans, J., Hsu, D. and Stern, S. (2002). When does start-up innovation spur the gale of creative destruction? RAND Journal of Economics 33(4): 571-586.

Gartner, W. (1989). 'Who Is An Entrepreneur?' Is The Wrong Question. Entrepreneurship Theory and Practice 13(4): 47.

Gompers, P. A. and Lerner, J. (2001). The venture capital revolution. Journal of Economic Perspectives 15: 145-168. 
Goss, D. (2007). Reconsidering Schumpeterian opportunities: the contribution of interaction ritual chain theory. International Journal of Entrepreneurial Behaviour \& Research 13(1): 3-18.

Hage, J. and Dewar, R. (1973). Elite values versus organizational structure in predicting innovation. Administrative Science Quarterly 18: 279-290.

Hair, J., Anderson, R., Tatham, R. and Black, W. (1995). Multivariate data analysis with readings. New Jersey, Simon \& Schuster Company.

Hamel, G. and Prahalad, C. K. (1991). Corporate imagination and expeditionary marketing. Harvard Business Review 69(4): 81-92.

Hannan, M. (1998). Rethinking age dependence in organizational mortality: Logical formalizations. American Journal of Sociology 104: 126-164.

Harris, L. C. (2001). Market orientation and performance: Objective and subjective empirical evidence from UK companies. The Journal of Management Studies 38(1): 1743.

Harris, L. C. (2002). Measuring market orientation: Exploring a market oriented approach. Journal of Market-Focused Management 5: 239-270.

Hayek, F. (1945). The use of knowledge in society. American Economic Review 35(4): $519-530$.

Helfat, C. E. and Raubitschek, R. S. (2000). Product sequencing: co-evolution of knowledge, capabilities and products. Strategic Management Journal 21(10/11): 961-979.

Hellmann, T. and Puri, M. (2002). Venture capital and the professionalization of start-up firms: empirical evidence. Journal of Finance 57: 169-197.

Hills, G. E., Shrader, R. C. and Lumpkin, G. T. (1999). Opportunity recognition as a creative process. Frontiers of entrepreneurship research. P. D. Reynolds, W. D. Bygrave, S. Manigart, C. M. Mason, G. D. Meyer, H. J. Sapienza and K. G. Shaver. Wellesley, MA, Babson College.

Hills, G. E. and Singh, R. P. (2004). Opportunity recognition. Handbook of Entrepreneurial Dynamics: The Process of Business Creation. W. B. Gartner, K. G. Shaver, N. M. Carter and P. D. Reynolds. Thousand Oaks: CA, Sage Publications. 
Hills, G. E., Singh, R. P., Lumpkin, G. T. and Baltrušaitytė, J. (2004). Opportunity recognition: Examining how search formality and search processes relate to the reasons for pursuing entrepreneurship. Frontiers of entrepreneurship research. Wellesley, MA, Babson College.

Hindle, K. and Yencken, J. (2004). Public research commercialisation, entrepreneurship and new technology based firms: an integrated model. Technovation 24(10): 793.

Holcombe, R. G. (2003). The Origins of Entrepreneurial Opportunities. Austrian Economics 16(1): 25.

Holt, K., Geschka, H. and Peterlongo, G. (1984). Need assessment, a key to user-oriented product innovation. Chichester, John Wiley \& Sons Ltd.

Hsieh, C., Nickerson, J. A. and Zenger, T. R. (2007). Opportunity Discovery, Problem Solving and a Theory of the Entrepreneurial Firm. Journal of Management Studies 44(7): $1255-1277$.

Hurley, R. F. and Hult, G. T. M. (1998). Innovation, market orientation, and organizational learning: An integration and empirical examination. Journal of Marketing 62: $42-54$.

Im, S. and Workman, J. P. J. (2004). Market orientation, creativity, and new product performance in high-technology firms. Journal of Marketing 68: 114-132.

Jaworski, B. J. and Kohli, A. K. (1993). Market orientation: Antecedents and consequences. Journal of Marketing 57(3): 53.

John, G., Weiss, A. M. and Dutta, S. (1999). Marketing in technology-intensive markets: Toward a conceptual framework Journal of Marketing 63: 78-92.

Kara, A., Spillan, J. E. and DeShields, J. O. W. (2005). The effect of a market orientation on business performance: A study of small-sized service retailers using MARKOR scale. Journal of Small Business Management 43(2): 105-118.

Katz, J. A. and Gartner, W. B. (1988). Properties of emerging organizations. Academy of Management Review 13: 429-441.

Kelley, D. J. and Rice, M. P. (2001). Technology-based strategic actions in new firms: the influence of founding technology resources. Entrepreneurship Theory and Practice 26(1): 55-73. 
Kermani, F. and Bonacossa, P. (2003). Current and future prospects for the global biotechnology industry. Journal of Commercial Biotechnology 10(2): 154-161.

Khandwalla, P. N. (1987). Generators of Pioneering-Innovative Management: Some Indian. Organization Studies 8(1): 39.

Khilstrom, R. and Laffont, J. (1979). A general equilibrium entrepreneurial theory of firm formation based on risk aversion. Journal of Political Economy 87(4): 719-748.

Kirca, A. H., Jayachandran, S. and Bearden, W. O. (2005). Market orientation: A metaanalytic review and assessment of its antecedents and impact on performance. Journal of Marketing 69(April): 24-41.

Kirzner, I. (1973). Competition and entrepreneurship. Chicago, IL, University of Chicago Press.

Kirzner, I. (1979). Perception, Opportunity and Profit. Chicago, IL, University of Chicago Press.

Kirzner, I. (1980). The Primacy of Entrepreneurial Discovery. The Prime Mover of Progress. A. Seldon. London, The Institute of Economic Affairs: 5-30.

Kirzner, I. (1997). Entrepreneurial discovery and the competitive market process. An Austrian approach. Journal of Economic Literature 35: 60-85.

Klofsten, M. (1997). Management of the early development processes in technologybased firms. Technology, innovation and enterprise. The European experience. D. JonesEvans and M. Klofsten. London, MacMillan Press Ltd.

Knight, F. H. (1921). Risk, uncertainty and profit. Chicago, IL, University of Chicago Press.

Knight, G. A. (1997). Cross-cultural reliability and validity of a scale to measure firm entrepreneurial orientation. Journal of Business Venturing 12: 213-225.

Kogut, B. and Singh, H. (1988). The effect of national culture on the choice of entry mode. Journal of International Business Studies 19: 411-432.

Kohli, A. and Jaworski, B. (1990). Market orientation: The construct, research propositions, and managerial implications. Journal of Marketing 54(2): 1-18. 
Kohli, A. K., Jaworski, B. J. and Kumar, A. (1993). MARKOR: A measure of market orientation. JMR, Journal of Marketing Research 30(4): 467.

Kollmer, H. and Dowling, M. (2004). Licensing as a commercialisation strategy for new technology-based firms. Research Policy 33: 1141-1151.

Krueger, N. (1993). The impact of prior entrepreneurial exposure on perceptions. Entrepreneurship Theory and Practice 18(1): 5.

Krueger, N. F. (2000). The cognitive infrastructure of opportunity emergence. Entrepreneurship Theory and Practice 24(3): 5.

Krueger, N. F., Reilly, M. D. and Carsrud, A. L. (2000). Competing models of entrepreneurial intentions. Journal of Business Venturing 15(5,6): 411.

Kyriakopoulos, K. and Moorman, C. (2004). Tradeoffs in marketing exploitation and exploration strategies: The overlooked role of market orientation. International Journal of Research in Marketing 21: 219-240.

Langerak, F. (2001). Effects of market orientation on the behaviors of salespersons and purchasers, channel relationships, and performance of manufacturers. International Journal of Research in Marketing 18(3): 221-234.

Lemarié, S., Looze, M.-A. D. and Mangematin, V. (2000). Strategies of European SMEs in biotechnology: the role of size, technology and market. Scientometrics 47: 541-560.

Leonard-Barton, D. (1995). Wellsprings of knowledge: Building and sustaining the sources of innovation. Boston, MA, Harvard Business School Press.

Leonard-Barton, D. and Rayport, J. (1997). Spark innovation through empathic design. Harvard Business Review 75(November): 102-113.

Li, T. and Calantone, R. J. (1998). The impact of market knowledge competence on new product advantage: Conceptualization and empirical examination. Journal of Marketing 62(4): 13-29.

Llobrera, J. T., Meyer, D. R. and Nammacher, G. (2000). Trajectories of industrial districts: Impact of strategic intervention in medical districts. Economic Geography 76(1): 68-98.

Long, W. and McMullan, W. E. (1984). Mapping the New Venture Identification Process. Frontiers of Entrepreneurship Research. Wellesley, MA, Babson College. 
Loo, R. (2002). A caveat on using single-item versus multiple-item scales. Journal of Managerial Psychology 17(1/2): 68-76.

Loyd, L. (2007). Local venture investing at 5-year high. The Philadelphia Inquirer. Philadelphia.

Lumpkin, G. T. and Dess, G. G. (1996). Clarifying the entrepreneurial orientation construct and linking it to performance. Academy of Management Review 21: 135-172.

Lumpkin, G. T., Hills, G. E. and Shrader, R. C. (2001). Opportunity Recognition. $\underline{A}$ CEAE White Paper.

Lumpkin, G. T., Hills, G. E. and Shrader, R. C. (2004). Opportunity recognition. Entrepreneurship: The Way Ahead. H. P. Welsch. London, Routledge: 73-90.

Lumpkin, G. T. and Lichtenstein, B. B. (2005). The Role of Organizational Learning in the Opportunity-Recognition Process. Entrepreneurship Theory and Practice 29(4): 451.

Maidique, M. A. and Hayes, R. H. (1984). The Art of High-Technology Management. Sloan Management Review (pre-1986) 25(2): 17.

Manion, M. T., Hills, G. E., Lumpkin, G. T. and Shrader, R. C. (2000). The recognition of new business opportunities: The search for a model. American Marketing Association. Conference Proceedings 11: 317.

March, J. G. (1991). Exploration and exploitation in organizational learning. Organization Science 2: 71-87.

Marvel, M. R. and Lumpkin, G. T. (2007). Technology Entrepreneurs' Human Capital and Its Effects on Innovation Radicalness Entrepreneurship Theory and Practice 31(6): 807-828.

Mason, C. and Stark, M. (2004). What do investors look for in a business plan? A comparison of the investment criteria of bankers, venture capitalists and business angels. International Small Business Journal 22(3): 227-249.

Matsuno, K. and Mentzer, J. T. (2000). The effects of strategy type on the market orientation-performance relationship. Journal of Marketing 64(4): 1-16.

Matsuno, K., Mentzer, J. T. and Ozsomer, A. (2002). The effects of entrepreneurial proclivity and market orientation on business performance. Journal of Marketing 66(3): 18. 
Mavondo, F. T., Chimhanzi, J. and Stewart, J. (2005). Learning orientation and market orientation, relationship with innovation, human resource practices and performance. European Journal of Marketing 39(11/12): 1235-1263.

McBeath, I. and Bacha, J. (2001). Mergers and acquisitions: A consideration of the drivers and hurdles. Journal of Commercial Biotechnology 8(2): 147-154.

McClelland, D. (1961). The achieving society. Princeton, NJ, D.Van Nostrand.

McCutchen, W. W. J. and Swamidass, P. M. (2004). Motivations for strategic alliances in the pharmaceutical/biotech industry: Some new findings. Journal of High Technology Management Research 15: 197-214.

McKelvey, M., Rickne, A. and Laage-Hellman, J. (2004). Stylized facts about innovation processes in modern biotechnology. The economic dynamics of modern biotechnology. M. McKelvey, A. Rickne and J. Laage-Hellman. Cheltenham, UK, Edward Elgar Publishing Limited: 43-57.

McKelvie, A. and Wiklund, J. (2004). How knowledge affects opportunity discovery and exploitation among new ventures in dynamic markets. Research in Entrepreneurship and Management. J. Butler. Greenwich, CT, Information Age Publishing. 4: 219-240.

McMullen, J. S., Plummer, L. A. and Acs, Z. J. (2007). What is an Entrepreneurial Opportunity? Small Business Economics 28(4): 273-283.

Miller, D. (1983). The correlates of entrepreneurship in three types of firms. Management Science (pre-1986) 29(7): 770.

Miller, D. and Friesen, P. H. (1982). Innovation in Conservative and Entrepreneurial Firms: Two Models of Strategic Momentum. Strategic Management Journal 3(1): 1.

Miller, K. D. (2007). Risk and rationality in entrepreneurial processes. Strategic Entrepreneurship Journal 1(1): 57-74.

Mitchell, R. K., Busenitz, L. W., Bird, B., Gaglio, C. M., McMullen, J. S., Morse, E. A. and Smith, J. B. (2007). The Central Question in Entrepreneurial Cognition Research 2007. Entrepreneurship Theory and Practice 31(1): 1-27.

Mitchell, R. K., Smith, B., Seawright, K. W. and Morse, E. A. (2000). Cross-cultural cognitions and the venture creation decision. Academy of Management Journal 43(5): 974. 
Mueller, P. (2007). Exploiting Entrepreneurial Opportunities: The Impact of Entrepreneurship on Growth. Small Business Economics 28(4): 355-362.

Murphy, P. J. and Shrader, R. C. (2004). Entrepreneurial Discovery and Prediction: Knowledge-based Shadow Options for Research Efforts. 64th Annual Meeting of the Academy of Management. New Orleans, LA.

Narver, J. C. and Slater, S. F. (1990). The Effect of a Market Orientation on Business Profitability. Journal of Marketing 54(4): 20.

Narver, J. C., Slater, S. F. and MacLachlan, D. L. (2004). Responsive and proactive market orientation and new-product success. Journal of Product Innovation Management 21: $334-347$.

Nelson, R. and Winter, S. (1977). In search of a useful theory of innovation. Research Policy 6(1): 36-76.

Nelson, R. R. and Winter, S. G. (1982). The evolutionary theory of economic change. Cambridge, MA, Belknap Press of Harvard University Press.

Nemeth, C. (1997). Managing innovation: When less is more. California Management Review 40(1): 59-74.

Ngai, J. C. H. and Ellis, P. (1998). Market orientation and business performance: Some evidence from Hong Kong. International Marketing Review 15(2): 119-139.

Nilsson, A. (2001). Biotechnology firms in Sweden. Small Business Economics 17(1/2).

Nunnally, J. C. (1978). Psychometric theory. New York, McGraw Hill.

Nunnally, J. C. and Bernstein, I. H. (1994). Psychometric Theory. New York, McGraw Hill.

O’Connor, G. C. (1998). Market learning and radical innovation: A cross case comparison of eight radical innovation projects. Journal of Product Innovation Management 15: 151-166.

O'Connor, G. C. and Veryzer, R. W. (2001). The nature of market visioning for technology-based radical innovation. Journal of Product Innovation Management 18: 231-246. 
Oakey, R. P. (2003). Technical entrepreneurship in high technology small firms: Some observations on the implications for management. Technovation 23(8): 679.

Ozgen, E. and Baron, R. A. (2007). Social sources of information in opportunity recognition: Effects of mentors, industry networks, and professional forums. Journal of Business Venturing 22(2): 174-192.

Park, J. S. (2005). Opportunity recognition and product innovation in entrepreneurial hitech start-ups: a new perspective and supporting case study. Technovation 25: 739-752.

Pavitt, K. (1985). Patent statistics as indicators of innovative activities: possibilities and problems. Scientometrics 7(1-2): 77-99.

Pech, R. J. and Cameron, A. (2006). An entrepreneurial decision process model describing opportunity recognition. European Journal of Innovation Management 9(1): 61 .

Pelham, A. M. and Wilson, D. T. (1996). A longitudinal study of the impact of marketing structure, firm structure, strategy, and marketing orientation culture on dimensions of small-firm performance. Journal of the Academy of Marketing Science 24(1): 27-43.

Penrose, E. T. (1959). The Theory of the Growth of the Firm. Oxford, Basil Blackwell.

Perrow, C. B. (1970). Organizational analysis: A sociological view. Belmont, CA, Brooks / Cole Publishing.

Perry, M. L. and Shao, A. T. (2002). Market orientation and incumbent performance in dynamic markets. European Journal of Marketing 36(9/10): 1140-1153.

Peter, J. P. (1979). Reliability: A review of psychometric basics and recent marketing practices. Journal of Marketing Research 16(February): 6-17.

Peter, J. P. (1981). Construct validity: A review of basic issues and marketing practices. Journal of Marketing Research 18(May): 133-145.

Peterson, R. A. (1994). A Meta-analysis of Cronbach's coefficient alpha. Journal of Consumer Research 21(2): 381-392.

Peterson, R. T. (1989). Small business adoption of the marketing concept versus other business strategies. Journal of Small Business Management 27(1): 37-46. 
Pfirrmann, O. (1999). Neither soft nor hard-Pattern of development of new technology based firms in biotechnology. Technovation 19: 651-659.

Podsakoff, P. M. and Organ, D. W. (1986). Self-reports in organizational research: Problems and prospects. Journal of Management 12(4): 531-544.

PriceWaterhouseCoopers (2005). Money for growth. The European Technology Investment Report 2005.

Ramani, S. V. and Looze, M.-A. d. (2002). Using patent statistics as knowledge base indicators in the biotechnology sectors: An application to France, Germany and the U.K. Scientometrics 54(3): 319-346.

Renko, M. (2006a). Market Orientation in Markets for Technology - Evidence from Biotechnology Ventures. Turku, Finland, Turun kauppakorkeakoulun julkaisuja.

Renko, M. (2006b). Sourcing market knowledge in biotechnology. Regional development in the knowledge economy. P. Cooke and A. Piccaluga, Routledge and Regional Studies Association: 111-134.

Renko, M., Carsrud, A., Brannback, M. and Jalkanen, J. (2005). Building market orientation in biotechnology SMEs: Balancing scientific advances. International Journal of Biotechnology 7(4): 250-268.

Reynolds, P. D. (2007). Entrepreneurship in the United States. The future is now., Springer.

Rice, M., Kelley, D., Peters, L. and O'Connor, G. C. (2001). Radical innovation: triggering initiation of opportunity recognition and evaluation. R\&D Management $31(4)$ : 409-420.

Roberts, E. B. (1991). Entrepreneurs in high technology, lessons from MIT and beyond. New York, Oxford University Press, Inc.

Rodriguez Cano, C., Carrillat, F. A. and Jaramillo, F. (2004). A meta-analysis of the relationship between market orientation and business performance: evidence from five continents. International Journal of Research in Marketing 21: 179-200.

Rothaermel, F. T. and Deeds, D. L. (2004). Exploration and exploitation alliances in biotechnology: A system of new product development. Strategic Management Journal 25: 201-221. 
Rothwell, R. (1992). Successful industrial innovation: critical factors for the 1990s. R\&D Management 22(3): 221-239.

Saemundsson, R. and Dahlstrand, A. L. (2005). How business opportunities constrain young technology based firms from growing into medium-sized firms. $\underline{\text { Small Business }}$ Economics 24: 113-129.

Sanders, M. (2007). Scientific Paradigms, Entrepreneurial Opportunities and Cycles in Economic Growth. Small Business Economics 28(4): 339-354.

Santomero, A. M. (2002). Forces shaping Philadelphia's future. Business Review, Federal Reserve Bank of Philadelphia.

Sanz-Velasco, S. A. (2006). Opportunity development as a learning process for entrepreneurs. International Journal of Entrepreneurial Behaviour \& Research 12(5): 251 271.

Sanz-Velasco, S. A. and Magnusson, M. G. (2003). Conceptualizing Opportunity Development in Knowledge-intensive Ventures. Research Workshop: Innovations and Entrepreneurship in Biotech/Pharma and IT/Telecom. Göteborg, Sweden.

Sarasvathy, S. (2001a). Efficient reasoning in expert entrepreneurial decisions: existence and bounds. Academy of Management, Best Paper Proceedings.

Sarasvathy, S. D. (2001b). Causation and effectuation: Toward a theoretical shift from economic inevitability to entrepreneurial contingency. Academy of Management Review 26(2).

Sarasvathy, S. D., Venkataraman, S., Dew, N. and Velamuri, R. (2003). Three views of entrepreneurial opportunity. Handbook of entrepreneurship research. An interdisciplinary survey and introduction. . Z. J. Acs and D. B. Audretsch. New York, Springer Science + Business Media: 141-160.

Schollhammer, H. (1982). Internal corporate entrepreneurship. Encyclopedia of Entrepreneurship. C. A. Kent, D. L. Sexton and K. H. Vesper. Englewood Cliffs, NJ, Prentice-Hall.

Schroeder, R. G., Ven, A. H. V. d., Scudder, G. D. and Polley, D. (2000). The Development of Innovation Ideas. Research on the Management of Innovation, The Minnesota Studies A. H. VandeVen, H. L. Angle and M. S. Poole. New York, Oxford University Press: 107-134. 
Schumpeter, J. A. (1934a). Entrepreneurship as innovation. Entrepreneurship - the social science view. R. Swedberg. Oxford, UK, Oxford University Press. 2000: 51-75.

Schumpeter, J. A. (1934b). The theory of economic development. London, Transaction Publishers.

Shadish, W. R., Cook, T. D. and Campbell, D. T. (2002). Experimental and quasiexperimental designs for generalized causal inference. Boston, MA, Houghton Mifflin Company.

Shah, S. K. and Tripsas, M. (2007). The accidental entrepreneur: the emergent and collective process of user entrepreneurship. Strategic Entrepreneurship Journal 1(1): 123 140.

Shane, S. (2000). Prior knowledge and the discovery of entrepreneurial opportunities. Organization Science 11(4): 448.

Shane, S. (2001). Technology opportunities and new firm creation. Management Science 47(2): 205-220.

Shane, S. (2003). A general theory of entrepreneurship. The individual-opportunity nexus. Cheltenham, UK, Edward Elgar.

Shane, S. and Venkataraman, S. (2000). The promise of entrepreneurship as a field of research. Academy of Management Review 25(1): 217-226.

Sheen, M. R. (2003). Evolving relations between the pharmaceutical industry and public sector research. International Journal of Technology Management 25(3/4): 268-283.

Shepherd, D. A., McMullen, J. S. P. and Jennings, D. (2007). The formation of opportunity beliefs: overcoming ignorance and reducing doubt (p 75-95). Strategic Entrepreneurship Journal 1(1): 75-95.

Shepherd, D. A. and Zacharakis, A. (1999). Conjoint analysis: A new methodological approach for researching the decision policies of venture capitalists. Venture Capital: An International Journal of Entrepreneurial Finance 1(3): 197-217.

Siguaw, J. A., Simpson, P. M. and Baker, T. L. (1998). Effects of supplier market orientation on distributor market orientation and the channel relationship: the distributor perspective. Journal of Marketing 62: 99-111. 
Singh, R., Hills, G., Hybels, R. and Lumpkin, G. T. (1999). Opportunity recognition through social network characteristics of entrepreneurs. Frontiers of Entrepreneurship Research. P. Reynolds, W. Bygrave, S. Manigart, C. Mason, G. Meyer and H. Sapienza. Wellesley, MA., Babson College Press: 228- 241.

Singh, R. P. (2000). Entrepreneurial opportunity recognition through social networks. New York, NY, Garland Publishing Inc. .

Singh, R. P. (2001). A comment on developing the field of entrepreneurship through the study of opportunity recognition and exploitation. Academy of Management. The Academy of Management Review 26(1): 10.

Slater, S. F. and Narver, J. C. (2000). The positive effect of a market orientation on business profitability: A balanced replication. Journal of Business Research 48(1): 69-73.

Stinchcombe, A. L. (1965). Social structure and organizations. Handbook of organizations. J. G. March. Chicago, Rand McNally: 142-193.

Strotmann, H. (2007). Entrepreneurial Survival. Small Business Economics 28(1): 84102.

Swedberg, R. (2000). The social science view of entrepreneurship: Introduction and practical applications. Entrepreneurship - The social science view. R. Swedberg. Oxford, UK, Oxford University Press.

Takayama, M. and Watanabe, C. (2002). Myth of market needs and technology seeds as a source of product innovation - an analysis of pharmaceutical new product development in an anti-hypertensive product innovation. Technovation 22(353-362).

Teach, R. D., Schwartz, R. G. and Tarpley, F. A. (1989). The recognition and exploitation of opportunity in the software industry: A study of surviving firms. Frontiers of Entrepreneurship Research. Wellesley, MA, Babson College. 3: 383-397.

Teece, D. J. (1986). Profiting from technological innovation. Research Policy 15(6): 285305.

Teece, D. J. (2007). Explicating dynamic capabilities: the nature and microfoundations of (sustainable) enterprise performance. Strategic Management Journal 28(13): 1319-1350.

Thieme, R. J. and Song, M. (2002). The effect of market intelligence acquisition on radical product innovation performance in entrepreneurial firms. American Marketing Association Conference Proceedings, Chicago. 
Thornton, P. H. (1999). The sociology of entrepreneurship. Annual Review of Sociology 25: $19-46$.

Tushman, M. L. and Anderson, P. (1986). Technological Discontinuities and Organizational Environments Administrative Science Quarterly 31(3): 439-465.

Tyebjee, T. T. and Bruno, A. V. (1984). A model of venture capitalist investment activity. Management Science 30(9): 1051-1066.

Usher, A. P. (1954). A history of mechanical inventions. Cambridge, Mass. , Harvard University Press.

Veldhuizen, E., Hultink, E. J. and Griffin, A. (2004). Exploring antecedents and consequences of market information processing for more innovative products. 11th International Product Development Management Conference. Dublin, Ireland.

Venkatarman, S. (1997). The distinctive domain of entrepreneurship research: an editor's perspective. Advances in Entrepreneurship, Firm Emergence and Growth. J. Katz and R. Brockhaus. Greenwich, CT, JAI Press.

Vesper, K. (1993). New Venture Mechanics. Englewood Cliffs, NJ., Prentice Hall.

Webb, E. J., Campbell, D. T., Schwartz, R. D. and Sechrest, L. (1966). Unobtrusive measures. Chicago, Rand McNally.

Wennekers, S. and Thurik, R. (1999). Linking Entrepreneurship and Economic Growth. Small Business Economics 13(1): 27-56.

Wiklund, J. (1999). The sustainability of the entrepreneurial orientation--performance relationship. Entrepreneurship Theory and Practice 24(1): 37.

Wiklund, J. and Shepherd, D. (2003). Knowledge based resources, entrepreneurial orientation, and the performance of small and medium-sized businesses. $\underline{\text { Strategic }}$ Management Journal 24: 1307-1314.

Wiklund, J. and Shepherd, D. (2005). Entrepreneurial orientation and small business performance: a configurational approach. Journal of Business Venturing 20: 71-91.

Zahra, S. (1991). Predictors and financial outcomes of corporate entrepreneurship: an explorative study. Journal of Business Venturing 6(259-285). 
Zahra, S. and Covin, J. (1995). Contextual influence on the corporate entrepreneurshipperformance relationship: A longitudinal analysis. Journal of Business Venturing 10: 4358.

Zahra, S. A. (1993). Environment, corporate entrepreneurship, and financial performance: A taxonomic approach. Journal of Business Venturing 8(4): 319. 


\section{Appendix 1: Questionnaire}

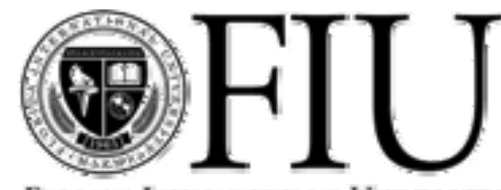

FUORDA INTERNATTONLL UNWERSHY

Miamis public research aniversity

\section{SURVEY QUESTIONNAIRE}

\section{RESEARCH ON ENTREPRENEURIAL OPPORTUNITIES IN BIOTECHNOLOGY FIRMS}

Dear Biotechnology Professional,

Thank you for your assistance in this research project that will help to understand the mechanisms through which market knowledge contributes to biotechnology firm success. I recognize that your time is extremely valuable.

Please follow the instructions on the survey form to fill in the blanks and to circle or check the answers of your choice. If you have any comments on the survey, please do not hesitate to write them down in the space provided on the last page. Once you have filled in the survey, please return it in the stamped envelope.

Because of the nature of the survey, it is important that you complete the questionnaire yourself. Please return the completed questionnaire as soon as possible.

Sincerely,

Maija Renko, D.Sc.

Visiting Assistant Professor

Eugenio Pino and Family Global Entrepreneurship Center

Florida International University, Miami

Maija.renko@,fiu.edu

786-218-2739

\begin{tabular}{|c|c|}
\hline Company name & $\begin{array}{l}\text { Year } \\
\text { founded }\end{array}$ \\
\hline Your name & \\
\hline Your position & \\
\hline Your e-mail address & \\
\hline $\begin{array}{l}\text { Your highest earned } \\
\text { educational degree }\end{array}$ & \\
\hline $\begin{array}{l}\text { Field of this highest earned } \\
\text { educational degree }\end{array}$ & \\
\hline Today's date & \\
\hline
\end{tabular}




\section{Section A}

1. Who are the customers of your firm?

2. Who are the competitors of your firm?

3. What are the most important sources of market related data for your firm?

4. What kinds of challenges are there when you try to integrate market data into your research and development $(\mathrm{R} \& \mathrm{D})$ ?

5. How would you describe the relations between people working in marketing or sales in your firm and other "departments", like R\&D? 


\section{Section B}

\begin{tabular}{|c|c|c|c|c|c|}
\hline $\begin{array}{l}\text { Please rank these performance indicators with the scale } \\
\text { given on the right. } \\
\text { Please circle one number for each statement. }\end{array}$ & $\begin{array}{c}1 \\
\text { very } \\
\text { weak } \\
\end{array}$ & $\begin{array}{c}2 \\
\text { weak }\end{array}$ & $\begin{array}{c}3 \\
\text { neutral }\end{array}$ & $\begin{array}{c}4 \\
\operatorname{good}\end{array}$ & $\begin{array}{c}5 \\
\text { very } \\
\text { good }\end{array}$ \\
\hline $\begin{array}{l}\text { 1.Our firm's overall performance relative to major } \\
\text { competitors last year. }\end{array}$ & 1 & 2 & 3 & 4 & 5 \\
\hline $\begin{array}{l}\text { 2. Our firm's success in completing business deals with } \\
\text { other firms last year. }\end{array}$ & 1 & 2 & 3 & 4 & 5 \\
\hline $\begin{array}{l}\text { 3. Capital invested in our firm last year relative to major } \\
\text { competitors. }\end{array}$ & 1 & 2 & 3 & 4 & 5 \\
\hline $\begin{array}{l}\text { 4. Our firm's progress in the development of our lead } \\
\text { product last year. }\end{array}$ & 1 & 2 & 3 & 4 & 5 \\
\hline $\begin{array}{l}\text { 5.Our firm's progress in overall product development } \\
\text { last year. }\end{array}$ & 1 & 2 & 3 & 4 & 5 \\
\hline $\begin{array}{l}\text { 6. Only firms with sales: Our firm's market share } \\
\text { growth in our primary market last year. }\end{array}$ & 1 & 2 & 3 & 4 & 5 \\
\hline $\begin{array}{l}\text { 7. Only firms with sales: Our firm's sales growth last } \\
\text { year. }\end{array}$ & 1 & 2 & 3 & 4 & 5 \\
\hline
\end{tabular}

\section{Section C}

\begin{tabular}{|c|c|c|c|c|c|}
\hline $\begin{array}{l}\text { To what extent does each of the following } \\
\text { philosophies help guide your business operation? } \\
\text { For each statement on the left, please circle one } \\
\text { number. }\end{array}$ & $\begin{array}{l}1 \\
\text { Does not } \\
\text { describe } \\
\text { my firm } \\
\text { at all }\end{array}$ & $\begin{array}{l}\quad 2 \\
\text { Does not } \\
\text { describe } \\
\text { my firm }\end{array}$ & $\begin{array}{c}3 \\
\text { Neutral }\end{array}$ & $\begin{array}{c}4 \\
\text { Describes } \\
\text { my firm }\end{array}$ & $\begin{array}{c}5 \\
\text { Describes } \\
\text { my firm } \\
\text { very well }\end{array}$ \\
\hline $\begin{array}{l}\text { 1. The key to business success is producing quality } \\
\text { goods and services at a reasonable cost. Good } \\
\text { products and services sell themselves. If possible, } \\
\text { products and services should be standardized to } \\
\text { keep costs down. }\end{array}$ & 1 & 2 & 3 & 4 & 5 \\
\hline $\begin{array}{l}\text { 2. The key to business success lies in persuading } \\
\text { potential customers to buy your goods and } \\
\text { services, through advertising, personal selling, or } \\
\text { other means. Potential customers must be informed } \\
\text { and convinced of the benefits of the products. }\end{array}$ & 1 & 2 & 3 & 4 & 5 \\
\hline $\begin{array}{l}\text { 3. The key to business success is to integrate all } \\
\text { company activities and personnel toward satisfying } \\
\text { customers, while providing satisfactory profits to } \\
\text { the firm. The firm should find out what benefits } \\
\text { customers want and then provide these benefits } \\
\text { through goods and services. }\end{array}$ & 1 & 2 & 3 & 4 & 5 \\
\hline
\end{tabular}


4. The key to business success lies in satisfying the important "publics" of the company. These publics include customers, employees, stockholders, governmental agencies, suppliers, 1 2 3 4 5 and the public at large. All of their interests should be considered when making decisions.

5. The key to business success is the ability and will to acquire a substantial technological background and use it in the development of new products / services. This includes the activities of $\mathrm{R} \& \mathrm{D}$ as well as technological scanning. Success is achieved by being more innovative than competitors.

Note: In the original questionnaire the line spacing and font were different from what is shown here, and the sections followed directly after one another. Here, the dissertation margin requirements force extra cut to the questionnaire. 


\section{Section D}

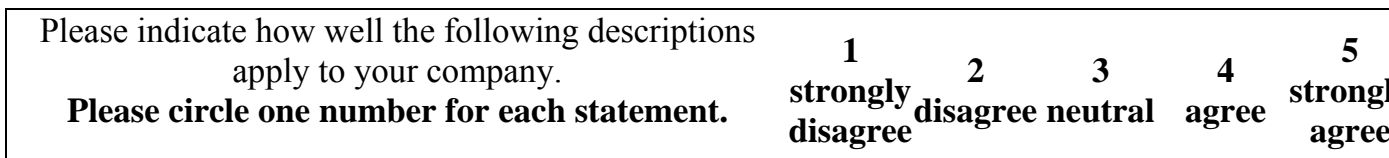

1. Our company meets end-customers or potential endcustomers of our products at least once a year to find out what their future needs are.

2. Our company meets opinion leaders (e.g. recognized medical doctors) at least once a year to find out about

$\begin{array}{lllll}1 & 2 & 3 & 4 & 5\end{array}$
the future needs of our end-customers.

3. Individuals from our R\&D and / or manufacturing department interact directly with customers to learn how to serve them better.

\begin{tabular}{|c|c|c|c|c|c|}
\hline 4. Our company conducts market research in-house. & 1 & 2 & 3 & 4 & 5 \\
\hline 5. Our company outsources market research. & 1 & 2 & 3 & 4 & 5 \\
\hline $\begin{array}{l}\text { 6. Our company subscribes to industry (market) } \\
\text { databases }\end{array}$ & 1 & 2 & 3 & 4 & 5 \\
\hline
\end{tabular}

7. Our company is slow to detect changes in our customers' or potential customers' product/service $\begin{array}{lllll}1 & 2 & 3 & 4 & 5\end{array}$ preferences.

8. We often talk with or survey those who can influence $\quad \begin{array}{llllll}1 & 2 & 3 & 4 & 5\end{array}$ our end-users purchases (e.g. medical doctors)

9. We collect industry information by informal means (e.g. lunch with industry friends)

10. In our company intelligence on our competitors is generated independently by several individuals / departments.

11. Our company is slow to detect fundamental shifts in our industry (e.g. competition, technology, regulation).

12. Our company periodically reviews the likely effect of changes in our business environment on customers $\begin{array}{lllll}1 & 2 & 3 & 4 & 5\end{array}$ (e.g. regulation, competition, technology)

13. A lot of informal "hall talk" in our company concerns our competitors' tactics or strategies.

$\begin{array}{lllll}1 & 2 & 3 & 4 & 5\end{array}$

14. Our company holds regular interdepartmental meetings to discuss market trends and developments 


\begin{tabular}{|c|c|c|c|c|c|}
\hline $\begin{array}{l}\text { Please indicate how well the following descriptions } \\
\text { apply to your company. } \\
\text { Please circle one number for each statement. }\end{array}$ & $\begin{array}{l}1 \\
\text { strongly } \\
\text { disagree }\end{array}$ & $\begin{array}{c}2 \\
\text { disagree }\end{array}$ & $\begin{array}{c}3 \\
\text { neutral }\end{array}$ & $\begin{array}{c}4 \\
\text { agree }\end{array}$ & $\begin{array}{c}5 \\
\text { strongly } \\
\text { agree }\end{array}$ \\
\hline $\begin{array}{l}\text { 15. Our company holds regular meetings with other } \\
\text { companies to discuss market trends and developments. }\end{array}$ & 1 & 2 & 3 & 4 & 5 \\
\hline $\begin{array}{l}\text { 16. Our company's marketing personnel / business } \\
\text { development personnel spends time discussing } \\
\text { customers' future needs with the other functions. }\end{array}$ & 1 & 2 & 3 & 4 & 5 \\
\hline $\begin{array}{l}\text { 17. Our company periodically circulates documents } \\
\text { (e.g. newspapers, e-mail alerts) that provide } \\
\text { information on customers. }\end{array}$ & 1 & 2 & 3 & 4 & 5 \\
\hline $\begin{array}{l}\text { 18. When something important happens to customers in } \\
\text { our (potential) markets, the whole company knows } \\
\text { about it within a short period. }\end{array}$ & 1 & 2 & 3 & 4 & 5 \\
\hline $\begin{array}{l}\text { 19. Our company disseminates data on customer } \\
\text { satisfaction at all levels in the company on a regular } \\
\text { basis. }\end{array}$ & 1 & 2 & 3 & 4 & 5 \\
\hline $\begin{array}{l}\text { 20. There is minimal communication between people in } \\
\text { this firm concerning market developments. }\end{array}$ & 1 & 2 & 3 & 4 & 5 \\
\hline $\begin{array}{l}21 \text {. There is a lot of market related communication } \\
\text { between individuals in our top management team. }\end{array}$ & 1 & 2 & 3 & 4 & 5 \\
\hline $\begin{array}{l}\text { 22. When someone in our firm finds out something } \\
\text { important about the market (e.g. customers, } \\
\text { competitors), (s)he is slow to share this information } \\
\text { with others. }\end{array}$ & 1 & 2 & 3 & 4 & 5 \\
\hline $\begin{array}{l}\text { 23. Our company interacts with regulators and } \\
\text { legislators that determine industry standards. }\end{array}$ & 1 & 2 & 3 & 4 & 5 \\
\hline $\begin{array}{l}\text { 24. Understanding markets drives new product } \\
\text { development efforts in this company. }\end{array}$ & 1 & 2 & 3 & 4 & 5 \\
\hline $\begin{array}{l}\text { 25. For one reason or another, our company tends to } \\
\text { ignore changes in our customer's product/service needs } \\
\text { (e.g. make no response to the changes) }\end{array}$ & 1 & 2 & 3 & 4 & 5 \\
\hline $\begin{array}{l}\text { 26. Our company periodically reviews our } \\
\text { product/service development efforts to ensure that they } \\
\text { are in line with what customers or potential customers } \\
\text { want. }\end{array}$ & 1 & 2 & 3 & 4 & 5 \\
\hline $\begin{array}{l}\text { 27. Our business plans are driven more by } \\
\text { technological advances than by market research. }\end{array}$ & 1 & 2 & 3 & 4 & 5 \\
\hline
\end{tabular}




\begin{tabular}{|c|c|c|c|c|c|}
\hline $\begin{array}{l}\text { Please indicate how well the following descriptions } \\
\text { apply to your company. } \\
\text { Please circle one number for each statement. }\end{array}$ & $\underset{\text { strongly }_{d}}{1}$ & $\begin{array}{l}2 \\
\text { lisagree }\end{array}$ & $\begin{array}{c}3 \\
\text { neutral }\end{array}$ & $\begin{array}{c}4 \\
\text { agree }\end{array}$ & $\begin{array}{c}5 \\
\text { strongly } \\
\text { agree }\end{array}$ \\
\hline $\begin{array}{l}\text { 28. Several departments get together periodically to } \\
\text { plan a response to changes taking place in our business } \\
\text { environment. }\end{array}$ & 1 & 2 & 3 & 4 & 5 \\
\hline $\begin{array}{l}\text { 29. Our firm gets together periodically with other } \\
\text { firms/organizations to plan a response to changes taking } \\
\text { place in our business environment. }\end{array}$ & 1 & 2 & 3 & 4 & 5 \\
\hline $\begin{array}{l}\text { 30. The product lines we develop depends more on } \\
\text { internal politics than real market needs. }\end{array}$ & 1 & 2 & 3 & 4 & 5 \\
\hline $\begin{array}{l}\text { 31. We are quick to respond to changes in the way our } \\
\text { competitors behave. }\end{array}$ & 1 & 2 & 3 & 4 & 5 \\
\hline $\begin{array}{l}\text { 32. The activities of the different departments or } \\
\text { functions in our company are well coordinated. }\end{array}$ & 1 & 2 & 3 & 4 & 5 \\
\hline $\begin{array}{l}\text { 33. Our company takes no action on customer's } \\
\text { complaints. }\end{array}$ & 1 & 2 & 3 & 4 & 5 \\
\hline $\begin{array}{l}\text { 34. Our company educates customers (or potential } \\
\text { customers) in the use of our products. }\end{array}$ & 1 & 2 & 3 & 4 & 5 \\
\hline $\begin{array}{l}\text { 35. Even if our company came up with a good } \\
\text { marketing plan, our company probably would not be } \\
\text { able to implement it in a timely fashion. }\end{array}$ & 1 & 2 & 3 & 4 & 5 \\
\hline $\begin{array}{l}\text { 36. Our company has little interaction with industry } \\
\text { regulators and legislators. }\end{array}$ & 1 & 2 & 3 & 4 & 5 \\
\hline $\begin{array}{l}\text { 37. When we find out that customers are unhappy with } \\
\text { the quality of our product / service, we take corrective } \\
\text { action immediately. }\end{array}$ & 1 & 2 & 3 & 4 & 5 \\
\hline $\begin{array}{l}\text { 38. When a product of our company is (will be) on the } \\
\text { market we modify (will modify) it if our customers } \\
\text { would like us to do so. }\end{array}$ & 1 & 2 & 3 & 4 & 5 \\
\hline
\end{tabular}




\section{Section E}

\begin{tabular}{|l|l|}
\hline Since June 2004, what is the number of ... & $\begin{array}{c}\text { Please insert number in } \\
\text { this column }\end{array}$ \\
\hline $\begin{array}{l}\text { 1. New inventions for which the firm has filed } \\
\text { domestic or international patent application(s): }\end{array}$ & \\
\hline $\begin{array}{l}\text { 2. Therapeutic areas where these inventions are } \\
\text { useful (your own estimate): }\end{array}$ & \\
\hline $\begin{array}{l}\text { 3. End products that are / have been developed } \\
\text { based on this/these inventions in your firm or your } \\
\text { partners: }\end{array}$ & \\
\hline $\begin{array}{l}\text { 4. Domestic patent applications: } \\
\text { 8. New product introductions to the markets: }\end{array}$ & \\
\hline $\begin{array}{l}\text { 5. International patent applications (The same } \\
\text { application submitted to multiple countries counts } \\
\text { as one): }\end{array}$ & \\
\hline
\end{tabular}




\section{Section $\mathbf{F}$}

Please circle the number on the scale (in the middle column) that best describes your company:

$\mathbf{2}=$ description in the left hand colum describes your firm more than description in the right hand column

$\mathbf{1}=$ description in the left hand column describes your firm very well
$3=$ neutral

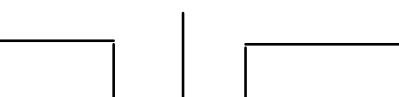

$\mathbf{4}=$ description in the right hand column describes your firm more than description in the left hand column

$\mathbf{5}=$ description in the right hand column describes your firm very well

A. How many new lines of products or services has your firm marketed since the year 2000?

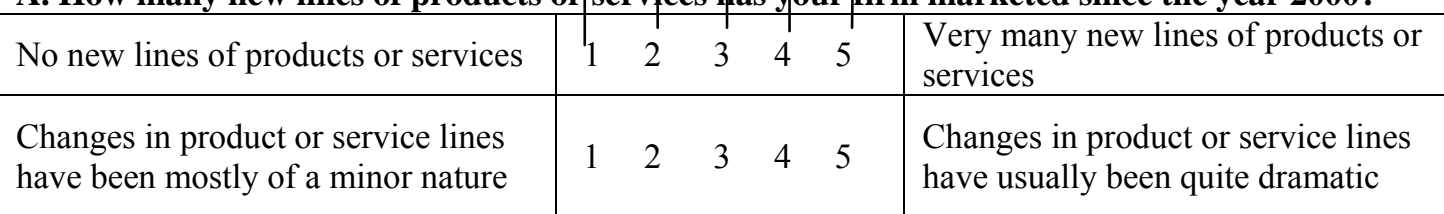

B. How many new lines of products or services does your firm have under research and development right now?

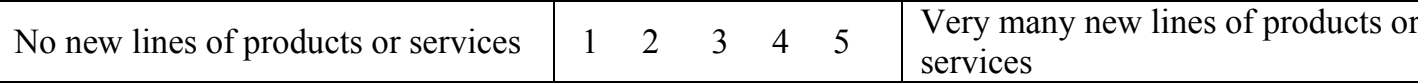

C. In general, top managers in my firm favor....

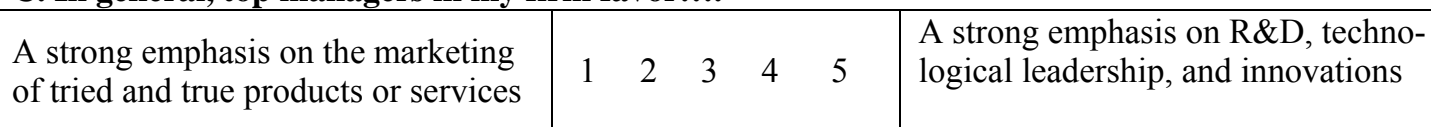

D. In dealing with competitors, my firm ...

\begin{tabular}{|c|c|c|c|c|c|c|}
\hline $\begin{array}{l}\text { Is very seldom the first business to } \\
\text { introduce or involve in the } \\
\text { development of new } \\
\text { products/services, administrative } \\
\text { techniques, operating technologies, } \\
\text { etc. }\end{array}$ & & 2 & 3 & 4 & 5 & $\begin{array}{l}\text { Is very often the first business to } \\
\text { introduce or involve in the } \\
\text { development of new products/services } \\
\text { administrative techniques, operating } \\
\text { technologies, etc. }\end{array}$ \\
\hline \multicolumn{7}{|c|}{ E. In dealing with competitors, my firm ... . } \\
\hline $\begin{array}{l}\text { Typically seeks to avoid cornpetitive } \\
\text { clashes, preferring a "live-and-let- } \\
\text { live" posture }\end{array}$ & 1 & 2 & 3 & 4 & 5 & $\begin{array}{l}\text { Typically adopts a very competitive, } \\
\text { "undo-the-competitors" posture }\end{array}$ \\
\hline
\end{tabular}

F. In general, the top managers at my firm ...

Have a strong proclivity for low-risk projects (with normal and certain rates of return)

$\begin{array}{lllll}1 & 2 & 3 & 4 & 5\end{array}$

Have a strong proclivity for highrisk projects (with chances of very high returns)

G. In general, the top managers at my firm . . .

Believe that, owing to the nature of the environment, it's best to explore it gradually via careful, incremental $\begin{array}{lllll}1 & 2 & 3 & 4 & 5\end{array}$

Believe that, owing to the nature of the environment, bold, wide-ranging acts are necessary to achieve the firm's objectives

behavior

H. When confronted with decision-making situations involving uncertainty, my firm. . .

Typically adopts a cautious, "waitand-see" posture in order to minimize the probability of making costly decisions
Typically adopts a bold, aggressive posture in order to maximize the probability of exploiting potential opportunities 


\section{Section G}

\begin{tabular}{|c|c|c|}
\hline \multirow{6}{*}{$\begin{array}{l}\text { 1. The nature of your } \\
\text { business and the } \\
\text { biotechnology industry } \\
\text { (Please check all that } \\
\text { apply) }\end{array}$} & $\square$ & Drug discovery/ development company \\
\hline & $\square$ & Fully integrated pharmaceutical company \\
\hline & $\square$ & Diagnostics firm \\
\hline & $\square$ & Medical device firm \\
\hline & $\square$ & Tool/platform company \\
\hline & $\square$ & Something else, please specify: \\
\hline \multirow{6}{*}{$\begin{array}{l}\text { 2. Phase of most advanced } \\
\text { product } \\
\text { (Please check one) }\end{array}$} & $\square$ & Marketed by our partner company \\
\hline & $\square$ & Marketed by our company \\
\hline & $\square$ & Late stage clinical development (III-IV) \\
\hline & $\square$ & Early stage clinical development (I-II) \\
\hline & $\square$ & Preclinical development \\
\hline & $\square$ & Something else, please specify: \\
\hline \multirow{5}{*}{$\begin{array}{l}\text { 3. Do you currently sell } \\
\text { products? } \\
\text { (Please check all that } \\
\text { apply) }\end{array}$} & $\square$ & We do not currently sell products \\
\hline & $\square$ & We have our own distribution and sales \\
\hline & $\square$ & We sell through a partner company \\
\hline & $\square$ & $\begin{array}{l}\text { Our original product(s) is on the market through a licensing } \\
\text { agreement }\end{array}$ \\
\hline & $\square$ & Something else, please specify: \\
\hline \multirow{4}{*}{$\begin{array}{l}\text { 4. In the future we plan to... } \\
\text { (Please check all that } \\
\text { apply) }\end{array}$} & $\square$ & Have our own distribution and sales \\
\hline & $\square$ & Sell through a partner company \\
\hline & $\square$ & $\begin{array}{l}\text { Have our product(s) on the market through a licensing } \\
\text { agreement }\end{array}$ \\
\hline & $\square$ & Something else, please specify: \\
\hline \multirow{5}{*}{$\begin{array}{l}\text { 5. Firm structure } \\
\text { (Please check one) }\end{array}$} & $\square$ & Privately held \\
\hline & $\square$ & Publicly held \\
\hline & $\square$ & Government-owned \\
\hline & $\square$ & University-owned \\
\hline & $\square$ & Something else, please specify: \\
\hline
\end{tabular}


6. Our most advanced product will reach the markets OR was launched to the markets in year:

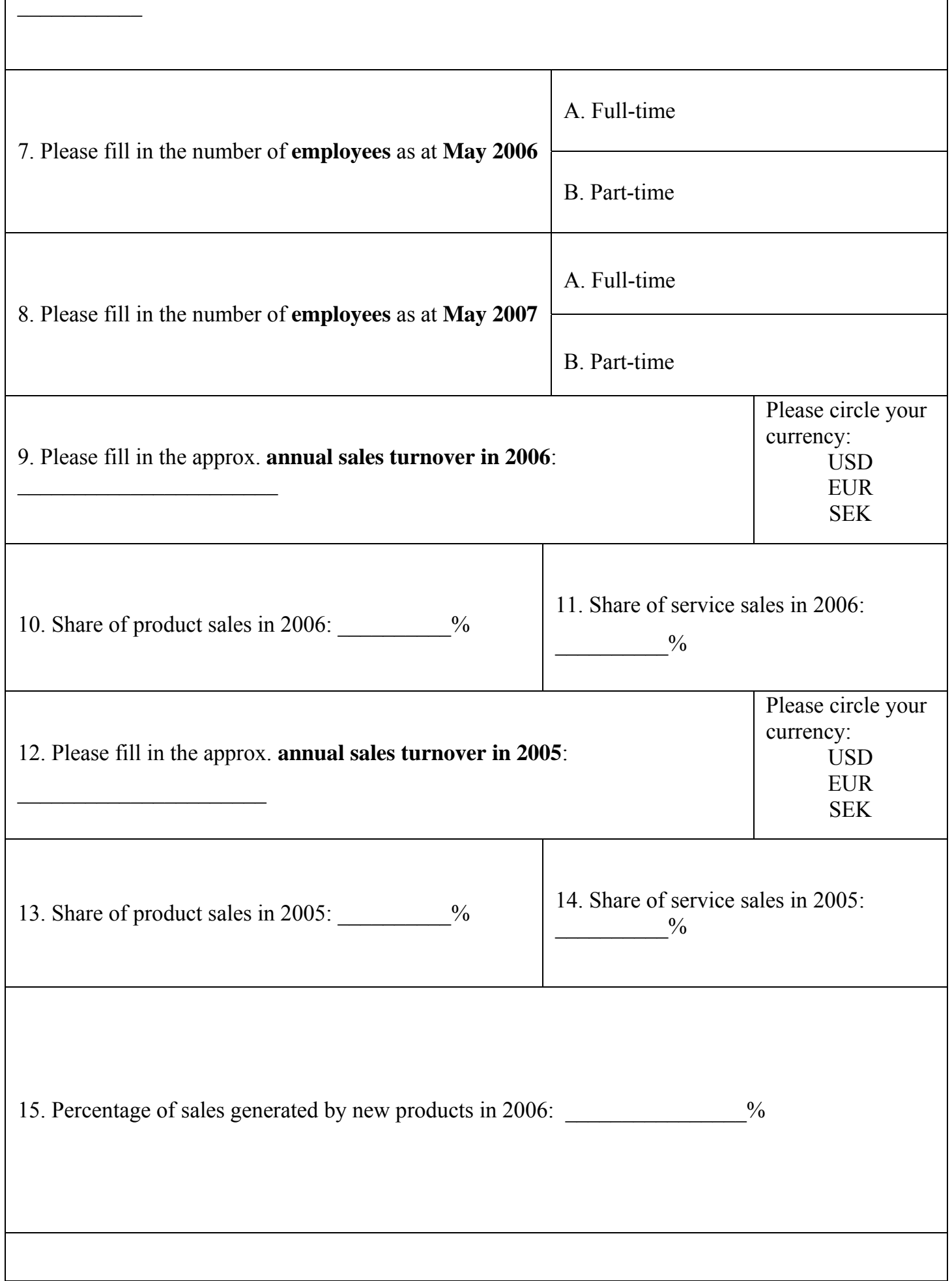


16. Technology licensing prior to year 2003 (Please fill in the blanks):

A. Our firm licensed (number of

B. Our firm sold (number of technologies) proprietary technologies out to (number of companies) firms. technologies) proprietary technologies to (number of companies) firms.

17. Technology licensing in 2004-2005 (Please fill in the blanks):

A. Our firm licensed (number of

B. Our firm sold (number of technologies) proprietary technologies out to technologies) proprietary technologies to (number of companies) firms. (number of companies) firms.

18. Technology licensing since the beginning of 2006 (Please fill in the blanks):

A. Our firm has licensed (number of technologies) proprietary technologies out to (number of companies) firms.
B. Our firm has sold (number of technologies) proprietary technologies out to (number of companies) firms.

19. Do you have a separate sales / marketing department in your firm?

YES

NO

20. Please fill in the total amount of capital raised by the company by May 2007:

Please circle your currency:

USD

EUR

SEK
21. R\&D intensity (Please fill in):
R\&D expenses comprise company.
$\%$ of all the expenses of our 


\section{Section $\mathbf{H}$}

1. Which one of the following five alternatives best describes your company? (Please check one)

a) Our firm's most important partnerships with other organizations are actually the informal contacts (e.g. friendships) the individuals in our management team have.

b) Our firm's most important partnerships are with a number of (non-profit) technology partners and universities.

c) Our firm's most important partnerships are with a number of commercial companies.

d) Our firm's most important partnership is actually our relationship with one major, dedicated partner company.

e) Our firm does not have any important partnerships with outside parties.

2. Which one of the following five alternatives best describes the commercial potential of your firm's most advanced product development project? (Please check one)

a) We do not know yet if this product we develop has any commercial potential.

b) We know that this product we develop has commercial potential in a number of markets (e.g. various indications) but we DO NOT know yet for which market(s) we actually develop this product.

c) We know that this product we develop has commercial potential in a number of markets (e.g. various indications) and we DO already know for which market(s) we actually develop this product. However, we are not selling the product yet.

d) We know that this product we develop has commercial potential in one market and we aim to launch this product in that market.

e) This product is already marketed and generates sales. 
Comments regarding the survey or specific questions:

Return mailing address:

Dr. Maija Renko

Eugenio Pino and Family Global Entrepreneurship Center

Florida International University

11110 Southwest 11th Street

University Park - VH 130

Miami, Florida 33199-0001, USA

Fax: 305-348-0011 


\section{Appendix 2: Pilot testing of the final questionnaire, relevant issues and actions taken.}

\section{Item in the questionnaire}

Firm level data: ROS and \% of sales generated by new products last year.

Company characteristics and performance: Number of

therapeutic areas where firm's inventions are useful.

Company characteristics and performance: Countries of international patent approvals.

Company characteristics and performance: New process introductions.

Questions about collaboration with other firms to identify market trends, etc.

Subjective performance

assessment on the 1-5 scale

Statement \#1 in Business

Philosophy (Section C)

Section D, MARKOR scale

\section{Comment(s) by the interviewees}

Difficult to assess.

$(\mathrm{n}=10)$

How do you define a therapeutic area?

Impossible to count, patents filed by areas, e.g. US, EU, not by national states only.

What is a process introduction? Not relevant for small R\&D firms.

Where are the limits of anticompetitive behavior? Collaboration with competitors may be illegal.

"What do you mean by competitors?"

The sentences within the statement are controversial. You can agree with one part of the statement but not another.

No departments or even different "functions" in small firms $\rightarrow$ statements about dissemination of information not relevant.
Action taken

Not an issue for respondents from firms with no sales. Question kept as such for firms with sales.

Formulating a definition for a therapeutic area

Question changed to "Do you file your patents internationally?'

Question dropped.

Questions kept as such, but comments taken into account when analyzing the data.

Respondents given the clarification that for each statement they should think of the relevant competition in the case of that question. None. The statement has been used by Harris 2002, Harris 2001, Deng and Dart (1994) and Peterson (1989)

None. In each of the 85 interviews the respondent was encouraged to comment on the statements that felt irrelevant for his / her firm for one reason or another. 


\section{Appendix 3: Descriptive figures}

These tables summarize some descriptives from the sample firms.

Table 29: Position of respondents

\begin{tabular}{lll|ll}
\hline & \multicolumn{2}{c|}{ Phase 1 } & \multicolumn{2}{c}{ Phase 2 } \\
\hline Position of the respondent & $\boldsymbol{N}$ & $\mathbf{\%}$ & $\mathbf{N}$ & $\boldsymbol{\%}$ \\
\hline CEO & 48 & 57 & 25 & 60 \\
Founder & 2 & 2 & 1 & 2 \\
CEO and Founder & 19 & 22 & 10 & 24 \\
Vice President, Bus. Dev. & 16 & 19 & 6 & 14 \\
Total & $\mathbf{8 5}$ & $\mathbf{1 0 0}$ & $\mathbf{4 2}$ & $\mathbf{1 0 0}$
\end{tabular}

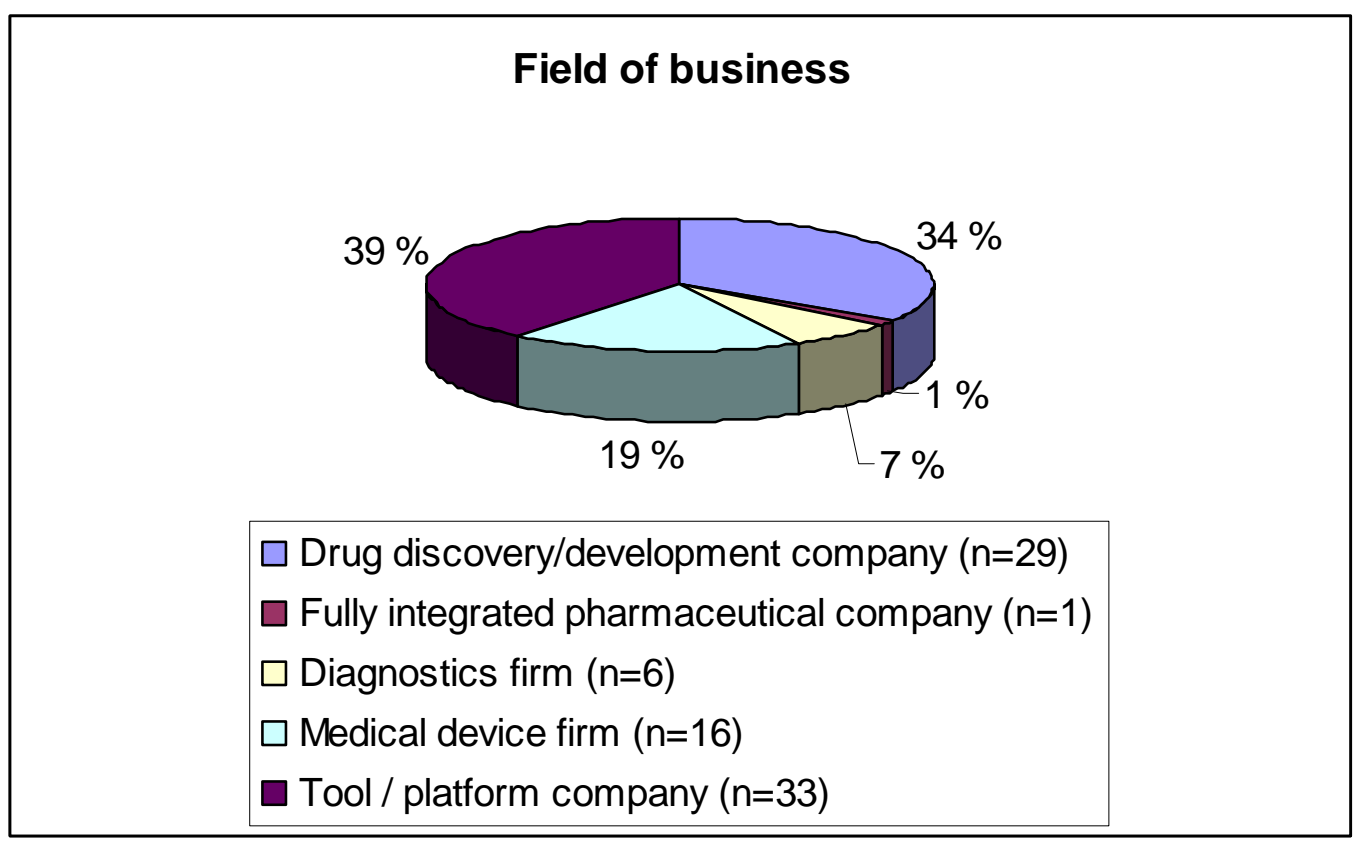

Figure 17: Sample companies (phase $1, \mathrm{n}=85$ ) by field of business ${ }^{29}$.

${ }^{29}$ Distribution remained similar in phase 2 
Table 30: Phase of most advanced product

\begin{tabular}{|c|c|c|c|c|}
\hline \multirow[b]{2}{*}{ Phase of most advanced product } & \multicolumn{2}{|c|}{ Phase 1} & \multicolumn{2}{|c|}{ Phase 2} \\
\hline & $N$ & $\%$ & $N$ & $\%$ \\
\hline Marketed by our partner company & 16 & 19 & 8 & 19 \\
\hline Marketed by our company & 24 & 28 & 13 & 31 \\
\hline $\begin{array}{l}\text { Late stage clinical development (Phase } \\
\text { III-IV) }\end{array}$ & 16 & 19 & 8 & 19 \\
\hline $\begin{array}{l}\text { Early stage clinical development } \\
\text { (Phase I-II) }\end{array}$ & 6 & 7 & 4 & 10 \\
\hline Preclinical development & 19 & 22 & 7 & 17 \\
\hline Other / Not applicable & 4 & 5 & 2 & 5 \\
\hline Total & 85 & 100 & 42 & 101 \\
\hline
\end{tabular}


VITA

\section{ANNA-MAIJA RENKO}

May $4^{\text {th }}, 1976$

2000

$1999-2002$

2003

2004

2005-2006

2006

2006-2007

2007-
Born, Hämeenkyrö, Finland

M.Sc. (Economics \& Business Administration)

Turku School of Economics, Finland

Researcher

Turku School of Economics, Innomarket unit, Finland

Visiting Scholar

Entrepreneurship Center, Florida International University, Miami, FL

Visiting Scholar

Stanford University, Scandinavian Consortium for

Organizational Studies,

Palo Alto, CA

Graduate Assistant

Entrepreneurship Center, Florida International University, Miami, FL

D.Sc. in Business Administration

Turku School of Economics, Finland

Visiting Assistant Professor of Entrepreneurship

College of Business Administration,

Florida International University, Miami, FL

Assistant Professor of Entrepreneurship

College of Business Administration, University of Illinois, Chicago, IL

\section{PUBLICATIONS}

Orava Markus \& Renko Maija (2002) Globalization in the field of pharmaceutical contract research - creating value through networks. In: Viewpoints on the economic dimension of globalization. Publications of Turku School of Economics and Business Administration, A-Series. Edited by Niina Nummela. 
Brännback Malin \& Renko Maija (2002) Technological and strategic change in the Finnish pharmaceutical industry: the emergence of a cluster. Pharmaceuticals Policy and Law, Vol. 5/ 2002, pp. 27-40.

Renko Maija, Carsrud Alan, Brännback Malin \& Jalkanen Juho (2005) Building market orientation in biotechnology SMEs: balancing scientific advances. International Journal of Biotechnology, Vol. 7, No. 4, pp. 250-268.

Kundu Sumit K. \& Renko Maija (2005) Explaining export performance: A comparative study of international new ventures in Finnish and Indian software industry. Advances in Entrepreneurship, Firm Emergence, and Growth, Volume 8, edited by Dean A. Shepherd and Jerome A. Katz, pp. 43-84, Elsevier 2005.

Tikkanen Joni \& Renko Maija (2006) Developing innovation networks - the art of interorganisational collaboration in high-technology innovation. International Journal of Entrepreneurship and Innovation Management, 6(6), pp. 573-590.

Renko Maija (2006) Sourcing Market Knowledge in Biotechnology. Regional Development in the Knowledge Economy, edited by Philip Cooke \& Andrea Piccaluga, pp. 111-134, Routledge and Regional Studies Association.

Renko, Maija (2006) Market Orientation in Markets for Technology - Evidence from Biotechnology Ventures. Dissertation published at Turku School of Economics, Finland, Series A-8:2006.

Jaakkola Elina \& Renko Maija (2007) Critical Innovation Characteristics Influencing Acceptability of a New Pharmaceutical Product Format. Journal of Marketing Management, Vol. 23, No. 3-4, pp. 327-346.

Brännback Malin, Carsrud Alan \& Renko Maija (2007) Exploring the born global concept in the biotechnology context. Journal of Enterprising Culture, Vol. 15, No. 1, pp. $79-100$.

Renko Maija \& Haar Jerry (2008) Innovation and entrepreneurship among born global enterprises. Small Firms, Global Markets. Competitive Challenges in the New Economy, edited by Jerry Haar and Jorg Meyer-Stamer, pp. 86-101, Palgrave MacMillan. 